



2ud issue. 1st is 1851 . 



\section{DELINEATIONS}

$$
\text { oF }
$$

\section{THE OX TRIBE.}








THE SAXGA OR GALLA OX OF ABYSSINIA, $v$ p. 120. 


\title{
A MONOGRAPH OF THE GENUS BOS.
}

\author{
THE NATURAL HISTORY OF
}

\section{BULLS, BISONS, AND BUFFALOES.}

ExHнiтiNo

ALL THE KNOWN SPECIES, AND THE MORE REMARKABLE VARIETIES.

WITI AN INTRODUCHION, CONTAINING AN ACCOUNT OF EXPERIMENTS ON RUMINATION, FROM TIIE FRENCIT OF M. FLOURENS.

\section{BY GEORGE VASEY.}

WITH 72 ENGRAVINGS ON WOOD, BX THE AUTHOR.

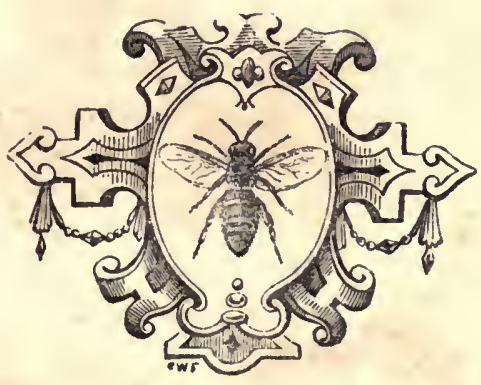

LONDON :

JOHN RUSSELL SMITH, SOHO SQUARE.

M.DCCO.LVIr. 



\section{WILLIAM YARRELL, Esa., F.L S., F.Z.S.,}

WHOSE SCIENTIFIC WORKS ON ZOOLOGY

PLACE HIM IN TIIE FIRST RANK OF NATURALISTS;

AND, MOREOVER,

WHOSE UNOSTENTATIOUS KINDNESS IN CONSULTING THE FEELINGS

AND ADVANCING TIIE INTERESTS OF OTIERS

IS. RARELY EQUALLED,

This Folume is inscribert,

BY IIS SINCERE FRIEND AND ADMIRER,

THE AU'THOR. 



\section{PREFACE.}

THE primary object of the present work, is to give as correct and comprehensive a view of the animals composing the Ox Tribe, as the present state of our knowledge will admit, accompanied by authentic figures of all the known species and the more remarkable varieties.

Although this genus (comprising all those Ruminants called Buffaloes, Bisons, and Oxen generally,) is as distinct and well characterised as any other genus in the animal kingdom, yet the facts which are at present known respecting the various species which compose it, are not sufficiently numerous to enable the naturalist to divide them into sub-genera. This is abundantly proved by the unsuccessful result of those attempts which have already been made to arrange them into minor groups. Nor can we wonder at this want of success, when we consider that even many of the species usually regarded as distinct are by no means clearly defined.

The second object, therefore, of this treatise, is (by bringing into juxta-position all the most important facts concerning the various individual specimens which have been described, and by adding several other facts of im. 
portance which have not hitherto been noticed,) to enable the naturalist to define, more correctly than has yet been done, the peculiarities of each species.

A third object is to direct the attention of travellers more particularly to this subject; in order that, by their exertions, our information upon this class of animals may be rendered more complete.

A new and important feature in the present Monograph, is the introduction of a Table of the Number of Vertebræ, carefully constructed from an examination of the actual skeletons, by which will be seen at a glance the principal osteological differences of species which have hitherto been confounded with each other. A Table of the Periods of Gestation is likewise added, which presents some equally interesting results.

Several of the descriptions have been verified by a reference to the living animals, seren specimens of which are at present (1847) in the Gardens of the Zoological Society, Regent's Park. The several Museums in the Metropolis have likewise been consulted with advantage.

I am indebted to Judge Furna M, of the United States, for some original information respecting the American Bison; and also to the late Mr. CoLe, who was forty year's park-keeper at Chillingham, for answers to several questions which I proposed to him on the subject of the Chillingham Cattle.

I beg to acknowledge my obligation to Mr. CATL1N for kindly allowing me, not only to make cxtracts, but also 
to copy some of the outlines from his 'Letters and Notes on the North American Indians,' a work which I do not hesitate to pronounce one of the most curious and interesting which the present century has produced,-whether we regard the graphic merits of its literary or pictorial department.

To Professor Owen and the Officers of the Royal College of Surgeons, to the Officers of the Zoological Society, and to the Officers of the Zoological Department of the British Museum, my sincere thanks are due for the kindness and promptness with which every information has been given, and every facility afforded to my inquiries and investigations.

With respect to the engraved figures, I have striven to produce correct delineations of form and texture, rather than to make pretty pictures by sacrificing truth and nature for the sake of ideal beauty and artistic effect.

I cannot conclude this Preface without expressing my thanks to Messrs. Aduard for the first-rate style in which this volume has been printed; particularly for the successful manner in which the impressions of the engravings have been produced, superior, in general, to India-proof impressions.

King Street, Camden Toron; May, 1851. 


\section{ADDENDUM.}

PENNANT-BUFFON-GOLDSMITH-BEWICK-BINGLEY.

IN addition to the critical remarks on the writings of others, on this subject, which the reader will find in the following pages, I have further to observe that, although Pennant and Buffon have held a very high character, for many years, as scientific naturalists, the portion of their works which treats of the Genus Bos, appears to have been the result of the most careless and superficial observation. With the exception of the facts and observations furnished by such men as Daubenton and Pallas, Buffon's works are little more than flimsy speculations. As to Pennant's history of the Ox Tribe, it is calculated rather to bewilder than to inform; it is, in fact, an incoherent mass of dubious statements, huddled together in a most inextricable confusion: as a piece of Natural History it is absolutely worse than nothing.

Goldsmith, Bewick, and Bingley, three of our most popular writers on Natural History, appear to have done little more than compile from Pennant and Buffon, and consequently are but little deserving of credit. These strictures apply exclusively to such portions of their works as relate to the Ox Tribe. 


\section{TABLE OF CONTENTS.}

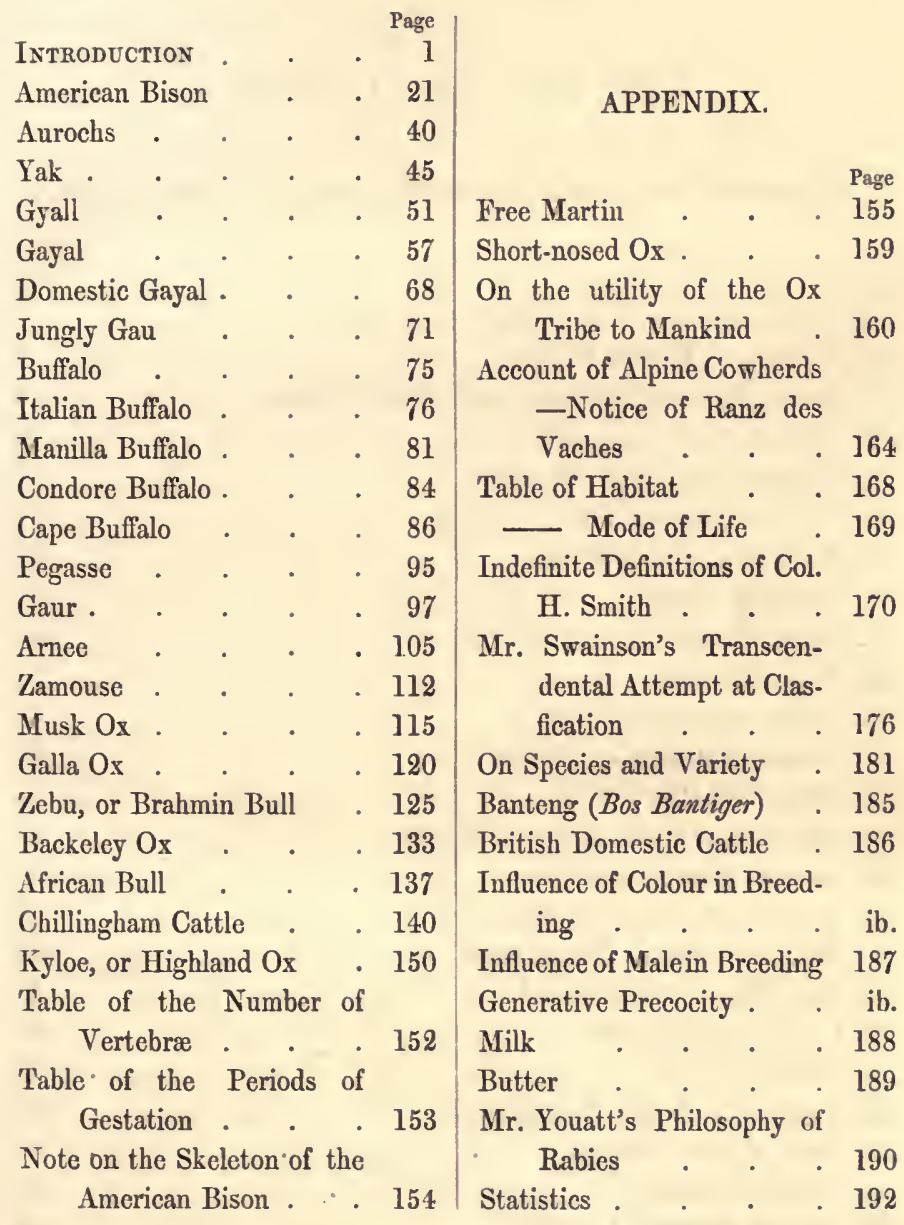




\section{LIST OF ENGRAVINGS.}

(The Engravings not otherwise acknowledged are from original Drawings.)

1. Frontrspiece. -The Sanga, or Abyssinian Ox . . i

2. Stomach of Manilla Bnffalo . . . . . 4

3. Gastro-duct (Esophagean Canal), after Flourens . $\quad 6$

4. Stomach of a young Calf . . . . . 12

5. Stomach of a full-grown Cow $\quad$. $\quad$. $\quad . \quad 13$

6. Skull of Domestic Ox . . . . . 17

7. Skeleton of Domestic Ox . . . . . 20

8. American Bison . . . . . . 21

9. Young Female Bison . . . . . . 23

10. Wounded Bison . . . . . . 24

11. Indian shooting a Bison $\quad$. $\quad$. $\quad$. $\quad 29$

12. Bison surrounded by Wolves . . . . . 32

13. Bison Calf, after Cuvier . . . . . 33

14. Skin Canoes of the Mandan Indians . . . $\quad 36$

15. Head of young Male Bison _ $\quad$. $\quad$. $\quad 39$

16. Aurochs, or European Bison . . . . . 40

17. Yak, from Asiatic Transactions . . . . . 45

18. Yak, from Oriental Annual . . . . . 49

19. Gyall (Bos Frontalis) . . . . . . 51

20. Head of Gyall . . . . . $\quad$. 53

21. Gayal, from Asiatic Transactions . . . . 58

22. Head of Asseel Gayal . • . . . $\quad$. 67



24. Skull of Domestic Gayal . $\quad$. $\quad$. $\quad$. 69

25. Occipital View of the same Skull . . . . ib.

26. Head of Domestic Gayal . . . . . . ib. 
27. Jungly Gau, after Cuvier .

28. Syrian $\mathrm{Ox}$, anon.

29. Italian Buffalo-Brandt and Ratzeburg . . . 76

30. Herefordshire Cow, after Howitt . . . 80

31. Manilla Buffalo . . . . . . 81

32. Outlines of Buffaloes Backs . . . . 82

33. Head of Manilla Buffalo . . . . . $\quad .83$

34. Pulo Condore Buffalo . . . . . 84

35. Short-horned Bull, after Howitt . . . . 85

36. Cape Buffalo . . . . . . 86

37. Young Cape Buffalo, after Col. Smith . . . 90

38. Head of Cape Buffalo . . . . . 94

39. Pegasse, from a Drawing in the Berlin Library . . $\quad 95$

40. Horns of Cape Buffalo a . . . . . $\quad 96$

41. Gaur, from Specimen in British Museum . . . 97

42. Horns of Gaur, Edin. Phil. Trans. . . . . 103

43. Head of Gaur . . . . . . 104

44. Arnee, from Shaw's Zoology . . . . . 105

45. Horns of Young Arnee, from 'The Bee' . . 107

46. Horns of Arnee, from Mus. Coll. Surg. . . . 108

47. Horns of Arnee, from British Museum . . . ib.

48. Arnee from Indian Painting . . . . . 111

49. Zamouse, or Bush Cow . $\quad$. $\quad$. $\quad$. 112

50. Head of Zamouse . . . . . . . 114

51. Musk Ox . . . . . . 115

52. Foot of Musk Ox, Griff., Cuv. . . . . 117

53. Head of Musk Ox $\quad$ - $\quad$. $\quad$. $\quad$. 119

54. Horns of Galla Ox, Mus. Coll. Surg. . . 123

55. Horns of Hungarian Ox, Brit. Mus. . . . 124

56. Brahmin Bull, Harvey, Zool. Gar. . . . . . 125

57. Zebu (var. $\beta$ ), after Cuvier _ . . . . 128

58. Zebus (var. $\gamma$ ) and Car, anon. $\quad . \quad . \quad . \quad . \quad 129$

59. Zebu (var. $\delta$ ), anon. . . . . . . 132

60. African Bull, Harvey . $\quad$. $\quad$. . 137

61. Eyes of African Bull, Harvey $\quad$. $\quad$ • $\quad$. 138

62. Lateral Hoofs of African Bull, Harvey . . . ib.

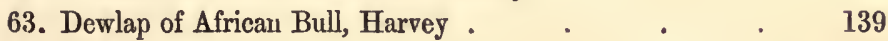

64. Chillingham Bull . . . . . . 140

65. Heads of Chillingham Cattle $\quad$. $\quad$. $\quad$. $\quad$. 148 
66. Kyloe, or Highland Ox, Howitt . . . . 150

67. Free Martin, Hunter's Animal Economy . . . 156

Skull of Domestic Ox, (repetition of fig. 6) . . . . 158

68. Skull of Short-nosed Ox of the Pampas . . . $\quad 159$

69. Outlines of Manilla Buffalo . . . . . . 174

70. Hungarian Ox, from British Museum . . . 175

71. Banteng, from a Specimen in Brit. Mus. . . . 185

72. Alderney Cow, after Howitt $\quad$. $\quad$. $\quad . \quad 189$ 


\section{INTRODUC'TION.}

Ruminantia is the term used hy naturalists to designate those mammiferous quadrupeds which chew the cud; or, in other words, which swallow their food, in the first instance, with a very slight mastication, and afterwards regurgitate it, in order that it may undergo a second and more complete mastication: this second operation is called ruminating, or chewing the cud. The order of animals which possess this peculiarity, is divided into nine groups or genera, namely :-

\begin{tabular}{l|l|l} 
Camels. & Deer. & Goats. \\
Llamas. & Giraffes. & Sheep. \\
Musks. & Antelopes. & Oxen.
\end{tabular}

The last named forms the subject of the following pages, and is called, in zoological language, the Genus Bos, in popular language, the Ox Tribe.

One of the most interesting occupations which the wide field of Zoology offers to the naturalist, is the investigation of those remarkable adaptations of organs to functions, and of these again to the necessities and well-being of the entire animal. Nor does it in the least diminish our interest in the investigation of indi- 
vidual adaptations, or our admiration on becoming acquainted with them, that we know, à priori, this universal truth, that all the constituents of every organised body, be that organisation what it may, are invariably adapted, in the most perfect manner, to each other, and to the whole.

It is by a knowledge of this exact harmony in the animal economy, that the comparative anatomist can determine, with almost unerring precision, the genus, or even species of an animal, by an examination of any important part of its organisation, as the teeth, stomach, bones, or extremities. In some cases, a single bone, or even the fragment of a bone, is sufficient to convey an idea of the entire animal to which it belonged.

In illustration of this :- if the viscera of an animal are so organised as only to be fitted for the digestion of recent flesh, we find that the jaws are so contracted as to fit them for devouring prey; the claws for seizing and tearing it to pieces; the teeth for cutting and dividing its flesh; the entire system of the limbs, or organs of motion, for pursuing and overtaking it ; and the organs of sense for discovering it at a distance. Moreover, the brain of the animal is also endowed with instincts sufficient for concealing itself, and for laying plans to catch its necessary prey.

Again, we are well aware that all hoofed animals must necessarily be herbivorous, or vegetable feeders, because they are possessed of no means of seizing prey. It is also evident, having no other use for their forelegs than to support their bodies, that they have no 
occasion for a shoulder so vigorously. organised as that of carnivorous animals; owing to which they have no clavicles, and their shoulder-blades are proportionally narrow. Having also no occasion to turn their forearms, their radius is joined by ossification to the ulna, or is at least articulated by gynglymus with the humerus. Their food being entirely herbaceous, requires teeth with flat surfaces, on purpose to bruise the seeds and plants on which they feed. For this purpose, also, these surfaces require to be unequal, and are, consequently, composed of alternate perpendicular layers of enamel and softer bone. Teeth of this structure necessarily require horizontal motions to enable them to triturate, or grind down the herbaceous food; and ac. cordingly the condyles of the jaw could not be formed into such confined joints as in the carnivorous animals, but must have a flattened form, correspondent to sockets in the temporal bones. The depressions, also, of the temporal bones, having smaller muscles to contain, are narrower and not so deep; and so on, throughout the whole organisation.

The digestive system of the ruminantia is more complicated in structure than that of any other class of animals; and, owing to this complexity, and the consequent difficulty of investigating it, its nature and functions have been less perfectly understood.

The stomach of the Manilla Buffalo, which will serve as an example of all the other species, is divided into four cavities or ventricles, which are usually (but improperly) considered as four distinct stomachs. 
The following figure represents the form, relative size, and position of these four cavities when detached from the animal, and fully inflated.

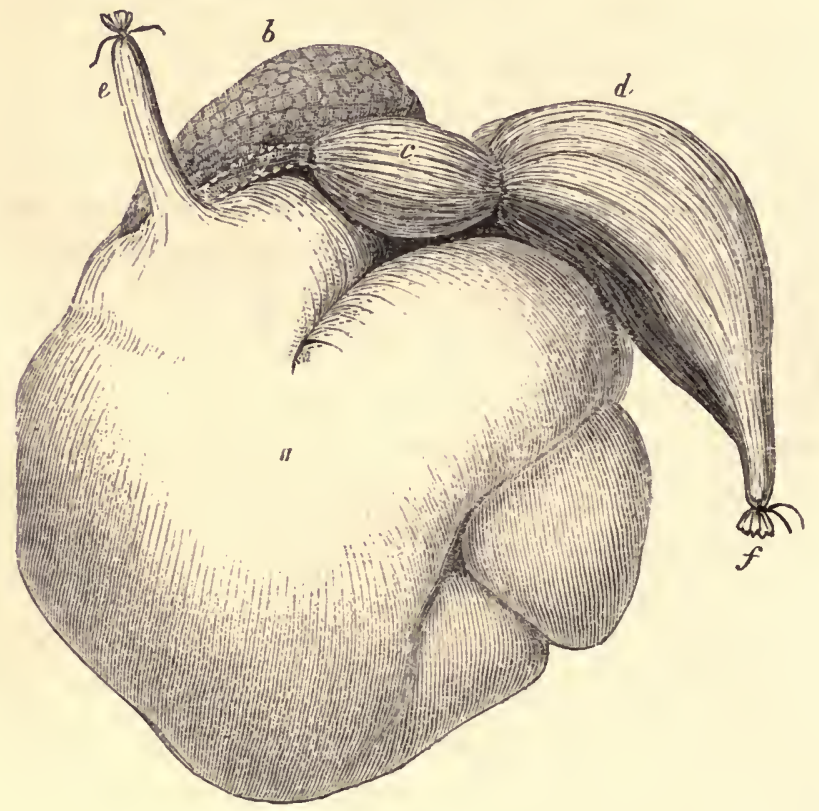

a. First carity, called the paunch.

b. Second ditto, the honeycomb bag.

c. Third ditto, the many-plies.

d. Fourth ditto, the reed, or rennet.

e. A portion of the œesophagus, showing its counection with the stomach.

$f$. The pylorus, or opening into the intestines.

The interior of those cavities present some remarkable differences in point of structure, which, in the present work, can only be alluded to in a very general manner. For a particular account of the internal anatomy of these complicated organs, the reader is referred to the interesting work on 'Cattle,' by W. Youatt. 
The paunch is lined with a thick membrane, presenting numerous prominent and hard papillæ. The inner surface of the second cavity is very artificially divided into angular cells, giving it somewhat the appearance of honeycomb, whence its name "honeycomb-bag." The lining membrane of the third cavity forms numerous deep folds, lying upon each other like the leaves of a book, and beset with small hard tubercles. These folds vary in breadth in a regular alternate order, a narrow fold being placed between each of the broader ones. The fourth cavity is lined with a velvety mucous membrane disposed in longitudinal folds. It is this part of the stomach that furnishes the gastric juice, and, consequently, it is in this cavity that the proper digestion of the food takes place; it is here, also, that the milk taken by the calf is coagulated. The reed or fourth cavity of the calf's stomach retains its power of coagulating milk even after it has been taken from the animal. We have a familiar instance of its operation in the formation of curds and whey.

The first and second cavities ( $a$ and $b$ ) are placed parallel (or on a level) with each other; and the œsophagus (e) opens, almost equally, into them both. On each side of the termination of the cesophagus there is a muscular ridge projecting, so that the two together form a sort of groove or channel, which opens almost equally into the second and third cavities ( $b$ and $c$ ).

[As there has not been, as far as I am aware, any appropriate name given to this very remarkable part of the stomach of ruminants, I here take the liberty of 
suggesting the term Gastro-duct, by which epithet this muscular channel will be designated in the following pages.]

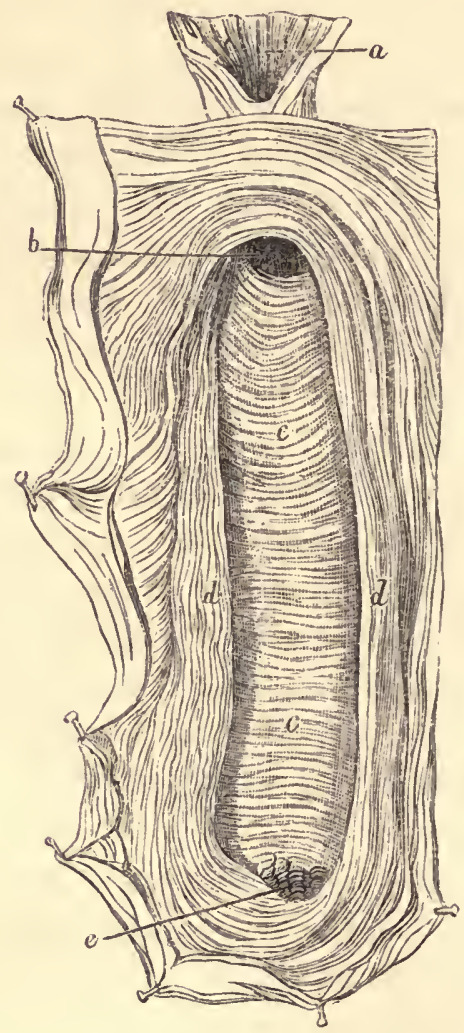

View of Gastro-duct, after Flourens.

a. A portion of the osophagus cut open, showing the iuternal folds of the niucous membrane.

b. The opening of the esophagus into the paunch.

$c, c$. The gastro-duct.

$d, d$. Muscular fibres passing completely round the clge of the gastro-duct, and forming a sort of sphincter.

c. The opening from the gastro-duct into the third cavity. 
All these parts, namely, the œsophagus, the gastroduct, and the first three cavities, not only communicate with each other, but they communicate by one common point, and that point is the gastro-duct. At the extremity of the third cavity, opposite to that at which the gastro-duct enters it, is an aperture which communicates immediately with the fourth cavity $(d)$.

Such is a very brief description of the complicated stomach of the Ox Tribe. In what manner the food passes through this curious arrangement of cavities is a problem which has engaged the attention of naturalists from a very early period. A host of great men might be cited who have failed to solve it. The French physiologist, M. Flourens, by his recent experiments, has done more than any or all of his predecessors to give clearness and precision to this intricate subject.

The following is an abstract of the most important of his experiments :-

A sheep having been fed on fresh trefoil, was killed and opened immediately, - that is, before the process of rumination had commenced. He (M. Flourens) found the greatest part of this herb (easily recognised by its leaves, which were still almost entire,) in the paunch; but he also found a certain portion (une partie notable) of those leaves (in the same unmasticated state) in the honeycomb. In the other two cavities, (the many-plies and the reed,) there was absolutely none. 
M. Flourens repeated this experiment a great many times, with herbs of various kinds, and the result was constantly the same: from which it appears, that herbaceous food, on its first deglutition, enters into the honeycomb, as well as into the paunch ; the proportion, however, being considerably greater into the paunch than into the honeycomb. It appears equally certain that, in the first swallowing, this kind of food only enters into the first two cavities, and never passes into the many-plies or the reed.

Having ascertained this fact with respect to herbs, he instituted a similar series of experiments, in which the animals were fed upon various kinds of grain,rye, barley, wheat, oats, \&c. The animals were killed and examined, as in the former experiments, immediately after being fed. He found the greater part of the grain unmasticated (tout entier) in the paunch; but, as in the case of the herbs, he also found a certain portion, in the same unmasticated state, in the honeycomb. Neither the many-plies nor the reed contained a single grain. He repeated these experiments many times, and always with the same result.

He then tried the effect of carrots cut into pieces, from half an inch to an inch in length; and in order that the animals might not chew them, he passed them into the pharynx by means of a tube. In one of these sheep he found all the morsels in the paunch; but, in the other two, some of the morsels were in the honeycomb, and some in the paunch. In all the three cases, 
there was none either in the many-plies or in the reed.

He then proceeded to ascertain the effect of substances previously comminuted. He caused a certain quantity of carrots to be reduced to a kind of mash, with which he fed two sheep, and opened them immediately afterwards. He found the greatest part of this mash in the paunch and in the honeycomb; but he likewise found a certain portion in the many-plies and in the reed.

His next experiments were made upon plain fluids. It is the opinion of the generality of authors on this subject that fluids pass immediately and entirely, along the gastro-duct, into the third and fourth cavities. But, according to the experiments of M. Flourens, this is not the case. He found, by making artificial openings (anus artificiel) in the stomachs of various sheep, that, as the animals drank, the fluid came directly out at the opening, in whatever cavity it might have been made.

It is clear, then, that fluids pass, in part, into the first and second cavities, and, in part, into the third and fourth; and they pass as directly into the former as into the latter.

The following is the result of some experiments which M. Flourens made respecting the formation of the pellets.

In the first place, after the animal has swallowed a certain quantity of food the first time, successive pellets are formed of this food, which remount singly to the 
mouth; secondly, there is a particular apparatus, which forms these pellets ; and, thirdly, this apparatus consists of the two closed apertures (ouvertures fermécs) of the many-plies, and of the œsophagus. Thus, the first two cavities, in contracting, push the aliments which they contain between the edges of the gastro-duct; and the gastro-duct, contracting in its turn, draws together the two openings of the many-plies and cesophagus; and these two openings, closed at this moment of their action, seize a portion of the food, detach it, and form it into a pellet.

The chief utility of rumination, as applicable to all the animals in which it takes place, and the final purpose of this wonderfully-complicated function in the animal economy, are still imperfectly known; what has been already suggested on these points is quite unsatisfactory. Perrault and others supposed that it contributed to the security of those animals, which are at once voracious and timid, by showing the necessity of their remaining long employed in chewing in an open pasture; but the Indian buffalo ruminates, although it does not fly even from the lion; and the wild goat dwells in Alpine countries, which are inaccessible to beasts of prey.

Whatever may be our ignorance of the cause or the object of rumination, it is certain that the nature of the food has a considerable influence in increasing or diminishing the necessity for the performance of that function. Thus, dry food requires to be entirely subjected to a second mastication, before it can pass into 
the many-plies and reed; whilst a great portion of that which is moist and succulent passes readily into those cavities, on its first descent into the stomach.

It has already been shown by the illustration, (p. 4,) that the paunch is the largest of the four cavities; but this is not the case with the stomach of the young calf, which, while it continues to suck, does not ruminate; in this case the reed, which is the true digestive cavity, is actually larger than the other three taken together.

When the calf begins to feed upon solid food, then it begins to ruminate; and as the quantity of solid food is increased, so does the size of the paunch increase, until it attains its full dimensions. In this latter case, the paunch has become considerably larger than the other three cavities taken together.

A curious modification of an organ to adjust itself to the altered condition of the animal is beautifully shown in the instance now under consideration, the nature of which will be easily understood by a reference to the following diagrams, giving the exact relative proportions of the different cavities of the stomach to each other in the young calf and in the full-grown cow.

[I am informed by Professor Symonds, of the Royal Veterinary College, that the two following sketches should be placed in the page so as to be viewed with the osophagus to the right, and the pylorus to the left, instead of being, as they now are, at the top and the bottom; but as the present object is only to show the relative sizes of the different cavities, the error is not of much consequeuce.] 
The letters refer to the same parts in each figure: $a$, the paunch; $b$, the honeycomb bag; $c$, the manyplies ; $d$, the reed.



()utline of the SLomach of a Calf about a fortnight old. 




Outline of the Stomach of a full-grown Cow.

[These engravings, illustrative of the comparative sizes of the different stomachal cavities, are copied from original drawings taken from preparations of the stomachs which I made expressly for this purpose.]

In all herbivorous animals, and especially those of the ruminating kind, the alimentary canal is of an enormous length; measuring in a full grown ox, as much as sixty yards. The paunch, in such an animal, will hold from fifteen to eighteen gallons. 
Blumenbach observes, that the process of rumination supposes a power of voluntary motion in the osophagus; and, indeed, the influence of the will throughout the whole process is incontestible. It is not confined to any particular time, since the animal can delay it according to circumstances, even when the paunch is quite full. It has been expressly stated of some men, who have had the power of ruminating, that it was quite voluntary with them. Blumenbach knew four men who ruminated their food, and they assured him they had a real enjoyment in doing it: two of them had the power of doing or abstaining from it at their pleasure.

A case of human rumination occurred some years ago at Bristol, the particulars of which are minutely recorded in the 'Philosophical Transactions.' It seemed, in this instance, to have been hereditary, as the father of the individual was subject to the same habit. The young man usually began to chew his food over again, within a quarter of an hour after eating. His ruminating after a full meal generally lasted about an hour and a half; nor could he sleep until this task was completed. The victuals, upon its return, tasted even more pleasantly than at first; and seemed as if it had been beaten up in a mortar. If he ate a variety of things, that which he ate first, came up again first; and if this return was interrupted for any length of time, it produced sickness and disorder; nor was he ever well till it returned. These singular cases are caused, no doubt, by some abnormal structure of the 
interior of the stomach. No account has yet been given of the dissection of an individual so constituted.

When cattle are at rest, or not employed in grazing or chewing the cud, they are observed frequently to lick themselves. By this means they raise up the hair of their coats, and often swallow it in considerable quantities. The hair thus swallowed gradually accumulates in the stomach, where it is formed into smooth round balls, which, in time, become invested with a hardish brown crust, composed, apparently, of inspissated mucilage, that, by continual friction from the coats of the stomach, becomes hard and glossy. It is generally in the paunch that these hair-balls are found. They vary in weight from a few ounces to six or seven pounds. Mr. Walton, author of an 'Account of the Peruvian Sheep,' makes mention of one that he had in his possession which weighed eight pounds and a quarter. This hair-ball had been taken from a cow that fed on the Pampas of Buenos Ayres. It was of a flat circular shape, and measured two feet eleven inches and a half in circumference; two fect eight inches round the flat part; nine inches diameter also in the flat part; eleven inches diameter in the cross part; and, on immersing it in water, it displaced upwards of eight quarts, which made its bulk correspond to 462 cubic inches. The digestive functions are sometimes seriously impaired by these concretions; a loss of appetite ensues, and general debility.

In the Museum of Daniel Crosthwaite, there is a very extraordiuary ball of hair, taken from a fatted 
calf only seven weeks old. The ball of hair, when taken out of the animal's stomach, and full of moisture, weighed eleven ounces. The calf was fatted by Daniel Thwaite, of Dale Head Hall, within six miles of Keswick; and slaughtered by John Fisher, butcher, Keswick. The calf was a particularly healthy animal.

Before closing this brief sketch of the digestive apparatus of the ox, it may not be uninteresting to quote some of the quaint speculations of Nathaniel Grew on this subject, from his 'Comparative Anatomy of Stomachs and Guts.'

He says: "The voluntary motion of the stomach is that only which accompanies rumination. That it is truly voluntary, is clear, from the command that ruminating animals have of that action. For this purpose it is, that the muscules of their venters are so thick and strong; and have several duplicatures, as the bases of those muscules, whereupon the stress of their motion lies. By means whereof they are able with ease to rowl and tumble any part of the meat from one cell of the same venter to another; or from one venter to another; or from thence into the gullet, whensoever they are minded to do it; so that the ejectment of the meat, in rumination, is a voluntary eructation. .

"The pointed knots, like little papillæ, in the stomachs of ruminating beasts, are also of great use, namely, for the tasting of the meat. The inncr membrane of the first three venters is fibrous (like the gustatory papillæe of the tongue) and not glandulous; the fourtl only being glandulous, as in a man. Of 
the fibres of this membrane, and the nervous, are composed those pointed knots, which are, both in substance and shape, altogether like to those upon the tongue. Whence I doubt not, but that the said three ventricles, as they have a power of voluntary motion, so, likewise, that they are the seat of taste, and as truly the organs of that sense, as is the tongue itself."



Skull of Domestic Ox, from a specimen in the Royal College of Surgeons.

The mouth of animals of the Ox Tribe contains, when full, thirty-two teeth. Six molars in each jaw, above, below, and on either side; and eight incisors in the 
lower jaw. In the upper jaw there are no incisors; but instead thereof a fibrous and elastic pad, or cushion, which covers the convex extremity of the anterior maxillary bone, and which is well worthy of observation.

The final cause of this pad (which stands in the place of upper incisor teeth) and the part it plays in the procuring of food, is thus described by Youatt. "The grass is collected and rolled together by means of the long and moveable tongue; it is firmly held between the lower cutting teeth and the pad, the cartilaginous upper lip assisting in this; and then by a sudden nodding motion of the head, the little roll of herbage is either torn or cut off, or partly both torn and cut.

The intention of this singular method of gathering the food, it is somewhat difficult satisfactorily to explain. It is peculiar to ruminants, who have one large stomach, in which the food is kept as a kind of reservoir until it is ready for the action of the other stomachs. While it is kept there it is in a state of maceration; it is exposed to the united influence of moisture and warmth, and the consequence of this is, that a species of decomposition sometimes commences, and a vast deal of gas is extricated.

That this should not take place in the natural process of retention and maceration, nature possibly established this mechanism for the first gathering of the food. It is impossible that half of that which is thus procured can be fairly cut through; part will be torn, and no little portion will be torn up by the roots. 
If cattle are observed while they are grazing, it will be seen that many a root mingles with the blades of grass; and these roots have sometimes no inconsiderable quantity of earth about them. The beast, however, seems not to regard this; he eats on, dirt and all, until his paunch is filled.

It was designed that this earth should be gathered and swallowed; it was the meaning of this mechanism. A portion of absorbent earth is found in every soil, sufficient not only to prevent the evil that would result from occasional decomposition, by neutralizing the acid principle as rapidly as it is evolved; but, perhaps, by its presence, preventing that decomposition from taking place. Hence the eagerness with which stall-fed cattle, who have not the opportunity of plucking up the roots of grass, evince for mould. It is seldom that a cow will pass a newly-raised mole hill without nuzzling into it, and devouring a considerable portion of it. This is particularly the case where there is any degree of indigestion."

The general disposition of animals of this class, when unmolested, is inoffensive and retiring; but when excited and irritated, they are fierce and courageous, and extremely dangerous to encounter. It is a remarkable circumstance in their history, that they are generally provoked to attack at the sight of red, or any very bright and glaring colour. 







\section{THE OX TRIBE, \\ or}

\section{Genus BOS,}

Is distinguished from other Genera of Ruminantia by possessing hollow persistent horns, growing on a bony core; the tail long, terminated by a tuft of hair; and four inguinal mammæ.

\section{THE BISON.}

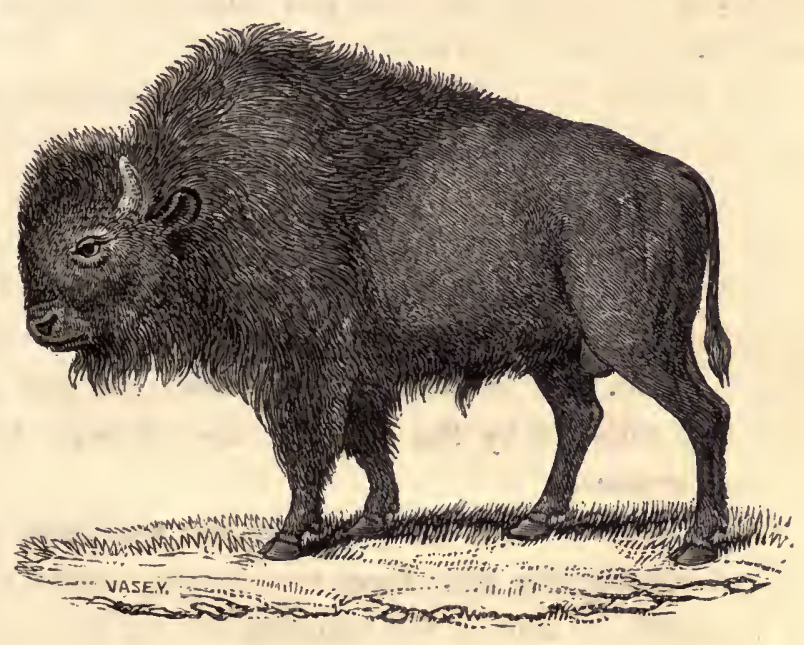

THE AMERICAN BISON.

Bos Americanus.

The head of this animal is enormously large; larger, in fact, in proportion to the size of its body, than that of 
any other species of the Ox Tribe. This huge head is supported by very powerful muscles, attached to the projecting spinous processes of the dorsal vertebræ; and these muscles, together with a quantity of fat, constitute the hump on the shoulders. The horns are short, tapering, round, and very distant from each other, as are also the eyes, which are small and dark. The head, neck, shoulders, and fore-legs, to the knee-joints, are covered with long woolly hair, which likewise forms a beard under the mouth. The rest of the body is clothed only by short, close hair, which becomes rather woolly in the depth of winter. The colour is of a deep brown, nearly black on the head, and lighter about the neck and shoulders. The legs are firm and muscular; the tail is short, with a tuft at the end.

The female is, in every respect, much smaller than the male; her horns are more slender, and the hair on her neck and shoulders is not so thick or long, nor the colour so dark. She brings forth in the spring, and rarely more than one. The calves continue to be suckled nearly twelve months, and follow the cows for a much longer period. It is said that the cows are not unfrequently followed by the calves of two, or even three, breeding seasons.

These animals, both male and female, are timid and shy, notwithstanding their fierce appearance; unless they are wounded, or during the breeding season, when it is dangerous to approach. Their mode of attack is to throw down, by pushing, as they run with their head; then to crush, by trampling their enemy under their fore-feet, which, surmounted as they are, by their tremcndous head and shoulder, form most effectual weapons of destruction. 


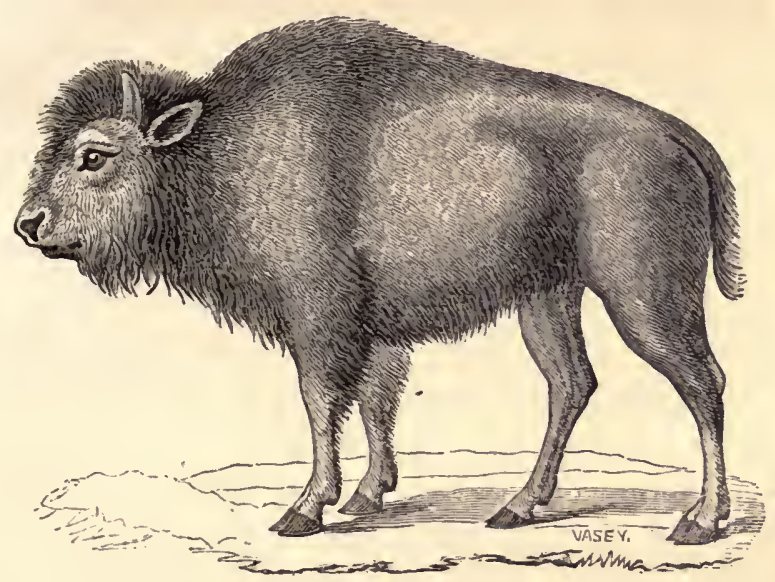

Young female Bison, after Cuvier.

The following account, by Dr. Richardson, affords an instance of the danger to be apprehended from these powerful animals, when wounded, and not disabled: "Mr. Finnan M'Donald, one of the Hudson's Bay Company's clerks was descending the Saskatchewan in a boat; and one evening, having pitched his tent for the night, he went out in the dusk to look for game. It had become nearly dark when he fired at a Bison bull, which was galloping over an eminence; and as he was hastening forward to see if this shot had taken effect, the wounded beast made a rush at him. He had the presence of mind to seize the animal by the long hair on the forehead, as it struck him on the side with its horn, and being a remarkably tall and powerful man, a struggle ensued, which continued until his wrist was severely sprained, and his arm was rendered powerless; he then fell, and after receiving two or three blows, became senseless. Shortly afterwards he was found by 
his companions, lying bathed in his blood, being gored in several places, and the Bison was couched beside him, apparently waiting to renew the attack, had he shown any signs of life. Mr. M'Donald recovered from the immediate effects of the injuries, but he died a few months afterwards. Many instances might be mentioned of the tenaciousness with which this animal pursues its revenge; and $I$ have been told of a hunter being detained for many hours in a tree, by an old bull, which had taken its post below, to watch him."

The capture of the Bison is effected in various ways, chiefly with the rifle, and on foot. Their sense of smelling, however, is so acute, that they are extremely difficult of approach, scenting their enemy from afar, and retiring with the greatest precipitation. Care, therefore, must be taken to go against the wind, in which case they may be approached very near, being almost blinded by the long hair hanging over their foreheads. The hunters generally aim at the shoulder, which, if effectually hit,

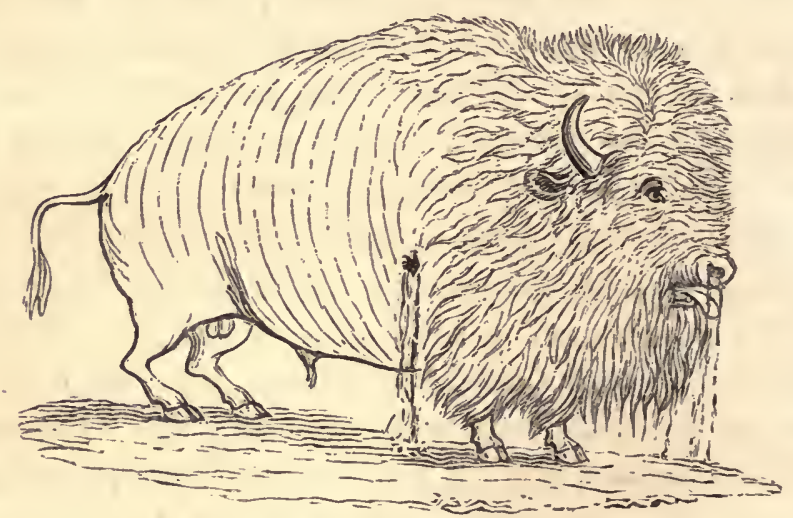

Wounded Bison, after Catlin. 
causes them to drop at once; otherwise they are infuriated, and become dangerous antagonists, as was proved in the result of Mr. M'Donald's adventure.

When flying before their pursuers, it would be in vain for the foremost to halt, or attempt to obstruct the progress of the main body, as the throng in the rear, still rushing onwards, the leaders must advance, although destruction await the movement. The Indians take advantage of this circumstance to destroy great quantities of this favorite game; and certainly no method could be resorted to more effectually destructive, nor could a more terrible devastation be produced, than that of forcing a numerous herd of these large animals to leap from the brink of a dreadful precipice upon a rocky and broken surface, a hundred feet below.

When the Indians determine to destroy Bisons in this way, one of their swiftest-footed and most active young men is selected, who is disguised in a Bison skin, having the head, ears, and horns adjusted on his own head, so as to make the deception very complete; and thus accoutred, he stations himself between the Bison herd and some of the precipices, which often extend for several miles along the rivers. The Indians surround the herd as nearly as possible, when, at a given signal, they show themselves, and rush forward with loud yells. The animals being alarmed, and seeing no way open but in the direction of the disguised Indian, run towards him, and he, taking to flight, dashes on to the precipice, where he suddenly secures himself in some previously ascertained crevice. The foremost of the herd arrives at the brink, - there is no possibility of retreat, no chance of escape; the foremost may, for an instant, shrink with 
terror, but the crowd behind, who are terrified by the approaching hunters, rush forward with increasing impetuosity, and the aggregate force hurls them successively into the gulf, where certain death awaits them.

Sometimes they are taken by the following method:A great number of men divide and form a vast square; each band then sets fire to the dry grass of the savannah, where the herds are feeding; seeing the fire advance on all sides, they retire in great consternation to the centre of the square; the men then close and kill them without the least hazard.

Great numbers are also taken in pounds, constructed with an embankment of such an elevation as to prevent the return of the Bisons when once they are driven into it. A general slaughter then takes place with rifles or arrows.

The following vivid sketch is from the narrative of John Tanner, who, when about seven or eight years of age, was stolen from his parents by the Indians, and remained with them during a period of thirty years.

"By the end of the second day after we left Pembinah we had not a mouthful to eat, and were beginning to be very hungry. When we laid down in our camp (near Craneberry River) at night, and put our ears close to the ground, we could hear the tramp of the buffaloes, but when we sat up we could hear nothing; and on the following morning nothing could be seen of them; though we could command a very extensive view of the prairie. As we knew they must not be far off in the direction of the sounds we had heard, eight men, of whom I was one, were selected and dispatched to kill some, and bring the meat to a point where it was agreed the 
party should stop next night. The noise we could still hear next norning, by applying our ears to the ground; and it seemed about as far distant, and in the same direction, as before. We started early, and rode some hours before we could begin to see them; and when we first discovered the margin of the herd, it must have been at least ten miles distant. It was like a black line drawn along the edge of the sky, or a low shore seen across a lake. The distance of the herd from the place where we first heard them could not have been less than twenty miles. But it was now the rutting season, and various parts of the herd were all the time kept in rapid motion by the severe fights of the bulls. To the noise produced by the knocking together of the two divisions of the hoof, when they raised their feet from the ground, and of their incessant tramping, was added the loud and furious roar of the bulls, engaged, as they all were, in their terrific and appalling conflicts. We were conscious that our approach to the herd would not occasion the alarm now, that it would at any other time, and we rode directly towards them. As we came near we killed a wounded bull, which scarcely made an effort to escape from us. He had wounds in his flanks, into which I could put my whole hand. As we knew that the flesh of the bulls was not now good to eat, we did not wish to kill them, though we might easily have shot any number. Dismounting, we put our horses in the care of some of our number, who were willing to stay back for that purpose, and then crept into the herd to try to kill some cows. I had separated from the others, and advancing, got entangled among the bulls. Before I found an opportunity to shoot a cow, the bulls began 
to fight very near me. In their fury they were totally unconscious of my presence, and came rushing towards me with such violence, that in some alarm for my safety, I took refuge in one of those holes which are so frequent where those animals abound, and which they themselves dig to wallow in. Here I found they were pressing directly upon me, and I was compelled to fire to disperse them, in which I did not succeed until I had killed four of them. By this firing the cows were so frightened, that I perceived I should not be able to kill any in this quarter; so regaining my horse, I rode to a distant part of the herd, where the Indians had succeeded in killing a fat cow. But from this cow, as is usual in similar cases, the herd had all moved off, except one bull, who, when I came up, still kept the Indians at bay. 'You are warriors,' said I, as I rode up, 'going far from your own country, to seek an enemy, but you cannot take his wife from that old bull, who has nothing 'in his hands.' So saying, I passed them directly towards the bull, then standing something more than two hundred yards distant. $\mathrm{He}$ no sooner saw me approach, than he came plunging towards me with such impetuosity, that, knowing the danger to my horse and myself, I turned and fled. The Indians laughed heartily at my repulse, but they did not give over their attempts to get at the cow. By dividing the attention of the bull, and crceping up to him on different sides, they at length shot him down. While we were cutting up the cow, the herd were at no great distance; and an old cow, which the Indians supposed to be the mother of the one we had killed, taking the scent of the blood, came running with great violence towards us. The Indians were alarmed and fled, many of them not having their 
guns in their hands; but I had carefully reloaded mine, and had it ready for use. Throwing myself down close to the body of the cow, and behind it, I waited till the other came up within a few yards of the carcase, when I fired upon her; she turned, gave one or two jumps, and fell dead. We had now the meat of two fat cows, which was as much as we wanted; accordingly we repaired, without delay, to the appointed place, where we found our party, whose hunger was already somewhat allayed by a deer one of them had killed."

In hunting the Bison, the spear and the arrow are still much in use among the Indians. The following sketch (after Catlin) represents an Indian in the act of shooting a Bison with the arrow :-



In the 'Letters and Notes on the North-American Indians,' by Catlin, there are a great many interesting details of the Bison (or Buffalo, as it is there called).

"Six days of severe travelling have brought us from the Camanchee village to the north bank of the Canadian, where we are snugly encamped on a beautiful plain, and in the midst of countless numbers of buffaloes; and halting a few days to recruit our horses and men, and dry meat to last us the remainder of our journey. 
"The plains around this, for many miles, seem actually speckled, in distance and in every direction, with herds of grazing buffaloes; and for several days, the officers and men have been indulged in a general license to gratify their sporting propensities; and a scene of bustle and cruel slaughter it has been, to be sure! From morning till night, the camp has been daily almost deserted. The men have dispersed in little squads, in all directions, and are dealing death to these poor creatures to a most cruel and wanton extent, merely for the pleasure of destroying, generally without stopping to cut out the meat. During yesterday and to day, several hundreds have undoubtedly been killed, and not so much as the flesh of half a dozen used. Such immense swarms of them are spread over this tract of country, and so divided and terrified have they become, finding their enemies in all directions where they run, that the poor beasts seem completely bewildered, running here and there, and, as often as otherwise, come singly advancing to the horsemen, as if to join them for their company, and are easily shot down. In the turmoil and confusion, when their assailants have been pushing them forward, they have galloped through our encampment, jumping over our fires, upsetting pots and kettles, driving horses from their fastenings, and throwing the whole encampment into the greatest consternation and alarm."

Speaking of the attacks made upon them by the Wolves, he says, "When the herd is together the Wolves never attack them, as they instantly gather for combined resistance, which they effectually make. But when the herds are travelling, it often happens that an aged or wounded one lingers at a little distance behind, and when 
fairly out of sight of the herd, is set upon by the voracious hunters, which often gather to the number of fifty or more, and are sure at last to torture him to death, and use him up at a meal. The Buffalo, however, is a huge and furious animal, and when his retreat is cut off, makes desperate and deadly resistance, contending to the last moment for the right of life, and oftentimes deals death by wholesale to his canine assailants.

"During my travels in these regions, I have several times come across such a gang of these animals surrounding an old or wounded bull, where it would seem, from appearances, that they had been for several days in attendance, and at intervals desperately engaged in the effort to take his life. But a short time since, as one of my hunting companions and myself were returning to our encampment, with our horses loaded with meat, we discovered at a distance a huge bull, encircled with a gang of white wolves. We rode up as near as we could without driving them away; and being within pistol-shot, we had a remarkably good view, where I sat for a few moments and made a sketch in my note-book. After which we rode up, and gave the signal for them to disperse, which they instantly did, withdrawing themselves to the distance of fifty or sixty rods, when we found, to our great surprise, that the animal had made desperate resistance, until his eyes were entirely eaten out of his head; the gristle of his nose was mostly gone; his tongue was half eaten off, and the skin and flesh of his legs torn almost literally into strings. In this tattered and torn condition the poor old veteran stood bracing up in the midst of his devourers, who had ceased hostilities for a few minutes, to enjoy a sort of parley, 
recovering strength to resume the attack in a few moments again. In this group, some were reclining to gain breath, whilst others were sneaking about, and licking their chaps in anxiety for a renewal of the attack; and others, less lucky, had been crushed to death by the feet or the horns of the bull. I rode nearer to the pitiable object, as he stood bleeding and trembling before me, and said to him,_ "Now is your" time, old fellow, and you had better be off." Though blind, and nearly destroyed, he straightener up, and, trembling with excitement, dashed off at full speed upon the prairie, in a straight line. We turned our horses, and resumed our march; and when we had advanced a mile or more, we looked back, and again saw the ill-fated animal surrounded by his tormentors, to whose insatiable voracity he unquestionably soon fell a victim."

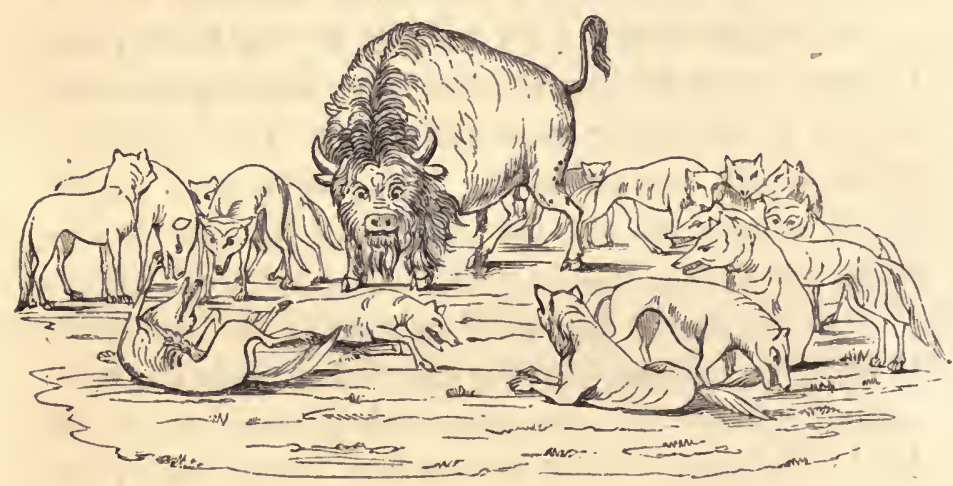

Bison surrounded by Wolves, after Catlin.

It has frequently been noticed, that whenever a female Bison, having a calf, is slain, the young one remains by its fallen dam, with signs of strong natural affection, 
and instinctively follows the inanimate carcase of its parent to the residence of the hunter. In this way many calves are secured.

According to Mr. Catlin's account these young animals are induced to follow any one who merely breathes in their nostrils. "I have often," says he, "in concurrence with a known custom of the country, held my hands over the eyes of the calf, and breathed a few strong breaths into its nostrils; after which I have, with my hunting companions, rode several miles into our encampment, with the little prisoner busily following the heels of my horse the whole way, as closely as its instinct would attach it to the company of its dam.

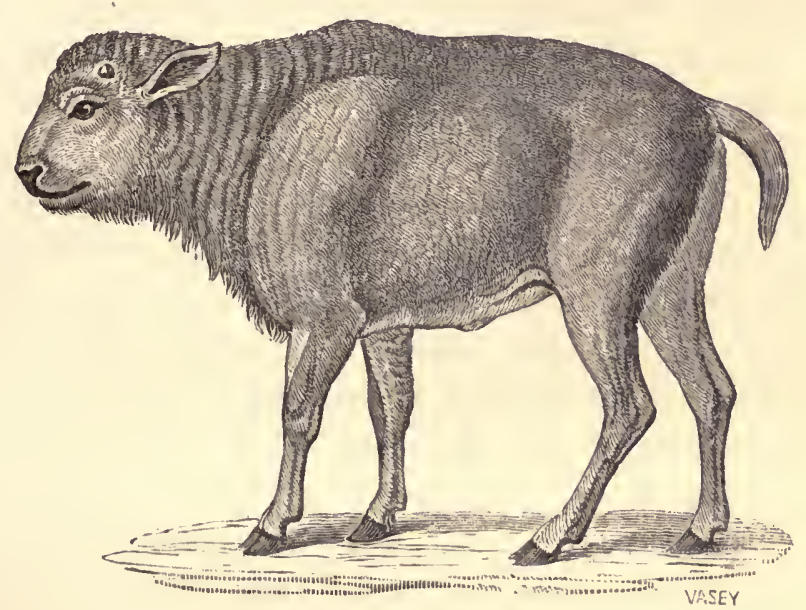

Bison Calf, about three weeks old.

"This is one of the most extraordinary things that I have met with in the habits of this wild country; and although $I$ had often heard of it, and felt unable exactly to believe it, I am now willing to bear testimony to the fact, from the numerous instances which I have witnessed 
since I came into the country. During the time that I resided at this post (Teton River) in the spring of the year, on my way up the river, I assisted in bringing in, in the above manner, several of these little prisoners, which sometimes followed for five or six miles close to our horse's heels, and even into the Fur Company's Fort, and into the stable where our horses were led. In this way, before I left for the head waters of the Missouri, I think we had collected about a dozen, which Mr. Laidlaw was successfully raising with the aid of a good milch cow, and which were to be committed to the care of Mr. Chouteau, to be transported, by the return of the steamer, to his extensive plantation in the vicinity of St. Louis."

The uses which are made of the various parts of the Bison are numerous. The hide, which is thick and rather porous, is converted by the Indians into mocassins for the winter; they also make their shields of it. When dressed with the hair on, it is made into clothing by the natives, and most excellent blankets by the European settlers; so valuable, indeed, is it esteemed, that three or four pounds sterling a piece are not unfrequently given for good ones in Canada, where they are used as travelling cloaks. The fleece, which sometimes weighs eight pounds, is spun and wove into cloth. Stockings, gloves, garters, \&c., are likewise knit with it, appearing and lasting as well as those made of the best sheep's wool. In England it has been made into remarkably fine cloth.

"There are," says Catlin, "by a fair calculation, more than 300,000 Indians who are now subsisting on the flesh of the buffaloes, and by these animals supplied 
with all the luxuries of life which they desire, as they know of none others. The great variety of uses to which they convert the body and other parts of that animal, are almost incredible to the person who has not actually dwelt amongst these people, and closely studied their modes and customs. Every part of their flesh is converted into food, in one shape or other, and on it they entirely subsist. The skins of the animals are worn by the Indians instead of blankets; their skins, when tanned, are used as coverings for their lodges and for their beds; undressed, they are used for constructing canoes, for saddles, for bridles, l'arrêts, lasos, and thongs. The horns are shaped into ladles and spoons; the brains are used for dressing the skins; their bones are used for saddle-trees, for war-clubs, and scrapers for graining the robes; and others are broken up for the marrow fat which is contained in them. The sinews are used for strings and backs to their bows, for thread to string their beads and sew their dresses. The feet of the animals are boiled, with their hoofs, for the glue they contain, for fastening their arrow points, and many other uses. The hair from the head and shoulders, which is long, is twisted and braided into halters, and the tail is used for a fly-brush."

Again (vol. ii, p. 138), he says, "I have introduced the skin canoes of the Mandans (of the Upper Missouri), which are made almost round like a tub, by straining a buffalo's skin over a frame of wicker-work, made of willow or other boughs. The woman, in paddling these awkward tubs, stands in the bow, and makes the stroke with the paddle, by reaching it forward in the water, and drawing it to her, by which means she pulls the 
canoe along with considerable speed. These very curious and rudely-constructed canoes are made in the form of the Welsh coracle; and, if I mistake not, propelled in the same manner, which is a very curious circumstance; inasmuch as they are found in the heart of the great wilderness of America, where all the surrounding tribes construct their canoes in decidedly different forms, and of different materials."

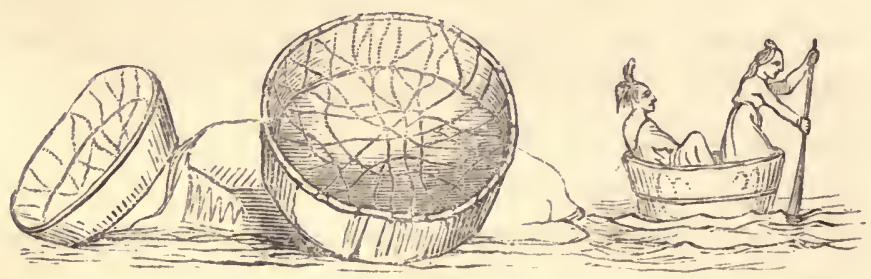

Skin Canoes of the Mandan Indians.

It is generally agreed by travellers, that the flesh of the Bison is little inferior to the beef of our domestic oxen. The tongue is considered a delicacy, and the hump is much esteemed. A kind of potted-beef, called pemmican, is made of the flesh of the Bison, in the following manner:-The flesh is spread on a skin, dried in the sun, and pounded with stones; then all the hair is carefully sifted out of it, and melted fat kneeded into it. This, when properly made and kept dry, will keep good for twelve months. The tallow of the Bison forms an important article of commerce; one fat bull yielding sometimes as much as 150 pounds weight.

Mr. Turner, a gentleman long resident in America, is of opinion, that the Bison is superior even to our domestic cattle for the purposes of husbandry, and has expressed a wish to see this animal domesticated on the 
English farms. He informs us, that a farmer on the great Kenhawa broke a young Bison to the plough; and having yoked it with a steer, taken from his tame cattle, it performed its work to admiration. But there is another property in which the Bison far surpasses the Ox, and this is his strength. "Judging from the extraordinary size of his bones, and the depth and formation of the chest, (continues this gentleman,) I should not think it unreasonable to assign nearly a double portion of strength to this powerful inhabitant of the forest. Reclaim him, and you gain a capital quadruped, both for the draught and for the plough; his activity peculiarly fits him for the latter, in preference to the ox."

As there are no Game Laws in America, (except in a very few confined instances on the Atlantic border,) the consequence is that the Bison is fast disappearing before the approach of the white settlers. At the commencement of the eighteenth century these wild cattle were found in large numbers all throughout the valley of the Ohio, of the Mississippi, in Western New York, in Virginia, \&c. In the beginning of the present century they were still existing in the extreme western or southwestern part of the State of New York. As late as 1812 they were natives of Ohio, and numerous in that State. And now they are not to be seen in their native state in any part of the United States, east of the Mississippi River; nor are they now to be found in any considerable numbers west of that great river, until you have travelled some eighty or a hundred miles into the interior of the country.

There were no Bisons west of the Rocky Mountains, when Lewis and Clarke travelled there in 1805 . On 
their return from the Colnmbia, or Oregon River, in July of that year, the first Bison they saw was on the day after they commenced their descent of the Rocky Mountains towards the east. On the second day after that, they saw immense herds of them on the banks of the Medicine River. One collection of these animals which they subsequently saw, on the borders of the Missouri River, they estimated as being at least 20,000 in number.

In 1823 it was discovered that the Bisons had crossed the Rocky Mountains, and some were to be seen in the vallies to the west of that range.

East of that range of mountains, these animals migrate from the uplands or mountains to the plains, and from north to south, about the beginning of November; and return from the south to the north, and from the plains to the uplands, soon after the disappearance of the snow in the spring.

The herds of Bisons wander over the country in search of food, usually led by a bull remarkable for strength and fierceness. While feeding, they are often scattered over a great extent of country; but when they move, they form a dense and almost impenetrable column, which, when once in motion, is scarcely to be impeded. Their line of march is seldom interrupted, even by considerable rivers, across which they swim, without fear or hesitation, nearly in the order in which they traverse the plains. The Bisons which frequent the woody parts of the country form smaller herds than those which roam over the plains, but are said to be individually of a greater size.

The rutting takes place the latter part of July and 
the beginning of August, after which the cows separate from the bulls in distinct herds. They bring forth their young in April : from which it appears that the term of gestation is about nine months.

The pair of American Bisons in the Zoological Gardens produced a calf in 1849 ; from the observations made in that instance, the period of gestation was calculated at 270 days.

The most important anatomical difference between the American and the European is, that the American has fifteen pairs of ribs, whereas the European has but fourteen.

The following are the dimensions of a large specimen:-

From the nose to the insertion of the tail . $\begin{array}{cc} & \text { Ft. In. } \\ 8 & 6 \\ 6 & 0 \\ \text { Height at the shoulder . } & \cdot \\ \text { Length of the head }\end{array}$

Their weights vary from 1200 to 2000 pounds.

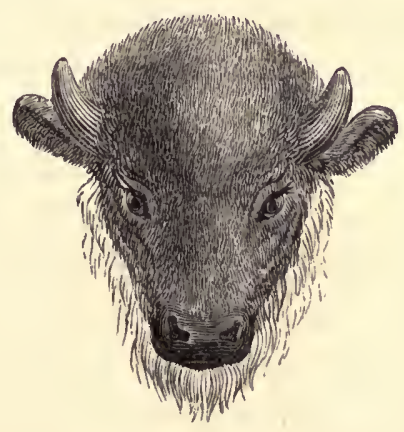

Head of young male Bison. 


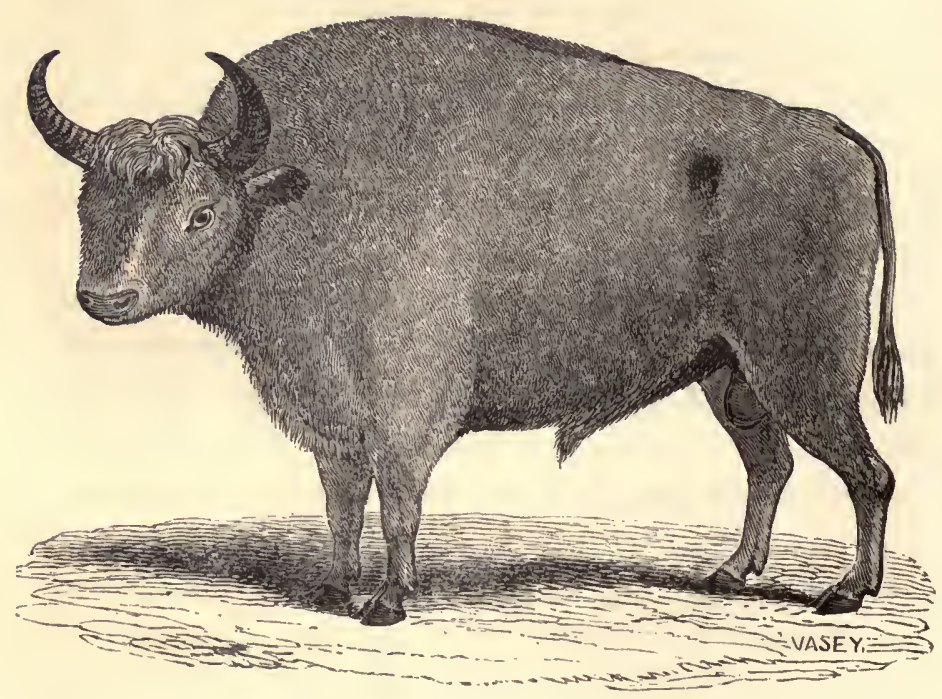

THE AUROCHS, OR EUROPEAN BISUN.

\section{Bos Bison.}

In this, as in the American species, the head is very broad, and the forehead arched; but the horns are longer, more curved, and end in a finer point than those of the American Bison. The eyes are large and dark; the hair on the forehead is long and wavy; under the chin and on the breast it forms a sort of beard. In winter, the whole of the neck, hump, and shoulders are covered with a long woolly hair of a dusky brown colour, intermingled with a short soft fur of a fawn colour. The long hair is gradually cast in the summer, to be again renewed as the inclemency of winter comes on. The legs, back, and 
posterior portions are covered with short, dark brown hair. The tail is of a moderate length, is covered with hair, and terminates in a large tuft.

The females are not so large as the males, neither are they characterised by that abundance of hair on the anterior parts, which is so conspicuous in the bulls.

These animals have never been domesticated, although calves have sometimes been caught, and confined in an enclosed pasture. An instance of this kind is recorded by Mr. Gilibert, who, while in Poland, had the opportunity of observing the character of four young ones thus reared in captivity. They were suckled by a she-goat, obstinately refusing to touch a common cow. This antipathy to the domestic cow, which they manifested so early, maintained its strength as they advanced in years; their anger was sure to be excited at the appearance of any domestic cattle, which, whenever introduced to them, they vigorously expelled from their pasture. They were, however, sufficiently tame to acknowledge the voice of their keeper.

The geographical range of this animal is now comparatively very limited, being confined to the forests of Lithuania, Moldavia, Wallachia, and some of the Caucasian mountain forests; yet there can be no doubt that, at an early period, they roamed at large over a great part of both Europe and Asia.

Although they have never been, strictly speaking, domesticated, yet herds of them are kept in certain localities in the forest of Bialowieza, under the special protection of the Emperor of Russia, and under the immediate superintendence of twelve herdsmen, each herdsman keeping the number allotted to his charge in a particular department of the forest, near some river 
or stream. The estimated number of the twelve herds is about 800 .

They feed on grass and brushwood; also on the leaves and bark of young trees, particularly the willow, poplar, ash, and birch. In autumn they likewise browse on heath, and the lichens which cover the bark of trees. In winter, when the ground is covered with snow, fodder is provided for them.

Their cry is quite peculiar, resembling a groan, or a grunt, more than the lowing of an ox.

They do not attain their full stature until after the sixth year, and live till between thirty and forty.

"The strength of the Zubr," says Dr. Weissenborn, " is enormous; and trees of five or six inches diameter cannot withstand the thrusts of old bulls. It is neither afraid of wolf nor bear, and assails its enemies both with its horns and hoofs. An old Zubr is a match for four wolves; packs of the latter animal, however, sometimes hunt down even old bulls when alone; but a herd of Zubrs has nothing to fear from any rapacious animal.

"Notwithstanding the great bulk of its body, the Zubr can run very swiftly. In galloping, its hoofs are raised above its head, which it carries very low. The animal has, however, but little bottom, and seldom runs farther than one or two English miles. It swims well, and is very fond of bathing.

"The zubr is generally exceedingly shy, and avoids the approach of man. They can only be approached from the leeward, as their smell is extremely acute. But when accidentally and suddenly fallen in with, they will passionately assail the intruder. In such fits of passion the animal thrusts out its tongue repeatedly, lashes its 
sides with its tail, and the reddened and sparkling eyes project from their sockets, and roll furiously. Such is their innate wildness, that none of them have been completely tamed. When taken young they become, it is true, accustomed to their keepers, but the approach of other persons renders them furious; and even their keepers must be careful always to wear the same sort of dress when going near them. Their great antipathy to the Bos Taurus, which they either avoid or kill, would render their domestication, if it were practicable, but little desirable. The experiments made with a view of obtaining a mixed breed from the Zubr and Bos Taurus have all failed, and are now strictly prohibited."

The rutting season is in August, and continues for about a fortnight; the calves are produced in May; thus, the period of gestation is between nine and ten months. The calves continue to suckle nearly twelve months, and the cows seldom calve oftener than once in three years.

The European Bison differs internally from the common $\mathrm{ox}$ in having fourteen pairs of ribs, whereas the common ox has but thirteen. The external differences between the two animals are too obvious to require pointing out.

In 1845, the Emperor of Russia presented to the British Museum a very fine stuffed specimen of this animal, from which the figure at the head of this chapter was taken.

The following are its dimensions :-

Length from the nose to the insertion of the tail . 910 Height at the withers . . . . . 56 " at the rump . . . . . . 411 Length of head . . . . . 18 " of tail . . . . . 30 
M. Dimitri de Dolmatoff, Master of the Imperial Forests in the Government of Grodno, in his note of the capture of the Aurochs, (written in 1847,) alludes to the statement (made by every writer who has treated of these animals), that the calves, although taken young, invariably refuse to be suckled by the Domestic Cow. This he contradicts in the most explicit manner, on the testimony of his own experience, having had several instances come under his observation, in which the young calves of the Aurochs were suckled and reared by cows of the common domestic species.

Cæsar, in his account of the "Sylva Hercynia"-the Black Forest-thus mentions the Urus, amongst other animals, there found :

"A third kind [of animals] are those called Uri. They are but little less than Elephants in size, and are of the species, colour, and form of a bull. Their strength is very great, and also their speed. They spare neither man nor beast that they see. They cannot be brought to endure the sight of men, nor be tamed, even when taken young. The people who take them in pit-falls, assiduously destroy them; and young men harden themselves in this labour, and exercise themselves in this kind of chase ; and those who have killed a great number-the horns being publicly exhibited in evidence of the fact-obtain great honour. The horns, in amplitude, shape, and species, differ much from the horns of our oxen. They are much sought after; and after having been edged with silver at their mouths, they are used for drinking vessels at great feasts." (De Bello Gallico, lib. vi.) 


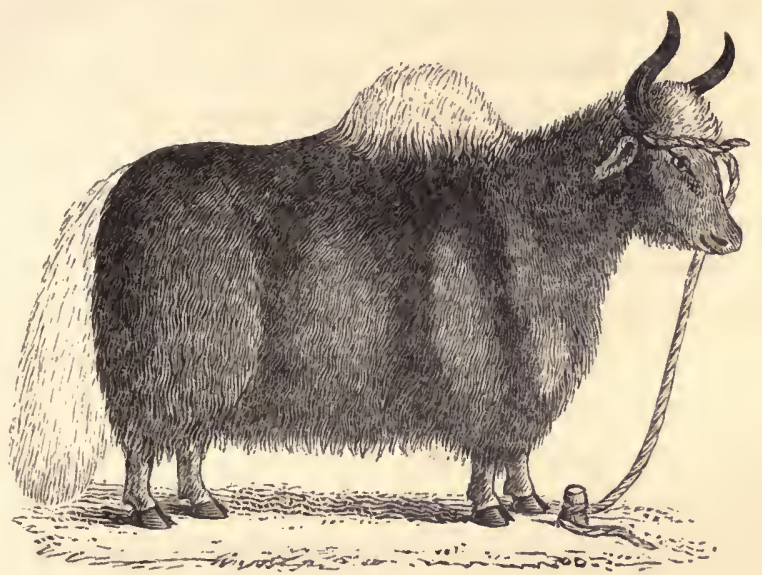

THE YAK, OR SOORA-GOY.

Bos Grunniens.

The following interesting and circumstantial account of this curious species of $\mathrm{Ox}$, is from the pen of Lieut. Samuel Turner. (Asiatic Researches, vol. iv.)

"The Yak of Tartary, called Soora-Goy in Hindostan, and which I term the Bushy-tailed Bull of Tibet, is about the height of an English Bull, which he resembles in the figure of the body, head, and legs. I could distinguish between them no essential difference, except only that the Yak is covered all over with a thick coat of long hair. The head is rather short, crowned with two smooth round horns, that, tapering from the setting on, terminate in sharp points, arch inwardly, and near the extremities are a little turned back. The ears are small; the forehead appears prominent, being adorned with much curling hair ; the eyes are full and large; the nose smooth and convex; 
the nostrils small. The neck is short, describing a curvature nearly equal both above and below; the withers high and arched; the rump low. Orer the shoulders rises a bunch, which at first sight would seem to be the same kind of exuberance peculiar to the cattle of Hindostan; but in reality it consists in the superior length of the hair only, which, as well as that along the ridge of the back to the setting on of the tail, grows long and erect, but not harsh. The tail is composed of a prodigious quantity of long flowing glossy hair, descending to the hock; and is so extremely well furnished, that not a joint of it is perceptible; but it has much the appearance of a large bunch of hair artificially set on. The shoulders, rump, and upper part of the body are clothed with a sort of thick soft wool, but the inferior parts with straight pendent hair that descends below the knee; and I have seen it so long in some cattle, which were in high health and condition, as to trail along the ground. From the chest, between the fore-legs, issues a large pointed tuft of hair, growing somewhat larger than the rest. The legs are very short. In every other respect, hoofs, \&c., he resembles the ordinary Bull. There is a great variety of colours among them, but black and white are the most prevalent. It is not uncommon to see the long hair upon the ridge of the back, the tail, the tuft upon the chest, and the legs below the knee white, when all the rest of the animal is jet black.

"These cattle, though not large boned, from the profuse quantity of hair with which they are provided, appear of great bulk. They have a down heavy look, but are fierce, and discover much impatience at the near approach of strangers. They do not low loud (like the 
cattle of England) any more than those of Hindostan; but make a low grunting noise, scarcely audible, and that but seldom, when under some impression of uneasiness. These cattle are pastured in the coldest part of Tibet, upon short herbage, peculiar to the tops of mountains and bleak plains. That chain of lofty mountains situated between lat. $27^{\circ}$ and $28^{\circ}$, which divides Tibet from Bootan, and whose summits are most commonly covered with snow, is their favourite haunt. In this vicinity the Southern glens afford them food and shelter during the severity of the winter; in milder seasons the Northern aspect is more congenial to their nature, and admits a wider range. They are a very valuable property to the tribes of illiterate Tartars, who live in tents, and tend them from place to place, affording their herdsmen a mode of conveyance, a good covering, and subsistence. They are never employed in agriculture, but are extremely useful as beasts of burden; for they are strong, surefooted, and carry a great weight. Tents and ropes are manufactured of their hair, and I have seen, though amongst the humblest ranks of herdsmen, caps and jackets worn of their skins. Their tails are esteemed throughout the East, as far as luxury or parade have any influence on the manners of the people; and on the continent of India are found, under the denomination of Chowries, in the hands of the meanest grooms, as well as, occasionally, in those of the first ministers of state. Yet the best requital with which the care of their keepers is at length rewarded for selecting them good pastures, is in the abundant quantity of rich milk they give, yielding most excellent butter, which they have a custom of depositing in skins or bladders, and excluding the air; it keeps in this cold 
climate all the year, so that after some time tending their flocks, when a sufficient stock is accumulated, it remains only to load their cattle, and drive them to a proper market with their own produce, which constitutes, to the utmost verge of Tartary, a most material article of commerce."

The soft fur upon the hump and shoulders is manufactured by the natives of Tibet into a fine but strong cloth; and, if submitted to the test of European skill, might no doubt be made to produce a very superior fabric.

The herdsmen commonly convert the hides into a loose outer garment that covers the whole of their bodies, hanging down to the knees; and it proves a sufficient protection against the lowest temperature of the cold and desolate region which they inhabit. It furnishes at once a cloak by day and a bed by night.

The Yak is not generally fierce, but, if intruded upon by strangers, it sometimes manifests very formidable symptoms of impatience, stamping its feet, whisking its tail aloft, and tossing its head. When excited, it is not easily appeased, and is exceedingly tenacious of injury, always showing great fierceness whenever any one approaches who has chanced to provoke it.

The cow is called Dhe, of which the wandering Tartars possess great numbers, having no means of subsistence but those supplied by their flocks and herds.

A fine male specimen of this Ox was brought to England by Warren Hastings, and several attempts were made to procure a cross between it and the common English Cow, but without success. He invariably refused to associate with ordinary cattle, and exhibited a decided antipathy to them. His portrait was painted, and is now 
in the Museum of the College of Surgeons, London. The following figure (taken from the 'Oriental Annual') is so much like the portrait of Warren Hastings's Yak, that it might almost be taken for a copy of it.

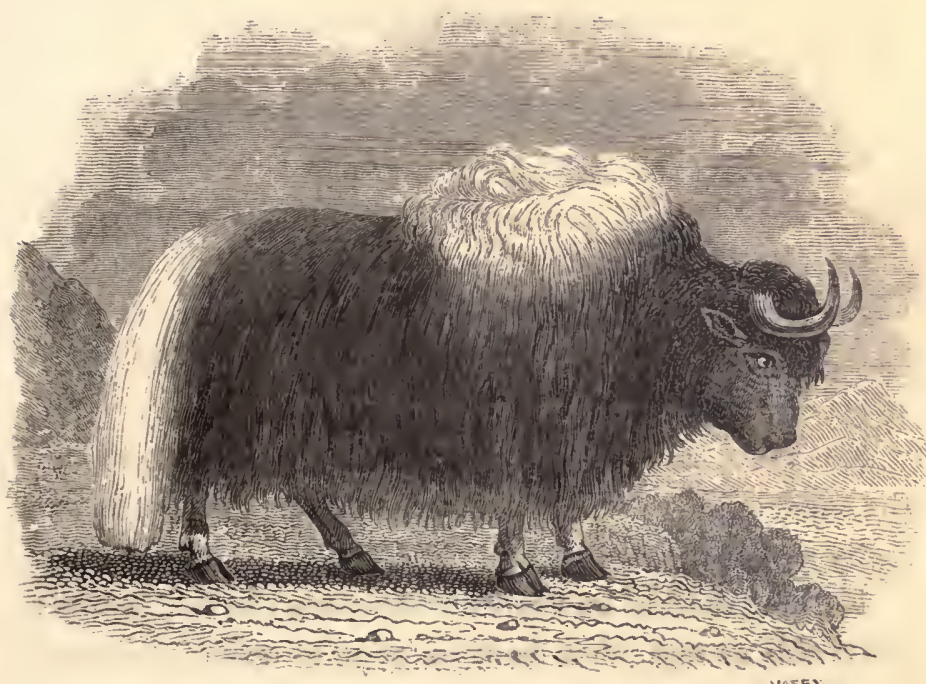

VASEV:

There is the skin of a Yak in the Zoological Museum, which coincides pretty ncarly with the foregoing description. There is also a stuffed specimen of a female in the British Museum.

- Like the European Bison, the skeleton of the Yak has fourteen pairs of ribs. Period of gestation not recorded. 


\section{THE GYALL,}

(Bos Frontalis of Lambert;)

THE GAYAL,

(Bos Gavaus of Colebrooke;)

THE JUNGLY GAU,

(Bos Sylhetanus of F. Cuvier.)

Of the animals named in the foregoing list, we have had several very interesting accounts; but none of these have been sufficiently precise to enable us to determine the specific character of the animals described.

Are they, as some affirm, merely different names for the same animal; or do they designate animals which are really and truly distinct?

Nothing short of an appeal to structure can satisfactorily settle this or any other disputed point of a similar nature; but, unfortunately for zoology, the opportunities for such appeals are rare, and, when they do occur, are seldom taken advantage of. Let us hope that this hint will not be lost on some of our intelligent countrymen in the East; and that before long we may be favoured with the result of their researches.

In the meantime, and in order to facilitate as much as possible the endeavours of those who may have opportunities for such inquiries, the following epitome is given of the various papers which have already appeared on the subject, but which, in their present scattered form, are of very little general utility. 


\section{THE GYALL.}

The earliest descriptive notice we have of the Gyall was that given in a paper read before the Linnean Society, in 1802, by Mr. Lambert, on the occasion of a bull of this species arriving in London from Indis.

\section{"Bos Frontalis.}

"General colour a blueish-black ; the frontal fascia gray ; the horns short, thick, and distant at their bases, the tail nearly naked, slender, and with a tuft at the end. The Gyall has no mane; its coat is soft ; the edge of the under lip is white, and is fringed with bristling hair. The horns are pale, with their bases included in the frontal fascia."

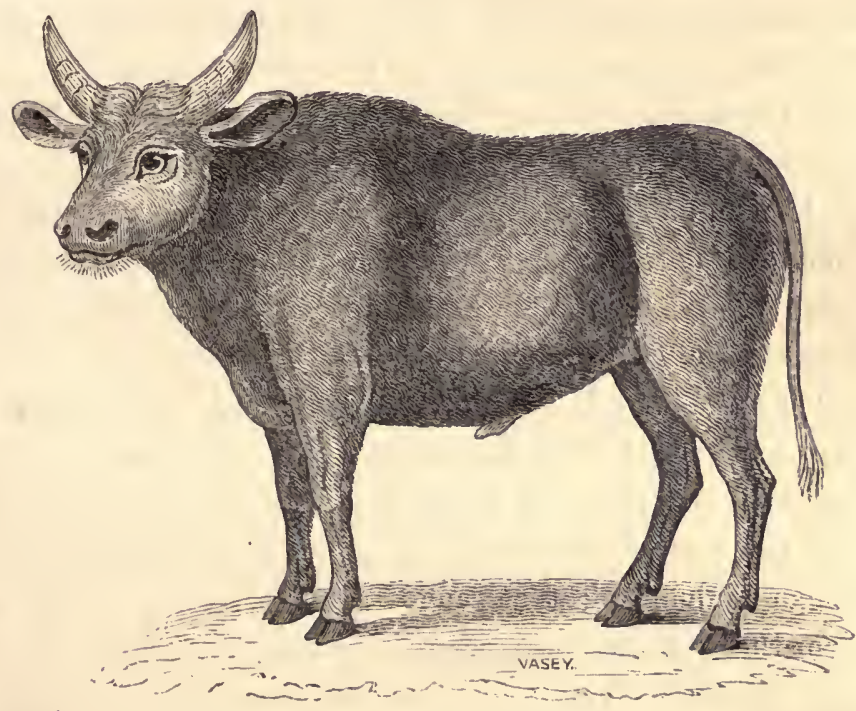

The Gyall, redueed-from the Linnean Trausactions.

The animal of which this description is given, appeared to be between two and three years old, very tame, and in- 
offensive. A drawing was taken of it, which was engraved and published in the Linnean Transactions.

The following are its dimensions :

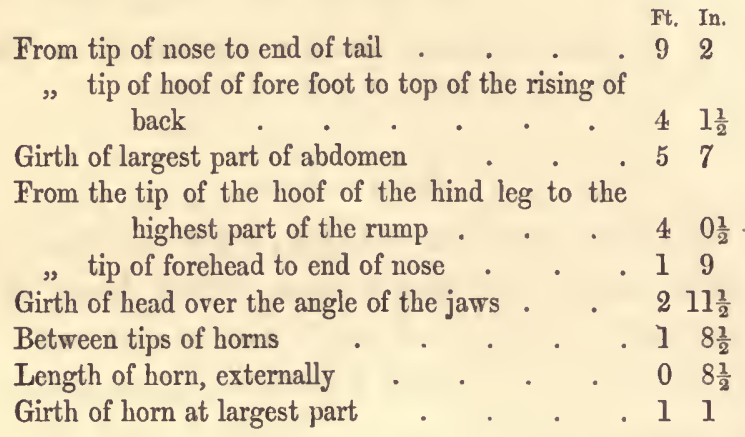

In reply to some inquiries respecting this animal which he made of a gentleman, (Mr. Harris,) resident in India, Mr. Lambert received the following :

"Dear Sir, - I have before me your note, with the drawing, which undoubtedly appears to me to be the figure of the animal I mentioned to have in my possession. Some parts of the drawing seem to be rather too much enlarged, as in the base of the horns, and the rising between the fore shoulders.

"The animal I described to you, and which $I$ have kept and reared these last seven years, and know by the name of the Gyall, is a native of the hills to the north east and east of the Company's province of Chittagong, in Bengal, inhabiting that range of hills which separates it from the country of Arracan.

" The male Gyall is like our Bull in shape and appearance, but I conceive not quite so tall; it is of a blackishbrown colour; the horns short, but thick and strong towards the base, round which, and across the frons, the 
hair is bushy, and of a dirty white colour; the chest and forehead are broad and thick. He is naturally very bold, and will defend himself against any of the beasts of prey.

"The female differs a little in appearance; her horns are not quite so large, and her make is somewhat more slender. She is very quiet, and is used for all the purposes of the dairy; as also, (I have been informed by the natives,) for tilling the ground, and is more tractable than the Buffalo. The milk which these cows give has a peculiar richness in it, arising, I should conceive, from their always feeding on the young shoots and branches of trees in preference to grass.

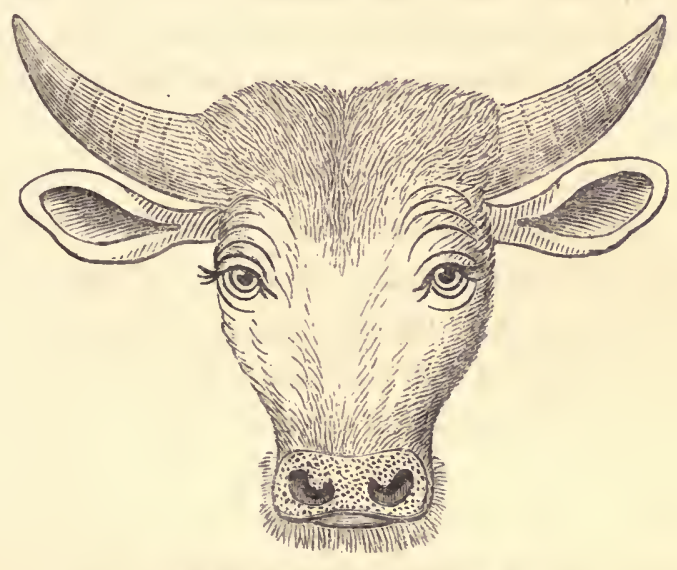

(Head of Gyall, from Linnean Transactions.)

"I constantly made it a practice to allow them to range abroad, amongst the hills and jungles at Chittagong, during the day, to browse; a keeper attending to prevent their straying so far as to endanger losing them. They do not thrive so well in any part of Bengal as in the 
afore-mentioned proviuce, and in the adjoining one, Pipperah, where, I believe, the animal is also to be found. I have heard of a female Gyall breeding with a common Bull. I wish it were in my power to give you more particulars, but I am describing entirely from memory."

In February, 1804, Mr. Lambert again addressed the Liunean Society on the same subject. He says, "Since I presented to the Society the last account of the Bos Frontalis, or Gyall of India, Mr. Fleming, a gentleman who has just returned from that country, has very obligingly communicated to me the following further particulars. This account was transmitted to Mr. Fleming by Mr. Macrae, resident at Chittagong, in a letter, dated March 22, 1802, and was accompanied with a drawing, by which it appears that the animal from which my figure was taken was full grown." (See the figure, p. 51.)

\section{Mr. Macrae's Account.}

The Gyall is a species of cow peculiar to the mountains, which form the eastern boundary of the province of Chittagong, where it is found running wild in the woods; and it is also reared as a domestic animal by the Kookies, or Lunclas, the inhabitants of those hills. It delights to live in the deepest jungles, feeding on the tender leaves and shoots of the brushwood; and is never met with on the plains below, except when brought there. Such of them as have been kept by the gentlemen at Chittagong, have always preferred browsing among the thickets on the adjacent hills to feeding on the grass of the plains.

It is of a dull heavy appearance, yet of a form that indicates both strength and activity; and approaches nearly to that of the wild Buffalo. Its head is set on 
like the Buffalo's, and it carries it much in the same manner, with the nose projecting forward; but in the shape of the head it differs materially from both the Buffalo and the Cow, the head of the Gyall being much shorter from the crown to the nose, but much broader between the horns than that of either. The withers and shoulders of the Gyall rise higher in proportion than those of Buffalo or Cow, and its tail is small and short, seldom falling lower than the bend in the ham. Its colour is in general brown, varying from a light to a deep shade; it has at times a white forehead, and white legs, with a white belly and brush. The hair of the belly is invariably of a lighter colour than that of the back and flanks. The Gyall calf is of a dull red colour, which gradually changes to a brown as it advances in age.

The female Gyall receives the bull at three years of age; her term of gestation is eleven months, when she brings forth, and does not again admit the male until the second year thereafter, thus producing a calf once in three years only. So long an interval between each birth must tend to make the species rare. In the length of time she goes with young, as well as in that between each conception, the Gyall differs from the Buffalo and Cow. The Gyall does not give much milk, but what she yields is nearly as rich as the cream of other milk. The calf sucks its dam for eight or nine months, when it is capable of supporting itself. The Kookies tie up the calf until he is sufficiently strong to do so.

The Gyalls live to the age of from fifteen to twenty. They lose their sight as they grow old, and are subject to a disease of the hoof, which often proves fatal at an early age. When the Kookies consider the disease beyond the 
hope of cure, he kills the animal and eats the flesh, which constitutes his first article of luxury.

The Kookies have a very simple method of catching the wild Gyalls, which is as follows:-On discovering a herd of wild Gyalls in the jungles, they prepare a number of balls, of the size of a man's head, composed of a particular kind of earth, salt, and cotton. They then drive their tame Gyalls towards the wild ones, when the two herds soon meet, and assimilate into one; the males of the one attaching themselves to the females of the other, and vice versâ. The Kookies now scatter their balls over such parts of the jungle as they think the herd most likely to pass, and watch its motions. The Gyalls, on meeting these balls as they pass along, are attracted by their appearance and smell, and begin to lick them with their tongues; and relishing the taste of the salt, and the particular earth composing them, they never quit the place until all the balls are consumed. The Kookies having observed the Gyalls to have once tasted their balls, prepare a sufficient supply of them to answer the intended purpose; and as the Gyalls lick them up, they throw down more; and it is to prevent their being so readily destroyed that the cotton is mixed with the earth and the salt. This process generally goes on for three changes of the moon, or for a month and a half, during which time the tame and the wild Gyalls are always together, licking the decoy balls; and the Kookie, after the first day or two of their being so, makes his appearance, at such a distance as not to alarm the wild ones. By degrees he approaches nearer and nearer, until at length the sight of him has become so familiar that he can advanec to stroke his tame Gyalls on the back and 
neck; without frightening away the wild ones. He next extends his hand to them, and caresses them also, at the same time giving them plenty of his decoy balls to lick. Thus, in the short space of time mentioned, he is able to drive them, along with the tame ones, to his parrah, or village, without the least exertion of force; and so attached do the Gyalls become to the parrah, that when the Kookies migrate from one place to another, they always find it necessary to set fire to the huts they are about to abandon, lest the Gyalls should return to them from the new grounds.

It is worthy of remark that the new and full moon are the periods at which the Kookies in general commence their operations of catching the wild Gyalls, from having observed that at these changes the two sexes are most inclined to associate. The same observation has been made with respect to Elephants.

\section{THE GAYAL.}

About four years after the publication of Mr. Macrae's account of the Gyall (namely in 1808, there appeared, in the Eightl volume of 'A siatic Researches,' a description of a species of $\mathrm{Ox}$, named Gayal, communicated by H. T. Colebrooke.

He commences by observing, that "the Gayal was mentioned in an early volume of the 'Researches of the Asiatic Society,' (vol. ii, p. 188, 1790,) by its Indian name, which was explained by the phrase "Cattle of the mountains." It had been obscurely noticed (if indeed the same species of Ox be meant) by Knox, in his historical relation of Ceylon (p. 21); and it has been imperfectly 
described by Captain Turner, in his journey through Bootan, ('Embassy to Tibet,' p. 160).

"Herds of this species of cattle have been long kept by many gentlemen in the eastern districts of Bengal, and also in other parts of this province; but no detailed account of the animal and of its habits has been yet published in India. To remedy this deficiency, Dr. Roxburgh undertook, at my solicitation, to describe the Gayal, from those seen by him in a herd belonging to the GovernorGeneral. Dr. Buchanan has also obligingly communicated his observations on the same cattle; with information obtained from sereral gentlemen at Tipura, Sylhet, and Chatgaon, relative to the habits of the animal. The original drawing from which the plate has been taken was drawn by a native artist."

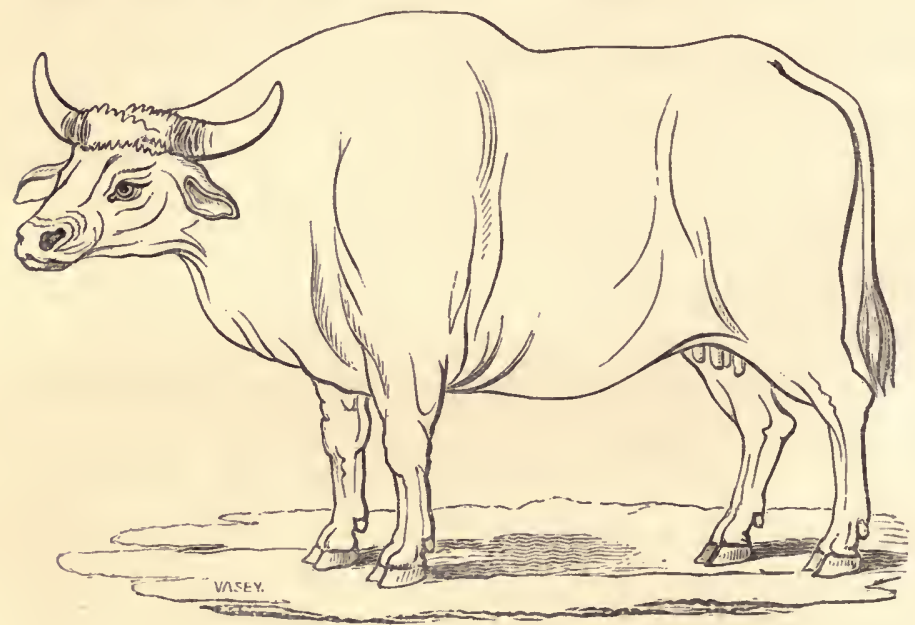

Reduced copy of the Plate just referred to.

This representation does not appear to have been taken from a specimen of the animals here described: 
it bears a much stronger resemblance to our figure of the Gaur, which was taken from the stuffed specimen in the British Museum (see p. 97), than it does to the Gyall (Bos frontalis of Lambert, see p. 51), or to the Gayal, which died in the Zoological Gardens in 1846, from which our figure was taken, which is given on p. 68.

Dr. Roxburgh, who undertook, at the solicitation of Mr. Colebrooke, to describe the Gayal, appears to have done so by the very simple method of copying Mr. Macrae's description of the Gyall, which appeared in the 'Linnean Transactions,' in 1804, to which he has added, that the dewlap is deep and pendant; and this, according to every other account, is not the fact.

With respect to the account given by Dr. Buchanan, I have thought it best to quote it in full; because (although it repeats several of the characteristics already given,) it appears to flow from the pen of one who really observed what he describes.

He says: "The Gayal generally carries its head with the mouth projecting forward, like that of a Buffalo. The head, at the upper part, is very broad and flat, and is contracted suddenly towards the nose, which is naked, like that of the common cow. From the upper angle of the forehead proceed two thick, short, horizontal processes of bone, which are covered with hair; on these are placed the horns, which are smooth, shorter than the head, and lie nearly in the plane of the forehead. They diverge ontward, and turn upward with a gentle curve. At the bases they are very thick, and are slightly compressed, the flat side being toward the front and the tail. The edge next the car is rather the thinnest, so that a 
transverse section would be somewhat ovate. Toward their tips the horns are rounded, and end in a sharp point. The eyes resemble those of the common Ox; the ears are much longer, broader, and blunter than those of that animal.

"The neck is very slender near the head, at some distance from which a dewlap commences, but this is not so deep, nor so much undulated as in the Zebu or Indian Ox. The dewlap is covered with strong longish hairs, so as to form a kind of mane on the lower part of the neck; but this is not very conspicuous, especially when the animal is young.

"In place of the hump (which is situated between the shoulders of the Zebu) the Gayal has a sharp ridge, which commences on the hinder part of the neck, slopes gradually up till it comes over the shoulder-joint, then runs horizontally almost a third part of the length of the back, where it terminates with a very sudden slope. The height of this ridge makes the neck appear much depressed, and also adds greatly to the clumsiness of the chest, which, although narrow, is very deep. The sternum is covered by a continuation of the dewlap. The rump, or os sacrum, has a more considerable declivity than that of the European Os, but less than that of the Zebu.

"The tail is covered with short hair, except near the end, where it has a tuft like that of the common Ox; but in the Gayal the tail descends no lower than the extremity of the tibia.

"The legs,' especially the fore ones, are thick and clumsy. The false hoofs are much larger than those of the Zebu. The hinder parts are weaker in proportion than the fore; and, owing to the contraction of the belly, 
the hinder legs, although in fact the shortest, appear to be the longest.

"The whole body is covered with a thick coat of short hair, which is lengthened out into a mane on the dewlap, and into a pencil-like tuft on the end of the tail. From the summit of the head there diverges, with a whirl, a bunch of rather long coarse hair, which lies flat, is usually lighter-coloured than that which is adjacent, and extends towards the horns and over the forehead. The general colour of the animal is brown, in various shades, which very often approaches to black, but sometimes is rather light. Some parts, especially about the legs and belly, are usually white; but in different individuals these are very differently disposed."

The following is the measurement of a full-grown cow :-



"The different species of the Ox kind may be readily distinguished from the Gayal by the following marks; the European and Indian oxen by the length of their tails, which reach to the false hoofs; the American Ox, by the gibbosity on its back; the Bovis moschatus, Caffer, and pumilus, by having their horns approximated at their 
bases; the Bos grunniens by its whole tail being covered with long silky hairs; the Bos bubalus, (at least the Indian buffalo,) by having the whole length of its horns compressed, and by their being longer than the head, and wrinkled -also by its thin coat of hair, by its want of a dewlap, and above all by its manners; the Bos barbatus, by the long beard on its chin.

"The cry of the Gayal has no resemblance to the grunt of the Indian Ox, but a good deal resembles that of the Buffalo. It is a kind of lowing, but shriller, and not near so loud as that of the European Ox. To this, howerer, the Gayal approaches much nearer than it does to the Buffalo."

Mr. Macrae, who furnished the account in 1804, is again consulted; and from his second account, the following additional particulars have been gleaned. [Now, however, as the reader will observe, the name is Gayal, and not Gyall; although, according to Mr. Macrae's own derivation of the word, it would appear to be more correctly Gyall.]

"The Gayal is found wild in the range of mountains that form the eastern boundary of the provinces of Aracan, Chittagong (Chatgaon), Tipura, and Sylhet.

"The Cucis, or Lunclas, a race of people inhabiting the hills immediately to the eastward of Chatgaon, have herds of the Gayal in a domesticated state. By them he is called Shial, from which, most probably, his name of Gayal [Gyall] is derived; as he is never seen on the plains, except when he is brought there. It appears, however, that he is an animal very little known beyond the limits of his native mountains, except by the inhabitants of the provinces above mentioned. 
"His disposition is gentle : even when wild in his native hills, he is not considered to be a dangerous animal; never standing the approach of man, much less bearing his attack.

"To avoid the noon-day heat, he retires to the deepest shade of the forest; preferring the dry acclivity of the hill to repose on, rather than the low swampy ground below; and never, like the Buffaln, wallowing in mud.

"Gayals have been domesticated among the Cucis from time immemorial; and without any variation in their appearance from the wild stock. No difference whatever is observed in the colour of the wild and tame breeds; brown of different shades being the general colour of both.

"The wild Gayal is about the size of the wild Buffalo of India. The tame Gayals among the Cucis, being bred in nearly the same habits of freedom, and on the same food, without ever undergoing any labour, grow to the same size with the wild ones.

"The Cucis makes no use whatever of the milk, but rear the Gayals entirely for the sake of their flesh and skins; they make their shields of the hides of these animals. The flesh of the Gayal is in the highest estimation among the Cucis; so much so, that no solemn festival is ever celebrated without slaughtering one or more Gayals, according to the importance of the occasion.

"The domesticated Gayals are allowed by the Cucis to roam at large during the day, through the forest, in the neighbourhood of the village; but as evening approaches, they all return home of their own accord; the young Gayal being early taught this habit, by being regularly fed every night with salt, of which he is very fond; and 
from the occasional continuance of this practice, as he grows up, the attachment of the Gayal to his native village becomes so strong, that when the Cucis migrate from it, they are obliged to set fire to the huts which they are about to leave, lest their Gayals should return thither from their new place of residence, before they become equally attached to it, as to the former, through the same means.

"The wild Gayal sometimes steals out from the forest in the night, and feeds in the rice fields bordering on the hills. The Cucis give no grain to their cattle. With us (at Chatgaon) the tame Gayals fecd on Calái (pha. seolus max); but as our hills abound with shrubs, it has not been remarked what particular kind of grass they prefer.

"The Hindus in this province will not kill the Gabay (or Gayal) which they hold in equal veneration with the cow. But the As'l Gayal, or Seloï, they hunt and kill, as they do the wild Buffalo. The animal here alluded to is another species of Gayal found wild in the hills of Chatgaon. He has never been domesticated, and is in appearance and disposition very different from the common Gayal which has just been described. The natives call him the As'l Gayal, in contra-distinction to the Gabay. The Cucis distinguish him by the name of Seloi ; and the Mugs and Burmas by that of P'hanj, and they consider him, next to the tiger, the most dangerous and fiercest animal of their forests."

Mr. Elliot, in writing from Tipura, says,-_ "I have some Gayals at Munnamutty, and from their mode of feeding I presume that they keep on the skirts of the vallies, to enable them to feed on the sides of the 
mountain, where they can browse; they will not touch grass, if they can find shrubs.

"While kept at Camerlah, which is situated in a level country, they used to resort to the banks, and eat on the sides; frequently betaking themselves to the water, to aroid the heat of the sun. However, they became sickly and emaciated, and their eyes suffered much; but, on being sent to the hills, they soon recovered, and are now (1808) in a healthy condition. They seem fond of the shade, and are observed in the hot weather to take the turn of the hills, so as to be always sheltered from the sun. They do not wallow in mud, like Buffaloes, but delight in water, and stand in it during the greatest heat of the day, with the front of their heads above the surface.

"Each Cow yields from two and a half to about four sérs [from fire to eight pounds] of milk, which is rieh, sweet, and almost as thick as cream; it is of a high flavour, and makes excellent butter."

We learn from Mr. Dick that the Gayal is called Gaujangali in the Persian language, Gavaya in Sanscrit, and Mat'hana by the mountaineers ; but others name the animal Gobay-goru.

The tame Gayals, however long they may have been domesticated, do not at all differ from the wild ones, unless in temper, for the wild ones are fierce and untractable. The colour of both is the same, namely, that of the Antelope, but some are white and others black, none are spotted or piebald. They graze and range like other cattle, and eat rice, mustard, chiches, and any cultivated produce, as also chaff and chopped straw.

According to this gentleman the Gayal lives to the age of twenty or twenty-five years, and reaches its full growth 
at five years. The female is generally higher than the male. She receives the bull in her fifth year, and bears after ten months.

In reference to the case of Mr. Bird's Gayal breeding with the common Zebu, I may observe that this proves nothing beyond the bare fact stated; no inference whatever of an identity of species can be drawn from a thousand such cases. It is pretty well known that animals of perfectly distinct species will, when artificially brought together, produce hybrids, as in the familiar examples of the Horse and the Ass, the Canary and the Goldfinch; but a hybrid is neither a species nor (zoologically speaking) a variety.

In a paper on the Gour, by General Hardwicke, ('Zoological Journal,' Vol. III,) he introduces the following observations on the Gayal: "Of the Gayal (Bos Gavceas of Colebrooke) there appears to be more than one species. The provinces of Chatgong and Sylhet produce the wild, or, as the Natives term it, the Asseel Gayal, and the domesticated one. The former is considered an untameable animal, extremely fierce, and not to be taken alive. It rarely quits the mountain tract of the south-east frontier, and never mixes with the Gobbay, or village Gayal of the plains. I succeeded in obtaining the skin, with the head, of the Asseel Gayal, which is deposited in the Museum of the Hon. East-India Company, in Leadenhall Street." [A drawing was taken of this head, of which the engraving on the opposite page is a copy.]

"I may notice another species of Gayal, of which a male and female were in the Governor General's park, at Barrackpore. This species differs in some particulars 
from the domesticated Gayal, and also from the Asseel, or true Gayal ; first, in size, being a larger animal than the domestic one; secondly, in the largeness of the dewlap, which is deeper and more undulated than in either the wild or tame species; and, thirdly, in the size and form of the horns."

Thus, according to the opinion of General Hardwicke, there are three distinct species of the Gayal; but in this matter nothing can be decided without further evidence, which we hope will soon appear in the shape of complete skeletons, and accurate drawings and descriptions.

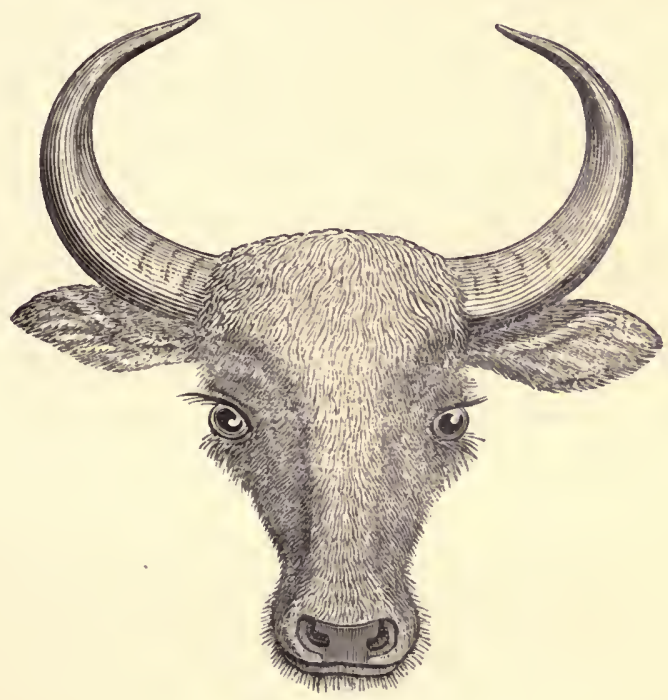




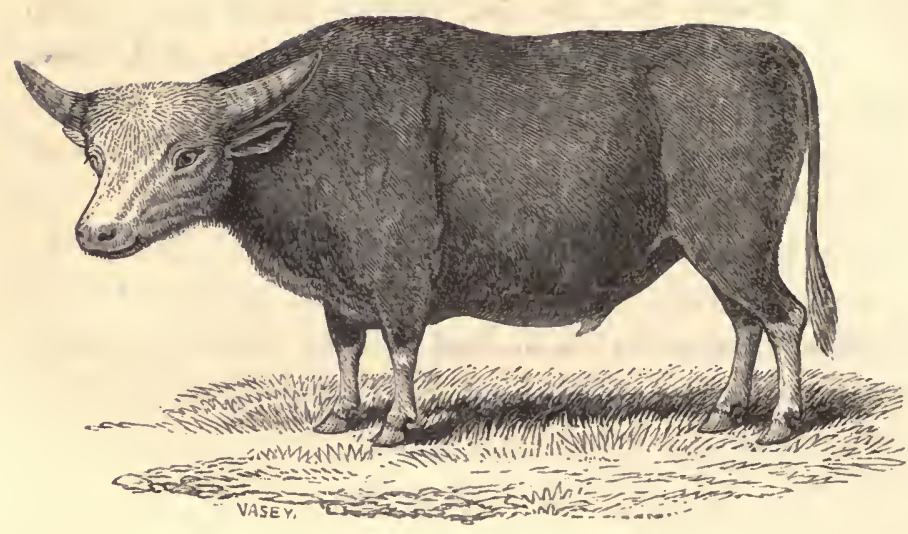

THE TAME OR DOMESTIC GAYAL.

The representation of the Gayal here given was taken from a living specimen in the Zoological Gardens, 1846.

The scanty information I was able to glean concerning it, consists in its having been procured at Chitagong, and shipped, as a commercial speculation, from Calcutta for London, in January 1844, when about two years and a half old. It remained in the Zoological Gardens till the summer of 1846, when it died from inflammation of the bowels, brought on chiefly by eating too much green food.

I had the above particulars from Mr. Bartlett, naturalist, \&c., "who had been commissioned to dispose of it. He preserved the skeleton, which he kindly allowed me to examine, and from which I made the sketches of the skull and horns, which appear on the following page.

The skeleton has fourteen pairs of ribs. 


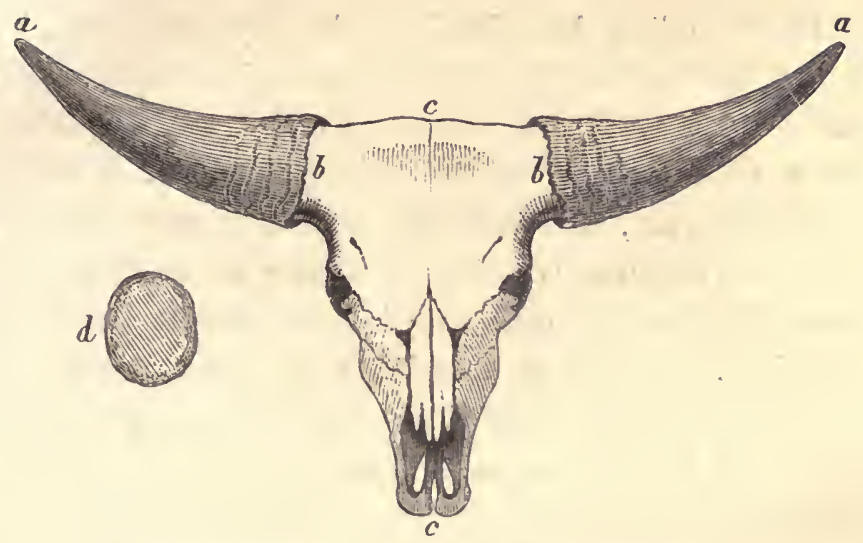

Skull of Domestic Gayal, viewed in front, with Section of Horn.

Inches.

Distance from tip to tip $(a$ to $a)$. . . . 39

Length of horn $(a$ to $b) \quad$. $\quad . \quad . \quad . \quad 16$

Circumference of horn at base $\quad . \quad$. 17

Distance of bases $(b$ to $b)$. . . . . 11

Length of skull $(c$ to $c)$. . . . . . 19

Fig. $d$, section of the horn, at the base.

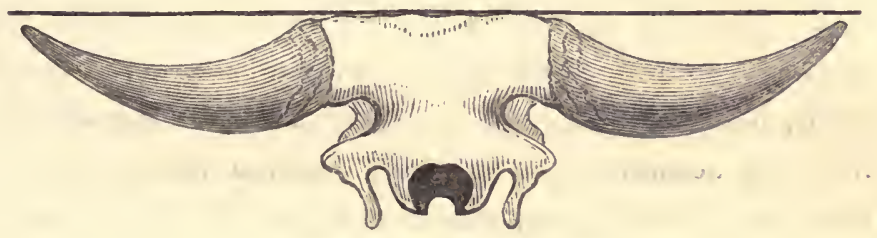

Occipital ricw of the same Skull.

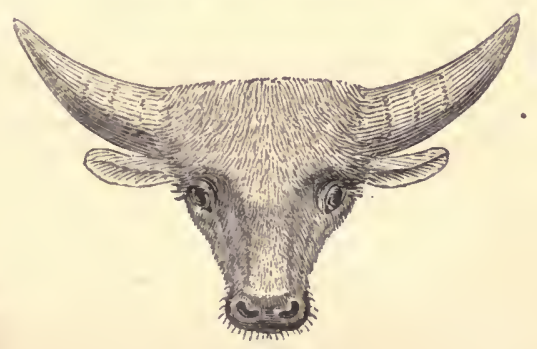

Head of Domestic Gayal. 
In concluding these details of the Gayal and Gyall, let it be remarked that, when we hear one animal called Gayal and another Gyall, we are not, on that account merely, to set them down as of the same species. It is hardly necessary to say, that similarity or even identity of name, is not the slightest criterion of identity of species. The name Elephant is popularly applied to that animal, whether brought from Africa or Asia ; they are, nevertheless, anatomically distinct. The same observation may be made respecting the Lions of those countries, and various other animals.

It may further be observed, that the value of external characters in determining a species is very different when applied to ascertain the distinctions of domestic races, to what it is when applied to ascertain the distinctions of animals living in a natural state. In domestication, varieties ramify to an indefinite extent, and under such circumstances external characters are comparatively valueless. But wild animals retain their external characters with underiating exactness; exceptional cases may indeed occur, but so very rarely, that they are not worth taking into the account; consequently, external forms, and in some cases even colours, become of importance in ascertaining specific distinction. 


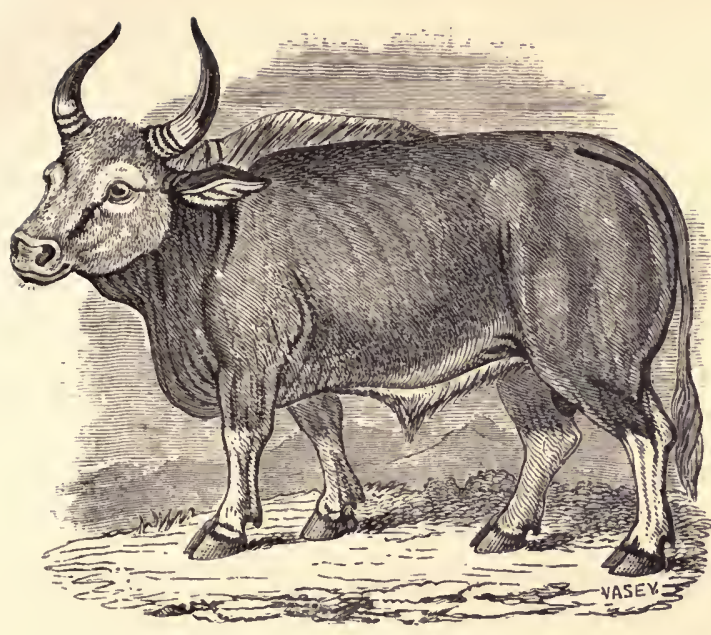

THE JUNGLY GAU.

Bos Sylhetanus. (Cuv.)

Further information is requisite to decide the specific character of this animal. According to the opinion of Col. Smith, (see 'Synopsis of the Species of Mammalia' in Griffith's 'Translation of Cuvier's Animal Kingdom,) it is a mere variety of the Gayal (Bos Gavaus); and Mr. J. E. Gray, in his 'List of the Specimens of Mammalia in the Collection of the British Museum,' classes it as a domestic variety of the same animal, but Mr. Fred. Cuvier regards it as an entirely new species.

The following account of the Jungly Gau (which is the only one that has been published), is a translation from the splendid folio work of Messrs. St. Hilaire and F. Cuvier.

This species of $\mathrm{Ox}$, which is entirely new, appears to 
be the most nearly allied to our domestic cattle. Those ruminants which are classed under the generic name of Ox, may be very naturally divided into two distinct groups. The first includes the Buffaloes, animals in some measure aquatic, living in low, swampy localities, or near rivers, in which they remain half immersed a great part of the day; having broad-based horns, partly spreading over their foreheads, flat on their internal side, and round on their external; tongue soft, \&c. The second is that of the Ox, properly so called. These are distinguished from the first by their dwelling on more clevated lands, or in the vicinity of forests; having smooth round horns, without enlargement at their base; tongue covered with horny papillæ, \&c.

It is to this second family, consisting of the American Bison, the Aurox, the Yak, and the domestic Ox, with its varieties, that the Jungly Gau undoubtedly belongs. It however differs from the first two in being entirely destitute of the thick shaggy mane; and, instead of the long silky hair of the third, it is clothed with close, short hair, equal in uniformity of texture to the sleekest of our domestic cattle. To judge from its general appearance, we might be even tempted to take it for a mere variety of the domestic species, so close is the resemblance. But the information furnished by M. Alfred Duvaucel, in the only description which has been given, leaves no doubt as to its being a new species.

The following is M. Duvaucel's account:-_"The horns of the Jungly Gau rise from the sides of the occiput, first outward, then forward, with a slight inclination backward of the upper extremity, forming a double lunation, and separated by a space which gradually diminishes as the 
animal grows older; standing equally apart in every individual of the same age and sex; are round, except at their base, which is slightly compressed; and they become smoother as the animal advances in age.

"The hump, which is characteristic of the generality of Indian oxen, is reduced in this to a slight prominence, extending to the middle of the back, and is covered with a grayish, woolly hair, rather longer than that on the other parts of the body, which spreads likewise over the occiput and the front. The rest of the hair is black except the legs, which are white from the knees downwards. The tail terminates in a large tuft of hair; and, in bulls of two or three years old, the under part of the neck is slightly furnished with long, black, silky hair.

"The female is smaller than the male, with horns of a still less proportionate size. The front of the head, instead of being convex, as in the male, appears to be slightly depressed, in consequence of the superior elevation of the muzzle. The colour of the female is not so deep a black; the gray on the top of the neck and the shoulders extends to the sides, and the inferior part of the muzzle is white.

"I have long entertained the opinion," continues M. Duvaucel, "that these oxen were essentially the same as the domestic - that they were both varieties of the same species; but this opinion was formed on the inspection only of such specimens as I had seen in the menagerie at Barracpour. Since that time, I have pursued them myself near the mountains of Sylhet; and I have likewise learned from various sources that they are as numerous and as generally diffused as the common Buffalo; but they appear to be wilder than the Buffalo, and not so 
bold, never approaching where man has established his dominion. Nevertheless, when caught, they are easily subdued, and become quite domesticated in a few months. The milk of this species is said to be more abundant and nourishing than that of any other."

From all that is at present known respecting this animal, it is regarded by M. F. Cuvier as a new species added to the genus $B o s$; and, from the circumstance of its having been first seen in a wild state near the mountains of Sylhet, he has given it the specific name of Sylhetanus.

The animal represented in the following vignette is the Syrian Ox, which is considered as a variety of Bos Taurus.

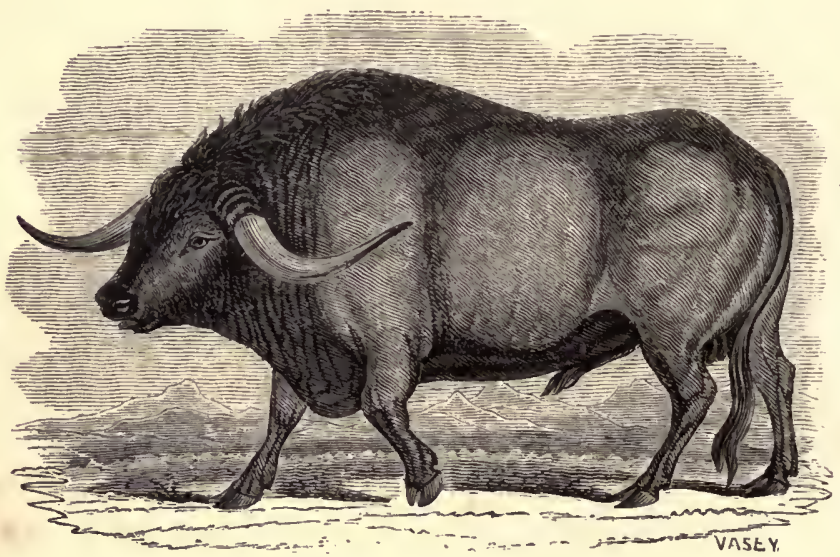




\section{THE BUFFALO.}

The animal generally known under the name of the Common Buffalo is evidently a different species from the Cape Buffalo. Much confusion, however, prevails in the accounts, both of travellers and naturalists, on the subject of these two animals. Descriptions of the one are mingled with descriptions of the other, and anecdotes are related of the one which, there is good reason for believing, ought to be referred to the other. It is highly probable that future and more accurate observations will show that more than one species has been confounded under the general epithets of "the common Buffalo," "the domestic Buffalo," "the tame Buffalo," or, more indeterminate still, " the Buffalo."

The accounts furuished by travellers of the various animals in Asia and Africa, described by them as Buffaloes, are altogether vague and unsatisfactory, and frequently erroneous; not from any desire on the part of the authors to deceive, but merely because their observations have been made in the most careless and indifferent manner; and, in many instances, their information is obtained from the verbal communications of ignorant natives.

In those descriptions which are confined to the Buffalo, as it at present exists in Italy and the south of Europe, tolerable reliance may be placed, as their character and habits are there well known, being of every day observation; yet, even in this case, little or nothing is known 
of the anatomy of the animal, and its period of gestation has never been precisely stated. The following information on this latter point is given in Griffith's 'Cuvier,' (vol. iv, p. 383,) "Gestation is said to last twclve months, but it appears not to exceed ten."

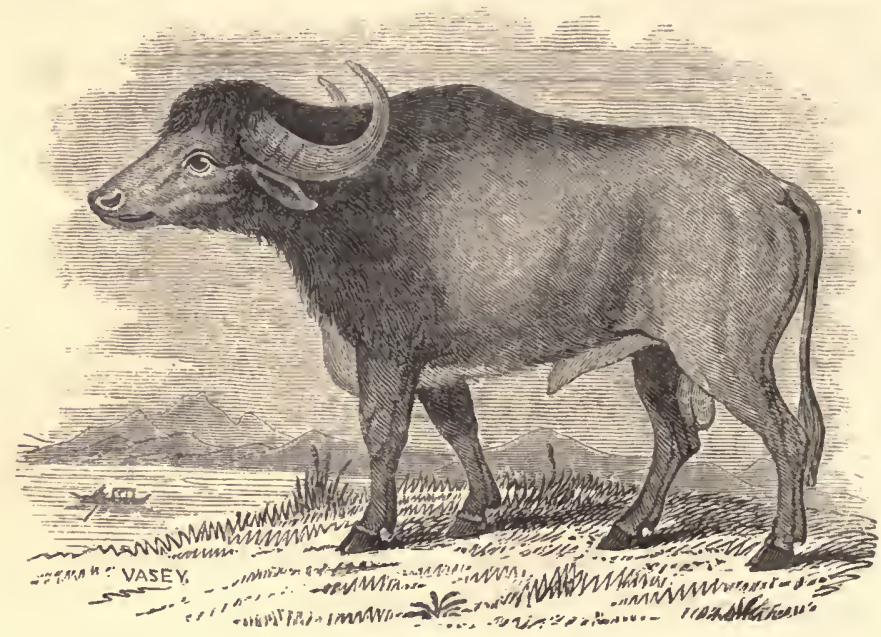

THE ITALIAN BUFFALO.

Bos Bubalus.

This animal is more bulky than the domestic $\mathrm{Ox}$, and its limbs are stouter. The head is larger, in proportion to the size of the body, than that of the domestic $\mathrm{Ox}$, and is generally carried with the muzzle projecting; the forehead is rather convex, and higher than broad; the horns are large, slightly compressed, and recline towards the neck, with the points turned up; dewlap of a moderate size. 
Throughout the whole range of the Italian peninsula Buffaloes are used as beasts of burden, and their immense strength renders their services invaluable in the marshy and swampy districts, where the services of horses, or ordinary oxen, would be totally unavailing. The roads through which they are obliged to pass are frequently covered to a depth of two or three feet, through which they work their way with wonderful perseverance.

On the great plain of Apulia the Buffalo is the ordinary beast of draught; and at the annual fair held at Foggia, at the end of May, immense droves of almost wild Buffaloes are brought to the town for sale. Fearful accidents occasionally happen; enraged animals breaking from the dense mass, in spite of all the exertions of their drovers, and rushing upon some object of their vengeance, whom they strike down, and trample to death. It is dangerous to overwork or irritate the Buffalo, and instances have been known in which, when released by the brutal driver from the cart, they have instantly turned upon the man and killed him on the spot.

The following part of their history is remarkable: They appear to be most numerous, and to thrive best in those districts which are most infected with malaria. In the Pontine marshes they find a favorite retreat, and in the pestilential Maremma scarcely any other animals are to be seen. In the northern portions of Italy, where malaria is much less frequent than in the south, Buffaloes are to be found in the greatest numbers precisely in those localities where malaria is the most prevalent.

They are particularly fond of the long rank herbage, which springs up in moist and undrained lands. In their 
habits they are almost amphibious, lying for hours half submerged in water and mud.

When travellers make use of the name "common Buffalo," they are usually understood to mean an animal identical with the Italian species; if this really be the case, its geographical range must be very extensive. It is said to inhabit the extensive regions of Hindostan, China, Cochin-China, Malabar, Coromandel, Persia, and the Crimea ; also Abyssinia, Egypt, and the south of Europe; to which may be added, most of the large islands in the Indian Sea.

As an article of food, the flesh of this animal is inferior to the beef of the domestic Ox, but the milk of the female is particularly rich and abundant; the semi-fluid butter, called ghee in India, is made from it. According to the testimony of Colonel Sykes, the long-horned variety is reared in vast numbers in the Mawals, or hilly tracts lying along the Ghauts :- "In those tracts much rice is planted, and the male Buffalo, from his superior hardihood, is much better suited to resist the effects of the heavy rains, and the splashy cultivation of the rice than the bullock. The female is also infinitely more valuable than the cow, from the very much greater quantity of milk she yields." The hide is also much valued for its strength and durability.

In India they are used as beasts of burden; but the nature of the goods they carry must be such as will not suffer from being wet, as they have an invincible propensity to lie down in water. The native princes use them to fight with tigers in their public shows; and from their fierce and active nature, when excited, they frequently prove more than a match for their formidable assailants. With the native herdsman, howevcr, they are generally 
docile : these men ride on their favorites, and spend the night with them in the midst of jungles and forests, without fear of wild beasts. When driven along, the herds keep close together, so that the driver, if necessary, walks from the back of one to the other, perfectly at his ease. In the south of Europe they are managed by means of a ring passed through the cartilage of the nose, but in India it is a mere rope.

Their fierceness and courage are well exemplified in the following anecdote, related by Mr. D. Johnson in his interesting 'Sketches of Indian Field Sports:' "Two Biparies, or carriers of grain and merchandise on the backs of bullocks, were driving a loaded string of these animals from Palamow to Chittrah : when they were come within a few miles of the latter place, a tiger seized on the man in the rear, which was seen by a Guallah (herdsman), as he was watching his Buffaloes grazing. He boldly ran up to the man's assistance, and cut the tiger severely with his sword; upon which he dropped the Biparie, and seized the herdsman. The Buffaloes observing it, attacked the tiger, and rescued the herdsman; they tossed him about from one to the other, and, to the best of my recollection, killed him. Both the wounded men were brought to me; the Biparie recovered, and the herdsman died?"?

Speaking of the Buffalo at Malabar, Dillon says, "It is an ugly animal, almost destitute of hair, goes slowly, but carries very heavy burdens. Herds may be seen, as of common cows; and they afford milk, which serves to make butter and cheese. Their flesh is good, though less delicate, than that of the ox: the animal swims perfectly well, and traverses the broadest rivers. Besides the tame 
ones, there are wild Buffaloes, which are extremely dangerous, tearing men to pieces, or crushing them with a single blow of the head; they are less to be dreaded in woods than elsewhere, because their horns often catch in the branches, and give time for the persons pursued to escape by flight. The skins of these animals serve for an infinity of purposes, and even cruses are made of them for holding water or liquors. The animals on the coast of Malabar are all wild, and strangers are not prevented from hunting them for their flesh."

Whether the animals alluded to, in all these cases, constitute only one species, or consist of several, the accounts which have been given of them (from their vagueness and want of precision) afford no means of deciding.

The following tail-piece is a representation of the Herefordshire Cow, Bos Taurus.

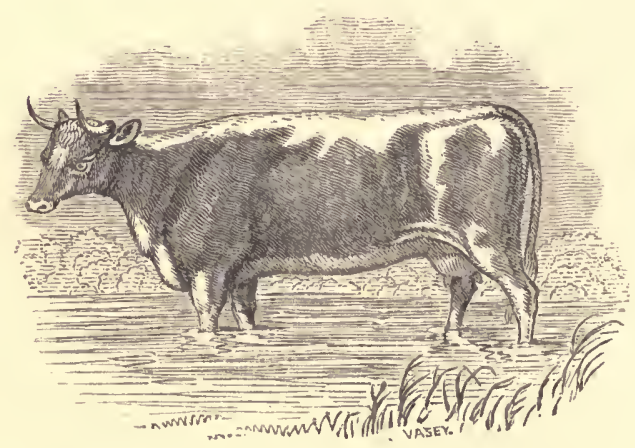




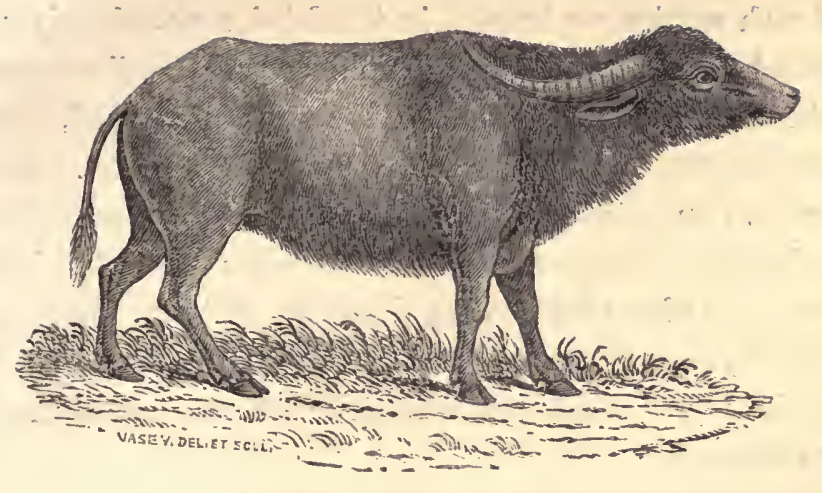

THE MANILLA BUFFALO.

\section{Bos Bubalis?}

The animal which is represented in the above engraving, was living in the Zoological Gardens, Regent's Park, in 1846, at which time the sketch was taken.

In size the Manilla Buffalo is about equal to the Kyloe Ox. The horns are of a similar shape, and take nearly the same direction, as those of the Italian Buffalo. They differ, however, from the horns of the Italian Buffalo in three particulars : first, in not being above lialf so thick or bulky; second, in having a much larger curve; and third, in being considerably more compressed, which compression exists throughout their entire length: the colour of the upper surface of the horn is lightish, on the lower side nearly black. The head is narrow, and the muzzle fine; the ears are long and nearly naked; the eyes large and bright, with a peculiarly timid and suspicious expression. The limbs are slender, and indeed the whole frame is slight, and seems to betoken greater speed than strength.

We liave a notable example of the uncertainty of framing generic characters, before the peculiar attributes 
of each species are known, in Griffiths' work, already referred to (vol. iv, p. 382). "Buffaloes in general" are there said to possess strong and solid limbs, large head, broad muzzle, long and slender tail, back rather straight. Here we have an animal (a Buffalo by universal consent) whose limbs are slender, head small, muzzle fine; whose tail is not long, and whose back is any thing but straight. The Cape Buffalo, also, (see p. 86,) has rather a small head, its tail is absolutely short, and its back has very considerable curvature.




The preceding outline of the backs of four Buffaloes will show how inappropriate the character of a straight back is, when applied to "Buffaloes in general." The lowest outline (5), inserted by way of contrast, represents the back of the Domestic Ox, to which the character of straight might very properly be applied. (1) Italian Buffalo. (2) Manilla Buffalo. (3) Pulo Condore Buffalo. (4) Cape Buffalo.

Generic characters should be such (and such only) as will apply to every specics included in the genus.

The period of gestation of the Manilla Buffalo is between forty-eight and forty-nine weeks. In two actual cases of a female now living in the Zoological Gardens, the periods were, in the one case, 340 days, in the other, 341 days; being 70 days longer than the ordinary term of the domestic Cow.

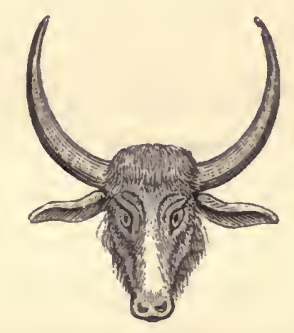

Head of Manilla Buffalo-female. 


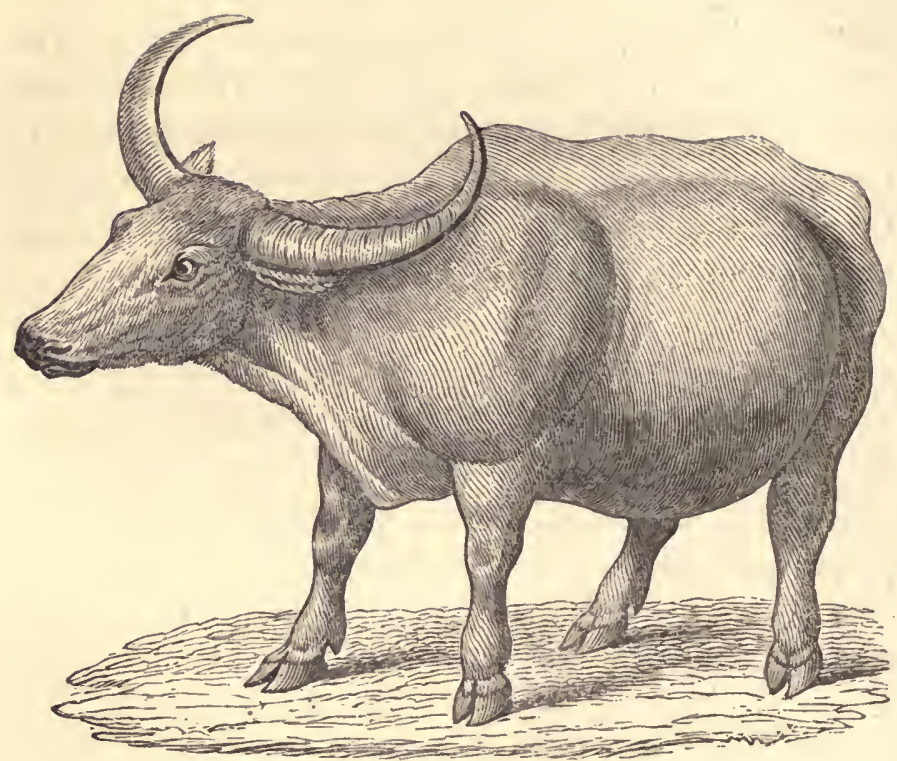

PULO CONDORE BUFFALO.

Bos Bubalus?

Not much is known of the Buffalo which is found in the island of Pulo Condore. It is related by those navigators who completed the voyage to the Pacific Ocean, begun by Captain Cook, that when at Pulo Condore, they procured eight Buffaloes, which were to be conducted to the ships by means of ropes put througl their nostrils and round their horns; but when they were brought within sight of the sailors, they became so furious that some of them tore out the cartilage of their nostrils, and 'set themselves at liberty. All attempts to get them on board would have proved fruitless, had it not been for some 
children, whom the animals would suffer to approach them, and by whose puerile management their rage was quickly appeased; and when the animals were brought to the beach, it was by their assistance, in twisting ropes around their legs, that the men were enabled to throw them down, and by that means get them into the boats. And what appears to have been no less singular than this circumstance was, that they had not been a day on board before they became perfectly gentle.

Whether this be a distinct species, or merely a variety, we have not, at present, the least means of ascertaining.

Osteology unknown.

Period of gestation unknown.

The tail-piece below represents a short-horned Bull of the Domestic species, Bos Taurus.

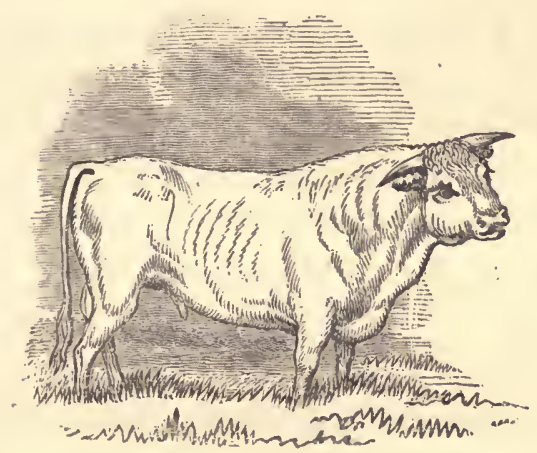




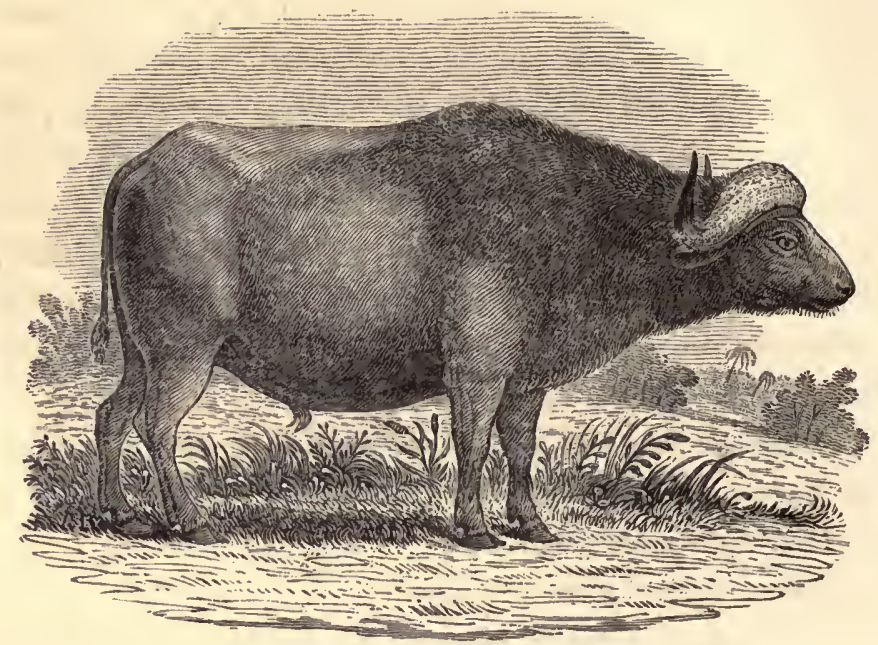

THE CAPE BUFFALO.

Bos Caffer.

This species of ox is only to be found in Africa, and is chiefly confincd to the wooded districts lying north of the Cape of Good Hope. What Lavater endeavours to prove of the human being, namely, that the face is the index of the mind or disposition, may be applied, with at least equal truth, to the Cape Buffalo. His broad, projecting muzzle, lowering eyebrows, shaggy pendulous ears, surmounted by a pair of huge horns, give a look of bold determination to this animal, which forms a tolerably correct index of his character; his firm-set limbs and bulky body convey a no less adequate idea of his enormous strength.

These animals are gregarious, living in small herds in the brushwoods or open forests, of Caffraria, occasionally uniting in large droves. Old bulls are often met with 
alone; but though they are fiercer than the young ones, they are less dangerous, because less active, and less inclined to exertion.

It is worthy of observation, that the males of every species of the Genus Bos are remarkably bold and courageous, as are likewise the females when they have calves. It is not, therefore, surprising that the hunting of this animal should be attended with danger, and fiequently with fatal consequences. The European colonists generally pursue the sport on horseback; but the Caffers and other natives, who are more active, and accustomed to the intricacies of the forest, prefer following the game on foot.

Professor Thunberg, whilst investigating the interior of Caffraria, in 1772, in company with a sergeant and a European gardener, who had resided in the colony some time, and who acted as guide on the occasion, met with the following perilous adventure :-

"We had not advanced far into the wood," says the traveller, "before we had the misfortune of meeting with a large old male Buffalo, which was lying down quite alonc, in a spot that was free from bushes for the space of a few square yards. He no sooner discovered Auge, the gardener, who went first, than, roaring horribly, he rushed upon him. The gardener turning his horse short round, behind a large tree, by that means got in some measure out of the Buffalo's sight, which now rushed straight forward towards the sergeant, who followed next, and gored his horse in the belly in such a terrible manner, that it fell on its back that instant, with its feet turned up in the air, and all its entrails hanging out, in which state it lived almost half an hour. The gardener and the sergeant, 
in the meantime, had climbed up into trees, where they thought themselres secure. The Buffalo, after this first achievement, still appeared to take his course in the same direction, and, therefore, could not have failed in his way to pay his compliments to me, who all the while was coming towards him, and, in the narrow pass formed by the boughs and branches of the trees, and on account of the rustling noise these made against my saddle and baggage, had neither seen nor heard anything of what had passed; as in my way I frequently stopped to take up plants, and put them into my handkerchief, I generally kept behind my companions.

"The sergeant had brought two horses with him for the journey. One of them had already been despatched, and the other now stood just in the way of the Buffalo, who was going out of the wood. As soon as the Buffalo saw this second horse, he became more outrageous than before, and he attacked it with such fury, that he not only drove his horns into the horse's breast, and out again through the very saddle, but also threw it to the ground with such violence, that it died that very instant, and most of its bones were broken. Just at the moment that he was occupied with this latter horse, I came up to the opening, where the wood was so thick that $I$ had neither room to turn my horse, nor to get on one side; I was, therefore, obliged to abandon him to his fate, and take refuge in a tolerably high tree, up which I climbed.

"The Buffalo, having finished this his second exploit, suddenly turned round, and shaped his course the same way which we had intended to take.

"From the height of my situation in the tree, I could plainly perceive one of the horses quite dead; the other 
sprawling with his feet, and endeavouring to rise, which it had not strength to do; the other two horses shivering with fear, and unable to make their escape; but I could neither see nor hear anything of my fellow-travellers, which induced me to fear that they had fallen victims to the first transports of the Buffalo's fury. I, therefore, made all possible haste to search for them, to see if I could, in any way, assist them; but not discovering any trace of them in the whole field of battle, I began to call out after them, when I discovered these magnanimous heroes sitting fast, like two cats, on the trees, with their guns on their backs, loaded with fine shot, and unable to utter a single word.

"I encouraged them as well as I could, and advised them to come down, and get away as fast as possible from such a dangerous place, where we ran the risk of being once more attacked. The sergeant at length burst out into tears, deploring the loss of his two spirited steeds; but the gardener was so strongly affected, that he could scarcely speak for some days after."

Speaking of a small settlement in the interior, he says: "Buffaloes were shot here by a Hottentot, who had been trained to the business by the farmer, and in this manner found the whole family in meat, without having recourse to the herd. The balls were counted out to him every time he went a shooting, and he was obliged to furnish the same number of dead Buffaloes as he received of balls. Thus the many Hottentots that lived here were supported without expense, and without the decrease of the tame cattle which constitute the whole of the farmer's wealth. The greatest part of the flesh of the Buffalo falls to the share of the Hottcntots, but the hide to that of the master." 


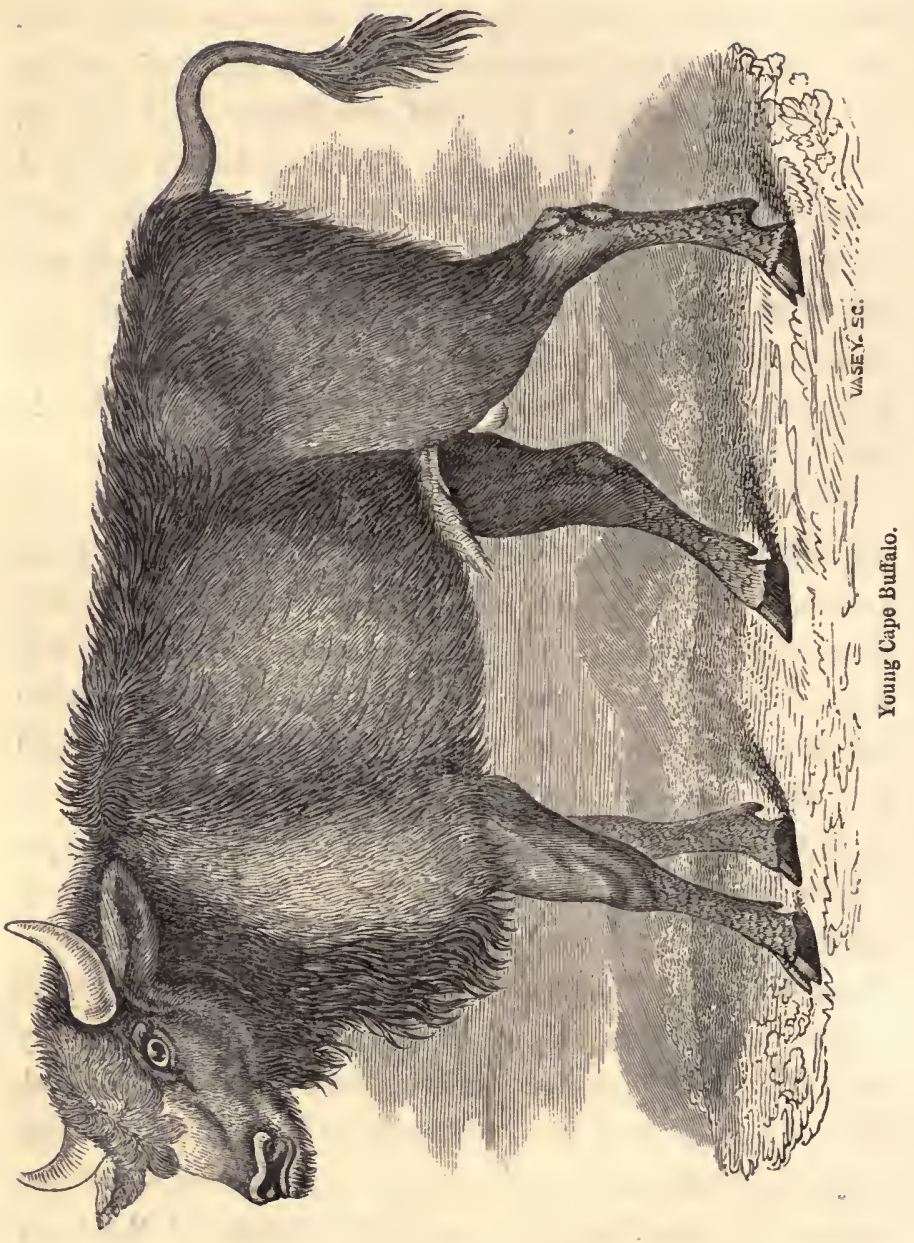


The Caffres, who at that time (1772) did not possess firearms, were, nevertheless, dextrous in the use of their javelins. When a Caffre has discovered a spot where several Buffaloes are assembled, he blows a pipe, made of the thigh-bone of a sheep, which is heard at a great distance. In consequence of this, several of his comrades run up to the spot, and surrounding the Buffaloes, at the same time approaching them by degrees, throw their javelins at them. In this case, out of ten or twelve Buffaloes, it is very rare for one to escape. It sometimes happens, however, that while the Buffaloes are running off, some one of the hunters, who stands in the way of them, is tossed and killed, which, by the people of this nation, is not much regarded. When the chase is over, each one takes his share of the game.

Since the introduction of firearms by the Europeans, the natives, as well as the colonists, bring down the Buffalo by means of the gun. Nevertheless, great circumspection is.required in following the sport, as the animal is sometimes capable of revenging himself even after being severely wounded. On one occasion a party of huntsmen discovered a small herd of Buffaloes grazing on a piece of marshy ground. As it was impossible to get near enough without crossing a marsh, which did not afford a safe footing for their horses, they left them in charge of the Hottentots, and proceeded on foot, thinking, that if the Buffaloes should turn upon them, it would be easy to retreat by crossing the quagmire, which, though firm enough to support a man, would not bear the weight of a Buffalo. They advanced accordingly, and, under shelter of the bushes, approached with such advantage, that the first volley brought down three of the fattest of the herd, 
and so severely wounded the great bull leader, that he dropped on his knees, bellowing most furiously. Supposing him mortally wounded, the foremost of the huntsmen issued from the covert, and began reloading his musket as he advanced, to give him a finishing shot; but no sooner did the enraged animal see his enemy, in front of him than he sprang up, and ran furiously upon him. The man, throwing down his gun, fled towards the quagmire; but the beast was so close upon him, that, despairing to escape in that direction, he suddenly turned round a clump of copsewood, and began to ascend a tree. The raging animal, however, was too quick for him, and bounding forward with a tremendous roar, he caught the unfortunate man with his terrible horns, just as he had nearly escaped his reach, and tossed him into the air with such force, that the body fell dreadfully mangled into the cleft of a tree. The Buffalo ran round the tree once or twice, apparently looking for the man, until weakened with loss of blood, he again sank on his knees. The rest of the party, recovering from their confusion, then came up and despatched him, though too late to save their comrade, whose body was hanging in the tree quite dead.

The length of a full-grown Buffalo is about eight feet from horns to root of tail, and the height five feet and a half. The horns are massive and heavy,-measuring from six to nine feet, following the curve from tip to tip. They are broad at the base, and very nearly meet on the centre of the forehead. Hamilton Smith says, they are "in contact at the base ;" but this is not the case in the several specimens which I have examined, namely, three in the College of Surgeons, four in the British Museum, and two in the Zoological Gardens. 
In the living specimen in the Zoological Gardens, from which the figure at the head of this article was taken, there is a good deal of hair of a dark brown colour on the neck and shoulders, and some small tufts on the fore-legs, but the rest of the body is almost naked. The tail is short, with a tuft at the end.

The individual here referred to is by no means a large specimen, being only four feet ten inches high at the shoulders; probably he is young, and not yet full-grown. $\mathrm{He}$ is so active, as to be able to clear a four-feet fence, and he frequently leaps over the half-door (about three feet high,) which separates his little enclosure from his dormitory. His intelligence is much 'superior to that of ordinary cattle : the entrance to his apartment is furnished with four doors, two on each door-post; and when closed, they of course meet in the middle of the entrance. When he is outside, (as the doors all open inwardly,) a mere push with his horns sends them open. But when he is inside, it requires four distinct operations to shut them, and these he performs with the greatest adroitness, going from one to the other, until all are closed. He opens them also from within with equal skill, by applying the tip of one of his horns to each separately, and retiring a step or two to allow them room to open.

The flesh of the Cape Buffalo is reckoned excellent eating, especially that of the young calf, which is equal to the veal of the domestic calf. The horns are made into various articles, having a fine close grain, and taking a beautiful polish. But the hide is the most valuable part of this animal, being so thick and tough, that shields, proof against a musket-shot, are formed of it; and it affords the strongest and best thongs for harness and 
whips. The skin of the living Buffalo is so dense that it is impenetrable, in many parts, to an ordinary musketball; the balls used by the huntsmen are, therefore, mixed with tin, and even these are often flattened by the resistance. In examining the skeleton of this Buffalo, the ribs are found to be remarkably strong and widemeasuring from three inches to three inches and seventenths in width, and overlapping each other like the scales of a fish: the difficulty of wounding this animal may be partly owing to this arrangement of the ribs.

Since the increase of the settlements about the Cape of Good Hope, the Buffalo has become rather a rare animal in the colony; but, on the plains of Caffraria, they are so common that herds of a hundred and fifty, or two hundred, may be frequently secn grazing together towards the evening, but during the day they lie retired among the woods and thickets. They range along the eastern side of Africa, to an unknown distance in the interior.

Sparrman says that the period of gestation is twelve months.

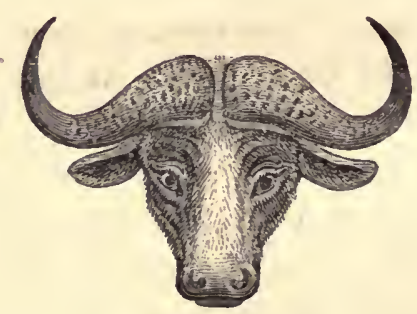

Ilead of Cape Buffalo. 


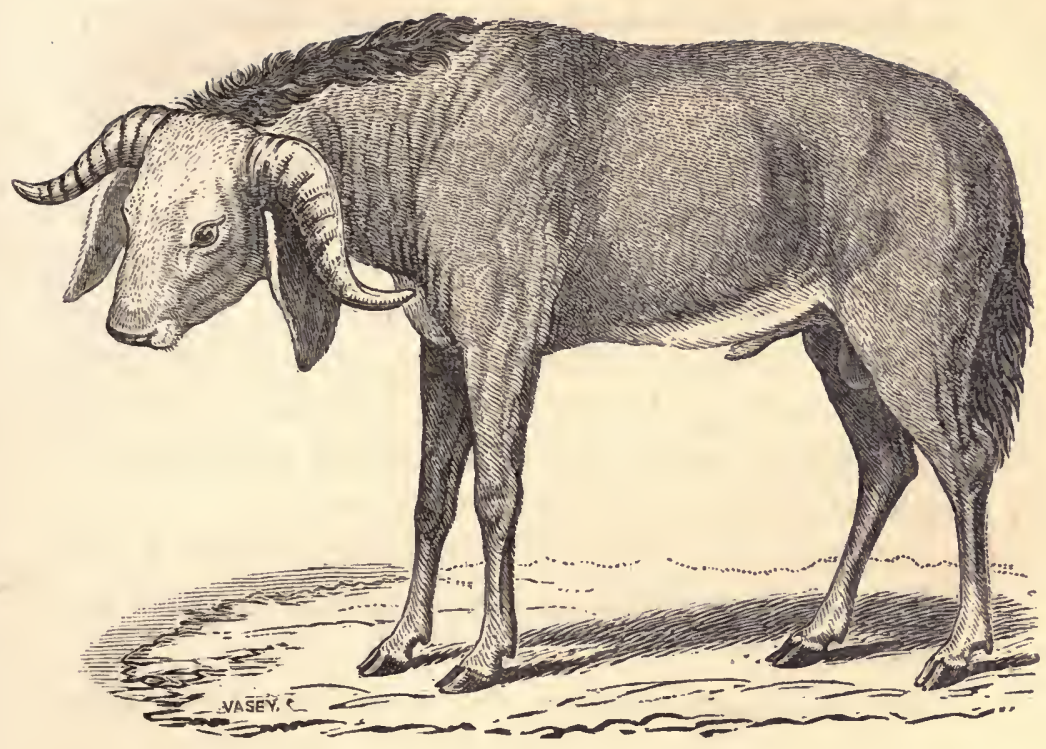

THE PEgASSE.

Bos Pegasus.

The above figure is copied from an engraving in the fourth volume of Griffiths' 'Cuvier,' of which the following account is given: "In the collection of drawings, formerly the property of Prince John Maurice of Nassau, now in the Berlin library, there is the figure of a ruminant with the name Pacasse written under it. Judging from the general appearance of the painting, it represents a young animal, although the horns are already about as long as the head. They are of a darkish colour, with something like ridges passing transversely, commencing at the sides of the frontal ridge, turned down and outwards, with the 
points slightly upwards; the head is short, thick, abrupt at the nose; the forehead wide; the eyes large and full, dark, with a crimson canthus; the neck maned with a dense and rough mane; the tail descending below the hough, entirely covered with dark, long hair, appearing woolly; the carcass short, and the legs high and clumsy; but the most remarkable character appears to consist in pendulous ears, nearly as long as the head. The mane and tail are dark; the head, neck, body, and limbs dark brown, excepting the pastern joints, which are white; this figure cannot be referred to a known species, and is sufficiently curious to merit an engraving."

Swainson says that this animal only occurs in the interior of Western Africa; but he does not mention on what authority.

As the exploration of the interior of Africa is becoming an object of increasing importance and interest, we may expect, before long, to be furnished with some authentic details of the Pegasse, if such an animal really exist.

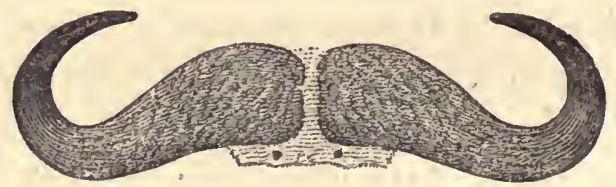

Occipital View of Horns of Bos Caffer, from a Specimen in the Zoological Society's Museum. 


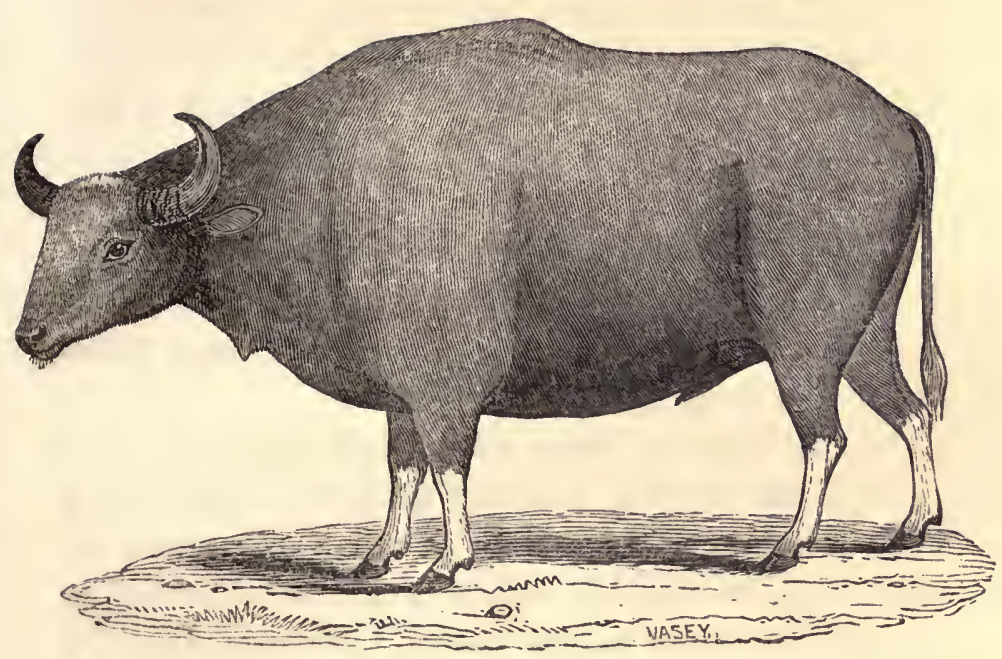

THE GAUR, OR GOUR.

Bos Gaurus.

The above representation of this animal was sketched from a stuffed specimen in the British Museum, the dimensions of which are given on p. 102.

The following interesting particulars are taken from Mr. T. S. Traill's paper on the Gour, in the 'Edinburgh Philosophical Journal,' October, 1824.

"The Gaur is considered by the Indians as of a species totally distinct from either the Arna or the common Buffalo. The only animal with which it appears to have affinity is the Gayal, or Bos Gavæus, described by Mr. Colebrook, in the 'Asiatic Researches,' vol. viii. That animal is said to exist, both wild and domestic, in 
the hilly countries of Upper India, and to have a high dorsal ridge, somewhat similar to what we shall immediately find in the Gaur; but the very different form of its head, the presence of a distinct dewlap, and the general habit of the Gayal, appear sufficient to distinguish it from the Gaur.

The Gaur occurs in several mountainous parts of central India, but is chiefly found in Myn Pat, or Mine Paut, (Pat or Paut, in Hindostanee, signifies table-land,) a high, insulated mountain, with a tabular summit, in the province of Sergojah, in South Bahar.

This table-land is about 36 miles in length, by 24 or 25 in medial breadth, and rises above the neighbouring plains probably 2000 feet. The sides of the mountain slope with considerable steepness, and are furröwed by streams that water narrow valleys, the verdant banks of which are the favorite haunts of Gaurs. On being disturbed, they retreat into the thick jungles (of saul-trees), which cover the sides of the whole range. The southeast side of the mountain presents an extensive mural precipice from 20 to 40 feet high. The rugged slopes at its foot are covered by impenetrable green jungle, and abound with dens formed of fallen blocks of rock, the suitable retreats of Tigers, Bears, and Hyænas. The western slopes are less rugged, but the soil is parched, and the forests seem withered by excess of heat. The summit of the mountain presents a mixture of open lawns and woods. There were once twenty-five villages on Myn Pat, but they have long been deserted, on account of the number and ferocity of the beasts of prey. On this mountain, however, the Gaur maintains his seat. The Indians assert that even the Tiger has no chance in combat 
with the full-grown Gaur, though he may occasionally succeed in carrying off an unprotected calf. The wild Buffalo abounds in the plains below the mountains; but he so much dreads the Gaur, according to the natives, that he rarely attempts to iuvade his haunts. The forests which shield the Gaur abound, however, in Hog-deer, Saumurs, and Porcupines.

The size of the Gaur is its most striking peculiarity. The following measurement of one not fully grown will show the enormous bulk of the animal :-

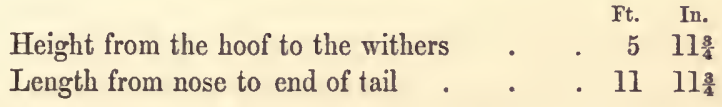

The form of the Gaur is not so lengthened as that of the Arna. Its back is strongly arched, so as to form a pretty uniform curve from the nose to the origin of the tail, when the animal stands still. This appearance is partly owing to the curved form of the nose and forehead, and still more to a remarkable ridge, of no great thickness, which rises six or seven inches above the general line of the back, from the last of the cervical to beyond the middle of the dorsal vertebræ, from which it gradually is lost in the outline of the back. This peculiarity proceeds from an unusual elongation of the spinous processes of the dorsal column. It is very conspicuous in the Gaurs of all ages, although loaded with fat; and has no resemblance to the hunch which is found on some of the domestic cattle of India. It bears some resemblance, certainly, to the ridge described as existing in the Gayal; but the Gaur is said to be distinguished from that animal by the remarkable peculiarity of a total want of a dewlap. Neither the male nor female Gaur, at any age, has the 
slightest trace of this appendage, which is found on every other known aninal of this genus.

The colour of the Gaur is a very deep brownish black, almost approaching to blueish black, except a tuft of curling dirty white hair between the horns, and rings of the same colour just above the hoof. The hair over the skin is extremely short and sleek, and has somewhat of the oily appearance of a fresh seal-skin.

The character of the head differs little from that of the domestic Bull, excepting that the outline of the face is more curved-the os-frontis more solid and projecting. The horns are short, thick at the base, considerably curved towards the tip, slightly compressed on one side, and in the natural state are rough. They are, however, capable of a good polish, when they are of a horn gray colour, with black solid tips. A pair in my possession measure one foot eleven inches along their convex sides; one foot from the centre of the base to the tip, in a straight line; and one foot in their widest circumference; but as they are cut and polished, a portion of their length and thickness has been lost. They are of a very dense substance, as their weight indicates, for even in their dressed state the pair weigh 5lbs. 11oz. avoirdupois.

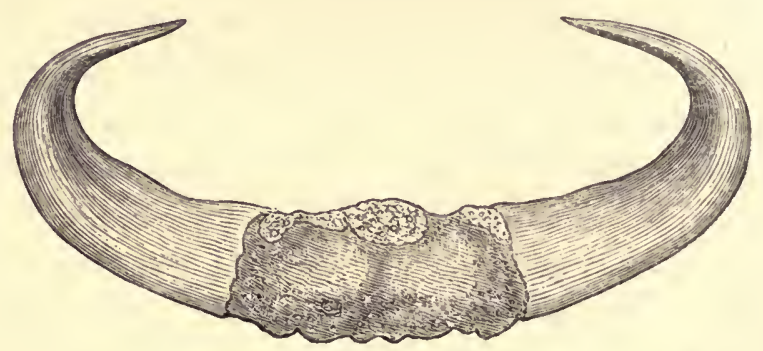


The limbs of the Gaur have more of the form of the deer than any other of the bovine genus. This is particularly observable in the acuteness of the angle formed by the tibia and tarsus, and in the slenderness of the lower part of the legs. They give the idea, however, of great strength combined with fleetness; and the animal is observed to canter with great velocity. The form of the hoof, too, is longer, neater, and strouger than in the ox, and the whole foot appears to have greater flexibility.

When wounded the Gaur utters a short bellow, which may be best imitated by the syllable--ugh-ugh.

It is said that the Gaur will not live in a state of captivity; even when taken very young, the calf soon droops and dies. The bull-calf of the first year is called, by the natives, Purorah; the female, Pareeah; and when full-grown the cow is called Gourin.

Gaurs associate in herds consisting usually of from ten to twenty animals. So numerous are they on Myn Pat, that, in one day hunting, the party computed that not less than eighty had passed through the station occupied by the sportsmen.

The Gaurs browse on the leaves and tender shoots of trees and shrubs, and also graze on the banks of the streams. During the cold season they remain concealed in the saul forests, but in hot weather come out to feed in the green vallies and lawns, which occur on the mountain of Myn Pat. They show no disposition to wallow in mire or swamps, like the Buffalo; a habit, indeed, which the sleekness of their skins renders not at all probable.

The period of gestation is said to be twelve months, and they bring forth usually in August."

To the preceding observations of Dr. Traill, I have to 
add the important fact (which of itself will be sufficient to constitute a specific difference between the Gaur and the Gayal), namely, that in the skeleton of the Gaur there are only thirteen pairs of ribs, whilst the skeleton of the Gayal possesses fourteen pairs. This fact I have ascertained from an examination of both the skeletons; that of the Gaur in the museum of the Zoological Society, and that of the Gayal, in the possession of Mr. Bartlett, Russell Street, Covent Garden. (See p. 68.)

The skeleton of the Gaur just refered to, strikingly confirms Dr. Traill's account of the elevated dorsal ridge of this animal; several of the dorsal vertebræ measuring, with their spinous processes, upwards of seventeen inches each, the longest being twenty inches and a half.

The Gaur, from which this skeleton was taken, was killed at Nicecond, November 8, 1843.

There is another fine specimen of the skull and horns of the Gaur, in the Museum of the Zoological Society, taken from an animal killed by Lieut. Nelson, on the Neilsburry Hills, Salem district. This animal measured nineteen hands and half an inch at the shoulder.

Dimensions of the Figure in the British Museum :-

Ft. In.

Length from nose to insertion of tail, measuring over the forehead and along the back . 110

Height at the highest part of the dorsal ridge $\quad \begin{array}{lll}5 & 7 \frac{1}{2}\end{array}$

Height at the croup . . . . . . 54

Length of the tail . . . . . . 31

In Mr. D. Johnson's Sketches, the Gaur is described as a kind of wild bullock, of prodigious size, residing in the Ramghur district, not well known to Europeans. Mr. Johnson says : "I have never obtained a sight of them, 
but have often seen the print of their feet, the impression of one of them covering as large a space as a common china plate. According to the account I received from a number of persons they are much larger than the largest of our oxen; light brown colour, with short horns, and inhabit the thickest covers. They keep together in herds, and a herd of them is always near the Luggo-hill; they are also in the heavy jungles between Ramghur and Nagpoor. I saw the skin of one that had been killed by Rajah Futty Narrain; its exact size I do not recollect, but I well remember that it astonished me, having never seen the skin of any animal so large. Some gentlemen at Chittrah have tried all in their power to procure a calf without success. The Shecarries and villagers are so much afraid of these animals, that they cannot be prevailed on to go near them, or to endeavour to catch any of their young. It is a prevailing opinion in the country, that if they are in the least molested, they will attack the persons disturbing them, and never quit them until they are destroyed; and should they get into a tree, they will remain near it for many days."

The word Gau, or Ghoo, as it is sometimes spelled by European writers, appears to be used both as a generic and specific term, in Persia and Hindostan; and as it has the same meaning, and nearly the same sound, as the German word Kuh, and the English Cow, it is highly probable that its origin is the same. As the word ur, in Hindostan, appears to have the meaning of wild, or savage, the name Gaur, or Gau-ur, literally signifies the wild cow: Should the prefix aur, in the German word Aurochs, be merely a form, or different mode of spelling the prefix ur, then the name Aurochs would he precisely synonymous 
with the Hindostanee Gau-ur. That aur is, in this instance, merely a different spelling of the prefix ur, would appear to be corroborated by the circumstance that the term Urus is the latinized form of the German Aurochs.From a MS. Note by Mr. W. A. Chatto.

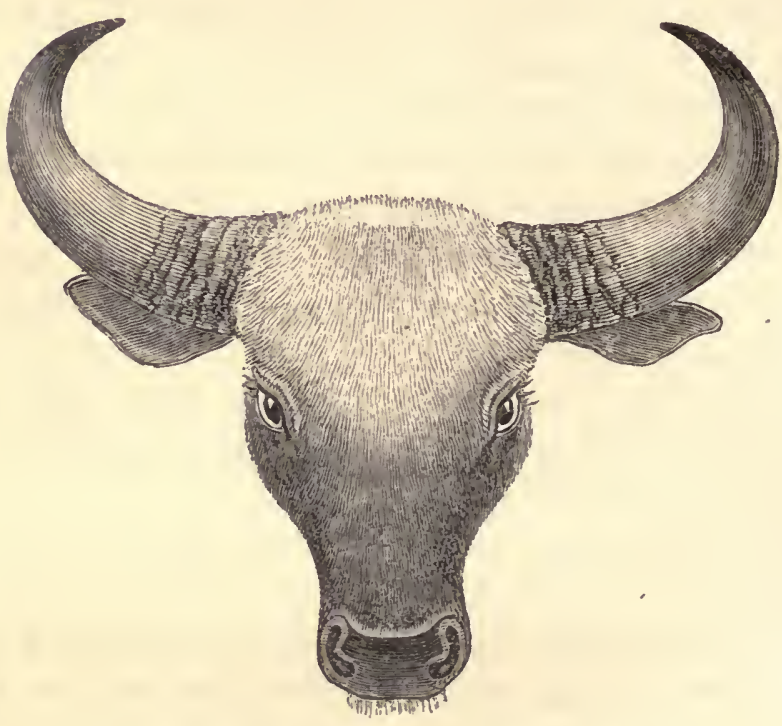

Head of Gaur, from the stuffed Specimen in the British Museum. 


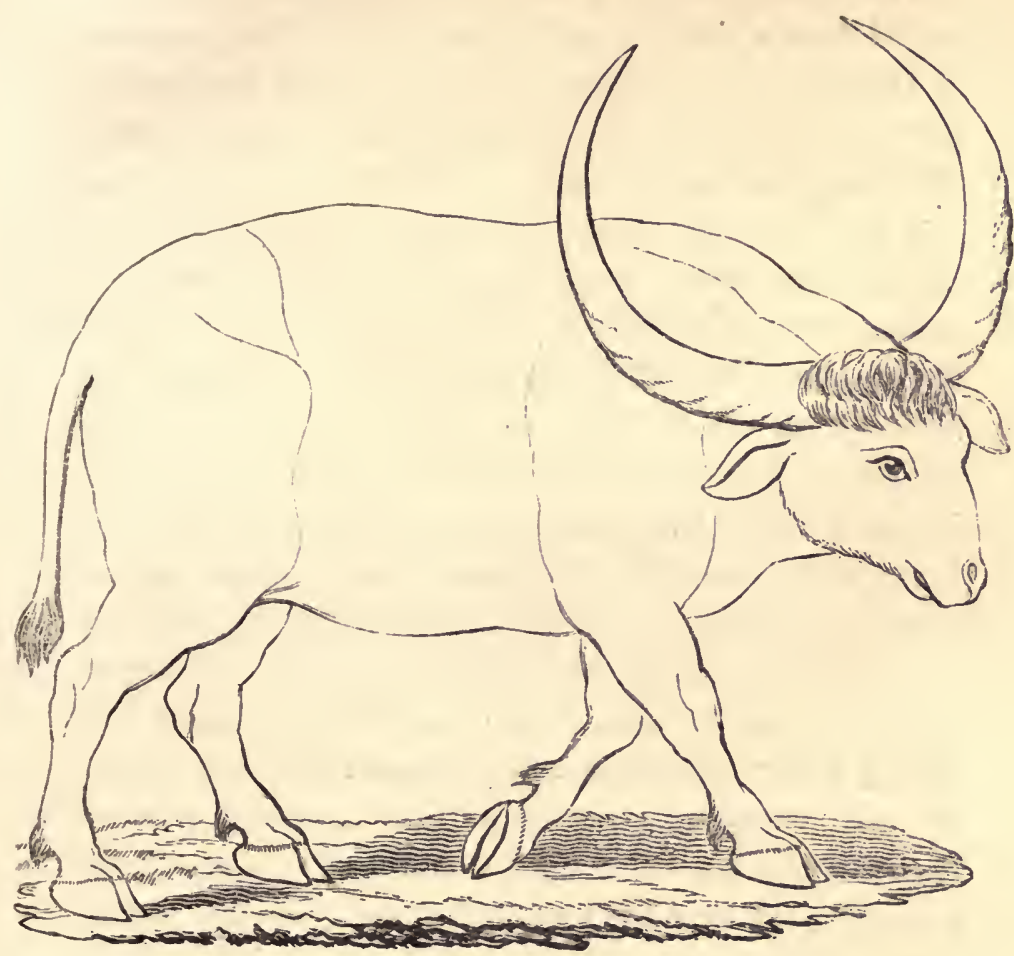

THE ARNEE, OR ARNA.

It does not appear, that the Arnee had been noticed by Europeans until the year 1792, when the following detailed account appeared in a weekly Miscellany, called 'The Bee,' conducted by Dr. J. Anderson.

This animal is hitherto unknown among the naturalists of Europe. It is a native of the higher parts of Hindostan, being scarcely ever found lower down than the Plains of Plassy, above which they are found in considerable numbers, and are well known by the natives. 
The figure, which is given at the end of this article, is copied from a curious Indian painting, in the possession of Gilbert Innes, of Stow. It forms one of a numerous group of figures, represented at a grand Eastern festival. There are two more of them in the same painting. In this and both the others, the horns bend inwards in a circular form; and it would seem, too, that if a transverse section of the horn was made at any place, that also would be circular. But this is a defect in the painting, for although all the horns of the Arnee tribe bend in a circular form, yet if the horn be cut transversely, the section is not circular, but rather of a triangular shape. The horns of the Arnee rise in a curve upwards, nearly in the same plane with the forehead, neither bending forward nor backward. That part of the horn which fronts you when the animal looks you in the face, is nearly flat, having a ridge projecting a little forward all along, nearer the outer curvature of the horn; from that ridge outward it goes backward, not at right angles, but bending a little outward; and near the back part there is another obtuse rounded ridge, where it turns inward, so as to join another obtuse, rounded angle, at the inner curvature of the horn. Along the whole length, especially toward the base of the horn, there are irregular transverse dimples, or hollows and rugosities, more nearly resembling those of a ram, than that of a common ox's horn, but no appearance of rings, denoting the age of the animal, as in the horns of our cattle.

This description of the horns is taken from a pair of real horns of the animal, now in the possession of Mr. James Haig, merchant in Leith, that were sent home to him this year (1792) by his brother, Mr. W. Haig, of 
the 'Hawkesbury' East-Indiaman, and of which the following cut represents a front view. The little figure marked $a$, represents a section of the horn near its base.

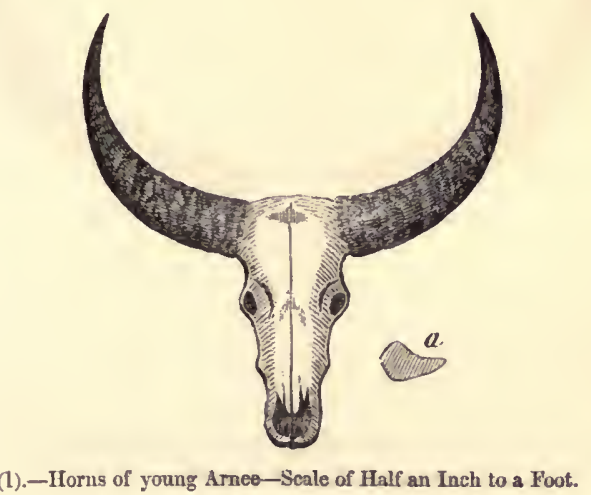

In this young specimen (1) the length of the skull is exactly two feet, and the distance between the tops of the horns thirty-five inches. In the following sketch (2) from the Museum of the College of Surgeons, the length of the skull is likewise two feet, and the distance between the tips of the horns three feet four inches and a half.

The young animal just referred to, was found in a situation near which no other animal of this sort had ever before been discovered: it was killed by the crew of the 'Hawkesbury,' in the river Ganges, about fifty miles below Calcutta, at the place where the ships usually lie.

The flesh was eaten by the ship's company, by whom it was considered very good meat. Although conjectured to be only two years old, it weighed, when cut up, $360 \mathrm{lbs}$. the quarter, which is 1440 lbs. the carcase, exclusive of head, legs, hide, and entrails. 
108

THE OX 'TRIBE.

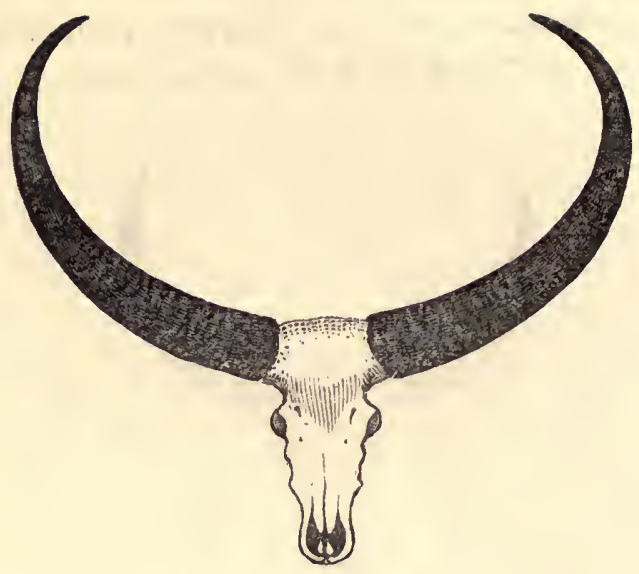

(2).-Horns of Arnee.-Scale of Half an Ineh to a Foot.

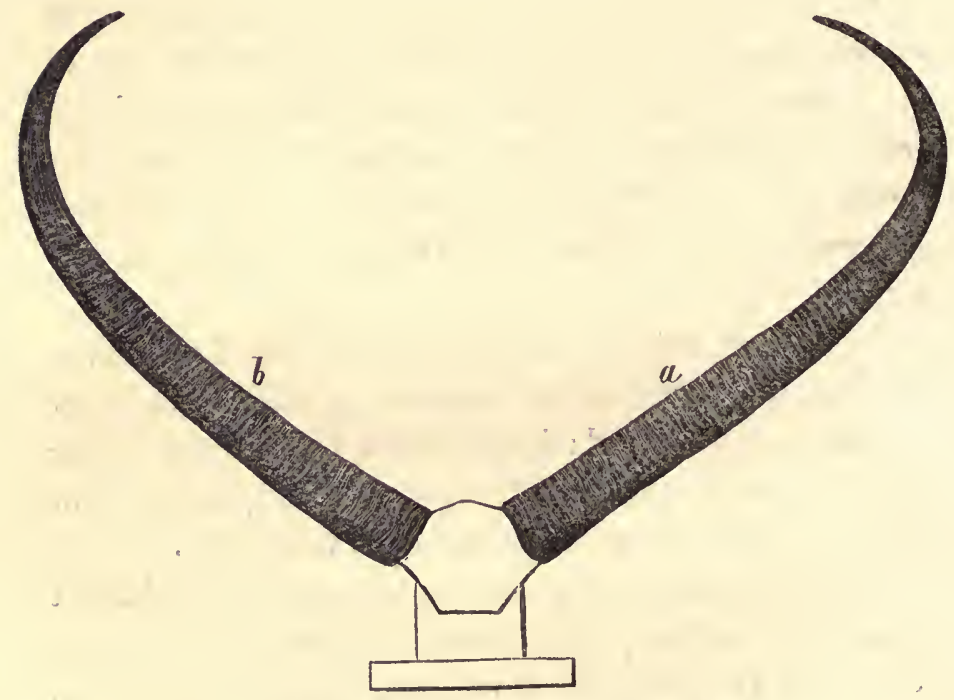

(3),-Horns of Arnee.m-Seale of Half an Ineh to a Foot. 
This last sketch (3) is from a pair of horns in the British Museum, of which the following are the dimensions :-

Ft. In.

The horn $a$, from tip to basc, along the outer curve $\quad \begin{array}{lll}6 & 6\end{array}$

$\begin{array}{llll}\text { The horn } b & \text { ditto ditto } & 6 & 3\end{array}$

Circumference at the base of horn $a$. . . 15

Ditto ditto of horn $b$. : . I $6^{*}$

The Arnee is by far the largest animal of the Ox tribe yet known. In its native country it is said to measure usually twelve, sometimes fourteen, feet from the ground to the highest part of the back! The one in the vignette, p. 111, comparing it with the man on its back, would not scem to be quite so tall.

From the appearance of the three Arnees in the painting before mentioned, it would seem that they are quite docile, and easily tamed; for they are all standing quietly, with a person on their back, who guides them by means of a rein, formed of a cord fastened to the gristle of the nose, in the Eastern manner. The colour of the animal, in all the three figures, is a pure black, except between the horns, where there is a small tuft of longish hair of a bright red colour.

From the accounts of more recent travellers, there seem to be two or three varieties of this animal, which exist, both in a wild and domestic state, in China as well as India.

According to Major Smith, the gigantic or Taurelephant Arnee, appears to be rare; found only single, or in small families, in the upper eastern provinces and

* In Shaw's 'Zoology,' it is mentioned that a Mr. Dillon saw some horns in India which were ten feet long. 
forests at the foot of the Himalaya. A party of officers of the British Cavalry, stationed in the north of Bengal, went on a three months' hunting expedition to the eastward, and destroyed in that time forty-two Tigers, and numerous wild Buffaloes, but only one Arnee. When the head of this specimen rested perpendicularly on the ground, it required the out-stretched arms of a man to hold the points of the horns. These are described as angular, with the broadest side to the rear; the two others anterior and inferior; they are of a brownish colour, and wrinkled; standing outwards, and not bent back; straight for near two thirds of their length, then curving inwards, with the tips rather back. The face is nearly straight, and the breadth of the forehead is carried down with little diminution to the foremost grinder.

There is a spirited figure of a long-horned Buffalo in Captain Williamson's ' Oriental Field Sports,' which Major Smith considers to be a representation of the great Arnee; and of which Captain Williamson relates the following anecdote :-

"The late Dr. Baillie, who was a very keen and capable sportsman, used, in my idea, to run many very foolish risks among Buffaloes. I often remonstrated with him on his temerity, but he was so infatuated, that it was all to no purpose. One morning, as we were riding on the same elephant to the hunting-ground, to save our horses as much as possible, we saw a very large Buffalo lying on the grass, which was rather short and thin; as usual, the doctor would have a touch at him, and, heedless of my expostulation, dismounted with his gun. The Buffalo, seeing him approach, rose and shook his head as a prelude to immediate hostilities. My friend fired, and hit him on the side. 
The enraged brute came thundering at the doctor, who lost no time in running round to the opposite side of the elephant; the mohout, at the same time, pushed forward, to meet and screen him from the Buffalo, which absolutely put his horns under the elephant's belly, and endeavoured to raise him from the ground. We had no other gun, and might, perhaps, have felt some more severe effects from the doctor's frolic, had not the Buffalo, from loss of blood, dropped at our side. The Buffalo was upwards of six feet high at the shoulder, and measured nearly a yard in breadth at the chest. His horns were above five feet and a half in length."

In systems of classification, even of very recent date, the Arnee is considered merely as a variety of the Buffalo. It appears to me, however, that our information on the subject is not yet sufficiently precise to determine this point.

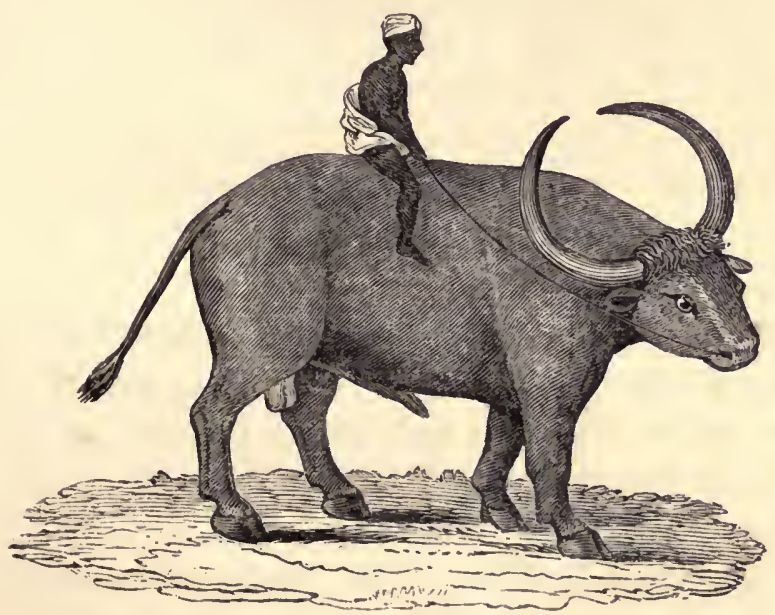




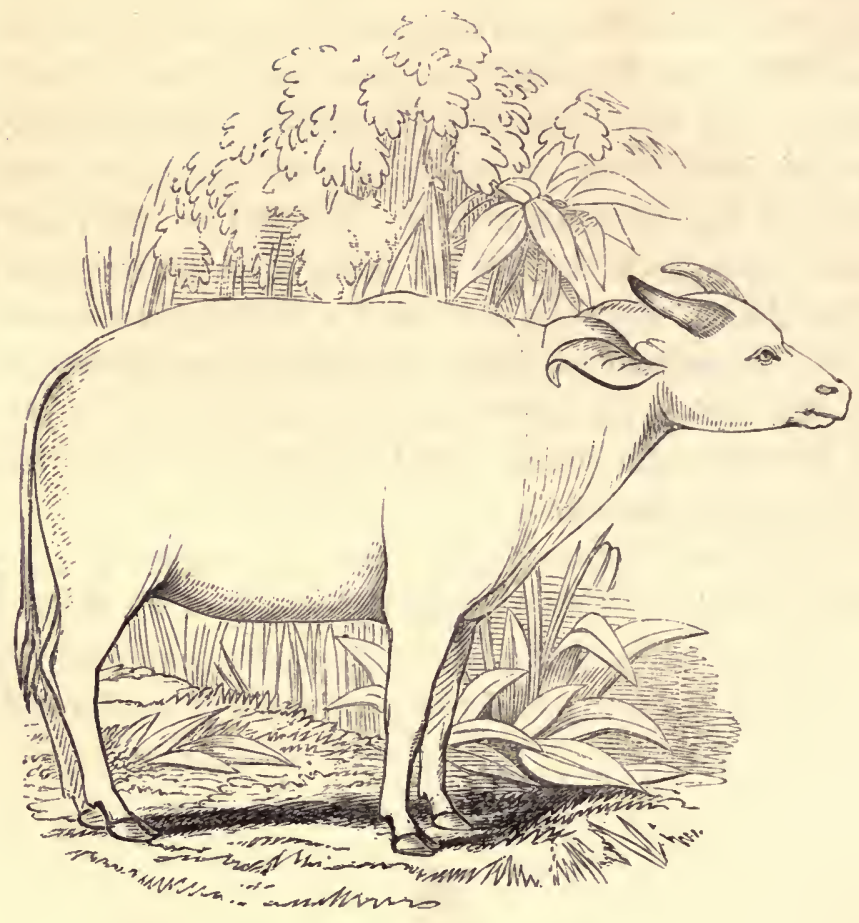

THE ZAMOUSE, OR BUSH COW.

Bos Brachyceros.

[The following extract, from the 'Annals of Nat. Hist.,' vol. ii, p. 284, is from the pen of Mr. J. E. Gray.]

"Captain Clapperton and Colonel Denham, when they returned from their expedition in Northern and Central Africa, brought with them two heads of a species of $\mathrm{Ox}$, covered with their skins. These heads are the specimens which are mentioned in Messrs. Children and Vigors' accounts of the animals collected in the expedition, as 
belonging to the Buffalo, Bos Bubalus, and they are stated to be called Zamouse by the natives; but, as no particular locality is given for the head, this name is probably the one applied to the common Buffalo, which is found in most parts of North Africa.

"Having some years ago compared these heads with the skull of the common Buffalo, Bos Bubalus, and satisfied myself, from the difference in the form and position of the horns, that they were a distinct species, in the ' Mag. of Nat. Hist.,' for 1837 (new series, vol. i, p. 589), I indicated them as a new species, under the name of Bos Brachyceros.

"In the course of this summer (1838), Mr. Cross, of the Surrey Zoological Gardens, received from Sierra Leone, under the name of the Bush Cow, a specimen which serves more fully to establish the species. It differs from the Buffalo and all other oxen in several important characters. especially in the large size and particular bearding of the ears, and in being totally deficient in any dewlap. It also differs from the Buffalo in its forehead, being flatter and quite destitute of the convex form which is so striking in all the varieties of that animal.

"Mr. Cross's cow is, like the head in the Museum, of a nearly uniform pale chesnut colour. The hair is rather scattered, and nearly perpendicular to the surface of the body. The legs, about the knees and hocks, are rather darker. The ears are very large, with two rows of very long hairs on the inner side, and a tuft of long hairs at the tips. The body is short and barrel-shaped, and the tail reaches to the hocks, rather thin and tapering, with a tuft of long hairs at the tip. The chest is rounded and rather dependent, but without the least appearance of a dewlap; and the horns nearly resemble those of the 
Museum specimen, but are less developed, from the sex and evidently greater youth of the animal. The Rev. Mr. Morgan informs me that the animal is not rare in the bush near Sierra Leone.

"I have added a slight sketch of Mr. Cross's animal, which I hope will enable any person to distinguish this very distinct and interesting addition to the species of this useful genus."

The engraving at the head of this article is a reduced copy of Mr. Gray's figure just alluded to. The following representation of the head is from a specimen in the British Museum.

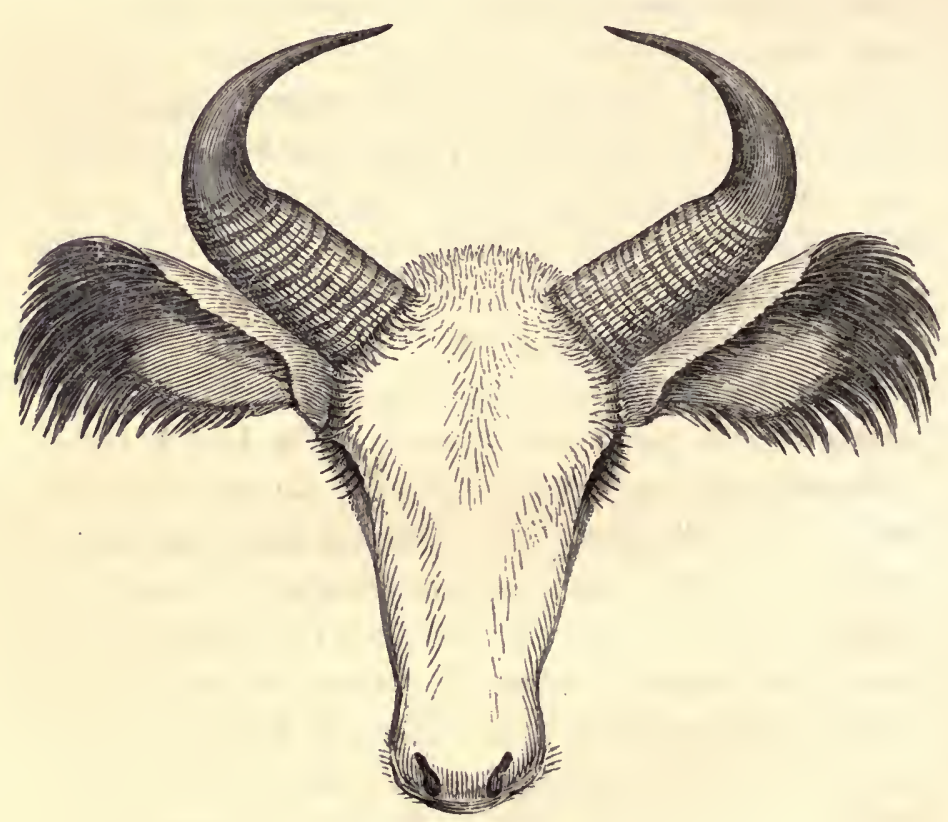




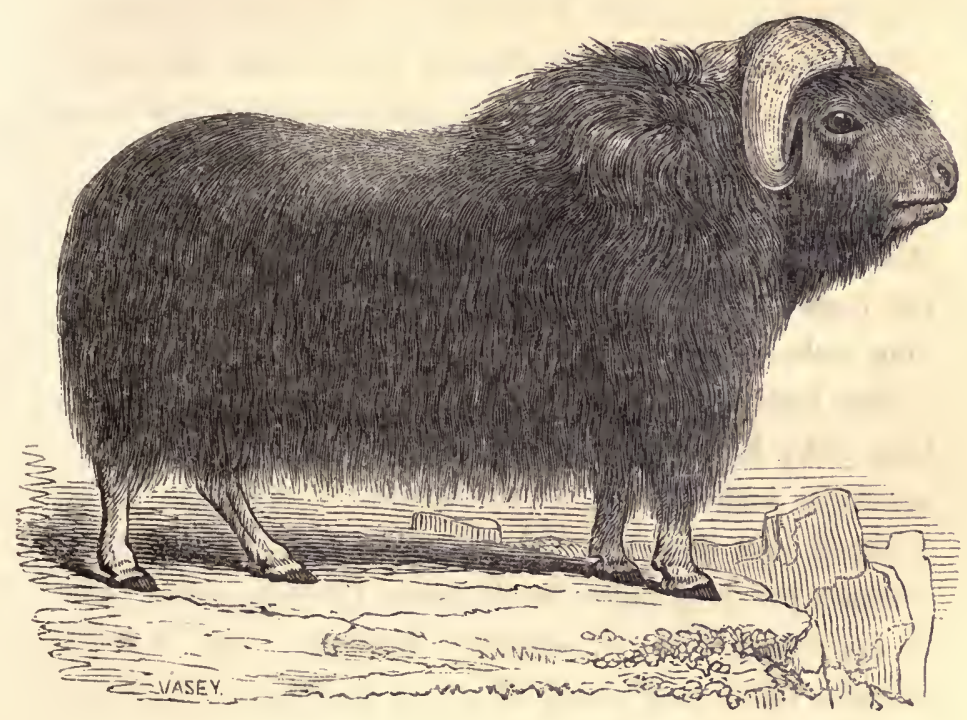

TIIE MUSK OX.

Bos Moschatus.

The Musk-ox, in its external appearance, more nearly resembles the Yak of Thibet than any other member of the Bos genus; and they both inhabit mountainous districts near regions of perpetual snow.

The horns of the Musk Bull are remarkably broad at their bases, which are closely united; they bend down on each side of the head, with an outward curve turning upwards towards their ends, which taper to a sharp point. They are two feet long measured along the curvature, and two feet in girth at the base; the weight of a pair of these 
horns is sometimes sixty pounds. The broad base of the horn is hollow on the inside, and of a form approaching to a square; when this is separated from the head and the other part of the horn, it forms a convenient dish, which is very generally used by the native Esquimaux for many domestic purposes.

The horns of the cow are nine inches distant from each other at the base, and are placed exactly on the sides of the head; they are thirteen inches long, and eight or nine inches round at the base.

The head and the body generally is covered with very long silky hairs of a dark colour; some of which are seventeen inches loug; on the middle of the back (which is broad and flat), the hair is lighter and not so long. Beneath the long hairs, in all parts, there is a thick coat of cimereous wool of exquisite fineness. M. Jeramie brought some to France, of which stockings were made more beautiful than silk.

The tail is only three inches long, and completely covered with very long hairs, so as to be undistinguishable to the sight. Of this tail, the Esquimaux of the northwest side of Hudson's Bay, make a cap of a most horrible appearance, for the hairs fall all round their heads, and cover their faces; yet it is of singular service in keeping off the musquitoes, which would otherwise be intolerable.

The ears are only three inches long, quite erect, and sharp pointed, but dilate much in the middle; they are thickly lined with hair of a dusky colour, marked with a stripe of white.

The frog in the hoof is soft, partially covered with hair, and transversely ribbed. The following sketch represents 
the under surface of the foot of the Musk-ox, the external hoof being rounded, the internal pointed.

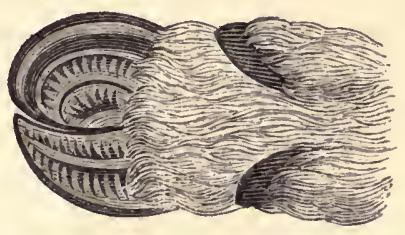

The foot-marks of the Musk-ox and those of the reindeer are so much alike, that it requires the eye of an experienced hunter to distinguish them. The mark of the Musk-ox's hoof, however, is a little narrower.

The food of the Musk-ox is the same with that of the rein-deer-lichens and grass; and sometimes twigs and shoots of willow, birch, and pine.

At present this animal is not found in a lower latitude than $66^{\circ}$; but formerly they came much further to the south; and their flesh used to be brought by the natives to Fort Churchill in latitude $58^{\circ}$. It would appear that they are retiring northward, probably owing to the alarm created by the attacks made upon them by firearms. It is worthy of remark, that the American Bison has also retreated considerably to the north. According to Dr. Richardson, the Musk-ox inhabits the North Georgian Islands in the summer months. They arrive in Melville Island in the middle of May, crossing the ice from the southward, and quit it on their return towards the end of September.

The Musk-oxen, like the Bison, herd together in bands, and generally frequent barren grounds during the summer 
months, keeping near the rivers; but retire to the woods in winter. 'They seem to be less watchful than most other wild animals; and when feeding are not difficult of approach, provided the hunters go against the wind. When two or three men get so near a herd as to fire at them from different points, these animals, instead of separating or running away, huddle closer together, and in this case they are easily shot down; but if the wound is not mortal, they become enraged, and dart in the most furious manner at the hunters, who must be very dexterous to evade them; for, notwithstanding the shortness of their legs, they can run with great rapidity, and climb hills and rocks, with great ease. They can defend themselves by their powerful horns against wolves and bears, which, as the Indians say, they not unfrequently kill.-(Capt. Franklin's 'Journey to the Polar Sea.')

They are hunted in their winter retreats by the Esquimaux only, the Indian tribes never visiting the barren grounds at that season.

When the Musk-ox is fat, its-flesh is well tasted, and it is then preferred by the Copper Indians to the rein-deer. The flesh of bulls is high-flavoured; but both bulls and cows smell strongly of musk, their flesh at the same time being very dark and tough. The contents of the paunch, and other intestinal parts, are relished as much by the Indian as the similar parts of the rein-deer.-(Appendix to Capt. Parry's ' Second Voyage.')

The weight of the bulls killed during Capt. Parry's Second Voyage was, on an average about $700 \mathrm{lbs}$., yielding about 400 lbs. of meat. Their height, at the withers, was about ten hands and a half.

They were observed by Capt. Franklin's party to rut 
in the end of August and beginning of September; and Hearne says, that they bring forth one calf in the latter end of May, or beginning of June; thus the period of gestation is about nine months.

The figure at the beginning of this article, as well as the following cut of the head, are from the beautiful specimen of the Musk Ox, in the British Museum.

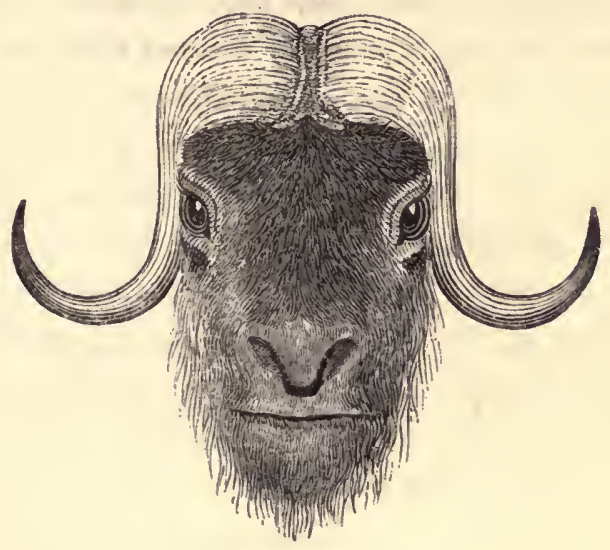

Ilead of Musk Ox. 
THE SANGA, OR GALLA OX.

(See Frontispiece). Bos - ?

'This singular animal is only found in Abyssinia, and is famous on account of its horns, which are of an almost incredible size.

Bruce the traveller, in speaking of these horns, says, "The animal furnishing these monstrous horns is a cow or bull which would be considered of a middling size in England. This extraordinary size of its horns proceeds from a disease that the cattle have in these countries, of which they die, and is probably derived from their pasture and climate. When the animal shows symptoms of this disorder, he is set apart in the very best and quietest grazing place, and never driven or molested from that moment. His value lies then in his horns, for his body becomes emaciated and lank, in proportion as the horns grow large; at the last period of his life, the weight of his head is so great that he is unable to lift it up, or at least for any space of time. The joints of his neck become callous at last, so that it is not any longer in his power to lift his head. In this situation he dies, with scarcely flesh to cover his bones, and it is then his horns are of the greatest value. I have seen horns that would contain as much as a common sized water-pail, such as they make use of in the houses in England."*

* Jerom Lobo, in his account of Abyssinia, mentions that some of the horns of the Buffaloes of that country will hold ten quarts. 
So far Mr. Bruce. Mr. Salt, who visited Abyssinia some years afterwards, gives a somewhat different account. He says: "Here [i.e. at Gibba], for the first time, I was gratified by the sight of the Galla Oxen, or Sanga, celebrated throughout Abyssinia for the remarkable size of its horns. Three of these animals were grazing among the other cattle in perfect health, which circumstance, together with the testimony of the natives, 'that the size of the horns is in no instance occasioned by disease,' completely refutes the fanciful theory given by Mr. Bruce respecting this creature. It appears by the papers annexed to the last edition of Mr. Bruce's work, that he never met with the Sanga; but that he made many attempts to procure specimens of the horns, through Yanni, a Greek, residing at Adowa. This old man very correctly speaks of them, in his letters, as being only brought by the Cafilas from Antalo; and I have now ascertained that they are sent to this country as valuable presents, by the chiefs of the Galla, whose tribes are spread to the southward of Enderta. So far, then, as to the description of the horns, and the purposes to which they are applied by the Abyssinians, Mr. Bruce's statements may be considered as correct; but with respect to 'the disease which occasions their size, probably derived from their pasture and climate,' 'the care taken of them to encourage this disease,' 'the emaciation of the animal,' and 'the extending of the disorder to the spine of the neck, which at last becomes callous, so that it is not any longer in the power of the animal to lift its head,' they all prove to be mere ingenious conjectures, thrown out by the author solely for the exercise of his own ingenuity.

"I should not venture to speak so positively upon this 
matter, had I not indisputably ascertained the facts; for the Ras having subsequently made me a present of three of these animals alive, I found them not only in excellent health, but so exceedingly wild, that I was obliged to have them shot. The horns of one of these are now deposited in the Museum of the Surgeons' College, and a still larger pair are placed in the collection of Lord Valentia, at Arley Hall. The length of the largest horn of this description was nearly four feet, and its circumference at the base twenty-one inches.

"It might have been expected that the animal, carrying horns of so extraordinary a magnitude, would have proved larger than others belonging to the same genus; but in every instance which came under my observation, this was by no means the case. The etching on the following page, which was copied from an original sketch (taken from the life), may serve to convince the reader of this fact; and it will convey a better idea of the animal than any description in writing I can pretend to give. I shall only further observe, that its colour appeared to vary as much as in the other species of its genus, and that the peculiarity of the size of the horns was not confined to the male, the female being very amply provided with this ornamental appendage to her forehead."

Notwithstanding the bold and confident tone of Mr. Salt's counter-statement, it must be confessed, that the figure which he himself gives from the life (and of which the frontispiece to this volume is an exact copy), seems rather to coincide with $\mathrm{Mr}$. Bruce's account, being, to all appearance, both "lank and emaciated." 
Engraving of the horns presented by Mr. Salt to the Museum of the College of Surgeons.

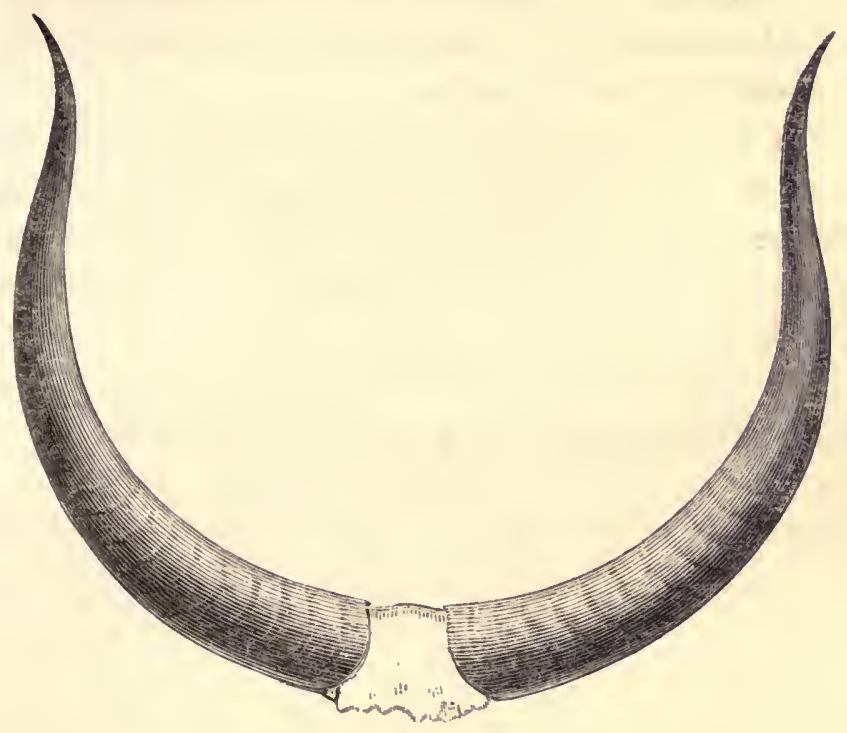

Horns of Galla Ox.

Ft. In.

Length of each round the outer curve . . $310 \frac{1}{2}$

Distance between the tips . . . . 34

Circumference at the base . . . . $\quad$. 13

Distance between the bases at the forehcad . $\quad \begin{array}{lll}0 & 3 \frac{1}{9}\end{array}$

The Sanga is usually considered as a mere variety of Bos Taurus. This may possibly be the fact; but we have no proof whatever that it is so: no information on this point has been presented beyond mere conjecture. This being the case, and in the absence of direct anatomical evidence, we may be pardoned in considering it, at least, as doubtful; especially as there are so many points of external dissimilarity. The principal differences are: 1st, in the shoulder, upon which there is a hump; $2 \mathrm{~d}$, in the 
back, which descends (as in the Buffaloes and Zebus), -abruptly towards the tail; $3 \mathrm{~d}$, in the greater length of the legs ; and 4th, in the forehead, which is only three inches and a half between the bases of the horns, whilst in the Common $\mathrm{Ox}$ it is nine inches.

The horns represented in the following sketch, are those of the Hungarian Ox (a variety of Bos Taurus), and are almost as remarkable for their length and expansion as those of the Abyssinian Sanga. The length of each horn is three feet four inches and a half, and the distance between the tips is five feet one inch. The sketch is from a specimen in the British Museum.

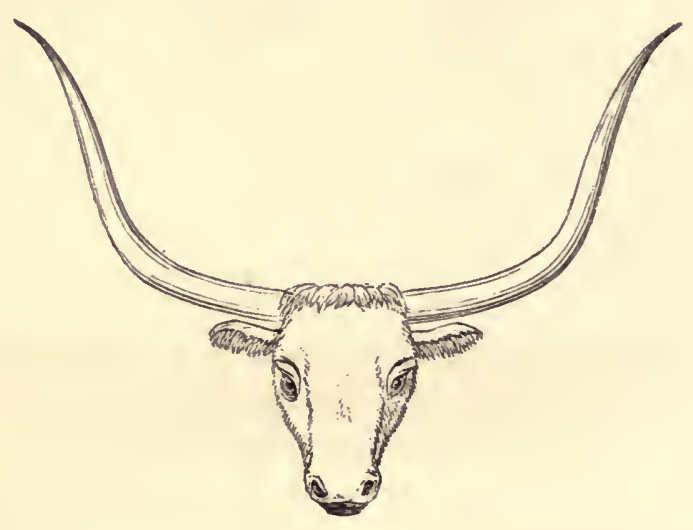




\section{INDIAN DOMESTIC CATTLE.}

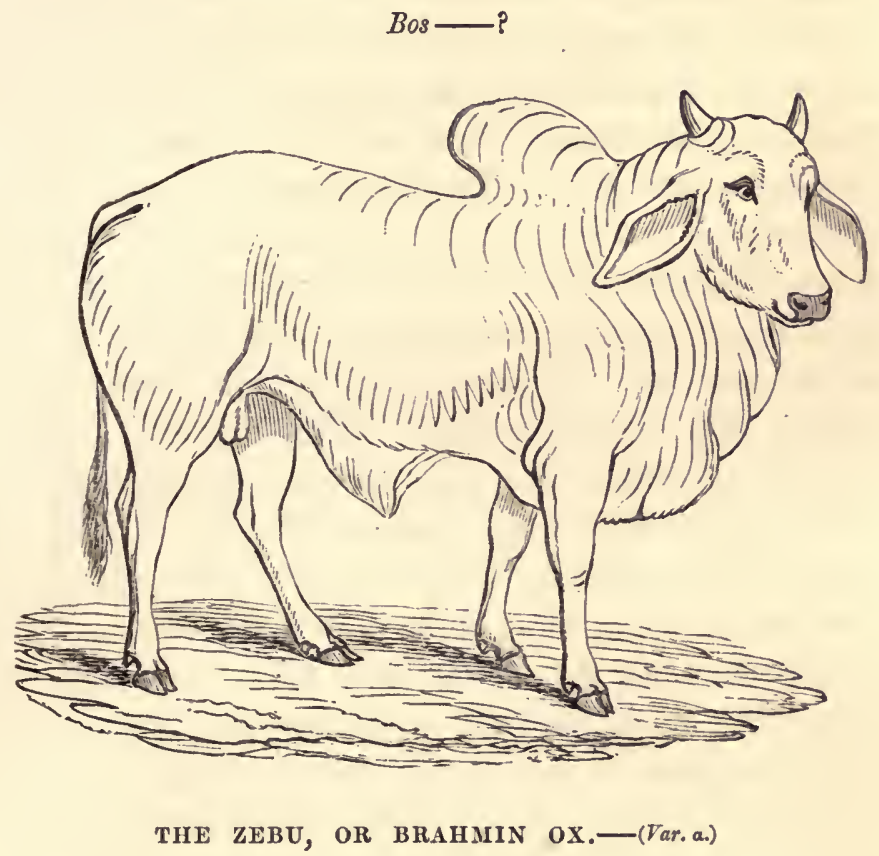

The opinions expressed in the following extract from Mr. Bennett's description of the Indian Ox (Gardens and Menag. of the Zool. Soc.), nuay be taken as a correct exposition of the views of naturalists generally on the subject:-

"There can be little doubt that the Zebu, or Indian Ox, is merely a variety of the Common Ox, although it is difficult to ascertain the causes by which the distinctive characters of the two races have been in the process of 
time gradually produced. But whatever the causes may have been, their effects rapidly disappear by the intermixture of the breeds, and are entircly lost at the end of a few generations. This intermixture and its results would alone furnish a sufficient proof of identity of origin; which, consequently, scarcely requires the confirmation to be derived from the perfect agreement of their internal structure, and of all the more essential particulars of their external confirmation. These, however, are not wanting; not only is their anatomical structure the same, but the form of their heads, which affords the only certain means of distinguishing the actual species of this genus from each other, presents no difference whatever. In both the forehead is flat, or more properly slightly depressed; nearly square in its outline, its height being equal to its breadth; and bounded above by a prominent line, forming an angular protuberance, passing directly across the skull between the bases of the horns. The only circumstances in fact in which the two animals differ, consists in the fatty hump on the shoulders of the Zebu, and in the somewhat more slender and delicate make of its legs."

In a scientific work, it is not sufficient for the author merely to make an assertion; it is not even sufficient for him to say that he has made an experiment or observation, and merely give the result; he should, in every case where it is practicable, describe the nature of his experiment, the when, the where, the how; - and the means and opportunity he had of making his observations, that the curious or sceptical inquirer may be enabled to perform the experiment, or make the observation for himself.

Mr. Bennett tells us, that the differences observable in the Indian Ox and the Common Ox "rapidly disappear 
by the intermixture of the breeds, and are entirely lost at the end of a few generations;" but he does not refer to a single instance of this, authentic or otherwise; nor are we aware that any such instance ever occurred.

Again, he states that "their anatomical structure is the same ;" but he does not inform us when, or where, or how, the comparison was made which enabled him to arrive at that conclusion.

Wishing to satisfy myself, as far as possible, on this point, I have examined the skeleton both of the British Domestic Ox and the Zebu ; and the following is the result of that examination :-

NUMBER OF VERTEBR木.

Cerv. Dors. Lumb. Sae. Caud. Total.

$\begin{array}{llllllll}\text { In the Zebu } & . & . & 7 & 13 & 6 & 4 & 18=48\end{array}$

$\begin{array}{lllllll}\text { In the Common Ox } & . & 7 & 13 & 6 & 5 & 21=52\end{array}$

The skeletons may still be seen in the Muscum of the College of Surgeons.

Furthermore, the period of gestation of the Brahmin Cow (according to the MS. records of the Zoological Soeiety), is 300 days, while that of the Common Cow is only 270 days.

Whether the differences here pointed out are sufficient to constitute specific distinction, is left for the umpires to decide. 


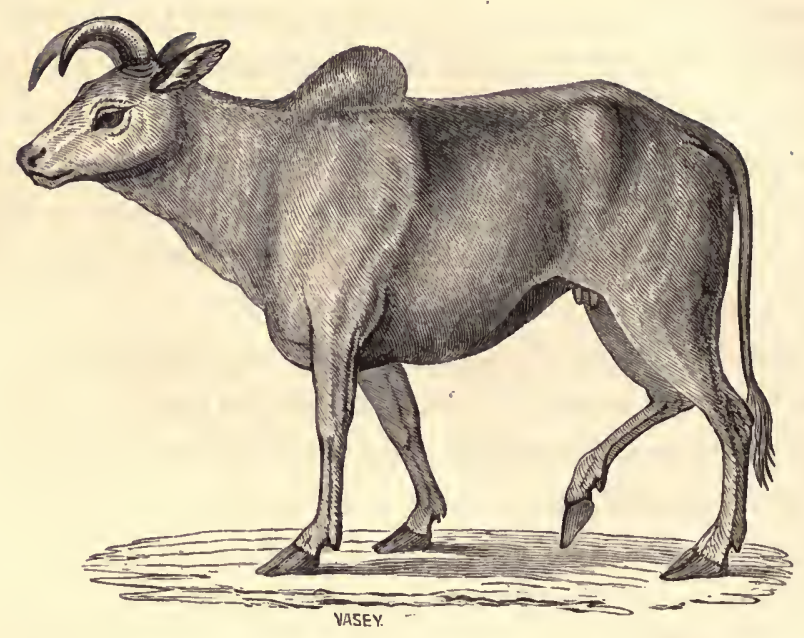

THE ZEBU.—(Var. $\beta$.)

These Indian Cattle are extremely gentle, and admirably adapted to harness. Some of the eastern princes attach them to their artillery; but generally they employ the finest to draw their light carriages, which in form are very similar to those of the ancients. In mountainous countries, they have them shod. Their pace is a kind of amble, and they are able to sustain a journey of about twenty leagues a day. Guided by a cord which passes through the nasal cartilage, they obey the hand with as much precision as a horse.

In the same provinces are seen a race of dwarf Bisons, which are scarcely as tall as our calves of two months old, generally described under the name of Zebu. They are lively, well proportioned, and trained to be mounted by children, or to draw a light car. In both cases their 
pace is a sort of amble, the same as that of the larger species.

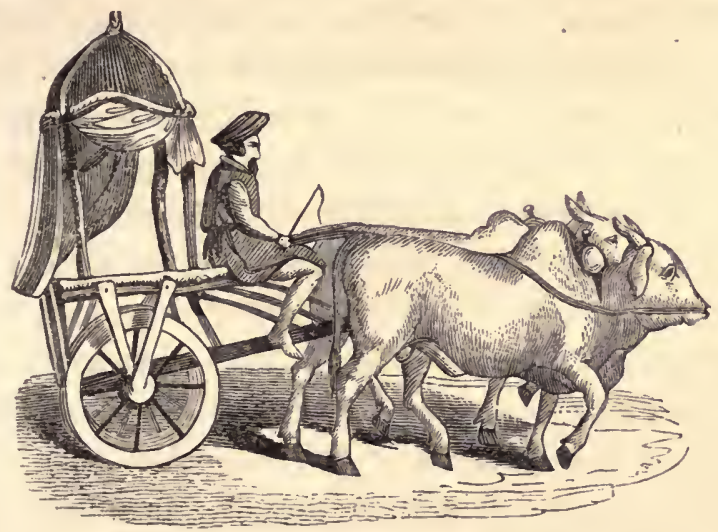

Zebus (Var. $\gamma$ ) and Car.

The curious Hindoo customs in relation to this animal have been recorded by almost every traveller.

Neither the horse, the sheep, nor the goat, have any peculiar sanctity annexed to them by the Braminical superstition; it is otherwise with the cow, which in India is everywhere regarded with veneration, and is an object of peculiar worship. Representations of objects are made upon the walls with cow-dung, and these enter deeply into their routine of daily observances. The same materials are also dried, and used as fuel for dressing their victuals; for this purpose the women collect it, and bake it into cakes, which are placed in a position where they soon become dry and fit for use. The sacred character of the cow probably gives this fuel a preference to every other in : the imagination of a Hindoo, for it is used in Calcutta, where wood is in abundance.

On certain occasions it is customary for the Hindoos to consccrate a bull as an offering to their deities; particular 
ceremonies are then performed, and a mark is impressed upon the animal, expressive of his future condition to all the inhabitants. No consideration will induce the pious Bengalee to hurt or even control one of these consecrated animals. You may see them every day roaming at large through the streets of Calcutta, and tasting rice, grain, or flour in the Bazar, according to their pleasure. The utmost a native will do, when he observes the animal doing too much honour to his goods, is to urge him, by the gentlest hints, to taste of the vegetables or grain of his neighbour's stall.-(Tennant's 'Indian Recreations.')

One of the doctrines of the Brahmins is to believe that kine have in them somewhat of sacred and divine; that happy is the man who can be sprinkled over with the ashes of a cow, burnt by the hand of a Brahmin; but thrice happy is he who, in dying, lays hold of a cow's tail and expires with it between his hands; for thus assisted, the soul departs out of the body purified, and sometimes returns into the body of a cow. That such a favour, notwithstanding, is not conferred but on heroic souls, who contemn life, and die generously, either by casting themselves headlong from a precipice, or leaping into a kindled pile, or throwing themselves under the holy chariot wheels, to be crushed to death by the Pagods, when they are carried in triumph about the town.-(Life of St. Francis Xavier, translated by Dryden, 1688.)

\section{AFRICAN AND OTHER VARIETIES.}

In Shaw's Zoology, the following species or varieties are noticed :-

This is said to be found in Abyssinia and in Madagascar, 
and is distinguished by pendulous ears, and horns attached only to the skin, so as to hang down on each side!

THE BOURY.

Of the size of a camel, and of a snowy whiteness, with a protuberance on the back, is a native of Madagascar and some other islands.

THE TINIAN OX.

Of a white colour, with black ears. Inhabits the island of Tinian.

Bewick mentions that in Persia there are many oxen entirely white, with small blunt horns and humps on their backs. They are very strong, and carry heavy burdens. When about to be loaded, they drop down on their knees like the Camel, and rise again when their burdens are properly fastened.

THE BORNOU OX,

which Col. Smith considers a distinct species, is likewise white, of a very large size, with hunched baek, and very large horns, which are eouched outwards and downwards, like those of the African Buffalo, with the tip forming a small half-spiral revolution. The corneous external coat is very soft, distinetly fibrous, and at the base not much thicker than a human nail; the osseous core full of vascular grooves, and inside very cellular, the pair scarcely weighing four pounds. The skin passes insensibly to the horny state, so that there is no exaet demarcation where the one commenees or the other ends. The dimension of a horn are:-length measured on the 
curve, three feet seven inches; circumference at base, two feet; circumference midway, one foot six inclies; circumference two thirds up the horn, one foot; length in a straight line, from base to tip, one foot five inches and a half. The species has a small neck, and is the common domestic breed of Bornou, where the Buffalo is said to have small horns.

Leguat, in his 'Voyages in 1720,' states that the oxen are of three sorts at the Cape of Good Hope, all of a large size, and very active; some have a hump on the back, others have the horns long and pendent, while others have them turned up and well shaped, as in English cattle.

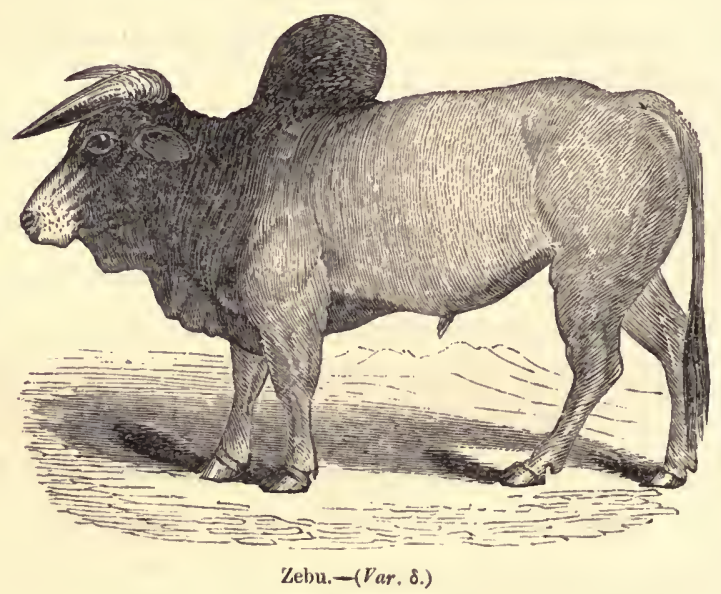


The domestic oxen of the hottentots, called BACKELEYS, BACKELEYERS, OR BAKELY-OSSE.

\section{Bos — ?}

The following particulars relating to these Oxen are taken from the highly interesting work 'The Present State of the Cape of Good Hope,' by Peter Kolben, who visited that colony in 1705, and remained there during a period of eight years.

"The Hottentots have a sort of oxen they call Backeleyers, or fighting oxen; they use them in their wars, as some nations do elephants; of the taming and farming of which last creatures upon the like discipline the Hottentots as yet know nothing. They are of great use to them, too, in the government of their herds at pasture; for, upon a signal from their commanders, they will fetch in stragglers, and bring the herds within compass. They will likewise run very furiously at strangers, and therefore are of good defence against the Buschies, or robbers who steal cattle. They are the stateliest oxen of the herd: every Kraal has half-a-dozen of these oxen at the least. When one of them dies, or grows so old, that, being unfit for business, his owner kills him, a young one is chosen out of the herd to succeed him, by an ancient Hottentot, who is judged best able to discern his capacity for instruction. This young ox is associated with an old Backeleyer, and taught; by blows and other means, to follow him. . At night they tie them together by the horns; and for some part of the day they fasten them together in the same manner, till at length, by this and I know not what other means, the 
young ox is fully instructed, and becomes a watchful guardian of the herds, and an able auxiliary in war.

"The Backeleyers (so called from the Hottentot word Backeley for war) know every inhabitant of the Kraal they belong to, men, women, and children, and pay them all just the same respect that is paid by a dog to every person who dwells in his master's house. Any of the inhabitants may, therefore, at any time present themselves very safely on any side of the herds; the Backeleyers will in nowise offend them. But if a stranger, especially a European, shall approach the herds, without the company of a Hottentot of the Kraal they belong to, he must look sharp to himself; for these Backeleyers, which generally feed at the skirts of the herds, quickly discover him, and make at him upon a full gallop. And if he is not within learing of any of the Hottentots who keep the herds, or has not a fire-arm, or a light pair of heels, or there is not a tree at hand which he can immediately climb, he is certainly demolished. The Backeleyers mind not sticks or the throwing of stones at them. This is one great reason why the Europeans always travel the Hottentot countries with fire-arms. But the first thing a European does, upon the appearance of such an enemy, is to shout and call to the Hottentots that look to the herds. The Hottentot that hears him hastens to his assistance, making all the way a very shrill whistling through his fingers. The Backeleyers no sooner hear the whistling of their keepers, which they very well know, than they stop, turn about, and return leisurely to the herds.

"But if a European, in such a case, does not (upon his shouting and calling to the keepers), hear the whistle, before the Backeleyers come up with him, he discharges 
his fire-arm,-frightened with the report of which, the Backeleyers run away.

"I have been often run at by the Backeleyers myself. As soon as I saw them sallying out upon me, I shouted and called to the keepers. But I could not often make them hear before the Backeleyers came up with me, when I have been obliged to discharge my fire-arm (for I always carried one about with me), upon which they always turned about and left me.

"In the wars of the Hottentots with one another, these Backeleyers make very terrible impressions. They gore, and kick, and trample to death, with incredible fury. Each army has a drove of them, which they take their opportunity to turn upon the enemy. And if an army, against which the Backeleyers are sent, is not alert and upon all its guard, these creatures quickly force their way through it, tearing, shattering, and confounding all the troops that oppose them, and paving for their masters an easy way to victory. The courage of these creatures is amazing; and the discipline upon which they are formed does not a little honour to the Hottentot genius and dexterity.

"The Hottentots have likewise great numbers of oxen for carriage. These, too, are very strong and stately creatures, chosen out of the herds, at about the age of two years, by old men, well skilled in cattle. When they have destined an ox to carry burdens, they take and throw him on his back on the ground; and fastening his head and feet with strong ropes to stakes firmly fixed in the ground, they make a hole with a sharp knife through his upper lip, between his nostrils. Into this hole they put a stick, about half an inch thick, and a foot and a half long, with a hook at top to prevent its falling 
through. By this hooked stick they break him to obedience and good behaviour; for if he refuses to be governed, or to carry the burdens they lay upon him, they fix his nose by this hooked stick to the ground, and there hold it till he comes to a better temper.

"It is an exquisite torture to an $\mathrm{Ox}$ to be fastened to the ground by the nose in this manner. $\mathrm{He}$ is not, therefore, long exercised this way, before he gets a notion of his duty, and becomes tractable. After which, the very sight alone of the stick, when he is wanton or refractory, will humble and reduce him to the will of his driver. The terror of this stick, likewise makes the carriage oxen so attentive to the words of command the Hottentots use to them, that they quickly conceive and, ever while they live, afterwards retain the intention of them. I have a thousand times been surprised at the ready obedience the carriage oxen have paid to a Hottentot's bare words. They are as quick at apprehending, and as exact in performing the orders of their driver, as is any taught dog in Europe at conceiving and accomplishing the orders of his master. The stick - the terrible stick-makes them all attention and diligence. 


\section{AFRICAN BULL.}

The following notice, which will explain itself, appeared in Loudon's 'Magazine of Natural History,' for July, 1828.

"Some Account of a particular Variety of Bull (Bos Taurus), now exhibiting in London. By Mrs. Harvey.

" Sir,-Agreeably to your request, Mr. Harvey has taken a portrait of this animal; and as he has made the drawing on the wood himself, the engraving will be a very perfect resemblance.* I have, on my part, drawn up the following particulars, from what my husband told me, and I shall be happy if they prove of any interest to you or your readers :-

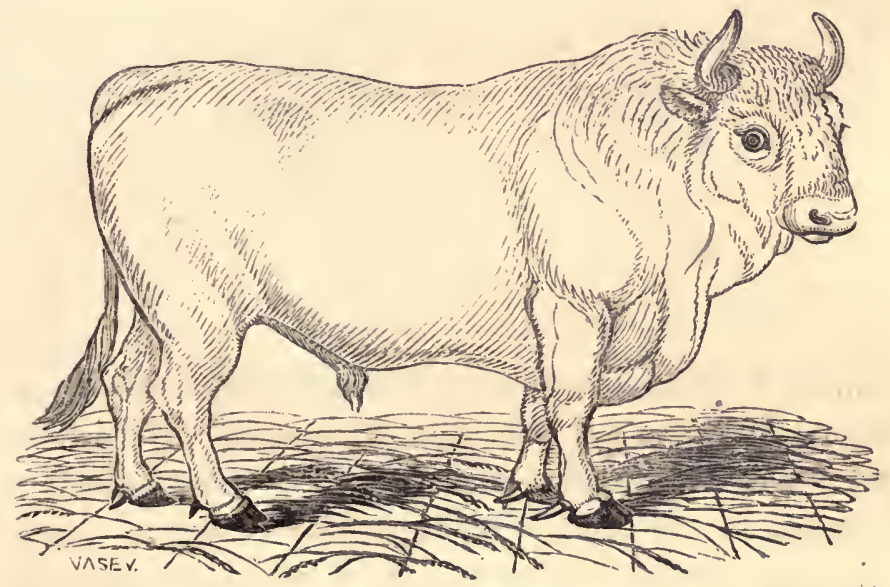

"This animal belongs to a French woman, who says he was brought from Africa to Bordeaux when a calf; and, after having been shown in different parts of the Continent, was taken to London, and exhibited at the Grand Bazaar in King's Street, Portman Square, last autumn. $\mathrm{He}$ is

* The engraving here given, as well as those of the eyes, hoofs, and dewlap, have been carefully copied from Mr. Harvey's originals. 
at present five years old, four feet high at the shoulder and seven feet in length, from the horns to the insertion of the tail. The length of his face is one foot eight inches, and the girth round the collar seven feet six inches. His hair is short and silky, and the colour a cream or yellowish white, except two black tufts which appear on each foot. On the back of the neck there is a hump or swelling, which seems confined to this variety. The general aspect of the animal is mild and docile; but, when irritated, his expression is very remarkable, exhibiting itself principally in the eye. This, in its ordinary state, is very peculiar, (fig. $1, a$,) rising more than one-half above the orbit, and
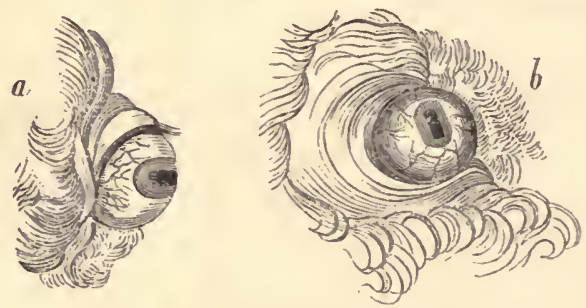

Fig. 1. Eyes of African Bull.

bearing a resemblance to a cup and ball, thus enabling the animal to see on all sides with equal case. The iris is naturally of a pale blue colour; but, when the animal is irritated, it varies from a very pale blue or lilac to a deep crimson. Its form is also very remarkable, being a small oval, or rather a parallelogram, with the ends cut off, and lying transversely across the ball, (fig. 1, b.)

"The black tufts, mentioned above, are the lateral hoofs (fig. 2), which the animal sheds annually, and which grow
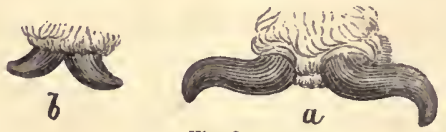

Fig. 2 
to the length of five or six inches. They are not shed together, or at stated periods; for those of the fore-feet, $(a, b$,$) in this example, are at present of different ages,$ and, consequently, of different lengths; the difference between them being exactly that represented in the sketch.

"On the hump or collar, the hair grows much longer than on the other parts of the body, forming a sort of curled mane, resembling, I should imagine, that of the Bison. It is perfectly white, growing to the length of one foot six inches, and adding greatly to the height of the rising part behind the horns. At present the hair is only beginning to grow; but it will be in full beauty at the approach of the winter months, and will fall off gradually again in the early part of the succeeding spring.

"The keeper pointed out to Mr. Harvey, as a remarkable peculiarity, that the dewlap (fig. 3 ), in passing between

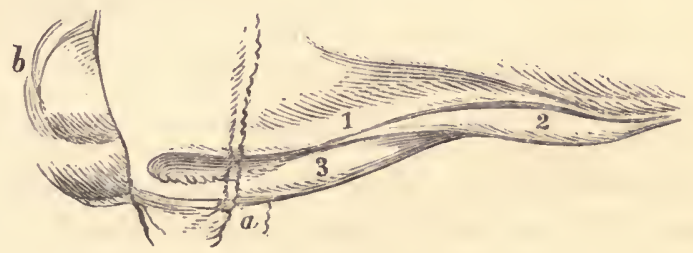

Fig. 3. Dewlap of African Bull.

the forelegs $(a)$, and under the body $(b)$, seemed to divide itself into three parts, which they called the three stomachs, $(1,2,3$,$) from their being very much acted on in the$ progress of digestion.

I remain, Sir, \&c.

M, Harvey. 


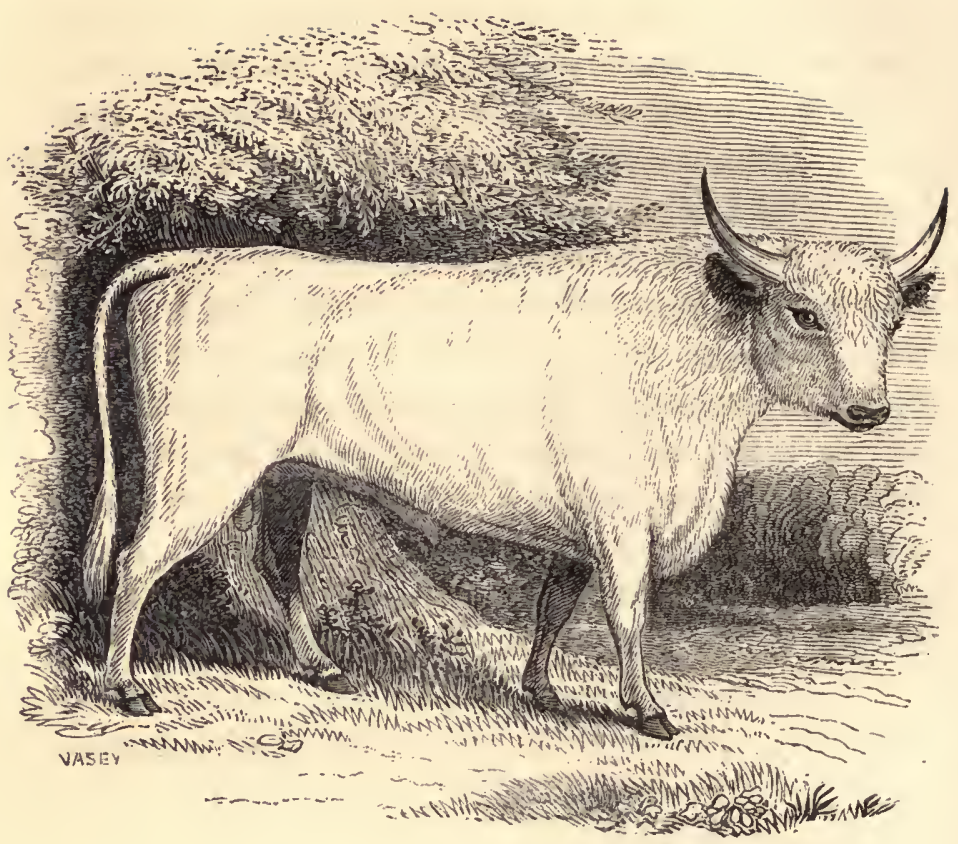

CHILLINGHAM WHITE CATTLE.

Bos Taurus.-Restricted Variety.

Considerable interest has always been connected with the history of those herds of white cattle which have been kept secluded, apparently from time immemorial, in the parks of some of our aristocracy.* It has been, and still is,

* Formerly these eattle were mueh more numerous, both in England and Scotland, than they are at present. Scanty hords are still preserved at the following plaees:-Chillingham Park, Northumberland; Wollaton, Nottinghamshire; Gisburne, in Craven, Yorkshire; Lime-hall, Cheshire; Chartley, Staffordshire; and Cadzow Forest, at Hamilton, Lanarkshire.

At Gisburne they are perfectly white, except the inside of their ears, which are brown.

From Garner's 'Natural History of Staffordshire,' we learn that the 
a matter of lordly pride to their noble owners, that these cattle are held to be of a distinct and untameable race.

Feeling a full share of the interest attached to them, and anxious to gain the most accurate and circumstantial information, I was induced to pay a visit, during the summer of 1845 , to the beautifully wooded and undulating Park of Chillingham, in which a herd of these cattle is preserved; and, although I have not been able to gather material for a perfect listory of these animals, I think it will not be difficult to show that matters respecting them have been set forth as facts which are fictions; and that from some points of their history which have been correctly detailed, inferences have been drawn, whiclı are by no means warranted by the facts.

In endeavouring to point out these errors and false reasonings, it will be nccessary to make quotations from the old history of the white cattle, in Culley's 'Observations on Live Stock,' which has been so often repeated in works on natural history, and is, moreover, so thoroughly accredited, that it may now appear something like presumption to call it in question. To what extent it is called in question on the present occasion, and the reasons for so doing, will be seen in the running commentary which accompanies these quotations.

Culley says : "The Wild Breed, from being untameable,

Wild Ox formerly roamed over Needwood Forest, and in the thirteenth century, William de Farrarus eaused the park of Chartley to be separated from the forest, and the turf of this extensive enclosure still remains: almost in its primitive state. Here a herd of wild cattle has been preserved down to the present day, and they retain their wild characteristics like those at Chillingham. They are cream-coloured, with black muzzles and ears; their finc sharp horns are also tipped with black. They are not easily approaclied, but arc harmless, unless molested. 
can only be kept within walls or good fences; consequently very few of them are now to be met with, except in the parks of some gentlemen, who keep them for ornament, and as a curiosity: those $I$ have seen are at Chillingham Castle, in Northumberland, a seat belonging to the Earl of Tankerville."

The statement of their being untameable is a mere assertion, founded upon no evidence whatever. But so far is it from being the fact, that, notwithstanding every means are used to preserve their wildness, such as allowing them to range in an extensive park-seldom intruding upon them-hunting and shooting them now and then-. notwithstanding these means are taken to preserve their wildness, they are even now so far domesticated as voluntarily to present themselves every winter, at a place prepared for them, for the purpose of being fed. From which it may reasonably be concluded, that were they restricted in their pasture, gradually familiarised with the presence of human beings, and in every other respect treated as ordinary cattle, they would, in the course of two or three generations, be equally tame and tractable.

Whilst writing the foregoing I was not aware that any attempt had been made to domesticate these so-called untameable oxen; but on reading an account of these cattle by Mr. Hindmarsh, of Newcastle-upon-Tyne, (bearing date about 1837,) I find the following paragraph.

"By taking the calves at a very early age, and treating them gently, the present keeper succeeded in domesticating an ox and a cow. They became as tame as domestic animals, and the ox fed as rapidly as a shorthorned steer. He lived eighteen years, and when at his best was computed at 8 cwt. 14 lbs. The cow only lived five or six years. She 
gave little milk, but the quality was rich. She was crossed by a country bull, but her progeny very closely resembled herself, being entirely white, excepting the ears, which were brown, and the legs, which were mottled." These facts speak for themselves.

Culley, in giving their distinguishing characteristics, says: "Their colour is invariably of a creamy white; muzzle black; the whole of the inside of the ear, and about one third of the outside, from the tips downwards, red; horns white, with black tips, very fine, and bent upwards; some of the bulls have a thin upright mane, about au inch and a half, or two inches long."

That their colour is invariably white is simply oring to the care that is taken to destroy all the calves that are born of a different description. It is pretty well known to the farmers about Chillingham (although pains are taken to conceal the fact,) that the wild cows in the park not unfrequently drop calves variously spotted. With respect to the redness of the ears, this is by no means an invariable character, many young ones having been produced without that distinctive mark; and Bewick records, that about twenty years before he wrote, there existed a few in the herd with black ears, but they were destroyed. So far from the character here given of the horns being confined to those white cattle, it is precisely the description of the horus of the Kyloe oxen, or black cattle. The investiture of some of the bulls with a mane is equally gratuitous; Cole, who was park-keeper for more than forty years, and of course had ample means of ohservation, distinctly informed me that they had no mane, but only some curly hair, about the neck, which is likcwise an attribute of the Kyloe Oxen. 
Culley goes on to say: "From the nature of their pasture, and the frequent agitation they are put into by the curiosity of strangers, it is scarce to be expected that they should get very fat; yet the six years old oxen are generally very good beef, from whence it may be fairly supposed, that in proper situations they would feed well,"

It would naturally be inferred from this, that the park in which they are kept is visited by strangers every day, who are allowed to drive them about, and disturb them in their feeding and ruminating, as boys hunt geese or donkeys on a common. This, however, is so far from being the case, that it frequently happens that the park is not visited for many weeks in succession, and certainly on an average it is not visited once a week. What is here meant by "the nature of their pasture," and "in proper situations they would feed well," it is difficult to say. The fact is, their pasture is both good and extensive, and they feed as well as animals always do who are left to themselves with plenty of food.

Their behaviour to strangers is thus described: "At the first appearance of any person, they set off at full speed, and gallop a considerable distance, when they make a wheel round, and come boldly up again, tossing their heads in a menacing manner; on a sudden, they make a full stop, at a distance of forty or fifty yards, looking wildly at the object of their surprise; but upon the least motion being made, they turn round again, and gallop off with equal speed; but forming a shorter circle, and, returning with a bolder and more threatening aspect, they approach much nearer, when they make another stand, and again gallop off. This they do several times, shorten- 
ing their distance, and approaching nearer, till they come within a few yards, when most people think it prudent to leave them."

In the instance in which I had an opportunity of witnessing their method of receiving visitors, the fashion was somewhat different. The park-keeper who accompanied me described, as we rode through the park in quest of them, what would be their mode of procedure on our approach. This he did from observations so repeatedly made, as to warrant him in saying that it was their invariable mode. It was perfectly simple, and I found it precisely as he had described it. When we came in sight of them, they were tranquilly ruminating under a clump of shady trees, some of the herd standing, others lying. On their first observing us, those that were lying rose up, and they all then began to move slowly away, not exactly to a greater distance from us, but in the direction of a thickly wooded part of the park, which was as distant on our left as the herd was on our right. To reach this wooded part they had to pass over some elevated ground. They continued to walk at a gradually accelerating pace, till they gained the most elevated part, when they broke out into a trot, then into a canter, which at last gave way to a full gallop, a sort of "devil-take-the-hindmost" race, by which they speedily buried themselves in the thickest recesses of the wood. What they may have done in Mr. Culley's time, we must take upon that gentleman's word; but at present, and for so long as the present park-keeper can recollect, they have never been in the habit of describing those curious concentric circles of which Mr. Culley makes mention in the last quotation.

The late mode of killing them is described as "perhaps 
the only modern remains of the grandeur of ancient hunting. On notice being given, that a wild bull would be killed on a certain day, the inhabitants of the neighbourhood came mounted and armed with guns, \&c., sometimes to the amount of a hundred horse, and four or five hundred foot, who stood upon walls or got into trees, while the horsemen rode off the bull from the rest of the herd until he stood at bay, when a marksman dismounted and shot. At some of these huntings twenty or thirty shots have been fired before he was subdued. On these occasions the bleeding victim grew desperately furious, from the smarting of his wounds, and the shouts of savage joy that were echoing from every side. But from the number of accidents that happened, this dangerous mode has been little practised of late years, the parkkeeper alone generally shooting them with a rifled gun at one shot."

This vivid portraiture of a scene, which the writer is pleased to consider grand, does not appear to have much relation to the history of the Genus Bos: it however, exhibits the brutal and ferocious habits of two varieties of Genus Homo, namely Nobility and Mobility-two varieties which, although distinguished by some external marks of difference, possess in common many questionable characteristics.

Culley proceeds :- " When the cows calve, they hide their calves for a week or ten days in some sequestered situation, and go and suckle them two or three times a day. If any person come near the calves, they clap their heads close to the ground, and lie like a hare in form, to hide themselves; this is a proof of their native wildness, and is corroborated by the following circum- 
stance that happened to Mr. Bailey, of Chillingham, who found a hidden calf, two days old, very lean and very weak. On stroking its head it got up, pawed two or three times like an old bull, bellowed very lond, stepped back a few steps, and bolted at his legs with all its force; it then began to paw again, bellowed, stepped back, and bolted as before; but knowing its intention, and stepping aside, it missed him, fell, and was so very weak that it could not rise, though it made several efforts. But it had done enough: the whole herd were alarmed, and, coming to its rescue, obliged him to retire; for the dams will allow no person to touch their calves without attacking them with impetuous ferocity."

It seems almost unnecessary to remind the reader that all animals are naturally wild; and that even those animals that have been the longest under the dominion of man, are born with a strong tendency to the wild state, to which they would immediately resort, if left to themselves : it appears, therefore, rather gratuitous to tell us that the NATURAL actions of young animals (whose parents have been allowed to run wild), are proofs of their native wildness!

The concluding paragraph requires no observation:"When a calf is intended to be castrated, the park-keeper marks the place where it is hid, and, when the herd are at a distance, takes an assistant with him on horseback; they tie a handkerchief round the calf's mouth, to prevent its bellowing, and then perform the operation in the usual way. When any one happens to be wounded, or is grown weak and feeble through age or sickness, the rest of the herd set upon it, and gore it to death." 
The following engraving exhibits the effects of castration on the curvature and length of the horns.

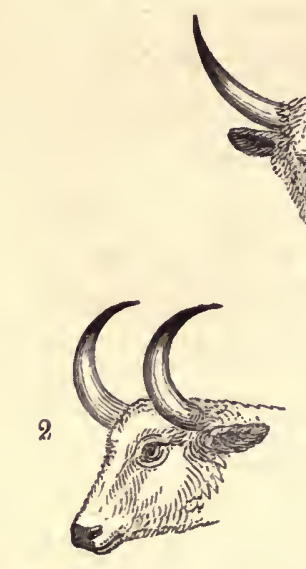

1. Head of the perfect animal.
1
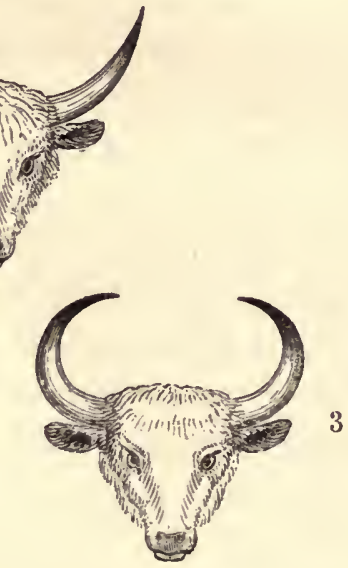

2, 3. Heads of the emasculated animal.

We learn, on the authority of the present Lord Tankerville, that during the early part of the life-time of his father, the bulls in the herd had been reduced to three; two of them fought and killed each other, and the third was discovered to be impotent; so that the means of preserving the breed depended on the accident of some of the cows producing a bull calf.

In 1844 I wrote to Mr. Cole, the late park-keeper at Chillingham, requesting information on the following queries, to which he returned the answers annexed; and although they are not so explicit as might be wished, they embody facts both interesting and important. 


\section{List of the Queries with their Answers.}

1. How many pairs of ribs are there in the skeleton of the Chillingham Ox? Thirteen pairs.

2. How many vertebræ are there (from the skull to the end of the tail)? Thirty in the back-bone, twenty in the tail.

3. Will the wild cattle breed with the domestic cattle? I have had two calves from a wild bull and common cow.

4. What is the precise time the wild cow goes with young? The same as the domestic cow.

5. At what age does the curly hair appear which constitutes the mane of the wild bull? They have no mane, but curly hair on their neck and head; more so in winter, when the hair is long.

6. In what month does the rutting take place among the wild cattle? At all times, -no particular time.

\section{J. Cole.}

Here we have precise information on the following points :-namely, the number of ribs; the period of gestation; their having no mane; their not being in heat at any particular period; in all which points, they perfectly agree with the ordinary domestic cattle; and it is important to observe, that in the last point, namely, that of not being in heat at any particular time, they differ from every known wild species of cattle, among which the rutting season invariably occurs at a particular period of the year. 


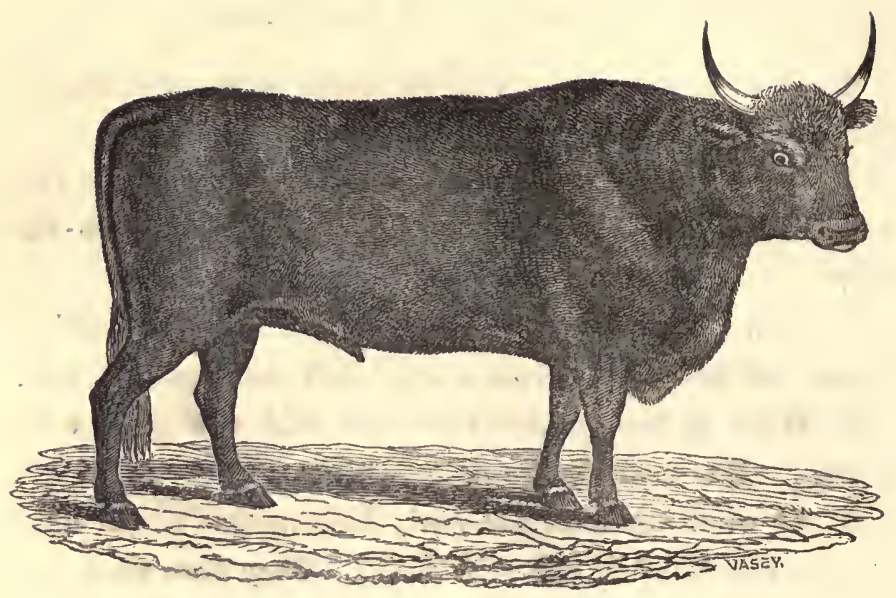

THE KYLOE, OR HIGHLAND OX.

\section{Bos Taurus,}

The Chillingham Cattle are white, and the Highland Cattle or Kyloes are generally black; but with this exception the same description might almost serve for both breeds.

In their natural and unimproved state, the Highland cattle are frequently well formed; their fine eyes, acute face, and lively countenances, give them an air of fierceness, which is heightened by their white, tapering, black-tipped, and sharp horns.

The Kyloe Oxen are very small (another respect in which . they resemble the Chillingham Oxen). They likewise partake much of the nature of wild animals, which might be expected from the almost unlimited extent of their pasture, and their being but little subject to artificial treatment. 
Upon a close comparison of these two breeds, there appears not to be so much difference between the Highland cattle and the cattle of Chillingham as there is between any two breeds or varieties of British cattle. Indeed so great is the similarity, that the Kyloe appears to be only a black variety of the Chillingham $\mathrm{Ox}$, and the Chillingham Ox only a white variety of the Kyloe.

Dr. Anderson speaks of having seen a kind of Highland cattle which had a mane on the top of the head, of considerable length, and a tuft between the horns that nearly covered the eyes, giving them a fierce and savage aspect. He likewise mentions another kind which have hair of a pale lead colour, very beautiful in its appearance, and in its quality as glossy and soft as silk.

The Kyloe Oxen are natives of the Western Highlands and Isles, and are commonly called the Argyleshire breed, or the breed of the Isle of Skie, one of the islands attached to the county of Argyle. They are generally of a dark brown colour, or black, though sometimes brindled.

The Cows of the Isle of Skie (as is recorded by Martin, in his 'Description of the Western Islands of Scotland,') are exposed to the rigour of the coldest seasons, and become mere skeletons in the spring, many of them not being able to rise from the ground without help; but they recover as the season becomes more favorable, and the grass grows up; then they acquire new beef, which is both sweet and tender; the fat and lean is not so much separated in them as in other cows, but as it were larded, which renders it very agreeable to the taste. A cow in this isle may be twelve years old, when at the same time its beef is not above four, five, or six months old. 
TABLE OF THE NUMBER OF VERTEBR $A$ IN THE VARIOUS SPECIES OF THE GENUS BOS.

\begin{tabular}{|c|c|c|c|c|c|c|c|c|}
\hline & & & Cerv. & Dors. & Lumb. & Sacr. & Caud. & Total. \\
\hline American Bison & . & 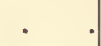 & 7 & 14 & 5 & 5 & $12+$ & \\
\hline European Bison, or & $\mathrm{Au}$ & $\operatorname{chs}$ & 7 & 14 & 5 & 5 & 19 & 50 \\
\hline Yak & - & - & 7 & 14 & 5 & 5 & 14 & 45 \\
\hline Gayal (Domestic) & . & . & 7 & 14 & 5 & 5 & 16 & 47 \\
\hline Gayal (Asseel) . & . & . & & & & & & \\
\hline Gyall & . & . & & & & & & \\
\hline Jungli Gau . & . & . & & & & & & \\
\hline Italian Buffalo . & . & . & & & & & & \\
\hline Indian Buffalo . & . & & & & & & & \\
\hline Skeleton of Buffa & Lo & n Surg. & & & & & & \\
\hline Coll. (locality & unk & own) & 7 & 13 & 6 & 5 & 16 & 47 \\
\hline Gaur . . & . & . & 7 & 13 & 6 & 5 & 19 & 50 \\
\hline Domestic Ox . & . & . & 7 & 13 & 6 & 5 & 21 & 52 \\
\hline Condore Buffalo & . & . & & & & & & \\
\hline Manilla Buffalo & . & - & 7 & 13 & 6 & & & \\
\hline Pegasse & . & . & & & & & & \\
\hline Arnee '. & . & . & & & & & & \\
\hline Cape Buffalo . & . & . & 7 & 13 & 6 & 4 & 19 & 49 \\
\hline Zamouse (Bos Brac & hyce & & 7 & 13 & 6 & 4 & 20 & 50 \\
\hline Banteng of Java ( $B$ & $\cos B$ & intinger) & 7 & 13 & 6 & 4 & 18 & 4.8 \\
\hline Zebu, or Bralımin & & . & 7 & 13 & 6 & 4 & 18 & 48 \\
\hline Galla Ox . . & & . & & & & & & \\
\hline Backeley (Caffraria) & . & . & & & & & & \\
\hline Musk Ox & . & . & & & & & & \\
\hline
\end{tabular}

The osteological details in the above Table (except those of the Yak, which are given on the authority of Pallas) are from the Author's own observations. 


\section{TABLE OF THE PERIODS OF GESTATION OF THE VARIOUS SPECIES OF THE GENUS BOS.}

\begin{tabular}{|c|c|c|c|c|c|}
\hline \multirow{3}{*}{\multicolumn{2}{|c|}{$\begin{array}{l}\text { American Bison . } \\
\text { European Bison. }\end{array}$}} & & & & \multirow{2}{*}{$\begin{array}{c}\text { Periods. } \\
270 \text { days.-Zool. Proc., } 1849 .\end{array}$} \\
\hline & & • & . & . & \\
\hline & & - & . & - & Between 9 and 10 months. \\
\hline Gayal (Domesti & & . & . & . & Over 10 months. \\
\hline Gyall & . & . & . & . & 11 months. \\
\hline Indian Buffalo & - & - & . & $\cdot$ & 10 months 10 days. \\
\hline Gaur & . & . & . & . & 12 months. \\
\hline Domestic Ox & . & . & - & . & 270 days. \\
\hline Manilla Buffalo & . & . & . & . & 340 days. \\
\hline Arnee & . & . & . & . & 12 months. \\
\hline Cape Buffalo & - & - & - & - & 12 months. \\
\hline Zebu, or Brahm & in $\mathrm{Cor}$ & & . & - & 300 days. \\
\hline Musk Ox . & . & - & . & . & 9 months. \\
\hline
\end{tabular}

To supply the deficiences in the foregoing Tables, the results of original observations are respectfully solicited. Address the Author or Publisher. 
NOTE ON THE AMERICAN BISON.

IT was Cuvier, I believe, who first made the statement, that the American Bison is furnished with fifteen pairs of ribs. In this particular he has been implicitly followed by every subsequent writer on the subject. Not being able to refer to a skeleton, and, moreover, never suspecting any inaccuracy in the statement, I followed the received account. But since this work has gone to press, I have had the opportunity of examining two skeletons, by which I find that-

The American Bison has only rourteen pairs of ribs.

I have, therefore, in the "Table of the Number of Vertebræ," (see p. 152,) set this species down as possessing only that number.

Of the two skeletons referred to (both of which are now in the British Museum), one is from a female Bison, some years a living resident in the Zoological Gardens; and the other is from a male, late in the possession of the Earl of Derby, at Knowsley, in Lancashire.

A corroborative circumstance (amounting, indeed, to a complete proof of the accuracy of these observations,) is presented by the fact, that, in both the cases the number of lumbar vertebre is precisely FIVE; thus making the true vertebræ to consist of nineteen, which Professor Owen* has shown to be the invariable number possessed by all ruminants.

* Sce, in the Proceedings of the Zoological Society, Professor Owen's 'Account of his Dissection of the Aurochs.' 


\section{A P PE N D IX.}

\section{THE FREE MARTIN.}

Cows usually bring forth but one calf at a birth; occasionally, however, they produce twins. John Hunter, in his 'Observations on the Animal Economy,' says : "It is a fact known, and I believe almost universally understood, that when a cow brings forth two calves, one of them a bull-calf, and the other to appearance a cow, that the cow-calf is unfit for propagation; but the bullcalf grows up into a very proper bull. Such a cowcalf is called, in this country, a Free Martin, and is commonly as well known among the farmers as either cow or bull. It has all the external marks of a cowcalf, namely, the teats, and the external female parts, called by farmers the bearing. It does not show the least inclination for the bull, nor does the bull ever take the least notice of it. In form it very much resembles the $\mathrm{Ox}$, or spayed heifer, being considerably larger than either the bull or the cow, having the horns very similar to the horns of an $\mathrm{Ox}$. The bellow of the Free Martin is similar to that of an Ox, having more resemblance to that of the cow than that of the bull."

Free Martins are very much disposed to grow fat with good food. The flesh, like that of the Ox or spayed heifer, is generally much finer in the fibre than either the bull or cow ; is even supposed to exceed that of the Ox and heifer 
in delicacy of flavour, and bears a higher price at market. However this superiority of the flavour does not appear to be universal, for Mr. Hunter was informed of a case which occurred in Berkshire, in which the flesh of a Free Martin turned out nearly as bad as bull beef. This circumstance probably arose from the auimal having more the properties of a bull than a cow.

Mr. Hunter, having had many opportunities of dissecting Frce Martins, has satisfactorily shown that their incapacity to breed, and all their other peculiarities, result from their having the generative organs of both sexes combined, in a more or less imperfect state of development; in some cases the organs of the male preponderating, in others those of the female.

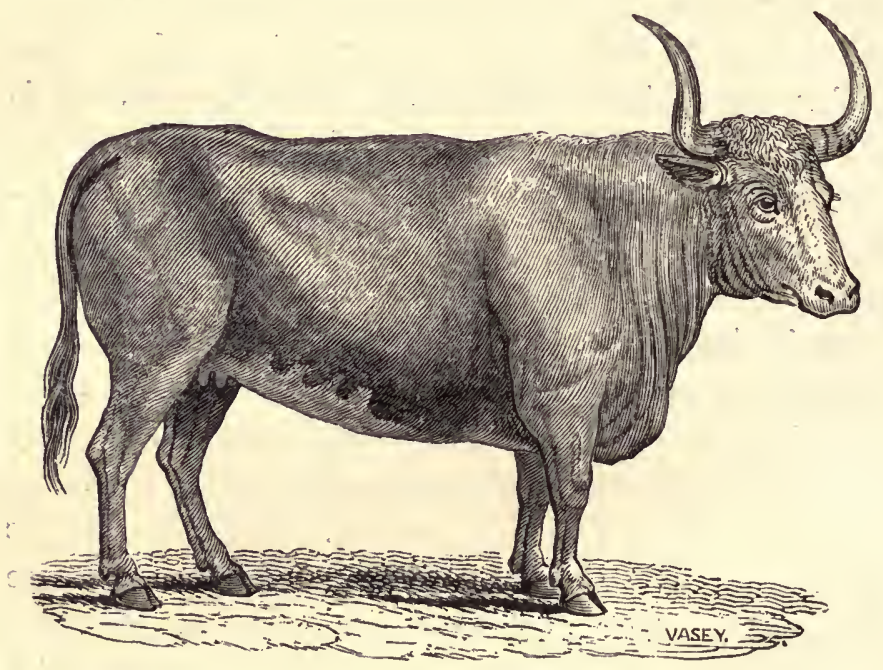

The above, which is copied from an engraving in Hunter's work on the 'Animal Economy,' is a representation of a Free Martin, five years old; it shows the ex- 
ternal form of that animal, which is neither like the bull nor cow, but resembling the Ox or spayed heifer.

Although, as Hunter observes, "it is almost universally understood, that when a cow brings forth two calves, one of them a bull-calf, and the other to appearance a cow, that the cow-calf is unfit for propagation," it is by no means universally the fact, as instances of such twins breeding were known even in Hunter's time, and have been witnessed more recently. The following is recorded in Loudon's 'Mag. of Nat. History,' and occurred a few years previous to 1826 : Jos. Holroyd, of Withers, near Leeds, had a cow which calved twins, a bull-calf and a cow-calf. As popular opinion was against the cow-calf breeding, it being considered a Free Martin, Mr. Holroyd was determined to make an experiment of them, and reared them together. They copulated, and in due time the heifer brought forth a bull-calf, and she regularly had calves for six or seven years afterwards.

"If," says Hunter, "there are such deviations as of twins being perfect male and female, why should there not be, on the other hand, an hermaphrodite, produced singly, as in other animals? I had the examination of one which seemed, upon the strictest inquiry, to have been a single calf; and I am the more inclined to think this true, from having found a number of hermaphrodites among black cattle, without the circumstance of their birtlı being ascertained."

If Hunter had carried this reasoning a little further, he might have asked,- Why should there not be a Free Martin, or hermaphrodite, produced in the case of twins, when they are both apparently males, or both apparently females? Had he done this, he would not, probably, 
have made the following observation: "I need hardly observe, that if a cow has twins, and they are both bullcalves, they are in every respect perfect bulls; or if they are both cow-calves, they are perfect cows." What is this but saying that a bull-calf is a bull-calf, and a cowcalf is a cow-calf? For a Free Martin, or hermaphrodite, is not, in any case, either a bull or a cow.

There does not appear to be anything known of the peculiar circumstances under which, what is termed a Free Martin is produced.

The most general observation that can be made on the subject appears to be, that cows sometimes produce calves, which, by reason of their imperfectly developed generative system, are incapable of procreating.

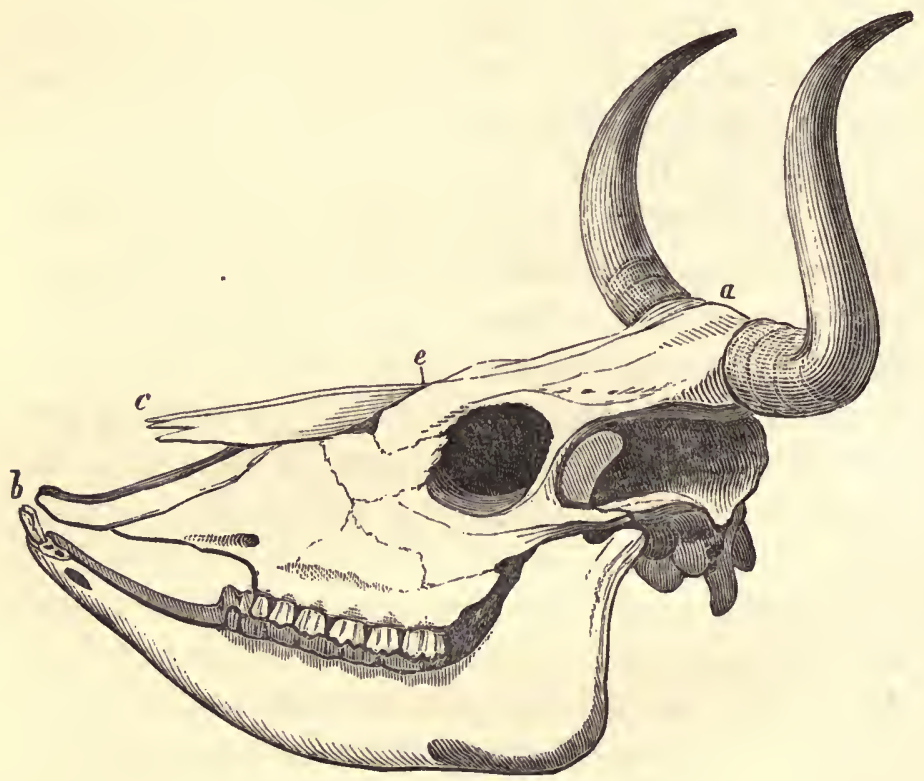

Skull of Domestic Ox. 


\section{THE SHORT-NOSED OX.}

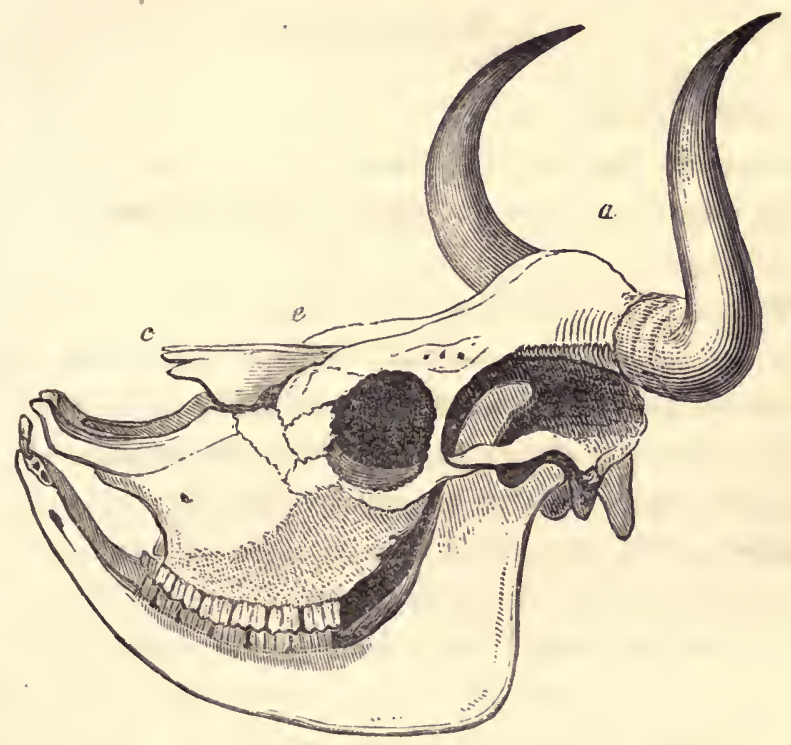

Skull of short-nosed Ox of the Pampas.

The common Ox, originally taken over to America by the early Spanish settlers, now runs wild in immense herds on the Pampas, where it is hunted and slain for its hide. Some idea may be formed of the immensity of these herds, from the circumstance that nearly a million of hides are annually exported from Buenos Ayres and Monte Video to Europe.

Some of the herds in these wild regions have undergone a most singular modification of the cranium, consisting in a shortening of the nasal bones, together with. the superior and inferior maxillaries. There is a skull of this varicty in the Museum of the College of Surgeons, of which the above is a sketch. 


\section{ON THE UTILITY OF THE OX TRIBE TO MANKIND.}

How eminently serviceable to man these animals are, is shown in the following table, in which are set forth the most important uses to which their various parts are applied :-

SkIN.-The skin has been of great use in all ages. The ancient Britons constructed their boats with osiers, and covered them with the hides of bulls; and these boats were sufficiently strong to serve for short coasting voyages. Similar vessels are still in use on the Irish lakes, and in Wales on the rivers Dee and Severn. In Ireland they are called curach, in England coracles, from the British cwrwgl, a word signifying a boat of that structure.

Boots, shoes, harness, \&c. for horses, and various kinds of travelling trunks are made from hides when tanned. The skin of the calf is extensively used in the binding of books, and the thinnest of the calf skins are manufactured into vellum: The skin of the Cape Buffalo is made into shields and targets, and is so hard that a musket ball will scarcely penetrate it.

HaIr. - The short hair is used to stuff saddles and other articles; also by bricklayers in the mixing up of certain kinds of mortar. It is likewise frequently used in the manuring of land. The long hair from the tail is used for stuffing chairs and cushions. The hair of the Bison is spun into gloves, stockings, and garters, which are very :strong, and look as well as those made of the finest sheep's wool ; very beautiful cloth has likewise been manufactured from it. The Esquimaux couvert the skin 
covering the tail into caps, which are so contrived that the long hair falling over their faces, defends them from the bites of the mosquitoes.

Horns. - The horns of cattle consist of an outside horny case, and an inside conical-shaped substance, somewhat between hardened hair and bone. The horny outside furnishes the material for the manufacture of a variety of useful articles. The first process consists in cutting the horn transversely into three portions.

1. The lowest of these, next the root of the horn, after undergoing several operations by which it is rendered flat, is made into combs.

2. The middle of the horn, after being flattened by heat, and its transparency improved by oil, is split into thin layers, and forms a substitute for glass in lanterns of the commonest kind. [The merit of the invention of these horn plates, and of their application to lanterns, is ascribed to King Alfred, who is said to have first used lanterns of this description to preserve his candle time-measurers from the wind.]

3. The tips of the horns are generally used to make knife-handles; the largest and best are used for crutchstick heads, umbrella handles, and ink-horns, and the smallest and commonest serve for the tops and bottoms of ink-horns.

Spoons, small boxes, powder flasks, spectacle frames, and drinking horns are likewise made of the outer horny case.

The interior or core of the horn is boiled down in water, when a large quantity of fat rises to the surface; this is sold to the makers of yellow soap.-The liquid itself is used as a kind of glue, and is purchased by the clothdressers for stiffening.-The bony substance which remains 
behind, is ground down, and sold to the farmers for manure.

Besides these various purposes to which the different parts of the horn are applied, the chippings which arise in comb-making are sold to the farmer for manure, at about one shilling a bushel. In the first year after they are spread over the soil they have comparatively little effect; but during the next four or five their efficiency is considerable. The shavings, which form the refuse of the lantern-maker, are of a much thinner texture. Some of them are cut into various figures, and painted and used as toys; for they curl up when placed in the palm of a warm hand. But the greater part of these shavings are sold also for manure, which from their extremely thin and divided form, produce their full effect upon the first crop.

Feet.-An oil is extracted from the feet of oxenhence called Neat's-foot-oil-of great use in preparing and softening leather.

Skiv, horns, hoofs, and cartilages are used to make glue.

Broon is used in the formation of mastic; also in the refining of sugar, oil, \&c.; and is an excellent manure for fruit trees.

Blood, horns, and hoofs in the formation of Prussian blue.

GALI is used to cleanse woollen garments, and to obliterate greasy and other stains.

Suet, Fat, TaLlow are chiefly manufactured into candles; they are also used to precipitate the salt that is drawn from briny springs.

Intestines, when dried, are used as envelopes for German and Bologna sausages; in some countries to 
carry butter to market. By gold-beaters, in the process of making gold-leaf. Gold-beater's skin, as it is called, forms the most innocent sticking plaster for small cuts on the hands or fingers.

The Stomachs vulgarly called inwards, after being washed and boiled, are sold as an article of food under the name of tripe.

The Excrementritous matrers are used to manure the land.

The Bones are used as a substitute for ivory in the manufacture of a variety of small articles of a common kind; also for manuring land. When calcined they are used as an absorbent to carry off the baser metals in refining silver. From the tibia and carpus is procured an oil much used by coach-makers and others in dressing and cleaning harness, and all trappings belonging to carriages.

Fresh, both fresh and salted, is generally esteemed as an article of food. Pemmican is made of the flesh of the American Bison : this is dried in the sun by the Indians, spread on a skin, and pounded with stones. When the Indians have got it into this state, they sell it to the different forts, where all the hair is carefully sifted out of it, and melted fat kneaded into it. If it be well made, and kept dry, it will not spoil for a year or two.

Mrnk, a nutritious beverage, per se, is used in the composition of innumerable articles of diet; from milk is obtained cream, butter, and cheese. 


\section{SOME ACCOUNT OF THE ALPINE COWHERDS,}

WITH A NOTICE OF THE CELEBRATED SWISS AIR

The Ranz des Vaches.

In the Alps, fine cattle are the pride of their keeper, who, not being satisfied with their natural beauty, also gratifies his vanity by adorning his best cows with large bells, suspended from broad thongs. Every Senn, or great cow-keeper, has a harmonious set of bells, of at least two or three, chiming in accordance with the famous Ranz des Vaches. The finest black cow is adorned with the largest bell, and those next in appearance wear the two smaller ones.

It is only on particular occasions that these ornaments are worn, namely, in spring, when they are driven to the Alps, or removed from one pasture to another; or in their autumnal descents, when they travel to the different farmers for the winter. On such days the Senn, even in the depth of winter, appears dressed in a fine white shirt, with the sleeves rolled above the elbows; neatly embroidered red braces suspend his yellow linen trowsers, which reach down to the shoes; he wears a small leather cap on his head, and a new and skilfully carved wooden milk-bowl hangs across his left shoulder. Thus arrayed, the Senn proceeds, singing the Ranz des Vaches, followed by three or four fine goats; next comes the finest cow, adorned with the great bell; then the other two with the smaller bells; and these are succeeded by the rest of the cattle, walking one after another, and having in their rear the bull, with a one-legged milking-stool on his horns ; the procession is closed by a traineau, or sledge, bearing the dairy implements. 
When dispersed on the Alps, the cattle are collected together by the voice of the Senn, who is then said to allure them. How well these cows distinguish the voice of their keeper, appears from the circumstance of their hastening to him, although at a great distance, whenever he commences singing the Ranz des Vaches.

This celebrated air is played on the bagpipes, as well as sung by the young Swiss cowherds while watching their cattle on the mountains. The astonishing effects of this simple melody on the Swiss soldier, when absent from his native land, are thus described by Rousseau :

"Cet air, se chéri des Suisses qu'il fut défendu sous peine de mort de le jouer dans leurs troupes, parce qu'il faisait fondre en larmes, déserter, ou mourir, ceux qui l'entendaient, tant il excitait en eux l'ardent desir de revoir leur pays. On chercherait en vain dans cet air les accens énergetiques capables de produire de si étonnans effets. Ces effets, qui n'ont aucun lieu sur les étrangers, ne viennent qui de l'habitude, des souvenirs de mille circonstances qui, retracées par cet air à ceux que l'entendent, et leur rappellant leur pays, leurs anciens plaisirs, leur jeunesse, et toutes leur façons de vivre, excitent en cux une douleur amère d'avoir perdu tout cela. La musique alors n'agit point précisément comme musique, mais comme signe memoratif. Cet air, quoique toujours le même, ne produit plus aujourd'hui les mêmes effets qu'il produisait ci-devant sur les Suisses, parce qu'ayant perdu le gôut de leur première simplicité, jls ne la regrettent plus quand on la leur rappelle. Tant il est vrai que ce n'est pas dans leur action physique qu'il faut chercher les plus graud effets des sons sur le cour humain." 
For the delectation of the musical reader, the notes of this celebrated air are here introduced, with the words, and an English imitation :

\section{AIR SUISSE}

Appellé le Ranz des Vaches.
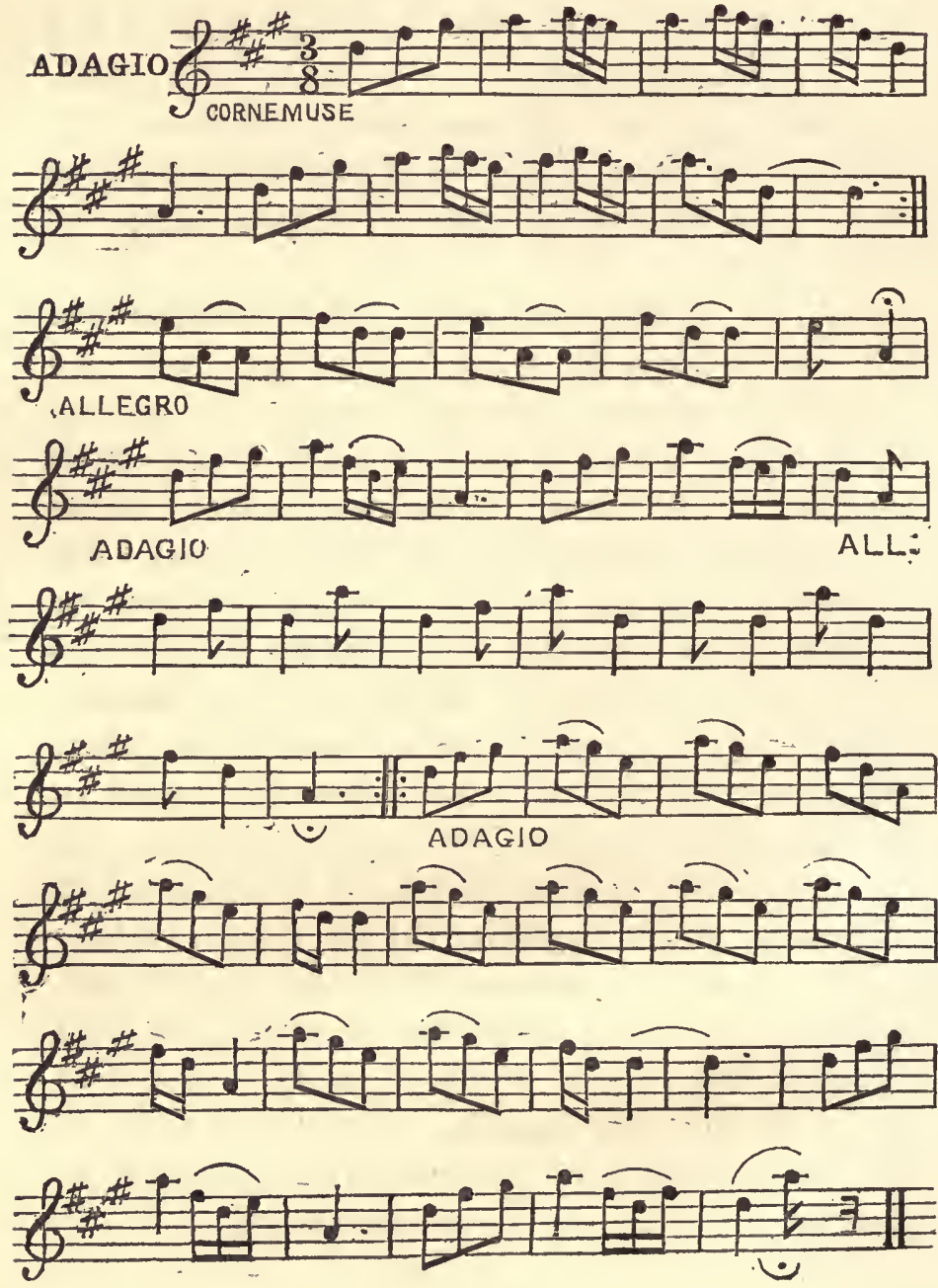


\section{The words are as follows:-}

Quand reverai-je en un jour,

Tous les objets de mon amour,

Nos clairs ruisseaux,

Nos hameaux,

Nos côteaux,

Nos montagnes,

Et l'ornament de nos montagnes,

La si gentille Isabeau ?

Dans l'ombre d'un ormeau,

Quand danserai-je au son du Chalameau?

Quand reverai-je en un jour,

Tous les objets de mon amour,

Mon père,

Ma mère,

Mon frère,

Ma soeur,

Mes agneaux,

Mes troupeaux,

Ma bergère?

INITATED.

When shall I return to the Land of the Mountains-

The lakes and the Rhone that is lost in the eartl-

Our sweet little hamlets, our villages, fountains,

The flour-clad rocks of the place of my birth?

0 when shall I see my old garden of flowers,

Dear Emma, the sweetest of blooms in the glade,

And the rich chestnut grove, where we pass'd the long hours

With tabor and pipe, while we danced in the shade?

When shall I revisit the land of the mountains,

Where all the fond objects of memory meet:

The cows that would follow my voice to the fountains,

The lambs that I call'd to the shady retreat:

My father, my mother, my sister, and brother;

My all that was dear in this valley of tears;

My palfrey grown old, but there's ne'er such another;

My dear dog, still faithful, tho' stricken in years :

The vesper bell tolling, the loud thunder rolling,

The bees that humm'd round the tall vine-mantled tree :

The smooth water's margin whereon we were strolling

When evening painted its mirror for me?

And shall I return to this scenery never?

These objects of infantine glory and love,-

O tell me, my dear Guardian Angel, that ever

Floats nigh me,- - safe guide to the regions above. 


\section{SYNOPTICAL TABLE OF HABITAT}

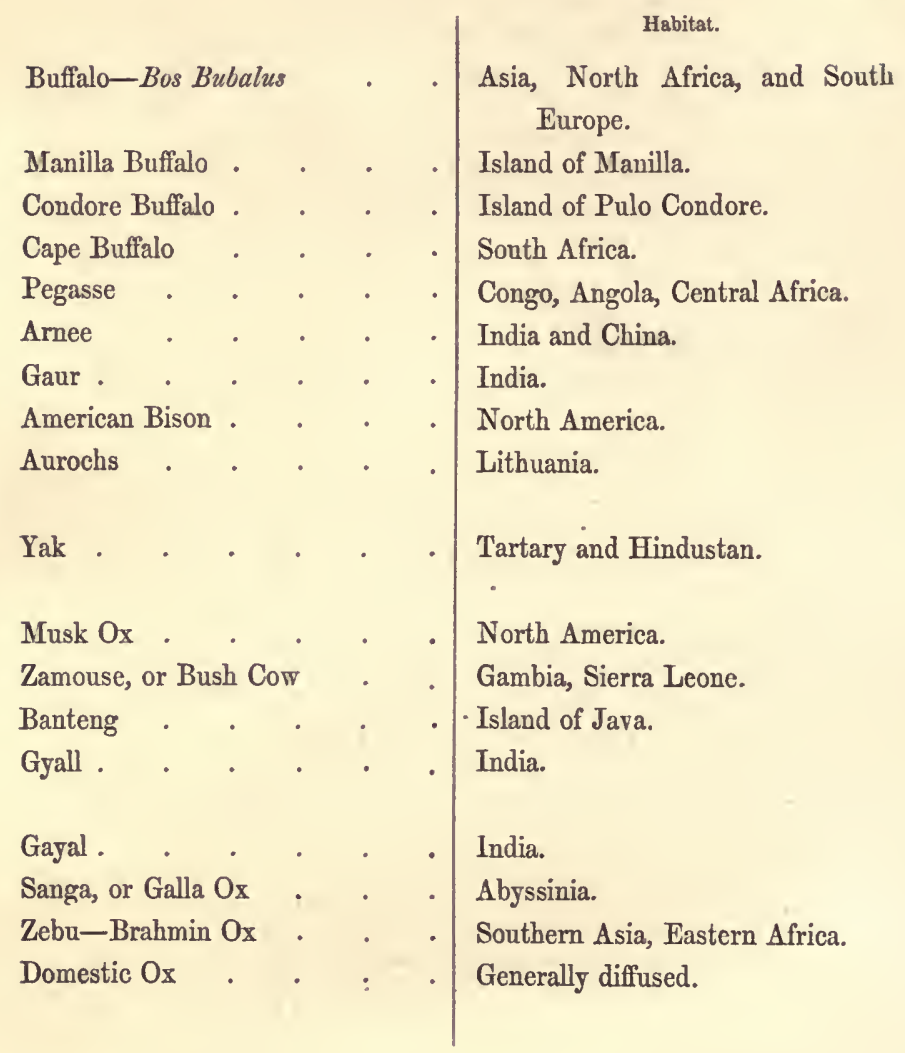




\section{AND MODE OF LIFE.}

\section{Mode of Life.}

Partial to water and mud, swampy localities.

Semi-aquatic in its habits,-sometimes called the Water Buffalo.

Fond of wallowing in mire, and swims well.

Lives much in the water, and feeds on aquatic plants.

Ranges in mountain forests, and feeds on leaves and buds of trees.

Migratory in its habits-fond of bathing in marshy swamps.

Lives chiefly on the woody banks of rivers-feeds on bark of trees, lichens, and herbaceous plants.

Feeds on the short herbage peculiar to the tops of mountains and bleak plains.

Lives chiefly on rocky mountains.

Delights in the deepest jungles-feeds on leaves and shoots of brushwood.

Lives entirely on woody-mountains-feeds on shoots and shrubs.

Half domesticated.

Domesticated, and artificially fed.

So completely domesticated, as to be subject to an endless variety of diseases, and generally requires medical attendance. 


\section{THE INDEFINITE DEFINITIONS OF COL. HAMILTON SMITH.}

On commencing this Monograph of the Genus Bos, I entertained the confident expectation, that in the voluminous work of Cuvier's 'Animal Kingdom,' translated and enlarged by Griffith and others, I should find all that related to generic and specific distinction so clearly exhibited, and so systematically arranged, that I should have no hesitation in adopting the classification there set forth, and no difficulty in determining the place of any new species or variety. With this expectation I diligently studied that portion of Col. H. Smith's volume on the Ruminantia, which treat of the Genus Bos, and I here subjoin (verbatim) the generic and subgeneric characters there given of that Genus, by which it will be seen how far they fall short of the clearness and precision which are indispensable to a scientific work.

\section{GENERIC CHARACTERS.}

"Genus BOS.-Skull very strong, dense about the frontals, which are convex, nearly flat, or concave; horns invariably occupying the crest, projecting at first laterally; osseous nucleus throughout porous, even cellular; muzzle invariably broad, naked, moist, black; ears, in general, middle sized ; body long ; legs solid ; stature large."

Generic characters should be such as will apply to every species in the genus; they should likewise be such as will 
distinguish the genus described from every other genus. From such observations as I have been enabled to make, the five last-mentioned characters do not appear to accord with either of these conditions.

1st. The muzzle is stated to be black; but in the Yak, and in domestic cattle (as may be observed by any one), the muzzle is very frequently white; and granting that it was invariably black, other genera of the ruminantia have the muzzle black: and therefore it cannot be said to be a distinguishing mark of the Genus Bos.

$2 d$. The ears are stated to be in general middle-sized. To pass over the extreme vagueness of the terms "in general" and "middle-sized," I may state that having measured the ears of several species, I find them to be of all lengths, varying from 5 inches to nearly 18 inches. Such a term as "middle-sized" may be applied "in general" to the ears of a vast variety of animals; and therefore it cannot be applied in particular to the Genus Bos.

3d. The body is said to be long. They are, indeed, of all lengths, from $4 \mathrm{ft} .6 \mathrm{in}$. to nearly $11 \mathrm{ft}$. Can the term long be equally applicable to animals of such different lengths?

4th. The legs are said to be solid. In some species the'legs are very slender, as the Zebu, Manilla Buffalo, and Domestic Ox.

5th. The stature is said to be large. From actual measurement I find the stature to vary from $2 \mathrm{ft} .8 \mathrm{in}$. to upwards of $6 \mathrm{ft}$; the smaller species weighing not more than $100 \mathrm{lbs}$., the larger weighing as much as $2000 \mathrm{lbs}$. Can the term large be equally applicable to animals of such different sizes? 
SUB-GENERIC CHARACTERS.

"Sub-genus I.-Bubalus.-Animals low in proportion to their bulk; limbs very solid; head large, forehead narrow, very strong, convex; chaffron straight; muzzle square, horns lying flat, or bending laterally with a certain direction to the rear; eyes large; ears mostly funnelshaped; no hunch; a small dew-lap; female udder with four mamme ; tail long; slender."

This sub-genus comprises Cape Buffalo, Pegasse, Arnee, Domestic Buffalo.

"Sub-genus II.-Bison. - Forehead slightly arched, múch broader than high; horns placed before the salient line of the frontal crest; the plane of the occiput forming an obtuse angle with the forehead and semicircular in shape; fourteen or fifteen pairs of ribs; the shoulders rather elevated; the tail shorter; the legs more slender; the tongue blue; the hair soft and woolly."

This sub-genus comprises Aurochs, Gaur, American Bison, Yak, Gayal.

"Sub-genus III.-Taurus.-Forehead square from the orbits to the occipital crest, somewhat concave, not convex, or arched as in the former; the horns rising from the sides of the salient edge or crest of the frontals; the plane of the occiput forming an acute angle with the froutal, and of quadrangular form; the curve of the horns outwards, upwards, and forwards; no mane; a deep dew-lap; thirteen pairs of ribs; tail long; udder four teats in a square."

This sub-genus comprises the Urus and the Domestic Ox. 
Subgeneric characters should be such as will clearly distinguish the animals of one sub-genus from those of another. But here we have set down, in the sub-genus Bubalus, tail long, slender; in the sub-genus Taurus, tail long; and although the epithet slender is not added in the latter case, yet in truth it ought to be, as the tail of Taurus is quite as slender as that of Bubalus.

The udder of Bubalus is said to have four mammæ; they are not stated to be in a square, but, on examination, I find they are so; the udder of Taurus has likewise four teats in a square.

Thirteen pairs of ribs are set down as a distinguishing character of the sub-genus Taurus; but the Cape Buffalo, Domestic Buffalo, and the Manilla Buffalo (in the subgenus Bubalus), and the Gaur (in the sub-genus Bison), all possess thirteen pairs of ribs.

In the sub-genus Bison the tail is said to be shorter than the tail of Bubalus; but on subjecting them to the infallible test of feet and inches, I find the tails of the Aurochs, Gaur, Yak, and Gayal, to be decidedly longer than those of the Cape or the Manilla Buffalo.

The legs of Bisons are stated to be more slender than those of Buffaloes, - the reverse of this is the fact in the instances which I have had an opportunity of observing.

SPECIFIC DETAILS.

The details of a system of scientific classification should be precise, methodical, and consistent; but the method observed by Col. Smith, in describing the lengths of animals, can scarcely be called either precise or consistent; for example, he states :- 
1st. That the Cape Buffalo is nine feet from nose to Root of tail.

2d. That the Gaur is twelve feet long to the END of tail.

3d. That the Aurochs is ten feet three inches from nose to tail.

4th. That the Domestic Buffalo is eight feet six inches long, without mentioning either nose or tail.

In none of these cases can we be even proximately certain of the length of the animal.

In the first instance we may err to the amount of the length of the head; as it is not stated whether the measurc was taken when the head was extended in a line with the back, or in a position at right angles with the back, or in any intermediate position.

The following outline will illustrate this:-

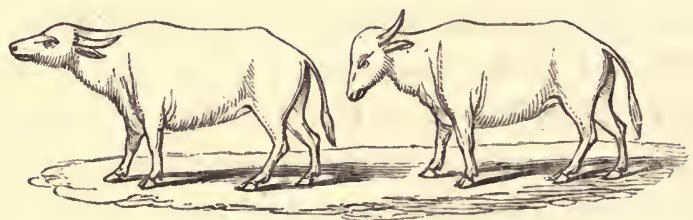

It is obvious that the length of a line from the nose to the tail will vary according to the different positions of the head of the animal.

In the second instance (taking it for granted that the measure was taken from the nose), the same difficulty exists with respect to the head, and another difficulty presents itself in our being left to guess the length of the tail, which might be eighteen inches, or it might be four feet. 
In the third instance, the same difficulty exists with respect to the head, and the difficulty is further complicated by our being left to guess whether the воот or the END of the tail is meant.

In the fourth we are completely "at sea."

The true value of these characteristic distinctions, definitions, or descriptions; are left to the appreciation of the judicious reader. Colonel Smith may doubtless be, what he has been styled, "an indefatigable naturalist," and "in general" an exact one; but in this special instance of the Genus Bos, his warmest admirers must allow that his accuracy and precision have not kept pace with his industry.

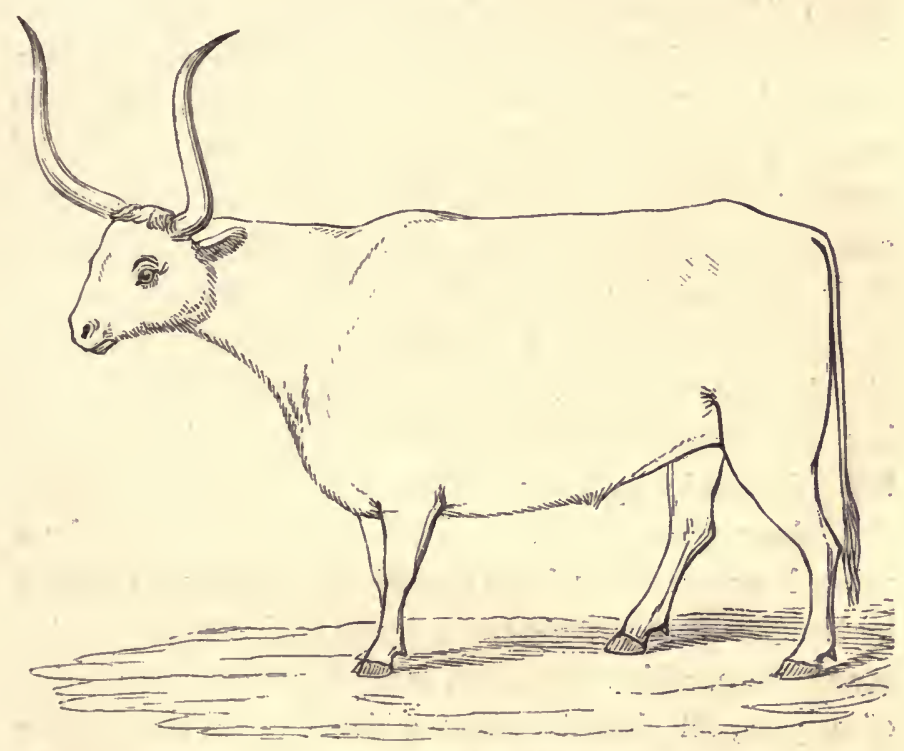

Hungarian Ox, Bos Taurus, from a speeimen in the British Museum. 


\section{MR. SWAINSON'S}

\section{TRANSCENDENTAL ATTEMPT AT CLASSIFICATION.}

The following very laboured attempt to arrange the various species of Genus Bos into groups, according to the Quinary or Circular System of $\mathbf{M}^{\circ}$ Leay, is from the pen of Mr. Swainson-the precise and fastidious Swainson-who, from the number and boldness of his hypothetical views in every department of Zoology, may be truly regarded as the beau-ideal of a speculative naturalist-one of those, in short, so well described by Swift, "whose chief art in division hath been to grow fond of some proper mystical number, which their imaginations have rendered sacred to a degree, that they force common reason to find room for it in every part of nature; reducing, including, and adjusting, every genus and species within that compass, by coupling some against their wills, and banishing others at any rate."

After describing the various members of the Bovine Family according to the Procrustean method of stretching and chopping, Mr. Swainson continues in his peculiarly dogmatic style- " The types of form of the Genus $B o s$, above enumerated, we shall now demonstrate to be a natural group. We have seen that the first represented by the Bos Scoticus, or Scotch Wild Ox, is an untameable savage race, which preserves, even in the domestication of a park, all that fierceness which the ancient writers attributed to the Wild Bulls of Britain and of the European Continent. Let those who imagine tinat the 
influence of civilization, of care, and of judicious treatment, will alter the natural instincts of animals, look to this as a palpable refutation of their doctrine. Where is that boasted power of man over nature? Where the fruits of long-continued efforts and fostering protection? The Bos Scoticus is as untameable now as it was centuries ago, simply for this reason, that it is in accordance with an unalterable law of nature; a law by which one type in every circular group is to represent the worst passions of mankind-fierceness, or cruelty, or horror. In the Urus we consequently have the type of the wild and untameable Ferce among quadrupeds, the eagles among birds, and the innumerable analogies which all the subordinate groups of these two great divisions present. Following this is the typical $\mathrm{Ox}-\mathrm{a} \operatorname{god}$ among the ancients, and that animal above all others, which, from its vital importance to man, we should naturally expect such a nation as the ancient Egyptians would exalt above all others. It is, in short, the typical perfection of the whole order of Ruminants, and consequently represents the Quadrumana among quadrupeds, and the Incessores among birds. The third type is no less beautiful; but it cannot be illustrated without going into details which it is not our present intention to make public : suffice it, however, to say, that in the prominent hump upon the shoulders we have a perfect representation of the Camel, one of the most striking types of the order, while it reminds us at the same time of the Buffalo, the genus Acronatus among the large Antelopes, and numerous other representations of the same form. The fourth type is our Bos Pusio: here we find the horns, when present, remarkably small, but in many cases abscut ; and 
the size is diminutive to an extreme. These also are distinguishing marks of the groups it is to represent: the Tenuirostres among birds, and the Glires, or mice, among quadrupeds, are the smallest of their respective classes; and both are typically distinguished by wanting all appendages to the head, either in the form of crests or horns. The fifth type is, perhaps, the most extraordinary of all; it should represent not only the order Rasores among birds, but also the Camelopardalis among ruminating quadrupeds. Hence we find that, in accordance with the first of these analogies, it is a peaceful domesticated race, and that it has horns of an unusually large size, even in its own group; while, at the same time, those horns have that peculiar structure which can only be traced in the Camelopardalis; they are covered with skin, which passes so imperceptibly to the horny state, that, as Captain Clapperton observes, "there is no exact demarcation where the one commences and the other ends." The five leading types of quadrupeds and birds being now represented, and in precisely the same order, we demonstrate the groups to be natural by the following table:-

\section{Genus BOS-the Natural Types.}

1. Bos Scoticus. Fierce, untameable. Fers. Raptores.

2. - Taurus. Pre-eminently typical. Primates. Incessores.

3. - Dermaceros. $\left\{\begin{array}{c}\text { Appendages on the head } \\ \text { greatly developed. }\end{array}\right\}$ Ungdiata. Rasolues.

4. - Pusio. $\quad\left\{\begin{array}{c}\text { Stature remarkably } \\ \text { small. }\end{array}\right\}$ Guires. Grallatores.

5. - Thersites. $\left\{\begin{array}{c}\text { Fore-part of the shoul- } \\ \text { ders elevated. }\end{array}\right\}$ Cetacea. Natatores.

In regard to the last type, the analogies can only be 
traced through the animals or types of other groups; but should the habits of Thersites lead it to frequent the water (like the Buffaloes) more than any other species of true oxen-a supposition highly probable-the analogy to the Cetacea and the Natatores would be direct. When we find in all the other four types such a surprising representation of the same peculiarities, we are justified in believing that want of information alone prevents this analogy from being so complete as the others. These analogies, in point of fact, may be traced through the whole of the principal groups in this order, the most important, and the most numerous of ungulated animals.". Our luminous classifier then triumphantly winds up :"Having now demonstrated, in one of the very lowest groups of quadrupeds, the validity of those principles of natural classification we have so often illustrated," \&c.

Let us not be confounded with high-sounding terms; let us rather endeavour to ascertain the meaning of them, if indeed they possess a meaning. . Here we have, under the head of "Genus Bos-the Natural Types"- (see p. 178), certain words arranged in regular columns, which, at a first glance, appear as though they were intended to bear some relation to each other. But let us ask the most ordinary observer, or the most profound observer, or the observer of any grade or shade between these two extremes, what resemblance-what relation-what ana$\operatorname{logy}$ — can be discovered between an ordinary bull (Taurus) and a man, a monkey, or a bat (Primates); or between Taurus and the Incessores (Percling Birds)? Or between Buffaloes, whose horns are partially covered with skin (Dermaceros), and cocks and hens (Rasores)? Can any one say wherein consists the similarity between a dwarf 
Zebu and a Mouse, or a Flamingo? Yet this is the material of which the columns are composed.

But one of the most unhappy of Mr. Swainson's speculations is that wherein he represents the Bos Scoticus, or wild ox, as the type of " an untameable savage race, which preserves, even in the domestication of a park, all that fierceness which the ancient writers attributed to the wild bulls of Britain and the European continent. Let those who imagine that the influence of civilization, of care, and of judicious treatment, will alter the natural instinct of animals, look to this as a palpable refutation of their doctrine. [!] Where is that boasted power of man over nature? Where the fruits of long-continued efforts and fostering protection? [!!] The Bos Scoticus is as untameable now as it was centuries ago, simply for this reason, that it is in accordance with an unalterable law of nature; a law by which one type in every group is to represent the worst passions of mankind-fierceness, or cruelty, or horror." $[! ! !]$

Who would for a moment imagine that all this grandiloquence is bestowed upon an animal, which is so far from being fierce and untameable, that young ones, taken and reared with ordinary cattle, become, even in the first generation, as tame as domestic animals? [See account of Chillingham White Cattle, p. 140.]

For a more complete satisfaction of his thought, the reader is referred to Mr. Swainson's volume "On the Natural History and Classification of Quadrupeds," p. 274, where he has given us an incoherent abstract of Colonel Smith's article on the Bovine, without, however, making the least attempt to verify the statements there recorded. The descriptions and characteristics are 
avowedly Colonel Smith's; but, in justice to the latter gentleman, it must be added, that the disquisitions on the circular succession of forms, and the analogical relations, are entirely $\mathrm{Mr}$. Swainson's.

\section{ON SPECIES AND VARIETY.}

What constitutes a species? And how far do the limits of varieties extend? Cuvier, who is, perhaps, the best authority we can have upon this subject, in defining a species, says:- $A$ species comprehends all the individuals which descend from each other or from a common parentage, and those which resemble them as much as they do each other. Thus, the different races which they have generated from them are considered as varieties but of one species. Our observations, therefore, respecting the differences between the ancestors and the descendants, are the only rules by which we can judge on this subject; all other considerations being merely hypothetical, and destitute of proof. Taking the word variety in this limited sense, we observe that the differences which constitute this variety depend upon determinate circumstances, and that their extent increases in proportion to the intensity of the circumstances which occasion them.

Upon these principles it is obvious, that the most superficial characters are the most variable. Thus colour depends much upon light; thickness of hair upon heat; 
size upon abundance of food, \&c. In wild animals, however, these varieties are greatly limited by the natural habits of the animal, which does not willingly migrate from the places where it finds, in sufficient quantity, what is necessary for the support of its species, and does not even extend its haunts to any great distances, unless it also finds all these circumstances conjoined. Thus, although the Wolf and the Fox inhabit all the climates from the torrid to the frigid zone, we hardly find any other differences among them, through the whole of that vast space, than a little more or less beauty in their furs. The more savage animals, especially the carnivorous, being confined within narrower limits, vary still less; and the only difference between the Hyæna of Persia and that of Morocco, consists in a thicker or a thinner mane.

Wild animals which subsist upon herbage feel the influence of climate a little more extensively, because there is added to it the influence of food, both in regard to its abundance and its quality. Thus the Elephants of one forest are larger than those of another; their tusks also grow somewhat longcr in places where their food may happen to be more favorable for the production of the substance of ivory. The same may take place in regard to the horns of Stags and Rein-deer. Besidcs, the species of herbivorous animals, in their wild state, seem more restrained from migrating and dispersing than the carnivorous species, being influenced both by climate, and by the kind of nourishment which they need.

We never see, in a wild state, intermediate productions between the Hare and the Rabbit, between the Stag and the Doe, or between the Martin and the Weasel. Human artifice contrives to produce all these 
intermixtures of which the various species are susceptible, but which they would never produce if left to themselves:

The degrees of these variations are proportional to the intensity of the causes that produce them, namely, the slavery or subjection under which these animals are to man. They do not proceed far in half-domesticated species.

In the domesticated herbivorous quadrupeds, which man transports into all kinds of climates, and subjects to various kiuds of management, both in regard to labour and nourishment, he procures certainly more considerable variations, but still they are all merely superficial: greater or less size; longer or shorter horns, or even the want of these entirely; a hump of fat, larger or smaller, on the shoulder; these form the chief differences among particular races of the Bos Taurus, or domestic Black Cattle; and these differences continue long in such breeds as have been transported to great distances from the countries in which they were originally produced, when proper care is taken to prevent crossing. .

Nature appears also to have guarded against the alterations of species which might proceed from mixture of breeds, by influencing the various species of animals with mutual aversion. Hence all the cunning and all the force that man is able to exert is necessary to accomplish such unions, even between species that have the nearest resemblance. And when the mule-breeds that are thus produced by these forced conjunctions happen to be fruitful, which is seldom the case, this fecundity never continues beyond a few generations, and would not probably proceed so far, without a continuance of the same causes which excited it at first. 
This being the case, it is quite clear that the fact of two animals producing an intermediate race is no proof whatever of their specific identity; for it is well known, and has been already alluded to, that several animals, Birds as well as Mammalia, produce offspring, and are nevertheless distinct, both as it regards anatomical structure and external form.

Neither does it constitute the species identical if either or both the hybrids be even capable of fruitful intercourse with the original or parent species. Hamilton Smith goes so far as to say, that "if it even were proved that a prolific intermediate race exist, produced by the intermixture of both, it would not fully determine that both form only one original species: wliat forms a species, and what a variety, is as yet far from being well understood."

It is, however, pretty generally agreed, that animals are of the same species, that is to say, have been derived from one common stock, when their offspring have the power, inter se, of indefinitely continuing their kind; and conversely, that animals of distinct species, or descendants of stocks originally different, cannot produce a mixed race which shall possess the capability of perpetuating itself.

To conclude, it must be obvious, that permanent anatomical differences are the only true criteria of distinctions of species. 


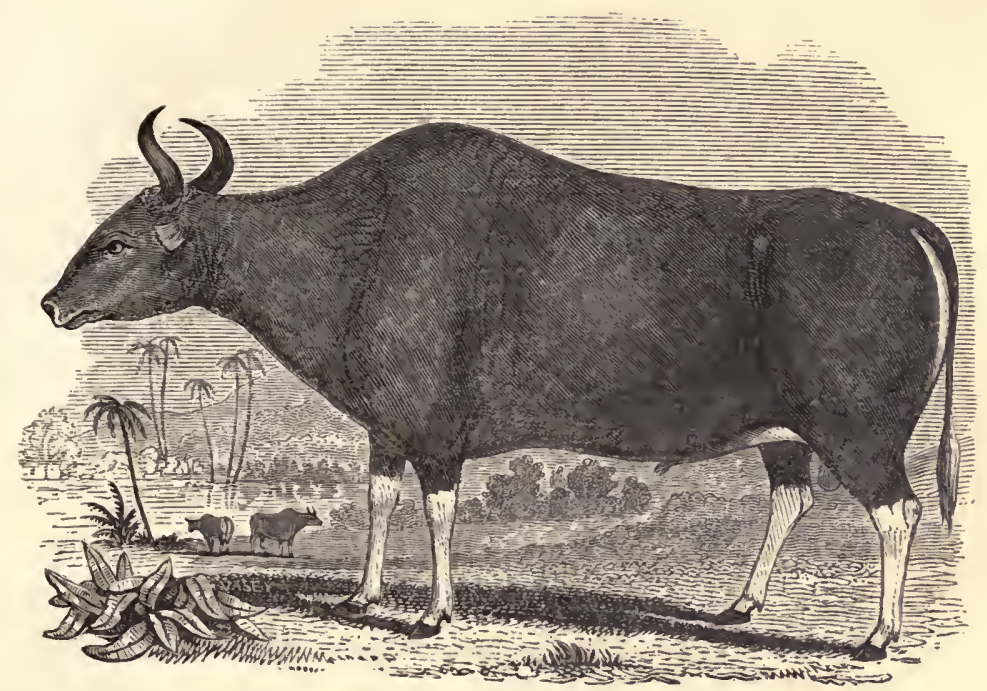

THE BANTENG OF JAVA.

Bos Bantinger, or Bantiger. Bos Sondaicus? '

The above figure was drawn from a stuffed specimen in the British Museum. In colour, shape, and texture of horns, and apparent want of dewlap, it bears some resemblance to the Gaur; but in the skeleton of the Gaur the sacrum consists of five vertebræ, and the tail of nineteen; while in the skeleton of the Banteng, the sacrum consists of but four vertebra, and the tail of eighteen. 


\section{BRITISH DOMESTIC CATTLE.}

Ir does not come within the scope of the present work to give the varieties of Domestic Cattle; for these the reader is referred to the many excellent works already published on the subject. It will be sufficient in this place to notice a few interesting facts-statistical, anecdotal, \&c.--in relation to their domestic history.

\section{INFLUENCE OF COLOUR IN BREEDING.}

The following remarkable fact, respecting the colour of the offspring being influenced by that of the external objects surrounding the Cow at the time of copulation, is stated by John Boswell, of Balmuto and Kingcaussie, in an essay upon the breeding of Live Stock, communicated to the Highland Society in 1825. He says:- "One of the most intelligent breeders $I$ have ever met with in Scotland, Mr. Mustard, an extensive farmer on Sir James Carnegie's Estate in Angus, told me a singular fact, with regard to what I have now stated. One of his cows happened to come into season while pasturing on a field which was bounded by that of one of his neighbours, out of which field an Ox jumped, and went with the Cow, until she was brought home to the Bull. The Ox was white with black spots, and horned. Mr. Mustard had not a horned beast in his possession, nor one with any white on it. Nevertheless, the produce of the following spring was a black and white calf, 
with horns." Another fact, which shows the great care required in keeping pure this breed-(the Angus doddies) -is related of the Keillor Stock, where, two different seasons, a dairy cow of the Ayrshire breed, red and white, was allowed to pasture with the black doddies. In the first experiment, from pure black Bulls and Cows, there appeared three red and white calves; and on the second trial, two of the calves were of mixed colours. Since that time care has been taken to have almost every animal on the farm, down to the Pigs and Poultry of a black colour.

\section{INFLUENCE OF THE MALE IN BREEDING.}

An ordinary Cow, and a Bull without horns, will produce a calf resembling the male in appearance and character, without horns and without that particular prominence of the transverse apophysis of the frontal bone. The milk of the female from this cross, also, proves the influence of the male: it has the peculiar qualities of the hornless breed-less abundant, containing less whey, but more cream and curd.

\section{GENERATIVE PRECOCITY.}

A Mr. Gordon relates the following singular instance of fecundity and early maturity in the Aberdeen Cattle. "On the 25th of Sept., 1805, a calf of five months old, of the small Aberdeenshire breed, happening to be put into an enclosure among other Cattle, admitted a male that was only one year old. In the month of June following, at the age of fourteen months, she brought forth a very fine calf, and in the Summer of 1807, another equally good. The first calf, after working in 
the Winter, Spring, and Summer of 1809, was killed in January, 1810, and weighed 6cwt. 3 qrs. 16lb. The second was killed December 16, 1810, aged three years six months, and weighed exactly $7 \mathrm{cwt}$.; and on Dec. 30, 1807, the mother, after having brought up these calves, was killed at the age of two years and eight months, and weighed 4cwt. 1qr. the four quarters, sinking the offal."

MILK.

Cows are usually milked three times a day over the greatest part of Scotland, from the time of calving till the milk begins to dry up during the Winter season, when the Cows are for the most part in calf; nor is it found that they suffer by that practice in any degree: and it is the general opinion of all who adopt it, that nearly one third more milk is thus obtained than if they were milked only twice.

A Cow, mentioned by Dr. Anderson in his 'Recreations,' (vol. v, p. 309,) was milked three times a day for ten years running, during the space of nine months, at least, every year; and was never seen, during all that period, but in very excellent order, although she had no other feeding than was given to the rest of the Cows, some of which were very low every winter, when they gave no milk at all.

A farmer of the name of Watkinson had a Cow that, for seventeen years, gave him from ten to twenty quarts of milk every day; was in moderate condition when taken up, six months in fattening, and being then twenty years old, was sold for more than £18. Mr. John Holt, of Walton, in Lancashire, had a healthy Cow-calf presented 
to him, whose dam was in her thirty-second year, and could not be said to have been propcrly out of milk for the preceding fifteen years.

Yorkshire Cows, which are those ehiefly used in the London Dairies, give a very great quantity of milk. It is by no means uncommon for them, in the beginning of the Summer, to yield thirty quarts a day; there are rare instances of giving thirty-six quarts; but the average measure may be estimated at twenty-two or twenty-four quarts.

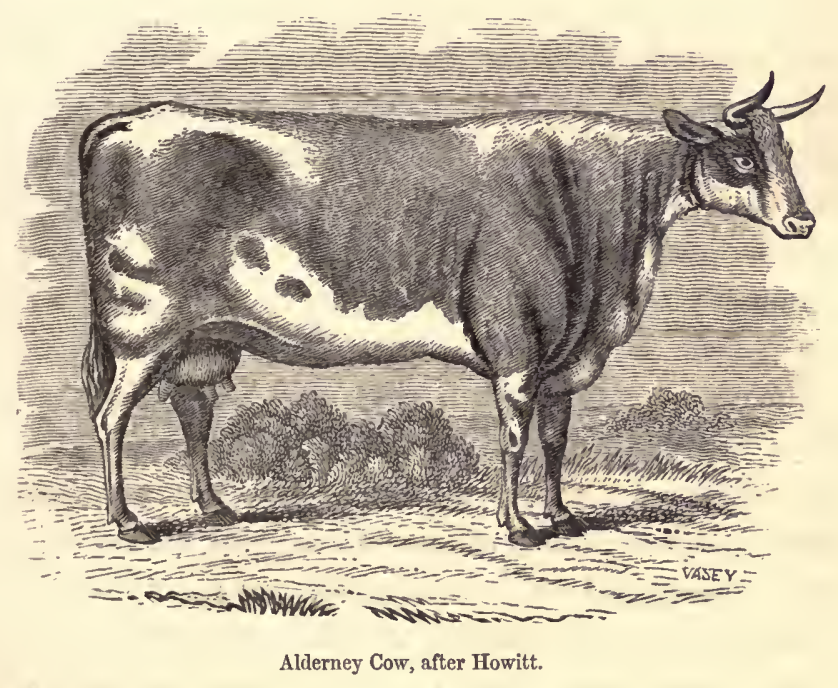

BUTTER.

The Alderney Cow, considering its voracious appetite, yields very little milk; that milk, however, is of an extraordinary excellent quality, and gives more butter than can be obtained from the milk of any other eow. John Lawrence states that an Alderney Cow that had straycd 
on the premises of a friend of his, and remained there three weeks, made 19 lbs. of butter each week; and the fact was held so extraordinary, as to be thought worthy of a memorandum in the parish books. The milk of the Alderney Cow fits her for the situation in which she is usually placed, and where the excellence of the article is regarded, and not the expense.

Lord Hampden; of Glynde, had a cow which in the height of the season yielded ten pounds of butter and twelve pounds of cheese every week, and yet her quantity of milk rarely exceeded five gallons per day. The next year the same cow gave nine pounds and a half of butter per week for several weeks, and then for the rest of the summer between eight and nine pounds per week; and until the hard frost set in, seven pounds; and four pounds per week during the frost. Yet as a proof of the quality of the milk, she at no time gave more than five gallons in the day. To this may be added that, "four or five years before, the same person had a fine black Sussex Cow from Lord Gage, which also gave, in the height of the season, five gallons per day, but no more than five pounds of butter were ever made from it." This is accounted for in a singular way; for there is a common opinion in the east of Sussex, that "the milk of a black cow never gives so much butter as that of a red one."

MR. YOUATT'S PHILOSOPHY OF RABIES, OR MADNESS.

In treating of Rabies, Youatt says :- "When a rabid or $\operatorname{mad} \operatorname{dog}$ is wandering about, labouring under an irrepressible disposition to bite, he seeks out first of all his own species; but if his road lies by a herd of cattle, he 
will attack the nearest to him; and if he meet with much resistance, he will set upon the whole herd, and bite as many as he can. .... If the disease is to appear at all, it will be about the expiration of the fifth week, although there will be no absolute security in less than the double number of months." After making these remarks, our author reasons himself into the sapient conclusion, that the poison in all rabid animals resides in the saliva, and does not affect any other secretion. "The knowledge that the virus is confined to the saliva," he opines, "will settle a matter that has been the cause of considerable uneasiness. A cow has been observed to be ailing for a day or two, but she has been milked as usual; her milk has been mingled with the rest, and has been-used for domestic purposes, as heretofore. She is at length discovered to be rabid. Is the family safe? Can the milk of a rabid cow be drunk with impunity? Yes, perfectly so, for the poison is confined to the saliva. The livers of hundreds of rabid dogs have been eaten in days of ignorance, dressed in all manners of ways, but usually fried as nicely as possible, as a preventive against madness. Some miscreants have sent the flesh of rabid cattle to the market, and it has been eaten without harm; and so, although not very pleasant to think about, the milk of the rabid cow may be drunk without the slightest danger."

Is it, indeed, possible for any of the secretions of an animal to be in a healthy state, and fit for human food, after it has had the virus of a rabid dog circulating in its system for at least five weeks? Furthermore, is it consistent in Mr. Youatt to call those miscreants who send the flesh of rabid cattle to market, whon he acknow- 
ledges, in the same breath, that it can be eaten without harm?

According to Mr. Youatt's philosophy, a cow in a rabid state is actually as good as a cow in a healthy state; for its milk may be drunk with impunity-the family is perfectly safe who uses it for domestic purposes; and, moreover, the flesh of rabid cattle may be eaten without harm. What more can be predicated of cattle in the purcst state of health?

STATISTICS.

The number of cattle in Great Britain was estimated by Youatt (1838) at upwards of eight millions. $\quad 160,000$ head of cattle are annually sold in Smithfield alone, without including calves, or the dead market, i.e., the carcases sent up from various parts of the country. $1,200,000$ sheep, 36,000 pigs, and 18,000 calves, are also sent to Smithfield in the course of a year.

A tenth part of the sheep and lambs die annually of disease (more than 4,000,000 perished by the rot alone in the winter of 1829.30), and at least a fifteenth part of the neat cattle are destroyed by inflammatory fever. and milk fever, red water, hoose, and diarrhœea.

If a tithe of the sheep and lambs, and a fifteenth of the neat cattle die of disease, what proportion are slaugh. tered and sent to market in the earlier stages of disease; and, in fact, in all the stages antecedent to those which are the immediate cause of death? 


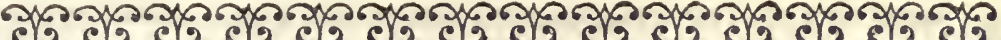

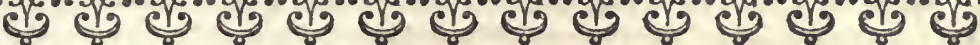 \\ raluable and 3 nteresting $300 k s$, PUBLISHED OR SOLD $B Y$ \\ JOHN RUSSELL SMITH, \\ 36 , SOHO SQUARE, LONDON.}

Literary History, Biography, and Criticism. Philolology and Early English Literature Provincial Dialects of Ėngland Archrology Numismatics Topography
Heraldry, Genealogy and Surnames . . 15 Fine Arts * . . 16 Popular Poetry, Stories, and Snperstitions . 17 Bibliography-Miscellanies

BIOGRAPHIA BRITANNICA LITERARIA, or Liography of Literary B Characters of Great Britain and Ireland. ANGLO-SAXON PERIOD. By THoMAs Wright, M.A., F.S.A., \&c., Membre de l'Institute de France. Thick 8vo, cloth. 6s. (original price 12s.)

THE ANGLO-NORMAN PERIOD. Thick 8vo, cloth. 6s. (originalprice 12s.)

Published under the superintendence of the Council of the Royal Society of Litcrature.

There is no work in the English Ianguage which gircs the reader such a comprehensive and connected History of the Literature of these periods.

T-ITERATURE OF THE TROUBADOURS. Histoire de la Poésie ProL vençale, par M. FAtrire, publié par J. MoHL, Membre de l'Institut de France. 3 vols, 8vo, nero, sewed. 14s. (original price £1. 4s.)

A valuable work, and forms a fit companion to the Literary Histories of Hallam, Ticknor, and Ginguene. J. R. S. is the ouly agent in London for the sale of it, at the above moderate price.

JUNIUS. The Authorship of the Letters of Junius elucidated, including a Biographical Memoir of Lient.-Col. Barré, M.P. By Jonn Britron, F.S.A., \&c. Royal 8ro, with portraits of Lord Shelburne, John Dunning, and Barré, from Sir Joshua Reynolds's picture, cloth. Gs LARGE PAPER, in 4to, cloth. 9s.

An exceedingly interesting book, giving many particulars of the American War, and the state of parties during that period.

WORTHIES OF WESTMORELAND, or Biographies of Notable Persons born in that County since the Reformation. By George Arrirsos, Erq., Barrister-at-Law. 2 vols, post $8 \mathrm{vo}$, cloth. 6s. (original price 16s.)

BARKER.- Literary Anecdotes and Contemporary Reminiscences of Professor B Porson, and others, from the Manuscript Papers of the late E. H. BARKER, Esq., of Thetford, Norfolk, with an Original Memoir of the Author. 2 vols. 8vo, cloth. 12s.

MILTON.-Considerations on Milton's Early Reading, and the prima stamina of 1 his "Paradise Lost," together with Extracts from a Poet of the XVIth Century, (Joshua Sylvester, ) by Cris. Dusster, M.A. 12mo, cloth. 2s. 6d. (original price 5s.)

MIITOIN. - A Sheaf of Gleanings, after his Biographers and Annotators. By the II Rev. Josephi Hunter. Post 8ro, sewed. 2s. $6 d$.

IFE, PROGRESSES, and REBELLIONof JAMres, Deke of MorMOUTH, etc. to his Capture and Execution, with a full account of the Bloody Assize, and copious Biographical Notices, by GEORGE ROBERTs, 2 vols. post $\$ \mathrm{vo}$, plates and cuts, new, extra cloth. 9s. (original price £1. 4s.)

Two very interesting volumes, particularly so to those connected with the West of England.

SHAKESPERIANA, a Catalogue of the Early Editions of Shakespeare's Plays, and of the Commentaries and other Publications illustrative of his Works. By J. O. Hallitweli. 8ro, cloth. $3 s$

"Indiepensable to everybody who wishes to carry on any inquiries connected with Slakesneare or who may have a fancy for Chakesperian Biblioorving "-spectalor. 
A NEW LIFE OF SHAKESPEARE, including many particulars respectA ing the Poet and his Family, nerer before published. By J.O. HALLIWELr, F.R.S., \&c. In one handsome volume, $8 v 0$, illestrated with 76 engravings on wood, of abjects, most of which are new, from drawings by FATBHOLT, cloth. 15s.

This work contains upwards of forty documents respecting Shakcspeare and lis Family, never before published, besides numerous others indirectly illustrating the Poet's Biography. All the anecdotes and traditions concerning Shakespeare are liere, for the first time collected, and much new light is thrown on his

personal history, by papers exhibiting him as selling Malt and Stone, \&c. Of the seventy+six engravings which illustrate the volume, more than fifty have never before been engraved.

It is the only Life of Shakespeare to be bought separately from his Works.

\section{Other Publications illustrative of Shakespeare's Life and Writings.}

MALONE'S Letter to Dr. Farmer (in Reply to Ritson), relative to his Edition of Shakespeare, published in 1790. 8vo, sewed. 1 s.

IRELAND'S (W. F.) Miscellaneous Papers and Legal Instruments, from the original MSS. (the Shakespeare Forgeries). 8vo, plate. 2s. $6 d$.

IRELAND'S (Sam.) Vindication of his Conduct, respecting the Publication of the supposed Shakespeare MSS., in reply to the Critical Labours of Mr. Malone. 8vo. 1s.6d.

IRELAND'S Investigation of Mr. Malone's Claim to the Character of Scholar or Critic, being an Examination of his "Inquiry into the Authenticity of the Shakespeare Manuscripts." 8vo. 1s. $6 d$.

IRELAND'S (W. Henry) Authentic Account of the Shakesperian Manuscripts, \&c. (respecting his fabrication of them). 8vo. 1s. $6 d$.

COMPARATIVE REVIEW of the Opinions of $\mathrm{J}_{\triangle \mathrm{S}}$. BOADEN, in 1795 and in 1796, relative to the Shakespeare MSS. 8vo. $2 s$.

GRAVES'S (H. M.) Essay on the Genius of Shakespeare, with Critical Remarks on the Characters of Rom6o, Hamlet, Juliet, and Ophelia. Post 8ro, cloth. 2s. $6 d$. (original price 5s. 6d.)

WIVELL'S Historical Account of the Monumental Bust of Shakespeare, in the Chancel of Stratford-on-Avon Church. 8vo, 2 plates. 1s. $6 d$.

IRELAND'S (W. H.) Vortigern, an Historical Play, represented at Drury Lane, Apri] 2, 1796, as a supposed newly discovered Drama of Shakespeare. New Edition, with an original Prefaoe, 8vo, facsimile. 1s. 6d. (Original price 3s. 6d.)

The preface is both interesting and curious, from the additional information it gives respecting the Shskespeare Forgeries, containing also the substance of his "Confessions."

BOADEN (Jas.) on the Sonnets of Shakespeare, identifying the person to whom they are addressed, and elucidating several points in the Poet's History. 8vo. 1s. 6d.

TRADITIONARY ANECDOTES OF SHAKESPEARE, collected in Warwickshire in 1693. 8vo, sewed. $1 s$.

MADDEN'S (Sir F.) Observations on an Autograph of Shakespcare, and the Orthography of his Name. 8vo, sewed. 1 s.

HALLIWELL'S Introduction to "Midsummer Night's Dream." 8ro, cloth. 3s.

HALLIWELL on the Character of Falstaff. 12mo, cloth. $2 s 6 d$.

COLLIER'S (J. P.) Reasons for a New Edition of Shakespeare's Worls. 8ro. 1s.

SHAKISPEARE'S LIBRARY.-A Collection of the Romances, Novels, Poems, and Histories used by Shakespeare as the foundation of his Dramas, now first collected and accurately reprinted from the original Editions, with Notes, \&c. By J. P. CoLLIEI. 2 vols. $8 \mathrm{vo}$, cloth. 10s. $6 d$. (Original price \&1. 1s.)

ACCOUNT of the only known Manuscript of Shakespeare's Plays, comprising some important variations and corrections in the "Merry Wives of Windsor," obtained from a Playhouse Copy of that Play recently discovered. By J.O. HALIIWELL. 8vo. 1s.

RIMBAULT'S "Who was 'Jack Wilson,' the Singer of Shakespeare's Stage?" An Attempt to prove the identity of this person with John Wilson, Doctor of Music in the University of Oxford, A.D. 1644. 8vo. 1s.

SHAKESPEARE'S WILL, copied from the Original in the Prerogative Court, preserv* ing the Interlineations and Facsimilies of the three Autographs of the Poet, with a few preliminary Observations. By J. O. Halliwril. 4to. $1 s$.

DYCE'S Remarks on Collier's and Knight's Editions of Shakespeare. 8vo, cloth. 4s.6d.

A FEW REMARKS on the Emendation "Who smothers her with Painting," in the Play of Cymbeline, discorered by Mr. Collier, in a Corrected Copy of the Second Edition of Shakespeare. By J. O. HALLIWELL, F.R.S., \&c. 880. 1s. 
IFE OF Mr. THOMAS GENT, Printer of York, written by himself. 8vo, fine portrait, engraved by Aug. Fox, cloth. 2s. 6d. (Original price 9s.)

The Author of this curious, and hitherto unpublished piece of Autobiography, is well known hy the several works of which lic was the author as wall as printer. The narrative is full, written in an easy and unaffected style, interspersed with several pieces of Poetry; and from the number of adrentures he went tlirough in early life, and the characters and stories incidentally introduced, is extremely amusing. Ilis occupation as

a printer necessarily introduced him to the acquaintance of many literary men, and his book abounds with notices of Autliors, Printers, \&c., of the times in which he lived; among others occur the names of Bishop Atterbury, with whom he relates a singular interview, Browne Willis, and Dr. Drakc, the historian of York, \&c. The Book requires no encomium to those who have read Southey's "Doctor."

ANGIAND'S WORTHIES, under whom all the Civil and Bloody Warres,

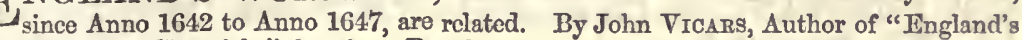
Parliamentary Chronicle," \&c., \&c. Royal 12mo, reprinted in the old style (similar to Lady Willoughby's Diary), with copies of the 18 rare portraits after Hollar, \&c., half morocco. 5s.

Copies of the original edition sold $\$ 16$ to 220 .

Tlie portraits comprise, Robert, Earl of Essex; Robcrt, Earl of Warwick; Lord Montaga, Earl of Denbigh, Earl of Stamford, Darid Leslcy, General

Fairfax, Sir Thomas Fairfax, 0. Cromwell, Skippon, Colonel Massey, Sir W. Brereton, Sir W. Waller, Colonel Langhorne, General Poyntz, Sir Thos. Middleton, General Brown, and General Mitton.
A ROT AMONGST THE BISHOTS;
or a Terrible Tempest in the Sea A of Canterbury, set forth in lively emblems, to please the judicious Reader. By Thomas STIRRY, 1641. 18mo (A satire on Abp. Laud), four very curious woodcut emblems, cloth. 3s
A facsimile of the very rare original edition, which sold at Bindlcy's sale for 213 .
CATWRIGHT.-Memoirs of the Life, Writings, and Mechanical Inventions of
Edmund Cartwright, D.D., F.R.S., inventor of the Power Loom, \&c. Post 8ro, engravings, bds. 2s. $6 d$. (original price 10s. 6d.)
It contains some interesting litcrary history, Dr. Cartwright numbering among his correspondents, Sir Cartwright numbering among his corres pondents, Sir Langhorne, and others; he was no mean Poet, as
his Legendary Tale of "Armine and Elvira" (given in the Appendix) testifies; Sir W. Scott says it con- tains some excellent poetry, expressed with unusual felicity.

FORMAN.-The Autobiography and Personal Diary of Dr. Simon Forman, the Celebrated Astrologer, 1552-1602, from unpublished MSS. in the Ashmolean Museum, Oxford. Edited by J. O. Halliwald. Small 4to, sewed. 5s.

Only 150 copies privately printed. It will form a companion to Dr. Dee's Diary, printed by the Camden Socicty, who also printed this work, but afterwards suppressed it.

RICHARDSON.-Extracts from the Literary and Scientific Correspondence of R Richard Richardson, M.D., F.R.S., of Brierley, Yorkshire. Edited by DAWsoN TURNRR, Esq. $8 \mathrm{vo}$, pp. 530, portrait and plates of Brierley Hall, cloth. 7s. $6 d$.

This is a very interesting volume, and contains much curious matter respecting the state and progress of Botany, the study of Antiquities and General Literature, \&c., in Grcat Britain, during the first half of tho

eightecnth century. It was printed for private cir. crilation only (at the expense of Miss Currer, of Eshton Hall), and copies have found their way into but few collections.

\section{T IFE, POETRY, AND LETTERS of EBENEZER ELLIOTT,} 1 the Corn Law Rhymer (of Sheffield). Edited by his Son-in-Law, JoHN WATkivs, post 8ro, cloth; (an interesting volume). 3s. (Original price 7s. 6d.)

SCOTT.-Extracts from the Letter-Book of Wintras Scort, Father of the Lords Stowell and Eldon, with Notes on their Family History and Pedigree. By M. A. RichaRDSON. Post 8vo, sewed. 1s. $6 d$.

A LCUIN OF BRITAIN.-The Life of Alcuin, the Learned Anglo-Saxon, and A Ambassador from King Offa, to the Emperor Charlemagne. By D. F. Lorens, Translated by Sleo. $12 \mathrm{mo}, \mathrm{pp} .280$, cloth. 2s. (Original price 6s.)

WESLEY.-Narrative of a Remarkable Transaction in the Early Life of John Wesley, now first printed from a MS. in the British Museum. 8vo, seved. 2s.

A very curious love affair between J.W. and his honsekecper; it gives a curious insight into the early cconomy of the Methodists. It is entirely unknown to all Wesley's biographers.

THE CONNECTION OF WALIS with the Early Science of England, 1. illustrated in the Memoirs of Dr. Robert Recorde, the first Writer on Arithmetic, Geometry, Astronomy, \&c., in the English Language. By J. O. HAIIIWELL. 8ro, seved. 1s. 
MORLAND. - Account of the Life, Writings, and Inventions of Sir Samuel seved. 1s.

COLLECTION OF LETTERS on Scientific Subjects, illustrative of the Progress of Science in England. Temp. Elizabeth to Cliarles II. Edited by

J. O. HALIIWELI. 8vo, cloth. 3s.

Comprising letters of Digges, Dee, Tyeho Brahe, Lowcr, Harriott, Lydyatt, Sir W. Petty, Sir C. Cavendish, Brancker, Pell, \&c.; also the autobiography of

Sir Samuel Morland, from a MS. in Lambeth Palace Nat. Tarpoley's Corrector Analyticus, \&ce. Cost the Subscribers $\mathbb{E} 1$.

QT. DUNSTAN.-The Iife and Miracles of St. Dunstan. By W. RoBinson, LL.D. 8vo, plate. 1s.

SIDNEY.-Brief Memoir of the Life of the Hon. Algernon Sidney (the Patriot); with his Trial in 1683 . By R. C. SIDNEx. With outline plate from Stephanols"s well known picture. $8 \mathrm{vo}$, sewed. $18.6 d$.

T OVE LETTERS OF MRS. PIOZZI, (formerly Mrs. Thrale, the friend of

Dr. Johnson, ) written when she was Eighty, to the handsome actor, William Augustus Conway, aged Twenty-seren. 8vo, sewed. 2s.

"—_ written at three, fonr, and five o'clock (in the morning) by an Octogenary pen, a heart (as Mrs. Lee says) twenty-six years old, and as $H$. L. P. feels it to be, all your onon."-Lelter $V, 3 d$ Feb. 1820.

"This is one of the most extraordinary collections of love epistles we have ever chanced to meet with, and the well known literary reputation of the ladythe Mrs. Thrale, of Dr. Johnson and Miss Burney celebrity-considerably enhances their interest. The letters themsclvcs it is not easy to characterise; nor shall we venture to decide whether they more bcsyeak the drivelling of dotage, or the folly of love; in citlice case they present human nature to ns under a $11 \mathrm{cw}$ aspect, and furnisl one of those ruldles which nothing yet dreamit of in our plilosophy can satisfactorily solve."-Polytechnic Reriev.

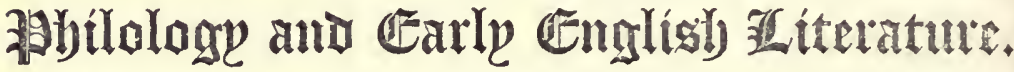

\section{COMPENDIOUS ANGLO - SAXON AND ENGLISH DIC-}

TIONARY. By the Rev. JosEph Bosworth, D.D., F.R.S., \&c. 8vo, closely printed in treble Columns. $12 s$.

IARGE PAPER. Royal 8vo. (to match the next article), cloth, f1.

"This is not a mere abridgment of the large Dictionary, but almost an entirely new work. In this compendious one will be found, at a very moderate

price, all that is most practical and valuable in th, former expensive edition, with a great accession of ncw words and matter."-Aulhor's Preface.

ON THE ORIGIN OF THE ENGLISH, Germanic, and Scandinavian Languages and Nations, with Chronological Specimens of their Languages. J3y J. BosworTH, D.D. Royal 8vo, bds. $£ 1$.

A new and enlarged edition of what was formerly the Preface to the First Edition of the Anglo-Saron Dictionary, and now published separately.

A NGLO-SAXON DELECTUS ; serving as a first Class-Book to the Lan2s. $6 d$.

guage. By the Rev. W. BarNes, B.D., of St. John's Coll. Camb. 12n10, cloth,

"To those who wish to possess a critical knowledge of thcir own Native English, some acquaintance with Anglo-Saxon is indispensable; and we have never seen an introdnction better calculated than the present to supply the wants of a bcyinuer in a sliort space of time. The declensions and conjugations are well

stated, and illustrated by refercnccs to Greek, the Latin, French, and other languages. A plilosopliceal spirit pervades every part. The Delectus consists of short pieces on various subjects, with extracts from AngloSaxon History and the Saxon Clironicle. Thicre is a good Glossary at the end."-Athenewm, Oct. 20, 1819.

GUIDE TO THE ANGLO-SAXON TONGUE: on the Basis of Professor Rask's Grammar; to which are added, Reading Lessons in Verse and Prose, with Notes for the use of Learners. By E. J. Versnon, B.A., Oxon. 12mo, cloth, $5 s .6 d$.

"The author of this Guide scems to hare made one step in the right direction, by compiling what may be pronounced the best work on the subject hitherto published in England."-Athenaum.

"Mr. Vernon has, we think, acted wisely in taking Rask for his Model; but lct no one suppose from the title that the hook is merely a compilation from the work of that philologist. The accidence is abridged from Rask, with constant rcvision, correction, and modification; but the syntax, a most important portion of the book, is original, and is compiled with great care and skill; and the latter half of the volume con. sists of a well-chosen selection of extructs from AngloSaxon writers, in prose and verse, for the practice of the student, who will find great assistance in reading them from the grammatical notes with whicli they are accompanied, and from the glossary which follows them. This volume, well studied, will enable any one to real with ease the generality of Anglo-Saxon writers; and its cheapness places it within the reach of every class. It has our hearty recommendation."-Literary Garette. 


\section{John Russell Smith, 36, Soho Square, London.}

A NALECTA ANGLO-SAXONICA.-Belections, in Prose and Verse, from A Anglo-Saxon Literature, with an Introductory Ethnological Essay, and Notes, Critical and Explanatory. By LOUIS F. KuIPSTEIN, of the University of Giessen. 2 thick vols, post 8vo, cloth. 12s. (original price 18s.)

Containing an immense body of information on a language which is now becoming more fully appreciated, and which contains fifteen-twentieths of what we daily think, and speak, and write. No Englishman, therefore, altogether iguorant of Anglo-Saxon, can

have a thorough knowledge of his own mother-tongue; while the langrage itself, to say nothing of the many valuable and interesting works preserved in it, may, in copiousness of words, strength of expression, and grammatical precision, vie with the modern German.

TNTRODUCTION TO ANGLO-SAXON READING; comprising Elfric's Homily on the Birthday of St. Gregory, with a copious Glossary, \&c. By I. LANGLEY, F.L.S. $12 \mathrm{mo}$, cloth, $2 s .6 d$.

Elfric's IIomily is remarkable for beauty of composition, and interesting as setting forth Augustine" misston to the "Land of the Angles."

A NGLO-SAXON VERSION OF THE LIFE OF ST. GUTHLAC, A Hermit of Croyland. Printed, for the first time, from a MS. in the Cottonian Library, with a Translation and Notes. By CHARles Wyolifws Goodwr, M.A., Fellow of Catharine Hall, Cambridge. $12 \mathrm{mo}$, cloth, $5 s$.

A NGLO-SAXON LEGENDS OF ST. ANDREW AND ST. A VERONICA, now first printed, with Tinglish translations on the opposite page. By C. W. Goodwin, M.A. 8ro, sewed. 2s. $6 d$.

A NGLO-SAXON VERSION OF THE HEXAMERON OF ST. A BASI, and the Anglo-Saxon Remains of St. Basil's Admonitio ad Filium Spiritualem; now first printed from MSS. in the Bodleian Library, with a Translation and Notes. By the Rev. H. W. Norman. 8vo, Second Edition, enlarged, sewed. 4s.

A NGLO-SAXON VERSION OF THE HOLY GOSPELS. A Edited from the original MISS. By Benjaurns Thorpe, F.S.A. Post 8vo, cloth. 8s. (original price $12 s$.)

\section{A NGLO-SAXON VERSION OF THE STORY OF APOLLO.}

A NIUS OF TYRE; - - upon which is founded the Play of Pericles, attributed to Shakespeare;--from a MS., with a Translation and Glossary. By BENJAMIN THoRpz. $12 \mathrm{mo}$, cloth. 4s. $6 d$. (original price 6s.)

A NALECTA ANGLO-SAXONICA.-A Selection in Prose and Verse, from A. Anglo-Sason Anthors of rarions ages, with a Glossary. By Bensamrs ThoRpe, F.S.A. A new edition, with correclions and improvements. Post 8vo, cloth. 8s. (original price 12s.)

DOPULAR TREATISES ON SCIENCE, written during the Middle Ages, in Anglr-Sason, Anglo-Norman, and English. Edited by THos. Wright, M.A. Sro, cloth, 3s.

Contents :-An Angu-Saxon Treatise on Astronomy of the Trsin Century, nowo first published from a MS. in the British Museum, with a Translation; Livre des Creatures, by Phillippe de Thaun, now first printed with a translation, (extremely valuable to Philologists, as being the earliest specimens of Anglo-Norman re.

maining, an! explanatory of all the symbotical signe in early sculpture and painting); the Bestiary of Phil. lippe de Thaun, ecith a transiation; Fragments on $\mathrm{Po}_{0}$ pular Science from the Wurly English Metrical Lives of the Saints, (the earliest piece of the kind in the English Language.)

FRAGMLENT OF FLFRIC'S ANGLO-SAXON GRAMMAR, AElfiric's Glossary, and a Poem on the Soul and Body of the XIIth Century, dis. eovered among the Archives of Worcester Cathedral, By Sir THosras PaunIPs, Bart. Fol., PRIVATELY PBINTED, sewed. $1 s .6 d$.

SKELTON'S (John, Poet Laureat to Henry VIIT) Poetical Works : the Bowge of N Court, Colin Clout, Why come ye not to Court? (his celebrated Satire on Wolsey), Phillip Sparrow, Elinour Rumming, \&c.; with Notes and Life. By tho Rev. A. Drce. 2 rols, 8vo, cloth. 14s. (original price £1. 12s.)

"'The power, the strangeness, the rolubility of his language, the audacity of his satire, and the perfcct originality of his manner, niade Skelton one of the most extraordinary writers of any age or country." - Southey.

"Skelton is a curious, able, and remarkable writer. with strong sense, a vein of humour, and some imagination; he had a wonderful command of the English language, and one who was stylcd, in lis turb, by an

great a scholar as erer lived (Erasmus), "the light and ornament of Britain.' $\mathrm{He}$ indulged very freely in his writings in censures on monks and Doninicans; and, moreoscr, had the hardiliood to reflect, in no very mild terms, on the manners and life of Cardinal Wolsey. We cannot help considering Skelton ag an ornament of his own time, and a benefactor to those who come after him." 
QEMI-SAXON.-The Departing Soul's Address to the Body, a Fragment of a Semi-Saxon Poem, discovered amoung the Archives of Worcester Cathedral, by Sir Thomas Phrumprs, Bart., with an English Translation by S. W. Sinazr. 8ro, only 100 PRIVATELY PRINTED. 2s.

DICTIONARY OF ARCHAIC AND PROVINCIAL WORDS, By JaMes ORCHARD HAlliwell, F.R.S., F.S.A., \&c. 2 vols, 8vo, containing upwards of 1000 pages, closely printed in double columns, cloth, $a$ new and cheaper edition. £1. $1 s$.

It contains ahove 50,000 words (embodying all the are not to befound in ordinary Dictionaries and books known scattered glossaries of the English language), of reference. Most of the principal Archaisms are ilforming a complete key for the reader of our old Poets, lustrated by examples selected from early inedited Dramatists, Theologians, and other authors, whose MSS. and rare books, and by far the greater portion works abound with allusions, of which explanations will be found to be original suthorities.

\section{GSSAYS ON THE LITERATURE, POPULAR SUPERSTI-} TIONS, and History of England in the Middle Ages. By Thovas Wrremt, M.A., F.R.S. 2 rols. post $8 \mathrm{ro}$, elegantly printed, cloth. $16 s$.

Contents.-Essay I. Anglo-Saron Poetry. II. AngloNorman Poetry. III. Chansons de Geste, or Historical Romances of the Middle Ages. IV. On Proverbs and Popular Sayings. V. On the Auglo-Latin Poets of the Twelfth Century. VI. Abelard and the Scholastic Philosoplyy. VII. On Dr. Grimm's German Mythology. VIII. On the National Fairy Mythology of England. IX. On the Popular Superstitions of Modern Greece, and their Connexion with the English. X. On Friar

Rush, and the Frolicsome Elves. XI. On Dunlop's History of Fiction. XII. On the History and trans. mission of Popular Stories. XIII. On the Poetry of History. XIV. Adventures of Hereward the Saxon. XV. The Story of Eustace the Monk. XVI. The History of Fulke Fitzwarine. XVII. On the Popular Cycle of Robin-Hood Ballads. XVIII. On the Conquest of Ireland by the Anglo-Normans. XIX. On Old English Political Songs. XX. On the Scottish Poet, Dunbar.

\section{FARLY HISTORY OF FREEMASONRY IN ENGLAND.}

Illustrated by an English Poem of the XIVth Century, with Notes. By J. O. Hatirwell, Post 8vo, Second Edition, with a facsimile of the original MSS. in the British Museum, cloth. 2s. $6 d$.

"The interest which the curious poem, of which this publication is chiefly composed, has excited, is proved by the fact of its having been translated into German, and of its having reached a second edition,

which is not common with such publications. Mr. Halliwell has carefully revised the new edition, and increased its utility by the addition of a complete and correct glossary." - Literary Gazette.

TORRENT OF PORTUGAL; an English Metrical Romance, now first pub1 lished, from an unique MS. of the XVth Century, preserved in the Chetham Library at Manchester. Edited by J. O. HAIJIWELL, \&c. Post 8vo, cloth, uniform with Ritson, Weber, and Ellis's publications. 5 s.

"This is a valuable and interesting addition to our list of early English metrical romances, and $8 n$ indispensable companion to the collections of Ritson, Weler, and Ellis."-Literary Gazette.

"A literary curiosity, and one both welcome and serviccable to the lover of black-lettered lore. Though the obsoleteness of the style may occasion sad stum-

bling to a modern reader, yet the class to which it rightly belongs will valne it accordingly; both because it is curious in its details, and possesses philological importance. To the general reader it presents one feature, riz., the reference to Wayland Smith, whom Sir W. Scott has invested with so much interest." Mretropolitan Mfagazine.

HARROWING OF HELL; a Miracle Play, written in the Reign of Edward II, now first published from the Original in the British Museum, with a Modern Reading, Introduction, and Notes. By JAMES OROMARD HaxirWELL, Esq., F.R.S., F.S.A., \&c. 8ro, sewed. $2 s$.

This curious piece is supposed to be the earliest specimen of dramstic composition in the English lan. guage; vide Hallam's Literature of Europe, Vol. I; Strutt's Manners and Customs, Vol. II; Warton's En.

glish Poetry; Sharon Turner's England; Collier's History of English Dramatic Poetry, Vol. II, p. 213. All these woriters refer to the Manuscript.

NUG E POETICA ; Select Pieces of Old English Popular Poetry, illustrating the Manners and Arts of the XVth Century. Edited by J. O. HALIIwELL. Post 8ro, only 100 copies printed, cloth. $5 s$.

Contents :-Colyn Blowbol's Testaneut; the Debate of the Carpenter's Tools; the Mcrchant and his Son; the Maid and the Magpie; Elegy on

Lobe, Henry VIIIth's Fool; Romance of Robert of Sicily; and five other curious pieces of the same kind.

A NECDOTA LITERARIA : a Collection of Short Poems in English, Latin,

and French, illustrative of the Literature and History of England in the XIIIth Century; and more especially of the Condition and Manners of the different Classes of Society. By T. WriaHT, M.A., F.S.A., \&c. 8vo, cloth, only 250 printed. $7 s .6 d$.

POPULAR ERRORS IN ENGLISH GRAMMAR, particularly in 1 Pronunciation, familiarly pointed out. By GEORGE JACrson. 12mo, Tirrm EDItIon, with a coloured frontispiece of the "Sedes Busbeiana." $6 d$. 
TARLY MYSTERIES, and other Latin Poems of theXIIth and XIIIth centuries. Edited, from original MSS. in the British Museum, and the Libraries of Oxford, Cambridge, Paris, and Vienna, by Thos. Wright, M.A., F.S.A. 8vo, bds. 4s. $6 d$.

"Besides the curious specimens of the dramatic style of Middle-Age Latinity, Mr. Wright has given two compositions in the Narrative Elegiac Verse (a favourite measture at that period), in the Comodia Babionis and the Geta of Vitalis Blesensis, which form a link of connection between the Classical and Middleage Literature; some rcmarkable Satyrical Rhymes

on the people of Norfolk, written by a Monk of Peterborough, and answered in the same style by John of St. Omer; and, lastly, some sprightly and often graceful songs from a MS. in the Arundel Collection, which afford a very farourable idea of the lyric poetry of our clerical forefather." -Gentleman's Mragazine.

RARA MATHEMATICA; or a Collection of Treatises on the Mathematics and

Subjects connected with them, from ancient inedited MSS. By J. O. HaIIIWELI. 8ro, Second Edition, cloth. 3s.

Contents:- Joharnis de Sacro-Bosco Tractacus de Arte Numerandi; Method used in England in the Fifteenth Century for taking the Altitude of a Steeple; Treatise on the Numeration of Algorism; Treatise on Glasses for Optical Purposes, by W. Bourne; Johannis Robyns de Cometis Commentaria; Two Tables showing the time of High Water at London Bridge, and the

Duration of Moonlight, from a MS. of the Thirteenth Century; on the Mensuration of Heights and Distances ; Alexandri de Villa Dei Carmen de Algorismo; Preface to a Calendar or Almanack for 1430, Johannis Norfolk in Artem progressionis summula; Notes on Early Almanacks, by the Editor, \&c. \&c.

PHILOLOGICAL PROOFS of the Original Unity and Recent Origin of the 1 Human Race, derived from a Comparison of the Languages of Europe, Asia, Africa, and America. By A. J. JoHNEs. 8vo, cloth. 6s. (original price 12s. 6d.)

Printed at the suggestion of Dr. Prichard, to whose works it will be found a useful supplement.

A MERICANISMS.-A Dictionary of Americanisms. A Glossary of Words and A. Phrases colloquially used in the UnitedStates. ByJ.R. BarTuETT. Thick 8vo, cloth. 12s. PHILOLOGICAL GRAMMAR, founded upon English, and framed from a comparison of more than Sixty Languages, being an Introduction to the Science of Grammar, and a help to Grammars of all Languages, especially English, Latin, and Greek. By the Rev. W. BARnes, B.D., author of the "Anglo-Saron Delectus," "Dorset Dialect," \&cc. Post 8vo, in the press.

\section{羽robintial 迥íalects of êngland.}

RIBLIOGRAPHICAL LIST of all the Works which have been published towards illustrating the Provincial Dialects of England. By JoHN Russell SMITH. Post 8vo. 18 .

"Very scrricuable to such as prosecute the study of our provincial dialects, or are collecting works on that curious subject. We very corlially recommend it to notice."-Metropolitan.

HALLIWELL'S HISTORICAL SKETCH OF THE PRO. VINCIAL DLALECTS OF ENGLATD. Illustrated by numerous Examples, (extracted from theIntroduction to the Dictionary of Archaic and Provincial Words.) 8vo. 2s. GIOSSARY OF PROVINCIAL AND LOCAL WORDS USED IN ENGLAND; by F. GROsE, F.S.A.; with which is now incorporated the SuPplement, by Saruel Peger, F.S.A. Post 8vo, cloth. 4s. $6 d$.

The utility of a Provincial Glossary to all persons de- would be entirely a work of supereregation. Grose sirous of understanding our ancient poets, is so uni- and Pegge are constantly referred to in Todd's "Johnversally acknowledged, that to enter into a proof of it son's Dictionary."

CORNWALL.-Specimens of Cornish Provincial Dialect, collected and arranged by UNCLE

JAN TRenNoODLE, with some Introductory Remarks and a Glossary by an Antiquarian Friend, also a Selection of Songs and other Pieces connected with Cornwall. Post

8vo. With curious portrait of Dolly Pentreath. Cloth. 4s.

CHESHIRE.-Attempt at a Glossary of some words used in Cheshire. By Roakn

WinBratraM, F.A.S., \&c. 12mo, bds. 2s.6d. (original price 5s.)

DEVONSHIRE.-A Devonshire Dialogue in Four Parts, (by Mrs. PALMren, sister to Sir Joshua Reynolds, ) with Glossary by the Rev. J. PmILIIPPs, of Membury, Deron. $12 \mathrm{mo}$, cloth. 2s. $6 d$.

DORSET.-Poems of Rural Life, in the Dorset Dialect, with a Disscrtation and Glossary.

By the Rev. Willinam Barnes, B.D. Second Edition, enlarged and corrected, royal $12 \mathrm{mo}$, cloth. $10 s$.

A fine poetic feeling is displayed through the various picces in this volume; according to some critics nothing has appeared equal to it since the time of

Burns; the "Gentleman's Magazine" for December, 1844, gave a review of the First Edition some pages in length. 
DURHAM.-A Glossary of Words used in Teesdale, in the County of Durham. Post $8 \mathrm{ro}$, with a Map of the District, cloth. 6 s.

"Contains about two thousand words ... It is believed the first and only collection of words and phrases peculiar to this district, and we hail it there. fore as a valuable contribution to the history of lan-

gusge and literature ... the anthor has evidently brought to bear an extensive personal acquaintance with the common language." - Darlington Times.

ESSEX.-John Noakes and Mary Styles : a Poem ; exhibiting some of the most striking lingual localisms peculiar to Essex; with a Glossary. By Chardes Clark, Esq., of Great Totham Hall, Essex. Post 8vo, cloth. $2 s$.

"The poem possesses considerable humour,-Tait's Magazine.

"A very pleasant trifle"-Literary Gaeetto.

"A very clcver production."-Essex Lit. Journah

"Full of rich humour."-Essex Mercury.

"Very droll."-Metropolitan.
“Exhibits the dialect of Essex perfectly."-Eclectic Reviero.

"Fuil of quaint wit and humour." - Gent.'s Mag., May, 1841 .

"A very clever and amusing piece of local description." - Archaologist.

KENT.-Dick and Sal, or Jack and Joan's Fair : a Doggrel Poem, in the Kentish Dialect. Third Edition. $12 \mathrm{mo}$. $6 d$.

LANCASHIRE.-Dialect of South Lancashire, or Tim Bobbin's Tummus and Meary ; revised and corrected, with his Rhymes, and AN ENLARGED GLOSSARY of Words and Phrases, chiefly used by the rural population of the manufacturing Districts of South Lancashire. By SAMUEL BAMFORD. 12mo, eloth. 3s. $6 d$.

LEICESTERSHIRE Words, Phrases, and Proverbs. By A. B. Evars, D.D., Head Master of Market-Bosworth Grammar School. 12mo, eloth. 5s.

NORTHAMPTONSHIRE.-The Dialect and Folk-Lore of Northamptonshire : a Glossary of Northamptonshire Provincialisms, Collection of Fairy Legends, Popular Superstitions, Ancient Customs, Proverbs, \&c. By Thomas Sxernberg. 12mo, cloth. 5s.

SUSSEX.-A Glossary of the Provincialisms of the County of Sussex. By W. DURrart CoOper, F.S.A. Post 8vo, Second Edition, enlarged, cloth. 5s.

SUSSEX.-Jan Cladpole's Trip to 'Merricur in Search for Dollar Trees, and how he got rich enough to beg his way home! Written in Sussex Doggerel. 12mo. 6d.

WESTMORELAND AND CUMBERLAND.-Dialogues, Poems, Songs, and Ballads, by various Writers, in the Westmoreland and Cumberland Dialects, now first collected; to which is added, a copious Glossary of Words peculiar to those Countics. Post 8ro, pp. 408, cloth. 9s.

This collection comprises, in the Westmoreland Dias lect, Mrs. Ann Wheeler's Four Familiar Dialogues, with Poems, \&c.; and in the Cumberland Dialect, 1. Poens and Pastorals by the Rev. Josiah Ralph; II. Pastorals, \&cc., by Ewan Clark; III. Letters from Dublin, by a young Borrowdale Shepherd, by Isaac Ritson; IV. Poems by John Stagg; V. Poems by Mark Lonsdale; VI. Ballads and Songs by Robert Anderson,

the Cumbrian Bard (including some now first printed); VII. Songs by Miss Blamire and Miss Gilpin; VIII. Songs by John Rayson; IX. An Extensive Glossary of Westmoreland and Cumberland Words.

All the poetical quotations in "Mr. and Mrs. Sandboy's Visit to the Great Exhibition," are to be found in this volume.

WILTSHIRE.-A Glossary of Provincial Words and Phrases in use in Wiltshire, showing their Derivation in numerous instances trom the Language of the Anglo-Saxons. By John Yonge Akerman, Esq., F.S.A. 12mo, cloth. 3s.

YORKSHIRE.-The Yorkshire Dialect, exemplified in various Dialogues, Tales, and Songs, applicable to the County; with a Glossary. Post 8ro. $1 s$.

"A shilling hook worth its money; most of the pieces of coniposition are not only harmless, but good and pretty. The eclogue on the death of ' $A$ wd Daisy,' an outworn borse, is an ontpouring of some of the best

feelings of the rustic mind; and the addresses to Riches and Poverty have much of the freedom and spirit of Burns." - Gentleman's Magazine, May

KORKSHIRE.-The Hallamshire (district of Sheffield) Glossary. By the Rev. JoskPH HUNTER, author of the History of "Hallamshire," "South Yorkshire," \&c. Post 8vo, cloth. 4s. (original price 8 s.)

YORKSHIRE.-Bairnsla Foak's Annual, on onny body els as beside fort 'y years 1842 and 1843, be TOM TREDDLEHOYLE; to which is added the Barnsley and Village Record, or the Book of Facts and Fancies, by NED NUT. $12 \mathrm{mo}, \mathrm{pp} .100 .1 \mathrm{~s}$.

YORKSHIRE.-Sum Thowts abaght Ben Bunt's Weddin;-Tom Treddlehoyle's Thowts abaght Nan Bunt's Chresmas 'Tea Party, \&c. Two Pieces, (Barnsley Dialect.) 12mo. $6 d$. 


\section{Artbarologe.}

A RCH EOLOGICAL INDEX to Remains of Antiquity of the Celtic, RomanoA British, and Anglo-Saxon Periods, by JoHr YoNGr AKERMan, Fellow and Secretary of the Society of Antiquaries. 8vo, illustrated with numerous engravings, comprising upvards of five hundred objects, cloth. 15 s.

This work, though intended as an introduction and a guide to the study of our early antiquities, will, it is hoped, also prove of gervice as a book of reference to the practised Archrologist. The contents are as follows:

Part I. Celtic Period. - Tumuli, or Barrows and Cairns-Cromelechs-Sepulchral Caves-Rocking Stones-Stone Circles, \&c. \&c.-Objects discovered in Celtic Sepulchres - Urns-Beads-Weapons-Implements, \&c.

Part II. Romano-British Period.-Tumuli of the Romano-British Periol-Burial places of the Romans - Pavemcnts - Camps - Villas - Sepulchral Monuments-Sepulchral Inscriptions-Dedicatory Inscriptions-Commemorative Inscriptions - Altars Urns - Glass Vessels - Fibulæ - Armillæ - Coins Coin-moulds, \&c. \&c.

Part III. ANglo-Saxon Prriod.-Tumnli-Detailed List of Objects discovered in Anglo-Saxon Bar-

rows-Urns-Swards-Spears-Knives-Umbones of Shields - Buckles - Fibulæ - Bullæ - Hair Pins Beads, \&c. \&c. \&c. \&c.

The ITINERARY of ANToninus (as far as relates to Britain). The Geographical Tables of PToLzMy, the NotTTIA, and the ITINRRABY of RICHARD of CiRENCEsTER, together with a classificd Index of the con. tents of the ARCB sologia (Vols. i to xxxi) are given in an Appendix.

"One of the first wants of an incipient Antiquary is the facility of comparison, and here it is furnished him at one glance. The plates, indeed, form the most valuable part of the book, both by their number and the judicions selection of types and examples which they contain. It is a book which we can, on this account, safely and warmly recommend to all who are interested in the antiquities of their native land." Literary Gazette.

REMAINS OF PAGAN SAXONDOM, principally from Tumuli in En. gland, drawn from the originals. Described and Illustrated by J. Y. AKERMaN, F.S.A. 4to, Publisiling iv Parts at 2s. $6 d$. each.

\section{DIRECTIONS FOR THE PRESERVATION OF ENGLISH}

ANTIQUITIES, especially those of the Three First Periods; or Hints for the Inexperienced. By J. Y. AKERMAN.

A small tract for distribution, at one shilling per dozen, useful to give to excarators, ploughmen, \&c., who are apt to destroy articles they find if not of precions metal.

A RCH EOLOGICAL ASSOCIATION JOURNAL. 8vo, vols. 2, 3, 4, A. 5, 6. £1. 1s. each; and vol. 7 just completed, with an extra quantity of letter-prese and plates. $£ 1.11 s .6 d$.

J. R. Smith haring been appointed Publisher to the Archrological Association, their Publications may be lad of him in future.

BRITISH ARCHFOLOGICAL ASSOCIATION.-A Report of the

Procecdings of the British Archæological Association, at the Worcester Session. August, 1848. By A.J. Dunkiv. Thic5 8vo, with engravings, cloth. 11.18 .

VERBATIM REPORT of the Proceedings at a Special General Meeting of the

British Archæological Association, held at the Theatre of the Western Literary Institution, 5th Marck, 1845, T. J. Pettigrew, Esq., in the Chair. With an Introduction by Thomes Wright. $8 \mathrm{vo}$, seved. $1 s .6 d$.

A succinct history of the division between the Archmological Association and Institute.

A NTIQUARIAN ETCHING CLUB.-The Publications of the AntiA quarian Etching Club, for the year 1849, consisting of 54 plates of Churches, Fonts, Castles, and other Antiquarian objects. 4to, boards. $8 s$.

for the year 1850 , containing 66 plates. 4to, bds. 10 s.

for the year 1851, containing 70 plates. 4to, bds. 10 s.

VESTIGES OF THE ANTIQUITIES OF DERBYSHIRE, and the Sepulchral Usages of its Inhabitants, from the most Remote Ages to the Reformation. By Thouras BaTrmax, Esq., of Yolgrave, Derbyshire. In one handsome vol. 8ro, with numerous woodcuts of Tumuli and their contents, Crosses, Tombs, \&ic., cloth. 15s.

1848

A N ESSAY ON THE ROMAN VILLAS of the Augustan Age, their 1 Architectural Disposition and Enrichmenta, and on the remains of Roman Domes tic Edifices discorered in Great Britain. By Tuomas MovLz. 8ro, 2 platos, cloth. 4s. $6 d$. (original price $8 \mathrm{~s}$.) 
CAMBRIDGE.-Historia Collegii Jesu Cantabrigiensis a J. SHerMarro, olim pres. ejusdem Collegii. Edita J. O. HALtrweLl. 8vo, cloth. 2s.

FISTORY AND ANTIQUITIES of the County of Hereford. By the F1. Rev. Jom Duncumb. 2 vols, 4to, portraits and plates, bds. £1. 4s. (original price £5. 5s.)

HELPS TO HEREFORD HISTORY, Civil and Legendary, in an Ancient Account of the Ancient-Cordwainers ${ }^{3}$ Company of the City, the Mordiford Dragon, and other Subjects, By J. D. DEvLIN. 12mo, cloth (a curious volume). 3s.6d.

"A series of very clever papers."-Spectator.

"A bitle work full of Antiquarian information, presented in a pleasing and popular form."-Nonconfurmist. HISTORY OF PORTSMOUTH, PORTSEA, LANDPORT, sbd. $4 s$.

NOTES ON THE CHURCHES in the Counties of KENT, SUSSEX, and

SURREY, mentioned in Domesday Book, and those of more recent date, with some Account of the Sepulchral Memorials and other Antiquities. By the Rev. ArTuUB HUSSEX. Thick 8ro, FINE PLATES, cloth. 18 s.

KENTISH CUSTOMS.-Consuetudines Kanciæ. A History of GAVELEIND, I and other Remarkable Customs, in the County of Krnt. By CHarLes SANdys, Esq., F.S.A. (Cantianus). Illustrated with facimilies, a very handsome volume, cloth. 15s. HISTORY AND ANTIQUITIES OF RICHBOROUGH, RECULVER, AND LYMNE, in Kent. By C. R. RоACH Sмiтн, Esq., F.S.A., Small 4to, with many engravings on roood and copper, by F. W. FAIRHOLT, cloth. £1. 1s.

"No antiquarian volume could display a trio of here represented-Roach Smith, the ardent explorer; names more zealous, successful, and intelligent, on Fairholt, the excellent illustrator; and Rolre, the the subject of Romano-British remains, than the three indefatigable collector."-Literary Gazette.

HISTORY AND ANTIQUITIES OF DARTFORD, in Kent with incidental Notices of Places in its Neighbourhood. By J. Dovkir, Author of the "History of the Hundreds of Bullington and Ploughley, in Oxfordshire;" "History of Bicester ;" "History of Bromley," \&c. 8vo, 17 plates, cloth. Only 150 printed. 218.

HISTORY OF THE TOWN OF GKAVTSEND, in Kent, and of the Port of Iondon. By R. P. CRUDEN, late Mayor of Gravesend. Royal 8vo, 37 fine plates and woodcuts, a very handsome volume, cloth. 10s. (original price \&1. 8s.)

A CCOUNT OF THE ROMAN AND OTHER ANTIQUITIES A discorered at Springhead, near Gravesend, Kent. By A. J. DunkIN. 8vo, plates, (only 100 printed, ) cloth. 6s. $6 d$.

HISTORY OF ROMNEY MARSH, in Kent, from the time of the Romans to 1833, with a Dissertation on the original Site of the Ancient Anderida. By W. Hownow $\Delta$, Esq., author of the "History of Rye." 8vo, with Maps and plates, cloth. 12s. CRITICAL DISSERTATION on Professor Willis's "Architectural History of Canterbury Cathedral." By C. SANDYs, of Canterbury. 8vo. 2s.6d.

"Written in no quarrelsome or captious spirit; the highest compliment is paid to Professor Willis, where it is due. But the author has made out a clear case, in some very important instances, of inaccuracies that have led the learned Professor into the construction of

serious errors throughout. It may be considered as an indispensable companion to his volume, containing a great deal of extra information of a very curious kind."-Art-Union.

FOLKESTONE FIERY SERPENT, together with the Humours of the Dovor Maror; being an Ancient Ballad, full of Mystery and pleasant Conceit, now first collected and printed from the various MS. copies in possession of the in. habitants of the South-east coast of Kent; with Notes. $12 \mathrm{mo} .1 \mathrm{~s}$.

HAND-BOOK OF LEICESTER. By JAues THompson. 12mo, Second Edition, woodcuts, bds. 28.

HISTORY AND ANTIQUITIES OF THE ISLE OF AXHOLME, in Lincolnshire. By the Venerable ARchonscon STONEnodse. Thick 4to, BLsm PLATES 18s. (original price £3. 3s.) 
HISTORY AND ANTIQUITIES OF GAINSBOROUGH, in Lin. H eolnshire. By AdaM STARE. Thick 8vo, SEcond Edition, GREATLY kNLARGED, cloth. 9s. (original price £1. 1s.)-LARGE PAPER, royal 8vo, cloth. $14 s$.

HISTORY AND ANTIQUITIES OF THE TOWN OF LAN. F CASTER. Compiled from Authentic Sources. By the Rev. RobrRT Simpson. 8vo, cloth. 8s.

MEMORIALS OF THE VICARAGE HOUSE AND GARDEN IV OF ALL SAINTS, King's-Lynn; with a List of the Vicars, and a quantity of other useful information. By J. N. CHADWICK. 8vo, four engravings, sewed. 2s. $6 d$.

DESCRIPTIVE ACCOUNT OF THE RUINS OF LIVEDEN, near Oundle, Northamptonshire; with Historical Notices of the Family of Tresham, and its eonnection with the Gunpowder Plot. By Troarss Bexr. Four plates and Tresham Pedigree. 4to. 6s.

REPRINTS OF RARE TRACTS, and Imprints of Ancient Manuscripts, \&c., 1 chiefly illustrative of the History and Biography of the Northern Counties. BRAU. TIRULIY PRINTED on thick paper, with facsimile titles, initial letters in colours, \&c., FORMING 7 vols., post 8vo, COMPLETE, with general titles and contents, bds. £5. 5 s. (original price £7. 7s.)

This Collection comprises no less than 62 Tracts of the most interesting kind, edited by M. A. Richardson, assisted by several antiquaries in the northern counties. Only 100 copies of the Collection were printed, which are all sold by the printer.

RIVER TYNE.-Plea and Defence of the Mayor and Burgesses of Newcastle against the Malevolent accusations of Gardiner, (author of "England's Grievance on the (coal Trade,") 1653; with Appendix of Unpublished Documents respecting the River Tyne. By M. A. Richardson. 8ro, (only 150 printed.) $2 s$.

TOPOGRAPHICAL MEMORANDUMS for the County of Osford. By 1 Sir Gregory PAge TuRner, Bart. 8vo, bds. 2s.

NOTICES OF THE HISTORY AND ANTIQUITIES OF 1 ISLIP, Oxon. By J. O. HALLIWELL. 8vo, (only 50 printed,) sewed. 1 s.

HISTORY OF BANBURY, in Oxfordshire; including Copious Historical and 11 Antiquarian Notices of the Neighbourhood. By ALFred BeEsLex. Thick 8vo 684 closely printed pages, with 60 woodcuts, engraved in the first style of art, by 0 . Jewett, of Oxford. 14s. (original price £1. 5s.)

"The neighbourhood of Banbury is equally rich in British, Roman, Saxon, Norman, and English Antiquitics, of all which Mr. Beesley has given regularly cleared accounts. Banbury holds an important place in the history of the Parliamentary War of the Seventeenth Century, and was the scene of the great Battle of Edgehill, and of the important figlit of Cropredy Bridge. Relating to the events of that period, the

anthor has collected a great body of local information of the most interesting kind. By no means the lcast valuable part of Mr. Beesley's work, is his acconnt of the numerous interesting early churches, which characterize the Banbury district." - The Archaologist.

Odd Parts to complete copies, 1s. 6d. instead of 2s. $6 d$.

HISTORY OF WITNEY, with Notices of the Neighbouring Parishes and H Hamlets in Oxfordshire. By the Rev. Dr. GiLes, formerly Fellow of C. C., Oxford. 8vo, plates, cloth, (only 150 printed.) $6 s$.

HISTORY OF THE PARISH AND TOWN OF BAMPTON, Dr. Gines. 8ro, plates, SECOND Edition, cloth. 7s. $6 d$.

FAUCONBERGE MEMORIAL.-An Account of Henry Fauconberge, LL.D., of Beccles, in Suffolk, and of the endowment provided by his will to encourage Learning and the Instruction of Youth; with Notes and Incidental Biographical Sketches. By S. W. RIX. Pot 4to, very nicely got up, vith 30 engravings of Old Houses, Seals, Autographs, Arms, \&c., bds. 5s.-LARGE PAPER, 7s. 6d. (VERX FEW COPIES PRINTED.)

Contents.-Fauconberges of Olden Time. II. Fan- Memoir of Robert Sparrow, Esq. Memoir of Dr. Joseph conberge of Beccles. III. Fanconberge Endowment.

IV. Fauconberge and Leman. V. Appendix, Pedigrees,

Arnold (by Dawson I'urner, of Yarmonth), Particulars of the Faueonberge Trust Estate, \&c. \&c.

SUSSEX ARCHÆOLOGICAL COLLECTIONS, illustrating the History and Antiquities of the County, published by the Sussex Archæologieal Society. 8vo, plates and woodcuts, cloth. Vol. I, 10s.; Vol. II, 15s.; Vol. III, 10s.; Vol, IV, 14s.; Vol. V, 14s. 
SUSSEX GARLAND; a Collection of Ballads, Sonnets, Tales, Elegies, Songs, Epitaphs, \&c., illustrative of the County Sussex, with Notices, Historical, Biographical and Descriptive. By JaMes TAYLot. Post 8vo, Engravings, cloth. 12s.

SUSSEX MARTYRS: their Examinations and Cruel Burnings in the time of Queen Mary; comprising the interesting Personal Narrative of Richard Woodman, extracted from "Foxe's Monuments;" with Notes. By M. A. Lower, M.A. 12mo, sewed. 1s.

CHURCHES OF SUSSEX, drawn by R. H. NIBEs, with Descriptions. 84 plates, 4to, a handsome volume, cloth. $£ 2.2 s$.

TISTORY AND ANTIQUITIES OF THE ANCIENT PORT AND TOWN OF RYE, in Sussex, compiled from Original Documents. By WiLliar Hollowat, Esq. Thick 8vo, (ONIY 200 PRINTED, cloth. £1. 1s.

HISTORY OF WINCHELSTA, in Sussez. By W. Durrant Coorer, F.S.A. IL 8vo. fine plates and woodents. 7s. $6 d$.

CHRONICLE OF BATTEL ABBEY, in Sussex; originally compiled in Latin by a Monk of the Establishment, and now frrst translated, with Notes, and an Abstract of the subsequent History of the Abbey. By MARI ANTONx Lower, M.A. 8ro, with illustrations, cloth. 98 .

"It will be fonnd to contain a real and living picture of the manners and customs, the modes of thought and speech prevalent in the times of which it is tie record. Mr. Lower has well discliarged his office of translator and editor."-Guardian.

"In no respect less interesting than Jocelin de Brakelond's famous Chronicle of Bury St. Edmund's Abbey."-Lit. Gaz.

"Mr. Lower has added to the completeness of the book by a summary sketch of the History of the Abley, and its succession of Ablots from the time when the Chronicle terminates to the period of the dissolution. Various intelligent notes, as well as the general style of the translation, are higlly creditable to his care and skill as editor."-Gentleman's Magazine.

DESCRIPTIVE CATALOGUE OF THE ORIGINAL CHAR-

TERS, GRANTS, DONATIONS, \&c., constituting tle Muniments of Battel Abbey, also the Papers of the Montagus, Sidneys, and Websters, embodying many highly interesting and valuable Records of Lands in Sussex, Kent, and Essex, with Preliminary Memoranda of the Abbey of Battel, and Historical Particulars of the Abbots. 8vo, 234. PAGES, cloth. ONLX 1s. $6 d$.

TAND-BOOK TO LEWES, in Sussex, Historical and Descriptire; with 1 Notices of the Recent Discoveries at the Priory. By Mark ANronx Lower. 12mo, many engravings, cloth. 1s. $6 d$.

CHRONICLES OF PEVENSEY, in Sussex. By M. A. Lower, 12mo, woodcuts. 1s.

HURSTMONCEUX CASTLE AND ITS LORDS. By the Rev. $\mathrm{I}$. Venables. (Reprinted foom Vol. IV of the Sussex Archæological Collections.) 8ro, many engravings, sewed, $3 s$.; cloth 4 s.

NOTES ON THE ANTIQUITIES OF TREVES, MAYENCE, WEISBADEN, NEIDERBIEBER, BONN, and COLOGNE. By CHARLFS Rosch Smitr, F.S.A. (Reprinted from Vol. II of the "Collectanea Antiqua.") 8ro, with many engravings. 78. 6 d.

\footnotetext{
A NNALS AND LEGENDS OF CALAIS; with Sketches of Emigro Notabilities, and Memoir of Lady Hamiton. By RoBfrt BeLI CALTON, author of "Rambles in Sweden and Gottland," \&c. \&c. Post 8ro, with frontispiece and vignette, clath. 5s.
}

Principal Contents:- History of the Siege by Edward IIt. in 1346-7, with a Roll of the Commanders in the British Museum; The Allotment of Lands and Houses to Edward's Barons; Calais as an English Bame; Henry VIIIth's Court there; Cardinal Wolsey and his Expenses; the English Pale, with the Names of Roads, Farmsteads, and Villages in the English Era; the Siege of Therouenne and Tournai; the Pier of Calais; Pros and Cons of the Place; the Hotel Dessin; Sterne's Chamber; Churches of Notre Dame and St. Nicliolas; the Hotel de Ville; Ancient Staple Iiall; The Chateau and Murder of the Duke of Glou-

cester; the Courgain; the Field of the Cloth of Gold; Notice of the Town and Castle of Guisnes, and its surprise by John de Lancaster; the town and Seigneurie of Ardres; the Sands and Duclling; Villages and Chatean of Sangatte, Coulonge, Mark, Eschalles and Hammes; Review of the English Occupation of Calais; its Re-capture by the Dnke de Guise; the lower Town and its Lace Trade; our Commercial Relations with France; Emigré Notabilities; Charles and Harry Tufton, Capt. Dormer and Edith Jacquemont, Beau Brummell, Jemmy Urquhart and his friend Fauntleroy, "Nimrod," Berkeley Craven, Mytton, Duchess of Kingston; a new Mcmoir of Lady Hamulton, \&c. 
MONT SAINT-MICHEL.-Histoire et Description de Mont St. Michel en 11 Normandie, texte, par Hericher, dessins par Bouet publés par Bourdon. Folio, 150 pp., and 13 beautiful plates, executed in tinted lithography, leather back, uncut. £2. $2 s_{\text {. }}$ A handsome volume, interesting to the Architect and Archæologist.

GENOA; with Remarks on the Climate, and its Influence upon Invalids. Henry Jones Bunnett, M.D. 12mo, cloth. 4s.

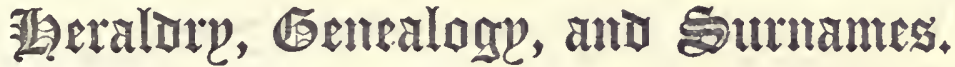

CURIOSITIES OF HERALDRY, with Illustrations from old English

Writers. By Mark Antony Lower, M.A., Author of "Essays on English Surnames;" with illuminated Title-page, and numerous engravings from designs by the Author. 8ro, cloth. 14s.

"The present volume is truly a worthy sequel (to the 'SURNAMES') in the same curious and antiquarian line, blending with remarkable facts and intelligence, such a fund of smusing anecdote and lliustration, that the reader is almost surprised to find that he has learncd so much, whilst he appearcd to be pursuing mere entertainment. 'The text is so pleasing that we scarcely dream of its sterling value; and it seems as if, in unison with the woodcuts, which so cleverly explain its points and adorn its various topics, the whole design were intended for a relaxation from study, rather

than an ample exposition of an extraordinary and nniversal custom, which produced the most important effect upon the minds and habits of mankind." Literary Gazelte.

"Mr. Lower's work is both curious and instructive, while the manner of its trcatment is so inviting and popular, that the subject to which it refers, which many liave hitherto had too good reason to consider meagre and unprofitable, assumes, under the hands of the writer, the novelty of fiction with the importance of historical truth." - Atheneum.

\section{PEDIGREES OF THE NOBILITY AND GENTRY OF HERT-}

FORDSHIRE. By WILIIAMr BERRY, late, and for fifteen years, Registering Clerk in the College of Arms, author of the "Encyclopædia Heraldica," \&c. \&c. Folio, (only 125 printed.) £1. 5s. (original price £3. 10s.)

\section{GENEALOGICAL AND HERALDIC HISTORY OF THE \\ EXTINCT AND DORMANT BARONETCIES of England, Ireland, and Scot-} Iand. By J. Burke, Esq. Mfedium 8vo, SeCond Editron, 638 closely printed pages, in donble columns, with about 1000 arms engraved on wood, fine portrait of JAMES I, and illuminated title-page, cloth. 10s. (original price £1. 8 s.)

This work engaged the attention of the author for several years, comprises nearly a thousand families, many of them amongst the most ancient and cminent in the kingdom, each carried down to its represent-

ative or representatives still existing, with elaborate and minute details of the alliauces, achievements, and fortunes; geueration after generation, from the earliest to the latest period.

FNGLISH SURNAMES. An Essay on Family Nomenclature, Historical, Etymological, and Humorous; with several illustrative Appendices. By MARK ANTONy LOWER, M.A. 2 vols., post 8ro, THIRD EDITION, ENLABGED, woodcuts, cloth. $12 s$.

This new and mnch improred Edition, besides a great enlargement of the Chapters, containcd in the previous editions, comprises several that are entirely new, together with Notes on Scottish, Irish, and Norman Surnames. The "Additional Prolusions," besides the articles on Rebuses, Allusive Arms, and the Roll of Battel Abbey, contain dissertations on Inn signs, and Remarks on Christian Namcs; with a copious INDEX of many thousand Names. These features render "English Surnames" rather a new work than a new edition.

"A curious, ingenions, and amusing book. Mr. Lower brings considerable knowledge to bear, both in his general history of the use of Surnamcs in England,

and in his chapters on the different ways in which particular classes of names have originated from names of places. occupations, dignities, oftices, personal and mental qualities, \&c."-Spectator.

"Mr. Lower has gone to work in the true spirit of antiquarian discovery, and a most amnsing and instructive book he has produced."-Brighton Herald.

"A curions work, and got np, moreover, with that commendable attention to paper and typography which is certain to make a book "tak the eye." . . . . Mr. Lower has been ' at a great feast of isnguages, and has stolcn more than the 'scraps.' He loth instructs and entertains." - John Bull.

TNDEX TO THE PEDIGREES AND ARMS contained in the Heralds' 1 Visitations and other Genealogical Manuscripts in the British Museum. By R. SrMs, of the Manuscript Department. 8vo, closely printed in double columns, cloth. 15 s.

An indispensable work to those engaged in Genealogical and Topograplical pursuits, affording a ready clue to the Pedigrecs and Arms of nearly 40,000 of the Gentry of England, thcir Resılences, \&c. (distinguishing the different families of the same nanje in any connty), as recorded by the Heralds in their Visita. tions between the years 1528 to 1686 .

"This work will be very acceptable to all who have occasion to examine the USS. alluded to, whether for study, amusement, or professionally; those who have experienced the toilsome labour of searching, with the lielp only of the existing rery imperfect Catalogues, can appreciate the perseverance and accurate examination necessary to produce such an Index as thint just published by Mr. Sims; it will be an induspensable companion to the Library table of all students in genealogical pursuits, snd those engaged in tlie History of Landed Property." - Journal of Archea logical Inslitute for Sepiersber, 18.19. 
ROLL OF ARMS OH THE REIGN OF KING EDWARD II. 1. Edited by Sir HARRIS Nrcolass; to which is added, an "Ordinary" of the Arms mentioned by Jos. Gwilt, Esq. 8vo, cloth. 4s. 6d. (original price 10s. 6d.) On LARGE PaPER, 4to, cloth, 10s. (original price 21s.)

CALENDAR OF KNIGHTS; containing Lists of Knights Bachelors, British Knights of the Garter, Thistle, Bath, St. Patrick, the Guelphic and Ionian Orders, from 1760 to 1828. By F. Townsend, Windsor Herald. Post 8vo, cloth. 3s. (original price 9s.)

A very useful volume for Genealogieal and Biographical purposes.

THE SLOGANS OR WAR-CRIES OF THE NORTH OF 1 ENGLAND, by M. AISLABIE DENHAM; with an Introduction on their Supposed Origin, by JoHN Fenwick; and Observations on Martial Mottoes, by W. HyLToN LoNGSTAFFE. Post 8vo, elegantly printed, with Coats of Arms, Seals, \&c., sewed. 6s. 6d.

GENEALOGISTS' MANUAL; or Guide to the various Public Records,

Registers, Wills, Printed Books, and other Documents necessary to be consulted in tracing a Pedigree. With particulars of the days and hours each Office or Registry is available, the charges made, the objects and dates of their Records, \&c. \&c.; the whole carefully compiled from Returns made expressly for this work; together with other Tables and Calendars useful to the Antiquary, Topographer, and Conveyancer. By Matrewew Cooke. Thick $12 \mathrm{mo}$, cloth. 6s. (nearly ready.)

\section{Jine Arts.}

DLAYING CARDS.-Facts and Speculations on the History of Playing Cards in Europe. By W. A. CHatro, author of the "History of Wood Engraving," with Illustrations by J. JACKsoN. 8vo, profusely illustrated with engravings, both plain and coloured, cloth. $£ 1.1$ s.

"The inquiry into the origin and signification of the suits and their marks, and the leraldic, thcological, and political emblems picturcd from time to time, in their changes, opens a new field of antiquarian interest; and the perseverance with which Mr. Chatto has explored it leaves little to be gleaned by his successors. The plates with which the volume is enriched add considerably to its value in this point of view. It is not to be denied that, take it altogether, it contains mere matter than has ever before becn collected in one view upon the same subject. In spite of its faults,

it is exccedingly amusing; and the most critical reader eannot fail to be entertained by the variety of curious outlying learning Mr. Chatto has somehow contrived to draw into the investigations."-Atlas.

"Indeed the entire production deserves our warmest approbation." - Lit. Gaz.

"A perfect fund of antiquarian research, and most interesting eveu to persons who never play at cards." -Tait's Mag.

"A curious, entertaining and really learned book." -Rambler.

HOLBEIN'S DANCE OF DEATH, with an Historical and Literary Introduction, by an Antiquary. Square post 8vo, with 53 Engravings, BEING TIIE MOST ACCURATE COPIES EVER EXECUTED OF THESE GEMS OF ART, and a frontispiece of an ancient bedstead at Aix-la-Chapelle, with a Dance of Death carved on it, engraved by Fairholt, cloth. $9 s$.

"The designs are executed with a spirit and fidelity quite extraordinary.--They are indeed most truthful." -dtheneum.

"Ces 53 Planches de Schlotthauer sont d'une ex. quise perfection-Langlois, Essai sur les Dances des Morts, 1852.

CATALOGUE OF THE PRINTS which have been Engraved after Martin Heemskerck. By T. KERRICH, Librarian to the University of Cambridge. $8 \mathrm{vo}$, portrait, bds. $3 s$. $6 d$.

CATALOGUE OF PICTURES, composed chiefly by the most admired Masters of the Roman, Florentine, Parman, Bolognese, Venetian, Flemish, and French Schools; with Descriptions and Critical Remarks. By ROBERT FoduIs. 3 vols. 12mo, cloth. 5s.

MEMOIRS OF PAINTING, with a Chronological History of the Importation 1 of Pictures by the Great Masters into England since the French Revolution. By W. BUCHANAN. 2 vols. $8 \mathrm{vo}, b d s ., 7 s .6 d$. (original price £1. $6 s$.)

HISTORY OF THE ORIGIN AND ESTABLISHMENT OF 1 GOTHIC ARCHITECTURE, and an Inquiry into the mode of Painting upon and Staining Glass, as practised in the Ecclesiastical Structures of the Middle Ages. By J. S. HAWIINs, F.S.A. Royal 8vo, 11 plates, bds. 4s. (original price 12s.) 


\section{羽opular 羽otru, Tales, and Superstitín.}

THE NURSERY RHYMES OF ENGLAND, collocted chieny from 1 Oral Tradition. Edited by J. O. Halliwest. The Foorth Edrtion, enlarged, with 38 Designs, by W. B. ScorT, Director of the School of Design, Newcastle-on-Tyne. $12 \mathrm{mo}$, illuminated cloth, gilt leaves. 4s. $6 d$.

"Illustrations! and here they are; clever pictures, which the three-year olds nnderstand hefore their A, B, C, and which the fifty-three-year olds like almost as well as the threes."-Literary Gazette.

"We are pursuaded that the very rudest of these jingles, tales, and rlymes, possess a strong imagination nourishing power; and that in infancy and early child-

hood a sprinkling of ancient nursery lore is worth whole cartloads of the wise saws and modern instances which are now as duly and carefully concocted by experienced littératenrs, into instructive tales for the spelling public, as are works of entertainmment for the reading public. The work is wortly of the attention of the popular antiquary."-Tait's Mag.

DOPULAR RHYMES AND NURSERY TALES, with Historical
Elucidations. By J. O. HALLIwELI. 12mo, cloth. 4s. 6d.
This rery interesting volnme on the Traditional Proverb Rhymes, Places, and Families, Superstition
Literature of England, is divided into Nursery Anti- Rhymes, Custom Rhymes and Nursery Songs; a large
quities, Fireside Ninrsery Staries, Game Rhymes, number are here printed for the first time. It may be
Alphabet Rhymes, Riddle Rhymes, Nature Songs, considered a aequel to the preceding article.
quities, Fireside Ninrsery Stories, Game Rhymes, OLD SONGS AND BALLADS. $\rightarrow$ A Little Book of Songs and Ballads, gathered from Ancient Music Books, MS. and Printed, by E. F. RIMBaUdT, LL.D., F.S.A., \&c., elegantly printed in post 8vo, pp. 240, half morocco. 6 s.

"Dr. Rimbault has been at some pains to collect the words of the Songs which used to delight tho Rnstics of former times."-Atlas.

ROBIN HOOD.-The Robin Hood Garlands and Ballads, with the Tale of "The R Little Geste," a Collection of all the Poems, Songs, and Ballads relating to this celebrated Yeoman; to which is prefixed his History, from Documents hitherto unrevised. By J. M. GUTCH, F.S.A. 2 vols. 8 ro, with numerous fine woodcuts, \&c., by Fairholt, extra cloth. \&1. 1s. (original price £1. 10s.)

Two very handsome volumes, fit for the drawing-room table.

BALLAD ROMANCES. By R. H. HoRNE, Esq., Author of "Orion," \&ce B $12 \mathrm{mo}$, pp. 248, cloth. 3s. (original price 6s. 6d.)

Containing the Nohle Heart, a Bohemian Legend; the Monk of Swineshead Abhey, a ballad Chronicle of the death of King John; the three Knights of Camelott, a Fairy Tale; The Ballad of Delora, or the Passion of Andrea Como; Bcdd Gelert, a Welsh Iegend; Ben Capstan, a Ballad of the Night Watch; the Elfo of the Woodlands, a Child's Story.

"Pure fancy of the most abundant and picturesque

description. Mr. Home ahould write us more Fairy Tales; we know none to eqnal him aince the days of Drayton and Herrick."-Ewaminer.

"The opening poem in this volume is a fine one, it is entitled the 'Noble Heart,' and not only in title but in treatment well imitates the style of Beaumont and Fletcher." - Athenaum.

SIR HUGH OF LINCOLN : or an Examination of a curious Tradition respecting the JEWS, with a Notice of the Popular Poetry connected with it. By the Rev. A. HUME, LL.D. 8ro. $2 s$.

FSSAY ON THE ARCHAOLOGY OF OUR POPULAR L PHRASES AND NURSERY RHYMES. By J. B. KER. 2 vols. 12mo, newo cloth. 4s. (original price 12s.)

A work which has met with much abuse among the reviewers, but those who are fond of philological pursuits will read it now it is to be bad at 80 very moderatc a price, and it really contains a good deal of

MERRY TALES OF THE WISE MEN OF GOTHAM. Edited by JAMES ORCHARd HALIIWELI, Esq, F.S.A. Post 8ro. 1 s.

These tales are supposed to have been composed in "In the time of Henry the Eighth, and after," says the early part of the sixteenth century, by Dr. Andrew Borde, the well.known progenitor of Merry Andrews.

gossiping matter. The author's attempt is to explain every thing from the Dutch, which he believes was the game language as the Anglo-Saxon.

SAINT PATRICK'S PURGATORY; an Essay on the Legends of Hell, Purgatory, and Paradise, current during the Middle Ages. By Thomas WRIGHT, M.A., F.S.A., \&c. Post 8vo, cloth. 6s.

"It must be observed that this is not a mere account of St. Patriek's Purgatory, but a complcte history of the legends and superstitions relating to the subjeet, from the earliest times, rescued from old MSS. as well as from old printed books. Moreover, it em. braces a singular chapter of literary history vitter by Warton and all furmer writers with whom we are acquainted; and we think we msy add, that it forms

the best introdnction to Dante that has yet been pnblished."-Literary Gazette.

"This appears to be a curions and even amusing book on the aingular sulject of Purgatory, in which the idle and fearful dreams of superstition are shown to be first narrated as tales, and then applied as means of dedincing the moral character of the age in whick they prevaled."-Spectator. 
NOBLE AND RENOWNED HISTORY OF GUY, EARL OF

WARWICK, containing a Full and True Account of his many Famous and Valiant Actions. Royal $12 \mathrm{mo}$, woodcuts, cloth. 4s. $6 d_{\text {. }}$

PHILOSOPHY OF WITCHCRAFT, (Chiefly with respect to Cases in Scot-

land). By J. MIтcheir, and J. Dickie. 12mo, cloth. 3s. (original price 6s.)

A curious volume, and a fit companion to Sir W. Scott's "Demonology and Witchcraft."

A CCOUNT OF THE TRIAL, CONFESSION, AND CONA. DEMNATION of Six Witches at Maidstone, 1652; also the Trial and Execution of three others at Faversham, 1645. 8vo. $1 s$.

These Transactions are unnoticed by all Kentish historians.

WONDERFUL DISCOVERY OF THE WITCHCRAFTS OF

MARGARET and PHILIP FLOWER, Daughters of Joan Flower, near Bever (Belvoir), executed at Lincoln, for confessing themselves Actors in the Destruction of Lord Rosse, Son of the Earl of Rutland, 1618. 87o. $1 s$.

One of the most extraordinary cases of Witchcraft on record.

\section{Bithlígraplye.}

BIBLIOTHECA MADRIGALIANA.-A Bibliographical Account of the

Musical and Poetical Works published in England during the Sixteenth and Seventeerith Centuries, under the Titles of Madrigals, Ballets, Ayres, Canzonets, \&c., \&c. By EDTARD F. RimbaUtT, LL.D., F.S.A. 8vo, cloth. 5s.

It records a class of books left undescribed by Ames, Catalogne of Lyrical Poetry of the age to which Herbert, and Dibdin, and fumishes a most valuable it refers.

THE MANUSCRIPT RARITIES OF THE UNIVERSITY OF 1 CAMBRIDGE. By J. O. HALIIWELI, F.R.S. 8vo, bds. 3s (original price 10s. 6d.) A companion to Hartshorne's "Book Rarities" of the same University.

SOME ACCOUNT OF THE POPULAR TRACTS, formerly in the Library of Captain Cos, of Coventry, A.D. 1575. By J. O. Harurwelr. 8vo, only 50 printed, sewed. 18.

CATALOGUE OF THE CONTENTS OF THE CODEX HOLBROOKIANUS. (A Scientific MS.) By Dr. John Holbrook, Master of St. Peter's College, Cambridge, 1418-1431). By J. O. HaLlrweld. 8vo. 1s.

A CCOUNT OF THE VERNON MANUSCRIPT. A Volume of A Early English Poetry, preserved in the Bodleian Library. By J. O. HALLIWELc. $8 \mathrm{ro}$, only 50 printed. 1 s.

BIBLIOTHECA CANTIANA. A Bibliographical Account of what has been B published on the History, Topography, Antiquities, Customs, and Family Genealogy of the CotNTY of KENT, with Biographical Notes. By JoHN RUSSEIr SMITr, in a handsome $8 \mathrm{vo}$ volume, pp. 370, with two plates of facsimiles of Autographs of 33 eminent Kentish Writers. 5s. (original price 14s.)-LARGE PAPER 10s. $6 d$.

\section{fitístellaníks.}

NEW FACTS AND VERIFICATIONS OF ANCIENT BRITISH HISTORY. By the Rev. BEALE POSTE. 8ro, with engravings, cloth.

THOMAS SPROTT'S (a monk of Canterbury, circa 1280) Chronicle of Profane 1 and Sacred History. Translated from the original MS., on 12 parchment skins, in the possession of Joseph Mayer, Esq., of Liverpool. By Dr. W. BELt. 4.to, half bound in morocco, accompanied with an exact Facsimile of the entire Codex, 37 feet long, in a round morocco case, PRIVATELX PRINTED, very curious. $£ 2.2 s$.

TONSTALL (Cuthbert, Bishop of Durham), Sermon preached on Palm Sunday, 1 1539, before Henry VIII, reprinted VERBATIM from the rare edition by Berthelet in An exceedingly interesting Sermon, at the commencement of the Reformation, Strype in his Memorials has
madc large cxtracts from it. 
TAPPENBERG'S HISTORY OF ENGLAND, under the Anglo-Saxon 1 Kings. Translated by BENJ. THORPE, with Additions and Corrections, by the Author and Translator. 2 vols. 8vo, cloth. 12s. (original price £1. 1s.)

"Of modern works I am most indebted to the History of England by lappenberg, the use of which, more particularly in conjunction with the translation given by Thorpe, and enriched by hoth those scholars, affords

the best and surest guide in penetrating the labyrinth of early English History."- "Konig Aelfred und seine Stelle in der Geschichte Englands, von Dr. Reinold Pauli."-Berlin, 1851.

I ETTERS OF THE KINGS OF ENGLAND, now first collected from 1 the originals in Royal Archives, and from other authentic sources, private as well as public. Edited with Historical Introduction and Notes, by J. O. HaLLIWELL. Two HANDSOME VOLUNES, post 8vo, with portraits of Henry VIII and Charles $I$, cloth. 8s. (original price $£ 11$ s.)

These volumes form a good companion to Ellis's Original Letters.

The collection comprises for the first time the love letters of Henry the VIII. to Anne Boleyn in a complete form, which may be regarded perhaps as the most singular documents of the kind that have deacended to our times; the series of letters of Edward VI will be found very interesting specimens of composition; some of the letters of James I, hitherto unpublished, throw light on the murder of Overbury, and prove beyond a doubt the King was implicated in it in some extraordinary and unpleasant way: but

his letters to the Duke of Bnckingham are of the most singular nature; only imagine a letter from a 80 vereign to his prime minister commencing thus; "MN own sweet and dear child, blessing, blessing, blessing on thy heart-roots and all thine." Prince Charles and the Dake of Buckingham's Journey into Spain has never been before so fnlly illustrated as it is by th documents given in this work, which also includes the very curious letters from the Duke and Ducheas of Buckingham to James I. Forming an essential com panion io overy History of England.

WALES.-Royal Visits and Progresses to Wates, and the Border Counties of ChESHIRE, SALOP, HEREFoRD, and MoNMOUTH, from Julius Cæsar, to Queen Victoria, including a succinct History of the Country and People, particularly of the leading Families who Fought during the Civil Wars of Charles I., the latter from MSS. never before published. By EDWARD PARRY. A handsome 4to volume, with many wood engravings, and fine portrait of the Queen, cloth. \&1. 1s.

HUNTER'S (Rev. Joseph) HISTORICAL AND CRITICAL 11 TraCTS. Post 8ro. 2s. 6d. each.

I. Agincourt; a contribution, towards an authentic List of the Commanders of the English Host in King Henry the Fifth's Expedition.

II. Collections concerning the Founders of New Plymouth, the first Colonists of New England.

III. Milton; a sheaf of Gleanings after his Biographers and Annotators.

IV. The Ballad Hero, "Robin Hood," his period, real cliaracter, \&c., investigated, and, perhaps, ascer-
tained.

A RCHERY.-The Science of Archery, shewing its affinity to Heraldry, and capa. A bilities of Attainment. By. A. P. Harrison. 8vo, seved. $1 s$.

TLLUSTRATIONS OF EATING, displaying the Omnivorous Character of 1. Man, and exhibiting the Natives of various Countries at feeding-time. By a BEEFEATER. Fcap. 8vo, with woodcuts. $2 s$.

ELEMENTS OF NAVAL ARCHITECTURE; being a Translation of the Third Part of Clairbois's "Traité Elémentaire de la Construction des Vaisseaux." By J. N. StraNGE, Commander, R.N. 8vo, with five large folding plates, cloth. 58 .

LECTURES ON NAVAL ARCHITECTURE; being the Substance of those delivered at the United Service Institution. By E. GARDINER FisHrodrNe,
Commander, R.N. 8vo, plates, cloth. 5s. 6d.

Both these works are published in illustration of the "Wave System."

NEW YORK IN THE YEAR 1695, with Plans of the City and Forts as they then existed. By the Rev. JoHn Mriler. Now first printed. 8vo, bds. 2s. 6 d. (original price 4s. $6 d$.)

\section{THOUGHTS IN VERSE FOR THE AFFLICTED. By a CodNTRY CuRATE. Square $12 \mathrm{mo}$, sewed. 1 s.}

POEMS, partly of Rural Life, in National English. By the Rev. WinIIAMr BARNES, author of "Poems in the Dorset Dialect." 12mo, cloth. 5s.

WAIFS AND STRAYS. A Collection of Poetry. 12mo, only 250 printed, chiefly for presents, seved. 1s. $6 d$.

MIRROUR OF JUSTICES, written originally in the old French, long before He the Conquest, and many things added by ANDREW HoRNE. Translated by W. $\Lambda$ curious, interesting, and authentic treatise on ancicnt English Law. 
CONTRIBUTIONS TO LITERATURE HISTORICAL, AN-

TIQUARIAN, and METRICAL. By MARK ANTONY LOWLr, M.A., F.S.A., Author of "Essays on English Surnames," "Curiosities of Heraldry," \&c. Post 8vo, woodeuts, cloth. $7 s 6 d$

1 On Local Nomenclature.

Contersts.

2 On the Battle of Hastings, an Historical Essay:

3 The Lord Dacre, his mournful end; a Ballad.

4. Historical and Archæological Memoir on the Iron Works of the South of England, with numerous illustrations.

5 Winchelsea's Deliverance, or the Stout Abbot of Battayle; in Three Fyttes.

6 The South Downs, a Sketch; Historical, Anecdotical, and Descriptive.

7 On Yew Trees in Church-yards.

8 A Lyttel Geste of a Greate Eeles a pleasaunt Ballade.

9 A Discourse of Genealogy.

10 An Antiquarian Pilgrimage in Normandy, with woodcuts.

11 Miscellanea, \&c. \&c. \&c.

There is a good deal of quaint and pleasing reading in this volume. Mr. Lower's jokes aro of the oldest-as befits the pleasantries of an antiquary, - hut, on the whole, we seldom meet with more readable antiquarian essays than these. Most of them have been printed elsewhere. One, on the South Downs, contains the best of the new matter. The anthor is at home on the wide expanse of these chalk ranges. He speaks with knowledge of the picturesque villages enclosed in their secluded nooks, $\rightarrow$ of the folk-lore and legends of old days which still abound amongst the sequestered inhabi. tants, and of the listorical associations which render celebrated manny spots otherwise of little interest.Athenaum.

Most of the papers in this volumo have already appcared in periodicals, and in the Collections of the Sussex Archæologfcal Soclety. They are well worthy of being printed in a collected form. The account of the Battle of Hastings and the memoir on the Sonthern Iron Works contain matter of lis torical value, in addition to their local interest in conncxion with the topography and arcliæology of Sussex. Among the papers now printed for the first time that on tlie South Downs is the most important, and will be read with much interest, hoth for the information it contains and the plessing style in which it is written. There are some cliarming descriptions of scenery, and acceptable notices of the history, traditions, and customs of the district. Among the minor contributions in the volume, the paper on Local Nomenclature is full of valuable ouggestions. Altogetlier it is a volume of very agreeable and instructive reading.- Lit. Gaz.

\section{HANDBOOK to the LIBRARY of the BRITISH MUSEUM,} containing a brief History of its Formation, and of the various Collections of which it is composed; Descriptions of the Catalogues in present use ; Classed Lists of the Manuscripts, \&c.; and a variety of Information indispensable for the "Readers" at that Institution; with some Account of the principal Public Libraries in London. By Richard Sims, of the Department of Manuscripts, Compiler of the "Index to the Heralds' Visitations." Small 8vo, pp. 438, with map and plan, cloth. $5 s$

It will be found a very nseful work to every literary person or public institution in ell parts of the world.

What Mr. Antonio Panizi, the keeper of the dejartment of printed books, says might be dons. Mr. Ricliard Sims, of the department of the manuseripts, says shall be done. His Hand-book to the
Library of the British Museum is a very comprehensive and instructive volume. I have tlie sixticth edition of "Synopsis of the Contents of the Britisl Muscum" before me-I eannot expect to see a sixtieth edition of the Hand-book, but it deserves to be placed by the side of the Synopsis, and I venture to predict for it a wide circulation. $-\boldsymbol{M} \boldsymbol{f r}$. Bolton Corney, in Notes and Queries, No. 213.

A GRAMMAR of BRITISH HERALDRY, consisting of "Blazon" and "Marshalling," with an Introduction on the Rise and Progress of Symbols and Ensigns. By the Rev. W. Slo upvards of 400 figures, cloth. 5 s.

One of the best introductions erer published.

\section{A PLEA FOR THE ANTIQUITY OF HERALDRY, with an A Attempt to Expound its Theory and Elucidate its History. By W. SMITH ELIIS Esq., of the Middle Temple. 8vo, sewed. 1s $6 d$}

\footnotetext{
A FEW NOTES ON SHAKESPEARE, with Occasional Remarks on A the Emendations of the Manuscript-Corrector in Mr. Collier's copy of the folio, 1632. By the Rev. AleXANDER DYce. 8ro, cloth. 5s

Mr. D ycc's Notes are peculiarly delightful, from the stores of illustration with which his extensire readlng not only among our writers, but among those of other countries, especially of the Italian poets,

hss ensbled him to enricl them. All that he has recorded is valuable. We read his little volume with pleasure and close it with regret.-Literary Gazet to.
} 
John Russell Smith, 30, Soho Square, London.

\section{A FEW WORDS IN REPLY TO MR. DYCE'S "FEW NOTES} ON SHAKESPEARE." By the Rev. JosEPH HUNTER. 8ro, sewed. 1s

\section{THE GRIMALDI SHAKESPEARE.-Notes and Emendations on the 1 Plays of Shakespeare from a recently-discorered annotated copy by the late Josepif Grisatid, Esq., Comedian. 8vo, cuts. 1s}

\section{$\Delta$ humourous Squib on the late Shakespeare Emendations.}

\section{SHAKESPEARE'S VERSIFICATION and its apparent Irregularities} explained by Examples from early and late English Writers. By the late Wilimaur SmneY Walker, formerly Fellow of Trinity College, Cambridges edited by W. Naxson LeTtsou, Esq. Fep. 8vo, cloth. 6s.

A PHILOLOGICAL GRAMMAR, grounded upon English, and formed A from a comparison of more than Sirty Languages. Being an Introduction to the Science of Grammars of all Languages, especially English, Latin, and Greek. By the Rev. W. Barines, B.D., of St. John's College, Cambridge. Author of "Poems in the Dorset Dialect," "Auglo Saxon Delectus," \&o. 8vo, pp. 322, cloth. 9s

\section{TIM BOBBIN'S LANCASHIRE DIALECT, with his Rhymes and an enlarged Glossary of Words and Phrases, used by the Rural Population of} South Lancashire. By SAmuex BaMrord. $12 \mathrm{mo}$, the second edition, cloth, $3 s$ w

BRITANNIC RESEARCHES : or, Now Facts and Rectifications of Ancient British History. By the Rev. Beale Poste, M.A. 8vo, (pp. 448) with engravings, cloth. 15 s

The author of this volume may justly claim credit for considerable learning, great industry, and, above all, strong faith in the interest and importance of his subject. On various points he has given us additional information and afforded us new views, for which we are bound to thank him. The body of the hook is followed by a very complete index, so as to render reference to any part of it easy : this was the more necessary on account of the multifariousness of the topics ureated, the variety of persons mentioned, and the many works quoted.-Athencum, Oct. 8, 1853.

The Rev. Beale. Poste has long been known to antiquaries as one of the best read of all those who have elacidatcd the earliest amuals of this country. He is a practical man, has investigated for himself monuments and mannscripts, and pre have in the above-named volume the fruits of many yeurs' pa. tient atndy. The objects which will occupy the attention of the reader are-1. The political position of the principal British powers before the Roman conquest-under the Roman dominion, and strug. gling unsuccessfully against the Anglo-Saxon race; 2. The geography of Ancicnt Britain; 3 . An investignti n of the Ancient British Historians, Gildas and Nennins, and the more obscure Bi:tisli clironiclers; 4. The ancient stone monuments of the Celtie period; and, lastly, some curious and intcrestin: notices of the early British church. Mrr. Poste has not touched on subjects which hare receired much attention from others, save in cases where he had somicthing new to offer, and the volume must be regarded, therefore, as an entirely new collection of discoveries and deductions tending to throw light on the darkest as well as the earliest portion of our national history.-Atlas.

\section{COINS OF CUNOBELINE and of the ANCIENT BRITONS.} By the Rev. BEALr Poste, B.C.L. 8vo, plates, and many woodcuts, cloth (only 40 printed). $£ 1.8 s$

\section{BARONIA ANGLIA CONCENTRATA; or a Concentration of all the Baronies called Baronies in Fee, deriving their Origin from Writ of Sum- mons, and not from any specific Limited Creation, showing the Descent and Line of Heirship, as well as those Families mentioned by Sir William Dudgale, as of those whom that celebrated author has omitted to notice; interspersed with Interesting Notices and Explanatory Remarks. Whereto is added the Proofs of Parliamentary Sitting from the Reign of Edward I to Queen Anuc; also a Glossary of Dormant English, Scotch, and Irish Peerage Titles, with references to presumed existing Heirs. By Sir T. C. BANKs. 2 vols. 4 to, cloth. $\mathfrak{L}^{2} 3.3 s$ Now OFFERED Fon $15 s$}

A book of great resesrch by the well-know $n$ anthor of the "Dormant and Extinct Peersge," and other heraldic and historical works. Those fond of genealogical pursuits ought to secure a copy while it is so clieap. It may be considered a Supplement to his former works. Vol. ii, pp, 210-300, contains III Iistorical Account of the first settlement of Nova Scotia, and tlic foundation of the Order of Nora Scotia Baronets, distinguishing those who had scisin of lands there. 
RETROSPECTIVE REVIEW (New Series); consisting of Criticisms upon, Analysis of, and Extracts from curious, useful, valuable, and scarce Old Books. Vol. 1, 8vo, pp. 436, cloth. 10s $6 d$

*" Published Quarterly at 2s. 6d. each Numbcr-DNo. VII is published this day.

Contents of No. V.

1 Sir William Davenant, Poet Laureate and Dramatist, 1673.

2 Cooke's "Poor Man's Case," 1648.

3 Old English Letter-writing; Angel Day's English Sccretary, 1592 ; W. Fulwood's Enemy of Idlenesse.

4 The Old Practice of Gardening; Thos. Hyll's Briefo and Pleasaunt Treatise, 1563.

5 English Political Songs and Satires, from King John to Gcorge I.

6 Medieval Travellers in the Holy Land.

7 The Athenian Letters, by Lord Hardwicke and others.

8 The Writings of Wace the Trouvère.

Axmcdota Literaria.-Pepy's Directions for the Disposition of his Library; A Legendary Poem of the 15th Century, the Story laid at Falmouth, in Cornwall : both now first printed.

\section{CoNTENTs of No. VI.}

1 Drayton's Polyolbion.

2 Penn's No Cross No Crown.

3 Lambarde's Perambulation of Kent.

4 Philosophy of the Table in the Time of Cliarles $I_{\text {. }}$

5 Russia under Peter the Great.

6 Life and Works of Leland, the Antiquary.

7 The Decay of Good Manners.

8 Stephen's Essayes and Characters, 1615.

ANecdota Limeraria. - The Child of Bristow, a Metrical Legend. Now first printed.

The title of this Renew explains its objects. It ts intended to supply a place unfilled in our periodical litersture, and this first number is very satisfactory. The papers are varied and interesting, not orerlaid by the display of too much learning for the general reader, but ghowing sufficient research and industry on the part of the writers to distinguish the articles from niere ephemeral reviews of passing publications. In the prospectus the editor says "It is our design to select, from the vast field of the literature of the past, subjects which are most likely to interest modern readers; we shall lay before them from time to time, essays on various branches of the literature of former days, English or foreign we shall gire accounts of rare and curious books; point out and bring forward beauties from forgotten authors; and tell the knowledge and opinions of other days." The design is well carried out in this number, and will, no doubt, be further developed as the work adrances. It is to be published quarterly, at a very moderate price, and will, we have no donbt, prove a successful undertaking.-Atlas.

REMAINS OF PAGAN SAXONDOM, principally from Tumuli in $\mathrm{R}^{\mathrm{E}}$ England. Drawn from the Originals. Described and Mllustrated by JoIr Yonge Akerman, Fellow and Secretary of the Society of Antiquaries. 4to, parts 1 to $9.2 s 6 d$ each (Pt. 10 in the press).

The plates are admirably executed by Mr. Basire, and coloured under the direction of the Author. It is a work well worthy the notice of the Archeologist.

WILTSHIRE TALES, illustrative of the Manners, Customs, and Dialect of that and Adjoining Counties. By JoHr YoNGe AKERMAN. 12mo, cloth. $2 s 6 d$

We will conclude with a simple, but bearty recommendation of a little book whieh is as humourons, for the drolleries of the stories, as it is in. teresting as a picture of rustic manners.-Tallis's Weekly Paper.

Mr. Akerman's Wiltenine Tales embody most of the provincialisms peculiar to this county and the districts of other counties lying on its northern borders, and possess the additional recom-

mendation of preserving the old songs (and the airs to which they are sung), which are still to be heard at most harvest homes and other merry makings, the well-known "Here's a health to our meester," and $\mathrm{a}$ " $\mathrm{A}$ pie upon the pear tree top" among tlie rest. Both to the philologist, therefore, and to the general reader, the book is an interesting one. Salisbury and Hinchester Journal.

\section{HISTORY AND ANTIQUITIES OF THE TOWN OF MARLBOROUGH, and more generally of the entire Hundred of Selkley in}

Wiltshire. By JAMES WAYLEN, Esq. Thick 8vo, woodcuts, cloth. $14 s$

This volume describes a portion of Wilts not occupicd by Sir R. C. Hoare and other topographers. 
SIGILLA ECCLESIE HIBERNICAE ILLUSTRATA. Tho

Episcopal and Capitular Seals of the Irish Cathedral Churches illustrated. By Richard CAULFIELD, A.B. 8vo. Part I-CASHEL and EMLX, with 12 engravings, sewed. $1 s 6 d$

ULSTER JOURNAL OF ARCH EOLOGY : conducted under the superintendence of a Committee of Archæologists at Belfast. Handsomely printcd in 4to, with engravings. Published quarterly. Annual Subscription, 12s. (Not sold in single Nos.) Nos. 1 to 5 are ready.

\title{
DESCRIPTIVE CATALOGUE OF THE COLLECTION OF ANTIQUITIES, and other Objects Tllustrative of Irish History, exhibited in the Belfast Museum, at the Meeting of the British Association, Sep. 1852, with Antiquarian Notes. 8vo, seved. $1 s 6 d$
}

\begin{abstract}
A NTIQUITIES OF SHROPSHIRE. By the Rev. R. W. Erton, A Rector of Ryton. Royal 8vo, with plates. Parts I to III. 5s each. Published Quarterly.

The Work will extend at least to five volumes or withdraw his name after the publication of any twenty parts. Any subscriber will be at liberty to fourth part or completed volnme.
\end{abstract}

A NTIQUITIES OF THE BOROUGH OF LEEDS, described $A$ and illustrated. By JAMES WARDELI, Esq. 8ro, 16 plates, mostly coloured. $7 s 6 d$-LARGE PAPER. 12s

\section{AISTORICAL ACCOUNT OF THE CISTERCIAN ABBEY of SALLEY, in Craven, Yorkshire, its Foundation and Benefactors, Abbots, Possessions, Compotus, and Dissolution, and its existing Remains. Edited by J. Harland. Royal Svo, 12 plates, cloth. 4s $6 d$}

A DESCRIPTIVE ACCOUNT OF LIVERPOOL, as it was during A the last Quarter of the Eighteenth Century, 1775-1800. By RICHARD Brooke, Esq., F.S.A. A handsome vol. Royal 8vo, with illustrations, cloth. £1. 5s

In addition to information relative to the Public Buildings, Statistics, and Commerce of the Town, the Work contains some curious and intercsting particulars, which have never bcen previously pub-

lished, respecting the Pursuits, Hahits, and Amusements of the Inlabitants of Livcrpool during that period, with Views of its Public Edifices.

\section{A GUIDE TO LYNTON AND PLACES ADJACENT, IN A NORTH DEVON, including Ilfracombe. By T. H. CoOPEr. 12mo; 5 plates, and Map of North Devon, cloth. $3 s 6 d$}

HISTORY OF GREAT YARMOUTH, containing the Origin, Foundation, and History of that Ancicnt Borough ; and an Account of its Government, Incorporation, Liberties, and Franchises; with a Description of the Public Buildings, Churches, Convents, and other Religious Houses of the Middle Ages, \&e. Compiled by HENRY ManshIP, Town Clerk temp. Queen Elizabeth. Edited by Charles Jomi Palmer, F.S.A. Thick vol, post 4to, pp. 456, with 11 illustrations, half bound. \&1. $1 s$

A RCH EOLOGICAL MINE, a Magazine in which will be comprised A the History of Kent, founded on the basis of Hasted. By A. J. DunkIx. 8vo; Parts 1 to 12. Published Monthly. 8d each.

\footnotetext{
DUNCUMB'S (Rev. John) HISTORY AND ANTIQUITIES \&1. 48 of the County of Hereford. 2 vols. 4to, portraits and plates, new, in boards.

This is the only History of the Connty published. This copy contains five additional sheets (the Hundred of Greytree) and the Index to the Second

Hereford, 1804-12

Volnme, which are wanting in all the Subscribers' copies.
} 
John Russell Smith, 36, Soho Square, London.

HISTORY OF OREGON AND CALIFORNIA and the other

Territories on the North West Coast of America, accompanied by a Geographical View and Map and a number of Proofs and Illustrations of the History. By RoBert Gremenow, Librarian of the Department of State of the United States. Thick 8ro, IARGE MAP, cloth. 6s (pub. at 16s)

PISTORY OF ANGLING LITERATURE, and on Matters connected with Fish and Fishers from the earliest period, to which is added a General Bibliography of Books on Angling. By an ANGLER. Fep. 8vo, cloth. 5s (nearly ready).

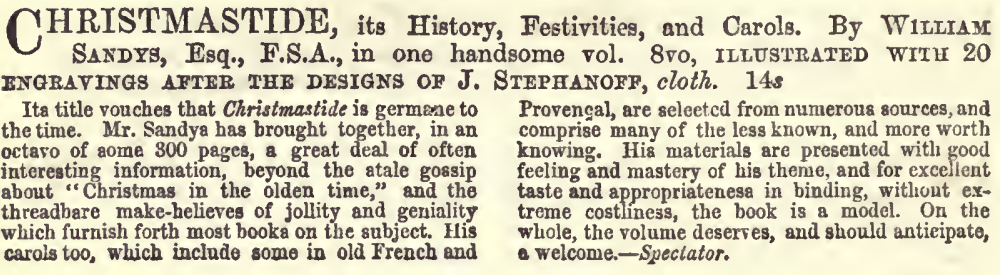

JUST IMPORTED.

HISTOIRE DE L'ARCHITECTURE SACREE du quatrième au dixième siècle dans les anciens éveches de Greneve, Lausanne et Sion. Par J. D. BravignaC, Architecte. One vol. $8 \mathrm{ro}, \mathrm{pp} .450$, and 37 plates, and a 4 to Atlas of 82 plates of Architecture, Sculpture, Frescoes, Reliquaries, \&c. \&c. \&2. $10 \mathrm{~s}$

A VERY REMARKABLF BOOK, AND WORTH THE NOTICE OP THE ARCHITECT, THE ARCHzLOLGIST, $A$ ND THE ARTIST.

\section{COPENHAGEN-THE TRAVELLER'S HANDBOOK TO}

COPENHAGEN and its Environs. By Avgricanos. 12mo, with large Map of Sealand, Plan of Copenhagen, and Views. 12mo, cloth. $8 s$

A NTGUEDADES PERUANAS, por Martano Eduardo dE Rivero, A. Director del Museo Nacional de Lima, y Dr. JUAN Diego DH Tschude (author of Travels in Peru). 4to, pp. 342, with woodcuts, and folio volume of COLOURED PLATES, bds. £5. 5 s

$\mathbf{A}$ description of remaing discovered in the sites of aneient cities and temples in Peru, those objects whieh arrested the attention and exeited the wonder of the philosophic Humboldt, when investigating the physical features of that remarkable country. The illustrative plates, exceuted at Vienna, from the drawings of the Artist, are among the marvels of lithography. They comprise repre. sentationa of mummified bodies, prepared in the manner peculiar to the Peruvians, vases of gro-

tesque form and characteristic idols in terra cotta and the precious metals, textile fabries, weapons of a very remote period, and view of temples and buildinge, whieh, for symmetry and beauty, may vie with those of Greece and Asia Minor in the dawn of civilisation, all exeeuted with a apirit and truthfulness nnsurpassed by any work of the kind that lias eome under our notice.-Literary Gazelte, Jan. 8, 1853.

FSSAI HISTORIQUE PHILOSOPHIQUE et Pittoresque sur les Danses des Morts. Par E. H. LAsalors; suivi d'une Lettre de Leber, ct une note de Depping sur le même sujet, publié par Pottier et Baudry, 2 vols, royal 8ro, with 54 plates of Death's Dance of various ages, also many vignettes, sewed, £1. Is

L A ROMAINE, ov HISTOIRE, LANGUE, LITTERATURE, OROGRAPHIE, statistique des Peuples de la Langue d'Or, Adrialiens, Vallaques, et Moldaves, resumés sous le nom de Romans. Par J. A. VAILIANT, 3 vols, 8ro sewed, 18 s.

VOYAGES, Relations, et Memoires originaux pour servir a l'Histoire de la Decouverte de l'Ainerique, publiés pour la première fois en Français. Par

H. TerNaUX-Compans. 20 vols. 8vo, both Series, and complete. Sewed, £3. 10s

A valuable collection of early royages and relations on South $\Delta$ merica; also translations of unpublished Spanish MSS., principally relating to Old and New Mexico. 

University of California

SOUTHERN REGIONAL LIBRARY FACILITY

Return this material to the library from which it was borrowed.

RECD LD-IIRL

OCT 111989

oi jan? 12000

जाइ. 2001 
1. 70 mo

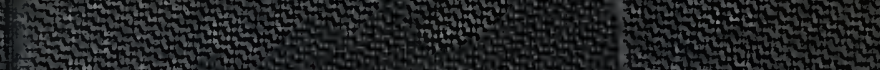

(3)

(4)

Fin

mint

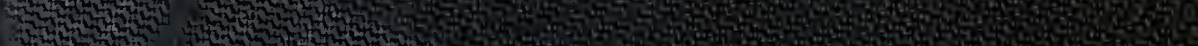

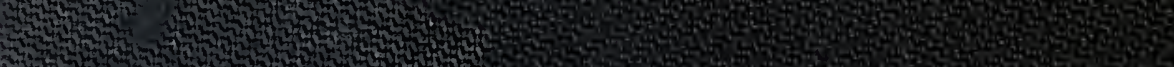

H.

M.

mo

w

fut

.

H.

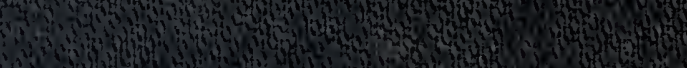

- in ${ }^{2}$.

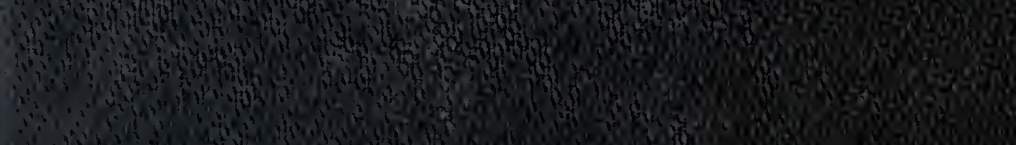

